\title{
Extreme properties, variances and the behavior of the Universe
}

\author{
Doctor of Philosophy in Physics Dissertation
}

\section{K.H.K. Geerasee Wijesuriya}

BSc (Hons) in Physics and Mathematics, University of Colombo, Sri Lanka geeraseew@gmail.com 


\section{Extreme properties, variances and the behavior of the Universe}

Author (Doctor of philosophy in Physics candidate):

K.H.K. Geerasee Wijesuriya

Doctor of Philosophy in Physics (Cosmology)

March 2021 
This Dissertation is submitted to the University, as the requirement for offering the Doctor of Philosophy Degree in Physics 


\section{Acknowledgement}

I would like to thankful to my parents who gave me the strength to achieve my scientific goals and who are in behind of my all achievements in my life. 


\begin{abstract}
At this moment, scientists don't have any significant explanation to explain 'why there are much matter particles than anti-matter particles' in the universe. But with this research, it is going to provide an explanation for that.
\end{abstract}

An attempt of this research is to provide detailed innovative arguments regarding the real nature of supermassive black holes also.

Here this is intending to explain why, the contribution to the accelerating expansion of the universe by the quantum vacuum is much bit than the contribution by other matters in the universe.

Scientists have confused on why the energy of the zero-point energy (quantum vacuum) state, does not contribute to the cosmological vacuum energy (cosmological constant) much. The goal of this research is to investigate a solution to that particular problem also.

This will explain why there is a difference between the observed energy of a satellite and the theoretically calculated energy of a satellite, which is orbiting around the Earth.

This research will argue regarding whether dark matter is responsible for differences in observed and theoretical speed of stars revolving around the center of Galaxies. 


\section{Content}

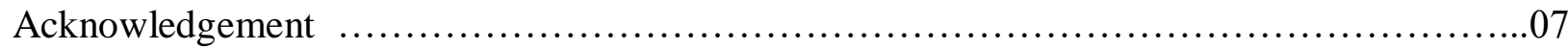

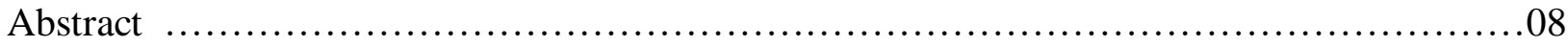

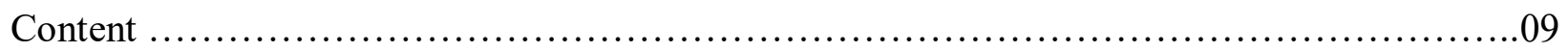

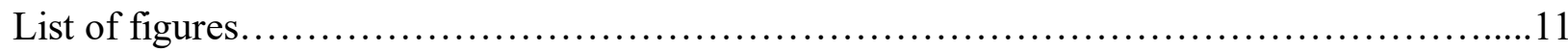

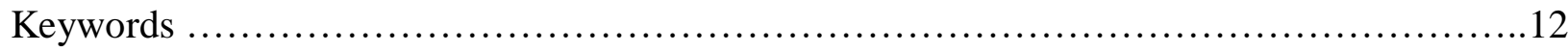

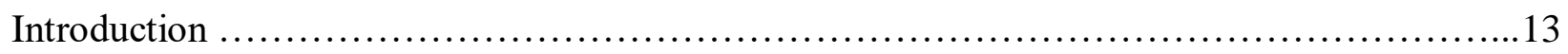

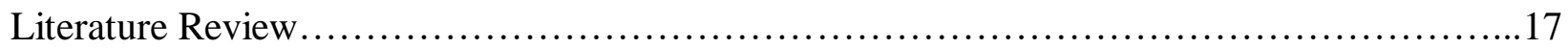

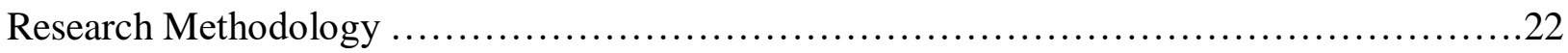

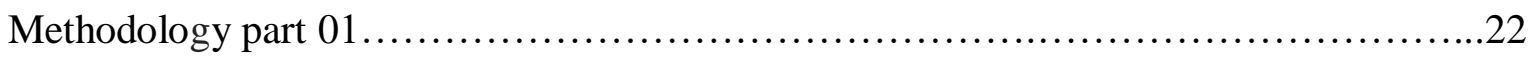

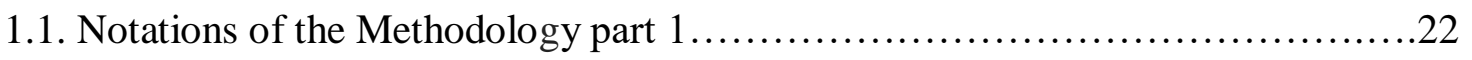

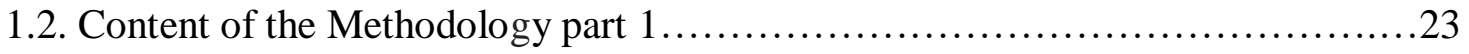

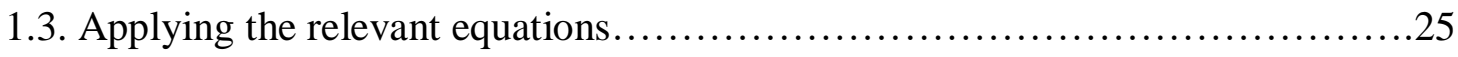

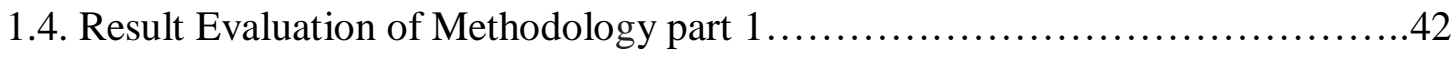

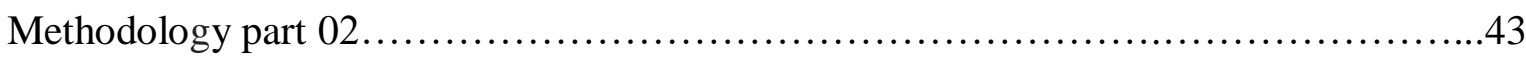

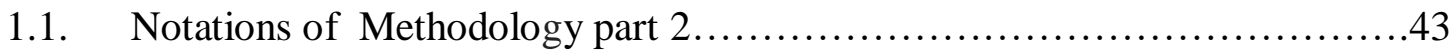

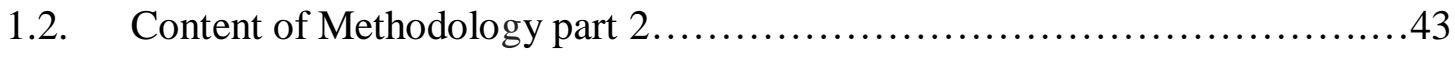

1.2.1. Section 01: How the black hole controls the solar winds of the nearby

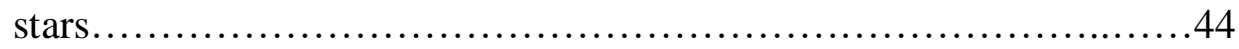

1.2.2. How the supermassive black hole controls the orbiting velocity of nearby stars/planets.................................................... 56

1.3. Result Evaluation of Methodology part 2 ..............................60

Methodology part 03

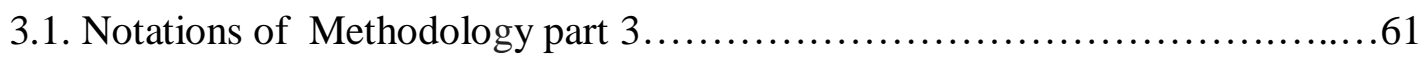

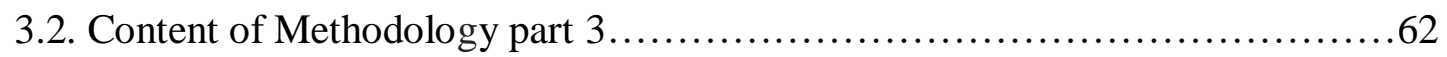

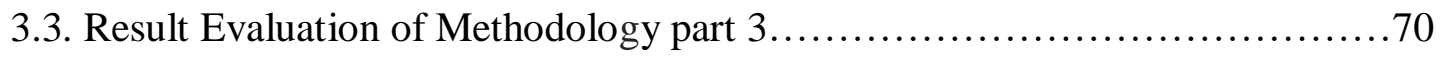


Methodology part 04

4.1. Notations of Methodology part 4...................................... 71

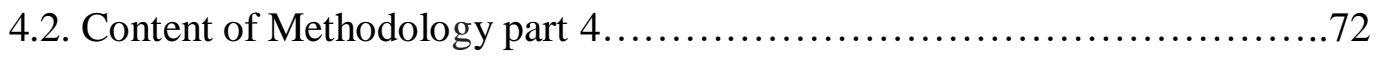

4.3. Result Evaluation of Methodology part 4............................. 87

Methodology part 05

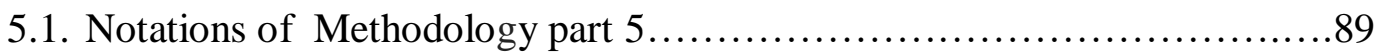

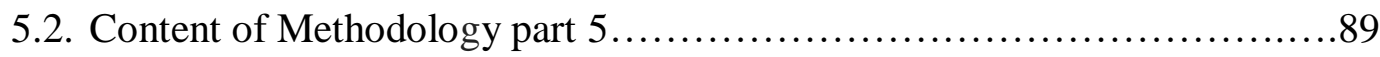

5.3. Understand Gravitational Redshift..................................90

5.4. Result Evaluation of Methodology part 5............................ 103

Methodology part 06

6.1. Notations of Methodology part 4..................................... 104

6.2. Content of Methodology part 4................................. 105

6.3. Result Evaluation of Methodology part $4 \ldots \ldots \ldots \ldots \ldots \ldots \ldots \ldots \ldots \ldots \ldots \ldots \ldots \ldots \ldots \ldots$

Discussion

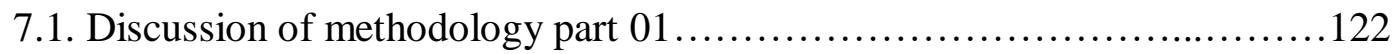

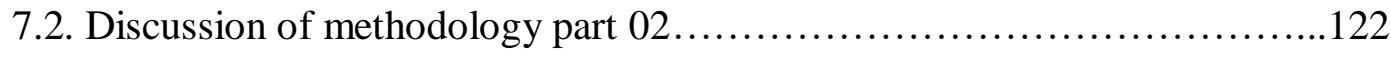

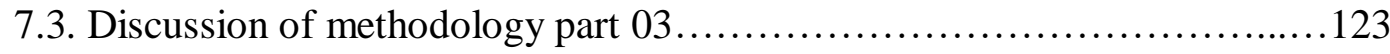

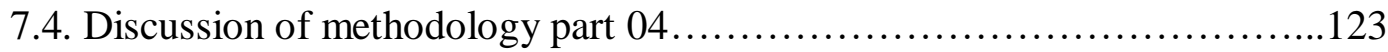

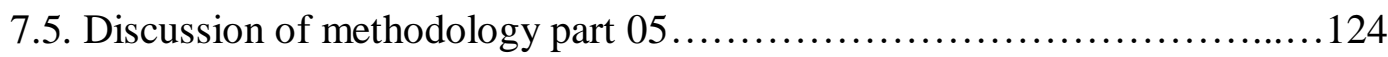

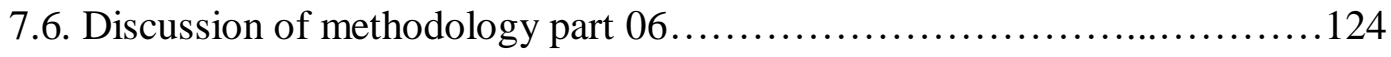

Conclusion

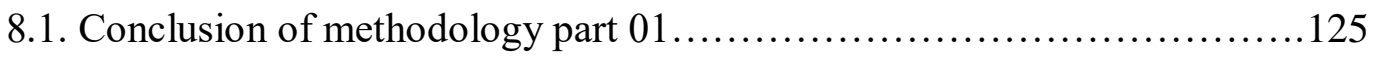

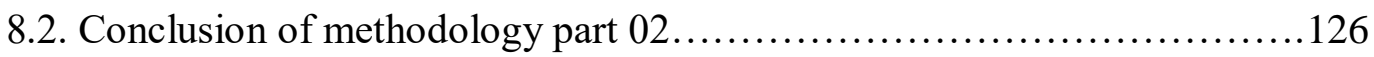

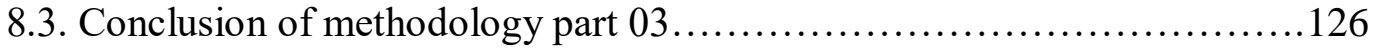

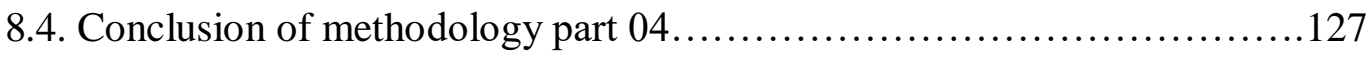

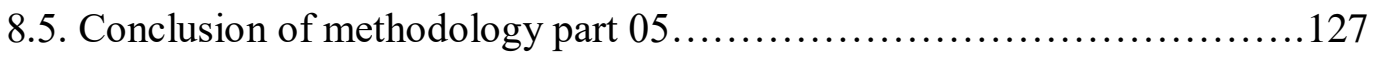

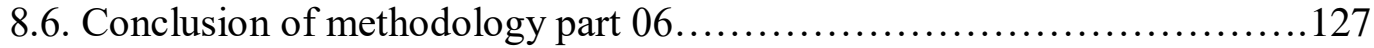

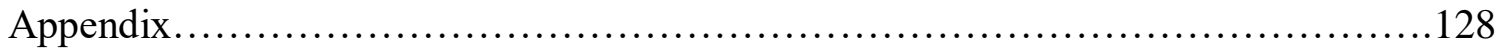

References............................................................ 130 


\section{List of Figures}

Figure 01 , How particles and anti-particles have located..............................23

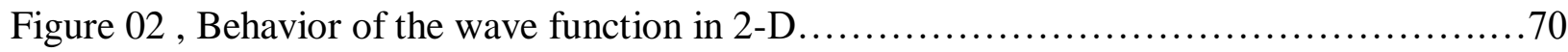

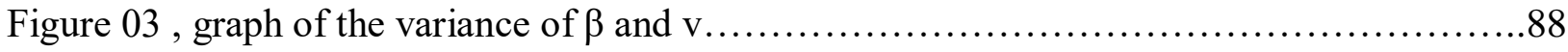

Figure 04 , Variance of $r_{s}$ with respect to the mass $M$ of the gravitational object................92

Figure 5, Gravitational red shift (zero for this case) VS radius of the object near to the

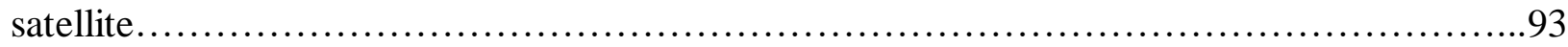

Figure 6, Gravitational red shift (positive) VS radius of the object near to satellite.............93

Figure 07 , Variance of $\mathrm{F}$ with respect to $\mathrm{U}$ for different $\mathrm{D}$ values............................. 109

Figure 08 , Hubble's Equation of Universal Expansion plotting...........................113 


\section{Keywords}

Potential energy; Kinetic Energy ; Magnetic field ; Matter particle; Gravitational potential energy ; Space; Universe ; Eigen function; Eigen value; Black hole; particle; Dark energy; Dark matter 


\section{Introduction}

Human Beings are very curious on the fundamentals of nature and therefore they are different from the other animal species. Since the ancient era, people were trying to explore the nature and the fundamentals of the environment and the universe as well, through mind based-experiments and also using physical equipment. Gradually scientists used mathematical equations to describe the nature of the universe and they discovered and explored the nature of the universe through mathematical formulations.

Scientists from very first ancient era of the scientific generation, thought that the Newton's laws of motions and other theories were the best explanations for the nature of the environment at that time. But with the development of the technology and science, later, scientists believed that Einstein's laws should be the correct point. But in the present era, innovative and challenging theories are coming in to the science world that even could challenge to the Einstein' theories as well. That's how science subjects developed to a better level.

People were much curious regarding the sky and the bright objects in the night sky. That should be the main starting point of the present 'Astronomy' subject field. More genius people tried explore the night sky. They identified several styles of locations of stars and planets. Moreover, more genius people called as scientists, investigated several relationships as the mechanism of the stars and galaxies and etc. During past 3 centuries, the astronomy subject field developed rapidly with the cause of the creation of advanced astronomical equipment.

Theoretical astronomers explored the beginning of the universe and then developed an innovative theory regarding the beginning of the universe called as 'Big Bang theory'. Cosmic Background radiation is an evidence for that Big Bang theory. According to recent discoveries, the universe that we are living, has much galaxies, planets, stars rather than we can imagine. But physicists are now arguing that there should be another matter type than usual matters we know. Those matter we call as "anti-matter". Those anti-matter is identical to matter in several aspects. But there are few differences between them also. Mass of an anti-matter and matter are same. The only difference between an anti-matter and matter is they have opposite charge. As example, electron has negative charge. But anti-matter of the electron (we call as positron) has positive 
charge with the same value of the magnitude of the charge of an electron. And as the other leptons, muon and tau also have anti-matter particles. But each anti-matter of muon and antimatter of tau has opposite charge in regards of muon and tau. But muon particle and the antimuon have same mass, spin. Same for tau and anti-tau particles. And when considering quark particles, there are 6 quark types. Label them as $u, d, t, b, c, s$. 'u' quark has $(+2 / 3)$.e charge. Here ' $e$ ' is the charge of an electron. Therefore anti-particle of ' $u$ ' quark has -(2/3).e charge. And ' $d$ ' quark has charge of (-1/3).e Therefore anti-particle of ' $d$ ' quark has $(+1 / 3)$.e charge. Same patterns are for other quark particles. And neutrino of the electron and the anti-neutrino of the electron have same masses. But the charge of neutrino and anti-neutrino are both 0 .

But we know that in the present era, there are much amount of matter particles than anti-matter particles in the universe. But at this moment, scientists don't have any significant explanation to explain 'why there are much matter particles than anti-matter particles' in the universe.

But with this research, it is intended to investigate an explanation to solve that problem, with the usage of Quantum Mechanics. I use several results in Quantum Mechanics such as Schrodinger equation for complex situations, logic in pure mathematics and etc.

Dark matter is different from ordinary matter such as fermions and bosons in the universe.

Dark matter has never been directly observed; however, its existence would explain number of astronomical observations. The name refers to the fact that it does not emit or interact with observable electromagnetic radiation, such as light, and is thus invisible to the entire electromagnetic spectrum.

Although dark matter has not been directly observed, its existence and properties are inferred from unexplained mass in gravitational lensing calculations, which affects the motions of baryonic matter and light. It influences the universe's large-scale structure, the formation of galaxies, and affects the cosmic microwave background.

The standard model of cosmology implies that the total mass-energy of the universe contains $4.9 \%$ ordinary matter, $26.8 \%$ dark matter and $68.3 \%$ dark energy. 
Dark matter primarily consists of weakly interacting massive particles those interact only with weak and gravitational forces.

Since dark matter deals with the gravitational force, those dark matter is capable to control gravitational systems in the distant Universe. But according to the standard model of cosmology, dark matters spread all across the universe. But recently, scientists have discovered that the universe that we are currently living is expanding with an accelerating rate. But scientists are in the position that the accelerating expansion of the universe causes by the dark energy/dark matter. Therefore in general, dark matter is a form of matter that causes gravitational repulsion across the universe.

Since the dark matters are almost everywhere in the universe, dark matter can affect to the motion of solar and planetary systems in the universe. Therefore, there may be a difference between observed and theoretical speeds of the stars revolving around the centers of Galaxies.

According to the Big Bang Theory (which predicts about the starting and the evolution of the universe) in Cosmology, the universe started to exist with the incident called the Big Bang Explosion. At the time of Big Bang, the universe was contracted to a very small volume (which tended to a zero volume) and the energy density of the universe tended to infinity and the temperature of the universe also considerably large. After the Big Bang explosion, the universe started to expand gradually and as an attempt of 'time'. Then elementary particles created all across the universe. Then gradually stars, planets, plasmas, solar systems, galaxies formed and therefore the gravitational forces among them generated naturally.

We already know that, according to recent experiments, scientists have found that the universe that we are currently living is expanding with a positive acceleration. But what causes this accelerating expansion of the universe ?

According to classical gravitational theories, any two matters gravitationally attracts and therefore according to classical gravitational theories, all matters are attracting towards each other. But the current universe contains matters/energy homogeneously and isotopically. Therefore according to classical gravitational theories, the current and recent universe would not expand gradually and instead of that the universe should contract gradually. But NO. Therefore there should be some materials that would cause the expansion of the universe. In order to cause 
the expansion of the universe, those materials should repulsive with respect to each other. Therefore those matters should be gravitationally repulsive. Therefore it is obvious that the gravitational repulsion among the matters and gravitationally repulsive energy in the universe, causes the accelerating expansion of the universe.

But the space all over the universe is not empty at all. The space we identify as 'Empty' is filled with an energy called as 'Vacuum Energy'. Vacuum energy lasts all across the universe.

Moreover, scientists are dealing with a term 'Quantum Vacuum' currently. But what is the meaning of a 'Quantum Vacuum'? Quantum Vacuum is the quantum state with the lowest possible energy. For the quantum vacuum, we should tend the temperature to absolute zero. In the space, the contribution to the accelerating expansion of the universe by the quantum vacuum is much bit/null than the contribution by other ordinary matters in the universe. But why the quantum vacuum has little effect on the expansion of the universe? That is a question that we should answer through this research.

Scientists are arguing that the contribution from the zero-point energy to the cosmological constant is not considerably large. The purpose of this research is to provide an explanation that would be able to explain why is the contribution from the zero-point energy (or in another words, minimum possible energy of the quantum vacuum) to the cosmological constant is not considerably large.

Although scientists observe that there is a difference between the observed energy of a satellite and the theoretically calculated energy of a satellite, there is no any sufficient solution to explain that result. The main attempt of this research part is to explain why the observed energy of a satellite is different from the theoretically calculated energy of a satellite that is orbiting around the Earth using the theory of dark matter/dark energy.

Black hole is an object that is frequently appearing at the center of most of the galaxies in the distant universe. Supermassive Black hole is a black hole with a high mass density in the core of the black hole inside. But astronomers have already dealt with the high massive black holes (in another words, supermassive black holes). But the attempt of this research is to provide detailed innovative arguments regarding the real nature of supermassive black holes. 


\section{Literature Review}

Since the ancient era, people were so confused in the Universe and the surrounding environment. Later, scientists were capable to carry out several secrets of the distant universe. Among them, major studies were focused on the visible matter objects such as galaxies, black holes, stars, planets and etc rather than invisible and detectable matter studies.

Particle physicists paid their major attention to the content of the matter particles and their features. Scientists have identified that there are two types of normal matters in the universe. They are 'Matters' and 'Anti-matters'. But they have already found that the difference between matter particle and its anti-matter particle is the sign of the charge of each matter and anti-matter particle. If $A$ is the matter particle and if $A^{\prime}$ is the anti-matter particle of $A$, then the sign of the charge of A and A' are opposite to each other. But mass of A and A' are same. And the spin of A and A' also same. If matter particle and its anti-matter particle annihilate, both matter particle and its anti-matter particle will vanish and the relevant energy emits as photons according to the famous equation $\mathrm{E}=\mathrm{mC}^{2}$. Where $\mathrm{E}$ is the emitting energy, $\mathrm{m}$ is the total mass of the particles and $\mathrm{C}$ is the speed of light. But scientists are creating some amounts of anti-matter particles inside laboratories everyday around the world. But they are still unable to create anti-matters vastly. But scientists believe that in the deep Universe, there may be much anti-matter particles rather than in the surrounding environment of the Earth's surface. But still scientists didn't able to explain why there are more matters than anti-matters in the Universe.

Although Newton's Universal theory of Gravitation was acceptable before several centuries, it has been limited by recent and present investigations. The most recent theory of gravity is Einstein's general theory of relativity. Instead of using the gravitational attractions to explain the nature of gravity, Einstein used the curvature of the space-time to explain the nature of the gravity. Since General theory of relativity has involved in all the areas of astrophysics all most, the applications of the theory are useful indeed.

According to Einstein's General theory of relativity, there is a radius limit, away from a black hole identified as 'Schwarzschild radius'. Once the radius of an object in the universe arrived this 
radius limit, no any electromagnetic wave or a particle can go away from the influence of the black hole. Near to a supermassive black hole, the curvature of space time is high. Therefore with regards of a black hole, it is possible to observe the "Gravitational Lensing" effect near to a black hole.

Usually at the center of a supermassive black hole, there is a place called as 'singularity'. At the singularity position, all the physics laws breaks down and no one did able to explain the nature of the singularity in detail. Astronomers are trying to discover the influences from the supermassive black hole to the nearby objects in the galaxy. But those are still under "Study level".

Moreover, scientists have theorized the existence of the quantum vacuum. Quantum vacuum is the quantum state which has the lowest possible energy. And usually it is considered that, to obtain the quantum vacuum, we have to tend the temperature of the system to the absolute zero. Then the energy of that particular quantum state takes the minimum possible lowest energy.

But researchers have observed that the contribution for the accelerating expansion of the universe by the quantum vacuum energy/matter is much low/null. But yet, there is no any suitable explanation for that argument.

Although some of classically acceptable theoretical concepts are talking about the perfect vacuum, a perfect vacuum is not ideal. That means there is a non-zero vacuum energy in the vacuum space all across the universe.

And when Einstein was discovering and building his General Theory of Relativity, he found that the universe was not steady and instead, the universe was expanding or contracting. But in order to avoid such expansion or contraction, he introduced a term called 'cosmological constant' to his equations. Above mentioned vacuum energy in the space is equivalent to the "Cosmological Constant".

But just around 10 years later, Edwin Hubble discovered that the universe was not steady and it is expanding with the flow of time. Then Einstein understood that his assumption (which he introduced a cosmological constant to avoid the non-steady state of the universe) should be his greatest blunder in his life. 
But in the most recent years, scientists have understood that there should be a positive cosmological constant in the universe. But researchers have identified that the universe that we are currently living is expanding with an acceleration rate. They have considered that there should be some repulsive energy density that causes this accelerating expansion of the universe.

And therefore they identified that the repulsive force induces due to the energy of the cosmological vacuum also. They have figured out that the repulsive force causes by the universal cosmological constant also.

The General Theory of Relativity mentions about the gravitational redshift of the objects in the sky. This redshift is much different from the Redshift in the Doppler Effect. The gravitational redshift causes due to the space-time curvature near a high massive object.

At the beginning of 1915 , the general theory of relativity did not have a solid and strong foundation. It was known that it was correctly accounted for the anomalous precession of perihelion of Mercury and on philosophical grounds, and considered to unify Newton's theory of gravity with special theory of relativity. That considered light appeared to bend in gravitational fields in line with the predictions of general theory that was found in 1919. But it was not perfect, until a program of precision tests was started during the year of 1959 which the various types of predictions of general theory of relativity were tested to any further degree of accuracy in the weak gravitational field limit, severely limiting possible deviations from the theory actually.

The study of astrophysical phenomena can involve several areas of general theory of relativity also. Experimental astrophysics and cosmology research can involve several areas of experimental physics, such as designing, and observing with new telescopes, developing and testing superconducting devices, and analyzing data from observatories to help addressed questions about our universe. Since General theory of relativity has involved in all the areas of astrophysics all most, the applications of the theory are useful and worthy for all of above.

Furthermore, as I mentioned above, the researchers have discovered that the universe that we are living is expanding with an acceleration rate. They analyzed the electromagnetic radiations those were coming from a distant supernova. For that particular discovery, those researchers received the Physics Nobel Prize in 2011. 
Although the researchers have discovered that the universe that we are living currently, is expanding with an accelerating rate, scientists didn't able to explain the reason for such accelerating expansion of the universe. But now there is an innovative notion that would explain that. That is the existence of 'Dark Energy' and 'Dark Matter'. They are arguing that more than $90 \%$ of the universe's energy/matter content is as the form of dark energy/dark matter.

The hypothesis of dark matter has an extraordinary history. In 1884, scientists estimated the number of dark bodies in the Milky Way from the observed velocity dispersion of the stars, those are orbiting around the center of the galaxy. By using these measurements, they estimated the mass of the galaxy, which they determined to be different from the mass of visible stars. Thus scientists concluded that "many of our stars, perhaps a great majority of them, may be the "dark bodies".

The first to attempt to prove the existence of dark matter, using stellar velocities, was done by Dutch astronomer ultimately during the year of 1922. Genius Fellow Dutchman and radio astronomy pioneer Jan Oort also hypothesized the existence of dark matter during 1930's. Oort was studying stellar motions in the local galactic neighborhood and found ultimately that the mass in the galactic plane must be greater than what was observed, but this measurement was determined to be erroneous ultimately.

In 1933, Swiss astrophysicist Fritz Zwicky, who studied galactic clusters while he was working at the California Institute of Technology USA, made a similar inference indeed. Zwicky applied the virial theorem to the Coma Cluster and obtained evidence of un-seen mass that he specifically called as Dunkle Materie 'dark matter'. Scientist Zwicky estimated its mass based on the motions of galaxies near to its edge and compared that to an estimate based on its brightness. He ultimately estimated that the cluster had about 400 times more mass than the visually observable content actually. The gravity effect of the visible galaxies was too small for such fast orbits, thus mass must be hidden from view actually. Based on these conclusions, Zwicky inferred that some unseen matter provided the mass and associated gravitation attraction holds the cluster together in the real world. This was the first formal and exact inference about the existence of dark matter. Zwicky's estimates were off by more than an order of magnitude, mainly due to an obsolete value of the Hubble constant, the same calculation today shows a 
much smaller fraction, using considerably greater values for luminous mass indeed. However, astronomer Zwicky did correctly infer that the bulk of the matter was absolutely dark.

A set of observations during the decade of 1980s indicated its presence, including gravitational lensing of background objects by galaxy clusters, the temperature distribution of hot gas in the considering clusters and the pattern of several anisotropies in the cosmic microwave background radiation. According to respects among lot of astronomers and cosmologists, dark matter is composed primarily of a not yet characterized type of subatomic particle. The search for this particle, is one of the major challenge in particle physics presently. 


\section{Research Methodology}

\section{Methodology part 1}

\subsection{Notations of the Methodology part 1}

$\mathrm{q}=$ Charge of the (charged) Particle,$\epsilon=$ Permittivity of the considering medium

$\mathrm{D}=$ Distance between considering two particles, $\mathrm{r}=$ Distance to the particle from the origin

$\hbar=$ Reduced plank constant, $\mathrm{m}=$ Mass of the considering particle

$\Psi=$ Eigen function of the particle, $\mathrm{E}=$ Eigenvalue of the particle

$V(r)=$ Electric potential energy which affects on the considering particle

$\mathrm{S}(\mathrm{s})=$ Spin function of the wave function of the particle

$\Delta \mathrm{H}=$ The potential energy associated with the interaction of the magnetic field

$\theta \quad=$ Polar angle $\varphi=$ Azimuthal angle

$l, \mathrm{~m}=$ two constants

$\mathrm{i} \quad=\sqrt{ }(-1)$

$\mathrm{e} \quad=$ Exponential function

$\mathrm{L}^{2 l+1} \mathrm{n}-l-1(\mathrm{x})=$ Lagrangian function of $\mathrm{x}$

$\mu_{\mathrm{B}}=$ The Bohr Magneton

$\Omega=$ the vacuum energy of the considering experimental vacuum. 


\subsection{Content of the Methodology part 1}

Let's choose two anti-particles and one particle from the Universe arbitrary. Let's label them as P', P', P. Where P is the particle, $\mathrm{P}$ ' and P' are two anti-particles of P. We place those particle and anti-particles in our research environment as below.

\section{BUT DO NOT COMPARE THE EQUATION NUMBERS AND THE SYMBOLS OTHER PARTS IN THE RESEARCH METHODOLOGY AND IN THIS METHODOLOGY PART NUMBER 01.}

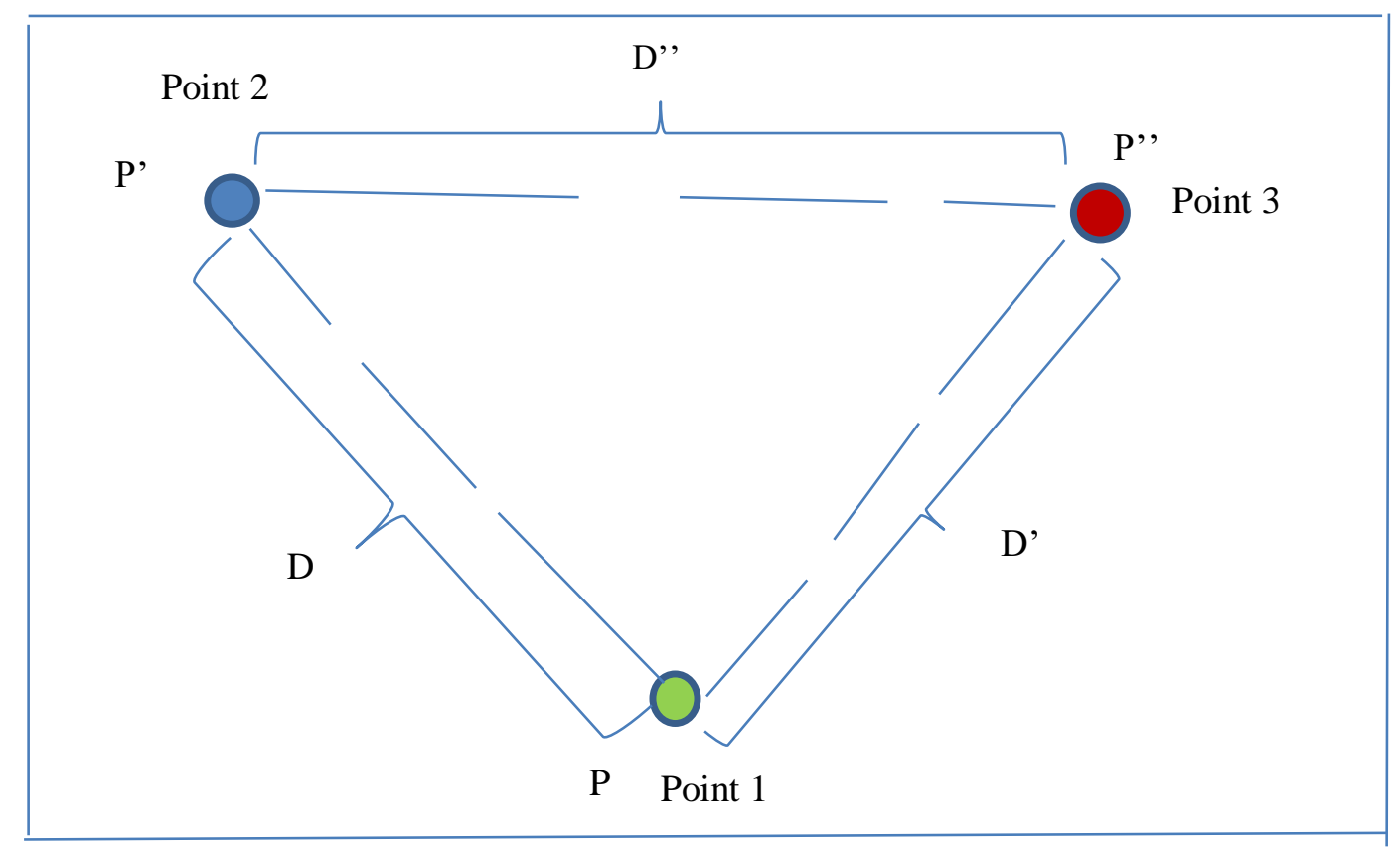

Figure 01 (How particles and anti-particles have located)

We know that the electric potential energy between two charges with $\mathrm{q}_{1}$ and $\mathrm{q}_{2}$ charges $=$

$\mathrm{q}_{1} . \mathrm{q}_{2} /[4 \pi \mathrm{C} . \mathrm{D}]$; where $\mathrm{D}$ is the distance between the two particles and $\mathrm{C}$ is the permittivity of the medium where the particles have located

Here the electric potential energy acting between $P$ and $P^{\prime}=-q^{2} /[4 \pi € . D]$

And the electric potential energy acting between $\mathrm{P}$ and $\mathrm{P}{ }^{\prime \prime}=-\mathrm{q}^{2} /\left[4 \pi \epsilon . \mathrm{D}^{\prime}\right]$ 
Total electric potential energy acting on $\mathrm{P}=-\mathrm{q}^{2} /\left[4 \pi € . \mathrm{D}_{0}\right]$

and

The electric potential energy acting between $\mathrm{P}^{\prime}$ and $\mathrm{P}{ }^{\prime}=+\mathrm{q}^{2} /\left[4 \pi \epsilon . \mathrm{D}{ }^{\prime}\right]$

Total electric potential energy acting on $\mathrm{P}^{\prime}=+\mathrm{q}^{2} /\left[4 \pi € . \mathrm{D}_{1}\right]$

Here $\left.\left(1 / \mathrm{D}_{0}\right)=(\mathrm{D}+\mathrm{D})^{\prime}\right) / \mathrm{D} . \mathrm{D}$ ' and $\left(1 / \mathrm{D}_{1}\right)=\left(\mathrm{D}-\mathrm{D}{ }^{\prime \prime}\right) / \mathrm{D} . \mathrm{D}$ ',

where $\mathrm{D}$ is the distance between $\mathrm{P}$ and $\mathrm{P}$ ', $\mathrm{D}$ ' is the distance between $\mathrm{P}$ and $\mathrm{P}$ ', , D' is the distance between $\mathrm{P}^{\prime}$ and $\mathrm{P}^{\prime}$,

Here P , $\mathrm{P}$ ' and $\mathrm{P}$ ', all are ' $\mathrm{r}$ ' distance away from the origin. And the above figure (01) is a 3-D figure.

*** But we are responsible to choose D , D' and D' such that: $2 / \mathrm{D}=\left(1 / \mathrm{D}^{\prime \prime}\right)-(1 / \mathrm{D}$ ').

Then $2 D^{\prime} \cdot D^{\prime \prime}=\left(D^{\prime}-D^{\prime \prime}\right) \cdot D$ then D'. $D+$ D'.D' = D'.D - D'.D',

Then $\left(\mathrm{D}+\mathrm{D}^{\prime}\right) / \mathrm{D}$ ' $=(\mathrm{D}-\mathrm{D}$ ') $) / \mathrm{D}$ ', . Then $\mathrm{D}_{0}=\mathrm{D}_{1}$. AND WE ARE RESPONSIBLE THAT $\mathrm{D}_{0}=\mathrm{D}_{1}=\mathrm{r}$.

i.e. we are responsible to choose D, D' and D" such that

$\left.2 / \mathrm{D}=\left[\left(1 / \mathrm{D}^{\prime \prime}\right)-\left(1 / \mathrm{D}^{\prime}\right)\right] \underline{\text { and }}\left[\mathrm{D} \cdot \mathrm{D}{ }^{\prime} /(\mathrm{D}+\mathrm{D})^{\prime}\right)\right]\left(=\mathrm{D}_{0}\right)=\mathrm{r}=\left[\mathrm{D} . \mathrm{D}{ }^{\prime} /\left(\mathrm{D}-\mathrm{D}{ }^{\prime}\right)\right]\left(=\mathrm{D}_{1}\right)$.

*** Please remember that in our research environment (the research environment is a mindenvironment), there should be a vacuum. And should assume that the particles P, P', P', all are at rest with respect to each other (we use some mechanism to keep all 3 particles at rest with respect to each other). But the total frame of 3 particles has orbital momentum. And the particles are not rest in regards with the spin motion. Since all P, P', P', are at rest with respect to each other, there is no any change of the distance (r) between each P or P' or P',

But due to the spin of the particles, there is a potential energy associated with the spin magnetic moment from other two particles upon the rest particle in the research environment. Since we keep all P, P', P', big difference away from each other, the forces those are acting on P , P' , P', are the Electric Force and magnetic force (Each spinning particle generates a magnetic field that 
affects on each other two particles. And the total orbital momentum of the reference frame, also induces an orbital magnetic moment with respect to the external rest space). But there is no any orbital momentum of each 3 particles with respect to each other. Therefore the potential energies those affect on $\mathrm{P}$ or $\mathrm{P}$ ' or P', are electric and magnetic potential energies.

And we keep P, P', P', all much away from any external object/matter. Therefore the only potential energies, those affect on $\mathrm{P}$ or $\mathrm{P}$ ' or P' are the electric potential energy due to other two particles, magnetic potential energy due to the spinning of each other two particles, orbital potential and orbital magnetic energies due to the orbital motion of the total frame and $\Omega$. i.e. the potential energy that acts on $\mathrm{P}$ ' are the electric potential energy due to $\mathrm{P}$ and $\mathrm{P}$ " and the magnetic potential energy due to the spin magnetic moments from other two particles upon the rest spinning particle P', orbital magnetic energies due to the orbital motion of the total frame, the electric potential due to $\mathrm{P}$ ', and $\Omega$.

\subsection{Applying the relevant equations}

The 3 dimensional Schrodinger equation for a particle is written as follows:

$-\left(\hbar^{2} / 2 \mathrm{M}\right) \nabla^{2} \psi+\mathrm{V} \psi=\mathrm{E} \psi$

Here $\mathrm{M}$ is the mass of the particle or anti-particle (because mass of the particle/anti-particle is same). *** refer the appendix.

So, that the equation is rewritten in spherical coordinates where,

$$
\nabla^{2}=\frac{1}{r^{2}} \frac{\partial}{\partial}\left(r^{2} \frac{\partial}{\partial}\right)+\frac{1}{r^{2} \sin \theta} \frac{\partial}{\partial \theta}\left(\sin \theta \frac{\partial}{\partial \theta}\right)+\frac{1}{r^{2} \sin ^{2} \theta}\left(\frac{\partial^{2}}{\partial \phi^{2}}\right) \text { Resulting in the following form of }
$$

the Schrodinger equation: 
$\left(-\hbar^{2} / 2 \mathrm{M}\right) \cdot \frac{1}{r^{2} \sin \theta}\left[\sin \theta \frac{\partial}{\partial r}\left(r^{2} \frac{\partial \psi}{\partial r}\right)+\frac{\partial}{\partial \theta}\left(\sin \theta \frac{\partial \psi}{\partial \theta}\right)+\frac{1}{\sin \theta} \frac{\partial^{2} \psi}{\partial \varphi^{2}}\right]+\mathrm{V}(\mathrm{r}) \psi+\Omega \cdot \psi+\Delta \mathrm{H} \psi+\mathrm{S} \psi=\mathrm{E}_{0} \psi$

With: $\psi=\psi(\mathrm{r}, \theta, \varphi), \mathrm{V}(\mathrm{r})=(+/-)\left[\mathrm{q}^{2} /[4 \pi \epsilon . \mathrm{r}]\right]$; here $\mathrm{q}$ is the magnitude of the charge of the particle or anti-particle. But here onwards, I consider $\mathrm{V}(\mathrm{r})=(+/-)\left[\mathrm{q}^{2} / \mathrm{r}\right]$ (because I substitute and consider that $\mathrm{q}^{2} \equiv \mathrm{q}^{2} / 4 \pi \epsilon$ ). And $\Omega$ is the vacuum energy of the considering experimental vacuum.

Here $\Delta \mathrm{H}=2 \cdot \mu_{\mathrm{B}} \cdot \mathrm{B} \cdot \mathrm{m}_{\mathrm{S}}$

Here $\Delta H$ is the potential energy associated with the interaction of the electron's spin magnetic moment with the magnetic field induced due to the magnetic field (induced due to the total magnetic moment of the reference frame due to the the spin of other particles in the frame).

Here the distance to $\mathrm{P}, \mathrm{P}$ ', $\mathrm{P}$ ', from the origin is ' $\mathrm{r}$ '. Moreover, the equivalent distance term that appears on the $\mathrm{V}(\mathrm{r})$ is also ' $r$ '. Because I arrange the locations of $\mathrm{P}, \mathrm{P}$ ', $\mathrm{P}$ ''(inside the experimental vacuum) as those locations give output term $\mathrm{D}_{0}=\left[\left(\mathrm{D}+\mathrm{D}^{\prime}\right) / \mathrm{D} . \mathrm{D}^{\prime}\right]=\mathrm{D}_{1}=$ [ (D - D') / D.D', ] as ' $r$ '. And here $\theta$ is the polar angle to P' (Which is $r$ distance away from the origin) and $\varphi$ is the azimuthal angle to P'. Here we should place P, ' $r$ ' distance away from the origin and the polar angle to $\mathrm{P}$ is $(\theta)$ and azimuthal angle to $\mathrm{P}$ is $(-\varphi)$.

\section{But we locate $P$ and $P '$ such that $\cos \theta>(1 / 2)$}

Beginning with the 3 dimensional form of the Schrodinger equation in spherical coordinates:

$\left(-\hbar^{2} / 2 \mathrm{M}\right) \cdot \frac{1}{r^{2} \sin \theta}\left[\sin \theta \frac{\partial}{\partial r}\left(r^{2} \frac{\partial \psi}{\partial r}\right)+\frac{\partial}{\partial \theta}\left(\sin \theta \frac{\partial \psi}{\partial \theta}\right)+\frac{1}{\sin \theta} \frac{\partial^{2} \psi}{\partial \varphi^{2}}\right]+\mathrm{V}(\mathrm{r}) \psi+\Omega \cdot \psi+\Delta \mathrm{H} \psi+\mathrm{S} \psi=$ $\mathrm{E}_{0} \cdot \psi$

Here $\Delta \mathrm{H}=2 . \mu_{\mathrm{B}} \cdot$ B. $\mathrm{m}_{\mathrm{s}}$ and $\mathrm{S}(\mathrm{s}) \psi=[\sqrt{ } \mathrm{s} .(\mathrm{s}+1)] . \hbar \psi$

Where $\mathrm{s}$ is the spin quantum number of the considering particle / anti particle. 
We want to separate the equation into its radially-dependent portion and its angularly-dependent portion. We use a form of the wave function that assumes this separation:

$\psi(\mathrm{r}, \theta, \varphi)=\mathrm{R}(\mathrm{r}) . \mathrm{Y}(\theta, \phi) . \mathrm{S}(\mathrm{s})$; Where $\mathrm{S}(\mathrm{s})$ is the spin function of the particle's wave function. $\mathrm{R}(\mathrm{r})$ is the radial function of the full wave function, $\mathrm{Y}(\theta, \phi)$ is the angular function of the full wave function.

And insert this into the above equation (03). When this is done the $\mathrm{Y}$ and $\mathrm{R}$ dependent portions of the wave function show up only in those portions of the equation when the relevant $r, \theta$ and $\varphi$ show up

$\left(-\hbar^{2} / 2 \mathrm{M}\right) .\left[\frac{Y . S}{r^{2}} \frac{d}{d r}\left(r^{2} \frac{d R}{d r}\right)+\frac{R . S}{r^{2} \sin \theta} \frac{\partial}{\partial \theta}\left(\sin \theta \frac{d Y}{d \theta}\right)+\frac{R . S}{\mathrm{r}^{2} \sin ^{2} \theta} \frac{\partial^{2} Y}{\partial \varphi^{2}}\right]+\mathrm{V}(\mathrm{r}) . \mathrm{R} . \mathrm{Y} . \mathrm{S}+\Delta \mathrm{H}(\mathrm{R} . \mathrm{Y} . \mathrm{S})+$ $\dot{S} .(Y . R . S)=$ E.R.Y.S

Here $\mathrm{E}=\left(\mathrm{E}_{0}-\Omega\right)$

All the usual matter particles are fermions. But all fermions have $s=(1 / 2)$ spin. And all antifermions also have $s=(1 / 2)$ spin.

Here $\Delta \mathrm{H}=2 \cdot \mu_{\mathrm{B}} \cdot \mathrm{B} \cdot \mathrm{m}_{\mathrm{s}}$

Here $\mu_{\mathrm{B}}$ is the Bohr Magneton.

$\left(-\hbar^{2} / 2 \mathrm{M}\right) .\left[\frac{Y . S}{r^{2}} \frac{d}{d r}\left(r^{2} \frac{d R}{d r}\right)+\frac{R . S}{r^{2} \sin \theta} \frac{\partial}{\partial \theta}\left(\sin \theta \frac{d Y}{d \theta}\right)+\frac{R . S}{\mathrm{r}^{2} \sin ^{2} \theta} \frac{\partial^{2} Y}{\partial \varphi^{2}}\right]+\mathrm{V}(\mathrm{r}) . \mathrm{R} . \mathrm{Y} . \mathrm{S}+\Delta \mathrm{H}(\mathrm{R} . \mathrm{Y} . \mathrm{S})+$ $\dot{S} .(Y . R . S)=$ E.R.Y.S

$\left(-\hbar^{2} / 2 \mathrm{M}\right) .\left[\frac{Y . S}{r^{2}} \frac{d}{d r}\left(r^{2} \frac{d R}{d r}\right)+\frac{R . S}{r^{2} \sin \theta} \frac{\partial}{\partial \theta}\left(\sin \theta \frac{d Y}{d \theta}\right)+\frac{R . S}{\mathrm{r}^{2} \sin ^{2} \theta} \frac{\partial^{2} Y}{\partial \varphi^{2}}\right]+\mathrm{V}(\mathrm{r}) . \mathrm{R} . \mathrm{Y} . \mathrm{S}+\Delta \mathrm{H}(\mathrm{R} . \mathrm{Y} . \mathrm{S})+$ $[\sqrt{ } \mathrm{s} .(\mathrm{s}+1)] . \hbar$.(Y.R.S $)=$ E.R.Y.S

Now, divide the entire equation by (Y.R.S) :

$\left(-\hbar^{2} / 2 \mathrm{M}\right) \cdot\left[\frac{1}{R \cdot r^{2}} \frac{d}{d r}\left(r^{2} \frac{d R}{d r}\right)+\frac{1}{Y \cdot r^{2} \sin \theta} \frac{\partial}{\partial \theta}\left(\sin \theta \frac{d Y}{d \theta}\right)+\frac{1}{\mathrm{Y}^{2} \sin ^{2} \theta} \frac{\partial^{2} Y}{\partial \varphi^{2}}\right]+\mathrm{V}(\mathrm{r})+\Delta \mathrm{H}+\left[\sqrt{ }_{\mathrm{s}} \cdot(\mathrm{s}+1)\right] \cdot \hbar=\mathrm{E}$

Multiply by $\mathrm{r}^{2}$ and $-2 \mathrm{M} / \mathrm{h}^{2}$ 


$$
\begin{aligned}
& {\left[\frac{1}{R} \frac{d}{d r}\left(r^{2} \frac{d R}{d r}\right)+\frac{1}{Y \cdot \sin \theta} \frac{\partial}{\partial \theta}\left(\sin \theta \frac{d Y}{d \theta}\right)+\frac{1}{Y \cdot \sin ^{2} \theta} \frac{\partial^{2} Y}{\partial \varphi^{2}}\right]-\left(2 \cdot \mathrm{M} \cdot \mathrm{r}^{2} / \hbar^{2}\right) \cdot \mathrm{V}(\mathrm{r})-\left(2 \cdot \mathrm{M} \cdot \mathrm{r}^{2} / \hbar^{2}\right) \cdot \Delta \mathrm{H}} \\
& =-\mathrm{E} \cdot\left(2 \cdot \mathrm{M} \cdot \mathrm{r}^{2} / \hbar^{2}\right)+[\sqrt{ } \mathrm{s} \cdot(\mathrm{s}+1)] \cdot \hbar \cdot\left(2 \cdot \mathrm{M} \cdot \mathrm{r}^{2} / \hbar^{2}\right) \\
& =-(\mathrm{E}-[\sqrt{ } \mathrm{s} \cdot(\mathrm{s}+1)) \cdot \hbar]) \cdot\left(2 \cdot \mathrm{M} \cdot \mathrm{r}^{2} / \hbar^{2}\right) \\
& =-(\mathrm{E}-[(\sqrt{ } 3 / 4) \cdot \hbar]) \cdot\left(2 \cdot \mathrm{M} \cdot \mathrm{r}^{2} / \hbar^{2}\right)
\end{aligned}
$$

(Because usually for all fermions and for all anti-fermions, $s=1 / 2$ )

$$
\begin{aligned}
& {\left[\frac{1}{R} \frac{d}{d r}\left(r^{2} \frac{d R}{d r}\right)+\frac{1}{Y \cdot \sin \theta} \frac{\partial}{\partial \theta}\left(\sin \theta \frac{d Y}{d \theta}\right)+\frac{1}{Y \cdot \sin ^{2} \theta} \frac{\partial^{2} Y}{\partial \varphi^{2}}\right]-\left(2 \cdot \mathrm{M} \cdot \mathrm{r}^{2} / \hbar^{2}\right) \cdot \mathrm{V}(\mathrm{r})} \\
& =-\left(\mathrm{E}-2 \cdot \mu_{\mathrm{B}} \cdot \mathrm{B} \cdot \mathrm{m}_{\mathrm{s}}-[\sqrt{ }(3 / 4) \cdot \hbar]\right) \cdot\left(2 \cdot \mathrm{M} \cdot \mathrm{r}^{2} / \hbar^{2}\right) \\
& =-\mathrm{E} \cdot\left(2 \cdot \mathrm{M} \cdot \mathrm{r}^{2} / \hbar^{2}\right)
\end{aligned}
$$

Where $E^{\prime}=\left(E-2 \cdot \mu_{B} \cdot B \cdot m_{s}-\sqrt{ }(3 / 4) . \hbar\right)$

The equation can now be separated into 2 portions, the radially-dependent portion and the angularly-dependent portion:

$\frac{1}{R} \frac{d}{d r}\left(r^{2} \frac{d R}{d r}\right)-\left(2 \cdot \mathrm{M} \cdot \frac{\mathrm{r}^{2}}{\hbar^{2}}\right) \cdot\left[\mathrm{V}-\mathrm{E}^{\prime}\right]+\frac{1}{Y \cdot \sin \theta} \frac{\partial}{\partial \theta}\left(\sin \theta \frac{d Y}{d \theta}\right)+\frac{1}{\mathrm{Y} \cdot \sin ^{2} \theta} \frac{\partial^{2} Y}{\partial \varphi^{2}}=0$

The radial portion of the equation has set to equal to a constant, $l(l+1)$, and the angularly dependent portion has set to equal to the negative of that same constant.

Thus

$\frac{1}{R} \frac{d}{d r}\left(r^{2} \frac{d R}{d r}\right)-\left(2 \cdot \mathrm{M} \cdot \frac{\mathrm{r}^{2}}{\mathrm{~h}^{2}}\right) \cdot\left[\mathrm{V}-\mathrm{E}^{\prime}\right]=l(l+1) \ldots \ldots \ldots \ldots \ldots \ldots \ldots \ldots$

and $\frac{1}{Y \cdot \sin \theta} \frac{\partial}{\partial \theta}\left(\sin \theta \frac{d Y}{d \theta}\right)+\frac{1}{Y \cdot \sin ^{2} \theta} \frac{\partial^{2} Y}{\partial \varphi^{2}}=-l(l+1)$

The angularly-dependent equation can be further separated into its $\theta$ and $\varphi$ portions. Begin by multiplying the angular equation by $\mathrm{Y} \sin ^{2} \theta$, resulting in, 
$\sin \theta \cdot \frac{\partial}{\partial \theta}\left(\sin \theta \frac{d Y}{d \theta}\right)+\frac{\partial^{2} Y}{\partial \varphi^{2}}=-l(l+1) \cdot Y \cdot \sin ^{2} \theta$

Then, redefine the angularly-dependent wave function to explicitly separate these two functions,

$\mathrm{Y}(\theta, \phi)=\Theta(\theta) . \Phi(\phi)$ and insert this new wave function into the angular equation,

$\sin \theta \cdot \frac{\partial}{\partial \theta}\left(\sin \theta \frac{d Y}{d \theta}\right)+\frac{\partial^{2} Y}{\partial \varphi^{2}}=-l(l+1) \cdot \Theta(\theta) \cdot \Phi(\varphi) \cdot \sin ^{2} \theta$

Divide by $[\Theta . \Phi]$ and group into 2 portions, the $\Theta$-dependent and the $\Phi$-dependent,

$[1 / \Phi \Theta] .\left[\sin \theta \frac{\partial}{\partial \theta}\left(\Phi \sin \theta\left(\frac{\partial \Theta}{\partial \theta}\right)\right)+\Theta \frac{d^{2} \Phi}{d \varphi^{2}}\right]=[1 / \Phi \Theta] .\left[-l(l+1) \cdot \Theta(\theta) \cdot \Phi(\varphi) \cdot \sin ^{2} \theta\right] \Rightarrow$

$\left.[1 / \Theta] \cdot\left[\sin \theta \frac{d}{d \theta}\left(\sin \theta\left(\frac{\partial \Theta}{\partial \theta}\right)\right)\right]\right]+l(l+1) \cdot \sin ^{2} \theta+\left[\frac{1}{\Phi}\right] \cdot \frac{d^{2} \Phi}{d \varphi^{2}}=0$

Again, the partial derivatives of the equation become ordinary derivatives once separated. The $\Theta$-dependent portion has set to equal to positive $m^{2}$ and the $\Phi$-dependent portion has set to equal to negative $m^{2}$.

$\left.[1 / \Theta] .\left[\sin \theta \frac{d}{d \theta}\left(\sin \theta\left(\frac{\partial \Theta}{\partial \theta}\right)\right)\right]\right]+l(l+1) \cdot \sin ^{2} \theta=\mathrm{m}^{2}$

$[1 / \Phi] \cdot d^{2} \Phi / d \varphi^{2}=-m^{2}$

$\Phi=\mathrm{e}^{\mathrm{im} \varphi}, \mathrm{m}=+/-\mathrm{m}$

And the solution to the $\theta$-dependent equation is (according to the research done by scientists before):

$\Theta(\theta)=$ C. $P_{l}^{m} \cdot \cos \theta$

Where $\mathrm{C}$ is a constant and $\mathrm{P}_{l}^{\mathrm{m}}$, the associated Legendre function, is described by:

$\mathrm{P}_{l}^{\mathrm{m}}=(-1)^{\mathrm{m}} \cdot\left(1-\mathrm{x}^{2}\right)^{\mathrm{m} / 2}\left(\frac{d}{d x}\right)^{|m|} \cdot \mathrm{P}_{l}(\mathrm{x})$

Where $\mathrm{P}_{l}(\mathrm{x})=\frac{1}{2^{l} l !}\left(\frac{d}{d x}\right)^{l}\left(x^{2}-1\right)^{l}$

Therefore, $\mathrm{Y}_{1}^{\mathrm{m}}(\theta, \varphi)=\mathrm{C} \cdot \mathrm{e}^{\mathrm{im} \varphi} \cdot \mathrm{P}_{l}^{\mathrm{m}}(\cos \theta)$ 
But scientists have already evaluated an expression for $\mathrm{C}$ as below.

$\mathrm{C}=\frac{\sqrt{(2 l+1)(l-\mathrm{m}) !}}{2(l+m) !}$

Therefore, $\quad \mathrm{Y}_{l}^{\mathrm{m}}(\theta, \varphi)=\alpha \cdot \frac{\sqrt{(2 l+1)(l-|\mathrm{m}|) !}}{2(l+|m|) !} \cdot \mathrm{e}^{\mathrm{i} \mathrm{m} \varphi} \cdot \mathrm{P}_{l}^{\mathrm{m}}(\cos \theta)$

where $\alpha=(-1)^{\mathrm{m}}$ for $\mathrm{m} \geq 0$ and $\alpha=1$ for $\mathrm{m}<0$

and $\mathrm{a}_{0}=(+/-)\left(\hbar^{2} /[\right.$ M.(q.q) $\left.]\right)$

Here, when the charges of the considering two particles are same sign; $a_{0}=(+) \hbar^{2} /[$ M.(q.q) ] and when the charges of the considering two particles are opposite signs; $a_{0}=(-) \hbar^{2} /$ [M.(q.q) ] ...(06)

by (3.1), $\frac{1}{R} \frac{d}{d r}\left(r^{2} \frac{d R}{d r}\right)-\left(2 \cdot \mathrm{M} \cdot \frac{\mathrm{r}^{2}}{\hbar^{2}}\right) \cdot\left[\mathrm{V}-\mathrm{E}^{\prime}\right]=l(l+1) \ldots \ldots .(3.1)$

$\left.\frac{1}{R} \frac{d}{d r}\left(r^{2} \frac{d R}{d r}\right)-\left(2 \cdot \mathrm{M} \cdot \frac{\mathrm{r}^{2}}{\hbar^{2}}\right) \cdot\left[\mathrm{V}-\mathrm{E}^{\prime}\right]-l(l+1)\right\}=0$

Then according to the literature scientific works already done by other scientists, we can express an expression for $\mathrm{R}(\mathrm{r})$ as below:

$\mathrm{R}_{\mathrm{n} 1}(\mathrm{r})=\left(\frac{2}{n \cdot a 0}\right)^{\frac{3}{2}}\left(\frac{(n-l-1) !}{2 n[(n+l) !]^{3}}\right)^{1 / 2} \cdot e^{-\frac{r}{n \cdot a 0}} \cdot\left(\frac{2 r}{n \cdot a 0}\right)^{l} \cdot \mathrm{L}_{\mathrm{n}-l-1}^{2 l+1}\left(2 \mathrm{r} / \mathrm{n} \cdot \mathrm{a}_{0}\right)$

Where

$L_{n-i-1}^{2 l+1}(\rho)=\sum_{i=0}^{n-i-1} \frac{(-1)^{i}[(n+l)]^{2} \rho^{i}}{i !(n-l-1-i)(2 l+1+i) !}$

where $\mathrm{a}_{0}=(+/-)\left[\hbar^{2} /[\right.$ (M.q.q) $\left.]\right] \quad($ refer the expression 06)

Therefore, 
$\Psi_{\mathrm{n} 1 \mathrm{~ms}}(\mathrm{r}, \theta, \varphi)=$

$\left(\frac{2}{n \cdot a 0}\right)^{\frac{3}{2}}\left(\frac{(n-l-1) !}{2 n[(n+l) !]^{3}}\right)^{1 / 2} \cdot e^{-\frac{r}{n \cdot a 0}} \cdot\left(\frac{2 r}{n \cdot a 0}\right)^{l} \cdot \mathrm{L}^{21+1}{ }_{\mathrm{n}-l-1}\left(2 \mathrm{r} / \mathrm{n} \cdot \mathrm{a}_{0}\right) . \mathrm{Y}_{1}^{\mathrm{m}}(\theta, \varphi) \cdot \mathrm{S}(\mathrm{s})$

we know that according to (3.2);

$[1 / \Phi(\varphi)] \cdot d^{2} \Phi(\varphi) / d \varphi^{2}=-m^{2}$

and $\Phi=\mathrm{e}^{\mathrm{im} \varphi}$,

When we put $-\varphi$ instead of $\varphi$ to (3.2),

$[1 / \Phi(-\varphi)] \cdot d^{2} \Phi(-\varphi) / d(-\varphi)^{2}=e^{i m \varphi} \cdot(i m)^{2} \cdot e^{-i m \varphi}=-m^{2}$

We know that the polar angle to $\mathrm{P}^{\prime}$ is $\theta$ and azimuthal angle to $\mathrm{P}^{\prime}$ is $\varphi$. And the polar angle to $\mathrm{P}$ is $(\theta)$ and the azimuthal angle to $P$ is $(-\varphi)$.

Therefore according to (09), although we change $\varphi$ to $(-\varphi)$, the value of $\left\{[1 / \Phi(\varphi)] . d^{2} \Phi(\varphi) / d \varphi^{2}\right\}$ does not change.

Therefore, $\left.\left\{[1 / \Phi(\varphi)] \cdot \mathrm{d}^{2} \Phi(\varphi) / \mathrm{d} \varphi^{2}\right\}\right|_{\varphi=-\varphi}=-\mathrm{m}^{2}=\left.\left\{[1 / \Phi(\varphi)] \cdot \mathrm{d}^{2} \Phi(\varphi) / \mathrm{d} \varphi^{2}\right\}\right|_{\varphi=+\varphi}=-\mathrm{m}^{2}$ (10)

And according to (3.1);

$\frac{1}{R} \frac{d}{d r}\left(r^{2} \frac{d R}{d r}\right)-\left(2 \cdot \mathrm{M} \cdot \frac{\mathrm{r}^{2}}{\hbar^{2}}\right) \cdot\left[\mathrm{V}-\mathrm{E}^{\prime}\right]=l(l+1) \ldots$

And both $\mathrm{P}$ and $\mathrm{P}$ ' have located same ' $\mathrm{r}$ ' distance away from the origin. And the masses of $\mathrm{P}$ and $\mathrm{P}^{\prime}$ (which is $\mathrm{M}$ ) are same.

If I have written (3.1) for P, then when we consider the equivalent expression (3.1) for P', we have to change the sign of V(r). But for both $\mathrm{P}$ and $\mathrm{P}$ ', the value ' $r$ ' are same.

Therefore the change of the sign of V (when we jump to consider about P' after considering P) depends on the signs of the two charges those we consider to get the potential energy $\mathrm{V}$

Because $V(r)=(+/-)\left[\mathrm{q}^{2} / \mathrm{r}\right]$ for $\mathrm{P}^{\prime}$ and $\mathrm{P}$ respectively. 
Therefore, if I have written (3.1) for P', then when we consider the equivalent expression (3.1) for $\mathrm{P}$, we have to change the sign of $\mathrm{V}(\mathrm{r})$. Therefore when we consider the equivalent $(l(l+1))$ value in the expression (3.1), for $\mathbf{P}$, we can observe that the change of the value of $(l(l+1))$ (from $\mathrm{P}^{\prime}$ to $\mathrm{P}$ ) depends on the change of the sign of $\mathrm{V}$.

Therefore the change of the value of $l(l+1)$ (when we shift our consideration from particle $\mathrm{P}$ ' to the particle $\mathrm{P}$ ) depends on the sign of $\mathrm{V}$

And there is no any change of the value of ' $\mathrm{n}$ ' for $\mathrm{P}$ and P'. i.e. value of ' $\mathrm{n}$ ' is same for both $\mathrm{P}$ and $\mathrm{P}^{\prime}$

Now let's write wave function $\Psi_{\mathrm{n} 1 \mathrm{~ms}}(\mathrm{r}, \theta, \varphi)$ for $\mathrm{P}$ and $\mathrm{P}$ ' as below:

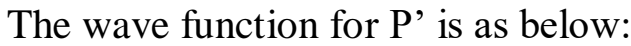

$$
\begin{aligned}
& \Psi_{\mathrm{n} 1 \mathrm{~ms}}(\mathrm{r}, \theta, \varphi)= \\
& \left(\frac{2}{n \cdot a 0}\right)^{\frac{3}{2}}\left(\frac{(n-l-1) !}{2 n[(n+l) !]^{3}}\right)^{1 / 2} \cdot e^{-\frac{r}{n \cdot a 0}} \cdot\left(\frac{2 r}{n \cdot a 0}\right)^{l} \cdot \mathrm{L}^{21+1}{ }_{\mathrm{n}-l-1}\left(2 \mathrm{r} / \mathrm{n} \cdot \mathrm{a}_{0}\right) \cdot\left(\mathrm{Y}^{\mathrm{m}}{ }_{l}(\theta, \varphi)\right) \cdot \mathrm{S}(\mathrm{s})
\end{aligned}
$$

Therefore

$$
\begin{aligned}
& \Psi_{\mathrm{n} 1 \mathrm{~ms}}^{*}(\mathrm{r}, \theta, \varphi)= \\
& \left(\frac{2}{n \cdot a 0}\right)^{\frac{3}{2}}\left(\frac{(n-l-1) !}{2 n[(n+l) !]^{3}}\right)^{1 / 2} \cdot e^{-\frac{r}{n \cdot a 0}} \cdot\left(\frac{2 r}{n \cdot a 0}\right)^{l} \cdot \mathrm{L}^{21+1}{ }_{\mathrm{n}-l-1}\left(2 \mathrm{r} / \mathrm{n} \cdot \mathrm{a}_{0}\right) \cdot \mathrm{S}(\mathrm{s}) \cdot\left(\mathrm{Y}_{l}^{\mathrm{m}}(\theta, \varphi)\right)^{*}
\end{aligned}
$$

But $\mathrm{Y}^{\mathrm{m}}{ }_{l}(\theta, \varphi)=\alpha \cdot \frac{\sqrt{(2 l+1)(l-|\mathrm{m}|) !}}{2(l+|m|) !} \cdot \mathrm{e}^{\mathrm{im} \varphi} \cdot \mathrm{P}_{l}^{\mathrm{m}}(\cos \theta) ; \mathrm{P}_{l}^{\mathrm{m}}=(-1)^{\mathrm{m}} \cdot\left(1-\mathrm{x}^{2}\right)^{\mathrm{m} / 2}\left(\frac{d}{d x}\right)^{|m|} \cdot \mathrm{P}_{l}(\mathrm{x})$ where $\mathrm{P}_{l}(\mathrm{x})=\frac{1}{2^{l} l !}\left(\frac{d}{d x}\right)^{l}\left(x^{2}-1\right)^{l}$, where $\alpha=(-1)^{\mathrm{m}}$ for $\mathrm{m} \geq 0$ and $\alpha=1$ for $\mathrm{m}<0$

Therefore $\left(\mathrm{Y}_{l}^{\mathrm{m}}(\theta, \varphi)\right)^{*}=\alpha \cdot \frac{\sqrt{(2 l+1)(l-|\mathrm{m}|) !}}{2(l+|m|) !} \cdot \mathrm{e}^{-\mathrm{im} \varphi} \cdot \mathrm{P}_{l}^{\mathrm{m}}(\cos \theta)$

Therefore, 


$$
\begin{aligned}
& \Psi^{*} \mathrm{n} 1 \mathrm{~m} \\
& (\mathrm{r}, \theta, \varphi)= \\
& \left(\frac{2}{n \cdot a 0}\right)^{\frac{3}{2}}\left(\frac{(n-l-1) !}{2 n[(n+l) !]^{3}}\right)^{1 / 2} \cdot e^{-\frac{r}{n \cdot a 0}} \cdot\left(\frac{2 r}{n \cdot a 0}\right)^{l} \cdot \mathrm{L}^{21+1}{ }_{\mathrm{n}-l-1}\left(2 \mathrm{r} / \mathrm{n} \cdot \mathrm{a}_{0}\right) \cdot \mathrm{S}(\mathrm{s}) \cdot \alpha \cdot \frac{\sqrt{(2 l+1)(l-|\mathrm{m}|) !}}{2(l+|m|) !} \cdot \mathrm{e}^{-\mathrm{im} \varphi} \cdot \mathrm{P}_{l}^{\mathrm{m}}(\cos \theta)
\end{aligned}
$$

Thus,

$\Psi_{\mathrm{n} 1 \mathrm{~ms}}^{*}(\mathrm{r}, \theta, \varphi) . \Psi_{\mathrm{n} 1 \mathrm{~ms}}(\mathrm{r}, \theta, \varphi)=$

$\left[\left(\frac{2}{n \cdot a 0}\right)^{\frac{3}{2}}\left(\frac{(n-l-1) !}{2 n[(n+l) !]^{3}}\right)^{1 / 2} \cdot e^{-\frac{r}{n \cdot a 0}} \cdot\left(\frac{2 r}{n \cdot a 0}\right)^{l} \cdot \mathrm{L}_{\mathrm{n}-l-1}^{2 l+1}\left(2 \mathrm{r} / \mathrm{n} \cdot \mathrm{a}_{0}\right) \cdot \frac{\sqrt{(2 l+1)(l-|\mathrm{m}|) !}}{2(l+|m|) !} \cdot \mathrm{P}_{l}^{\mathrm{m}}(\cos \theta)\right]^{2} \cdot[\mathrm{S}(\mathrm{s})]^{2}$

$=\left[\left(\frac{2}{n \cdot a 0}\right)^{3}\left(\frac{(n-l-1) !}{2 n[(n+l) !]^{3}}\right) \cdot e^{-\frac{2 r}{n \cdot a 0}} \cdot\left(\frac{2 r}{n \cdot a 0}\right)^{2 l} \cdot\left(\mathrm{L}_{\mathrm{n}-l-1}^{21+1}\left(2 \mathrm{r} / \mathrm{n} \cdot \mathrm{a}_{0}\right)\right)^{2} \cdot \frac{(2 l+1)(l-|m|) !}{[2(l+|m|) !]^{2}} \cdot\left[\mathrm{P}_{l}^{\mathrm{m}}(\cos \theta)\right]^{2} \cdot[\mathrm{S}(\mathrm{s})]^{2}\right.$

$=|\Psi(\mathrm{r}, \theta, \varphi)|^{2}=$ probability of the existance of $\mathrm{P}^{\prime}$ at point 02

For particle $\mathrm{P}$, we must put the value of $\varphi$ as $(-\varphi)$ or put the value of $\varphi$ as $(\varphi)$ according to below Conditions (C).

If $\left(-e^{i m \varphi}>-e^{-i m \varphi}\right)$. Then for particle $P$, we must put the value of $\varphi$ as $\varphi \quad 7$ Conditions (C) If $\left(-\mathrm{e}^{-\mathrm{im} \varphi}>-\mathrm{e}^{\mathrm{im} \varphi}\right)$. Then for particle $\mathrm{P}$, we must put the value of $\varphi$ as $(-\varphi)$

' $\mathrm{r}$ ' is same for both $\mathrm{P}$ and $\mathrm{P}$ '. Moreover, ' $\mathrm{m}$ ' is same for both $\mathrm{P}$ and $\mathrm{P}$ ' according to (10). And ' $\mathrm{n}$ ' is also same for both $\mathrm{P}$ and $\mathrm{P}$ ' according to (13). And we must change the value of ' $l$ ' as ' $l$ ', when shifting from $\mathrm{P}^{\prime}$ to $\mathrm{P}$.

\section{And we must consider a wave function for $\mathbf{P}$ as $\left(l-l^{\prime}\right)$ is an even number condition $(\mathbf{X})$}

And that change of ' $l$ ' depends on the change of the sign of ' $\mathrm{V}$ '. But for the anti-particle and for the particle, spin value is $(1 / 2)$. Thus the spin function $\mathrm{S}(\mathrm{s})$ is same for both $\mathrm{P}$ and $\mathrm{P}$ '. And when shifting from $\mathrm{P}^{\prime}$ to $\mathrm{P}$, I have to change the sign of $\mathrm{a}_{0}$. i.e. we have to put $\left(-\mathrm{a}_{0}\right)$ instead of $\mathrm{a}_{0}$. Let's consider the wave function (which is for the particle P) $\Psi_{\mathrm{n}, l}, \mathrm{~ms}(\mathrm{r}, \theta,-\varphi)$ as below. 
$\Psi_{\mathrm{n}, l} l_{\mathrm{ms}}(\mathrm{r}, \theta,-\varphi)=$

$\left(\frac{2}{n \cdot(-a 0)}\right)^{\frac{3}{2}}\left(\frac{\left(n-l^{\prime}-1\right) !}{2 n\left[\left(n+l^{\prime}\right) !\right]^{3}}\right)^{1 / 2} \cdot e^{+\frac{r}{n \cdot a 0}} \cdot\left(\frac{-2 r}{n \cdot a 0}\right)^{l^{\prime}} \cdot \mathrm{L}^{2 l^{\prime}+1}{ }_{\mathrm{n}-l^{\prime}-1}\left(-2 \mathrm{r} / \mathrm{n} \cdot \mathrm{a}_{0}\right) \cdot\left(\mathrm{Y}_{l^{\prime}}^{\mathrm{m}}(\theta,-\varphi)\right) \cdot \mathrm{S}(\mathrm{s})$

But

$$
L_{n-l-1}^{2 l+1}(0)=\sum_{i=0}^{n-l-1} \frac{(-1)^{i}[(n+l) !]^{2} \rho^{i}}{i !(n-l-1-i) !(2 l+1+i) !}
$$

Thus, $\mathrm{L}^{2 l^{\prime}+1}{ }_{\mathrm{n}-l^{\prime}-1}\left(-2 \mathrm{r} / \mathrm{n} \cdot \mathrm{a}_{0}\right)=-\mathrm{L}^{2 l^{\prime}+1}{ }_{\mathrm{n}-l^{\prime}-1}\left(2 \mathrm{r} / \mathrm{n} \cdot \mathrm{a}_{0}\right) \cdot \delta_{\mathrm{i}}$

Where $\delta_{\mathrm{i}}=\left\{\begin{array}{l}-1 ; \mathrm{i}=2 . \mathrm{k} \\ +1 ; \mathrm{i}=2 . \mathrm{k}+1 \quad \text {; where } \mathrm{k} \text { is a integer }\end{array}\right.$

Thus,

$\Psi_{\mathrm{n}, l} l_{\mathrm{ms}}(\mathrm{r}, \theta,-\varphi)=$

$\left(\frac{2}{n \cdot(a 0)}\right)^{\frac{3}{2}}\left(\frac{\left(n-l^{\prime}-1\right) !}{2 n\left[\left(n+l^{\prime}\right) !\right]^{3}}\right)^{1 / 2} \cdot e^{+\frac{r}{n \cdot a 0}} \cdot\left(\frac{-2 r}{n \cdot a 0}\right)^{l^{\prime}} \cdot \mathrm{L}^{2 l^{\prime}+1}{ }_{\mathrm{n}-l^{\prime}-1}\left(2 \mathrm{r} / \mathrm{n} \cdot \mathrm{a}_{0}\right) \cdot\left(\mathrm{Y}^{\mathrm{m}} l^{\prime}(\theta,-\varphi)\right) \cdot\left[(-1)^{3 / 2} \cdot(-1)\right] \cdot \mathrm{S}(\mathrm{s}) \cdot \delta_{\mathrm{i}}$

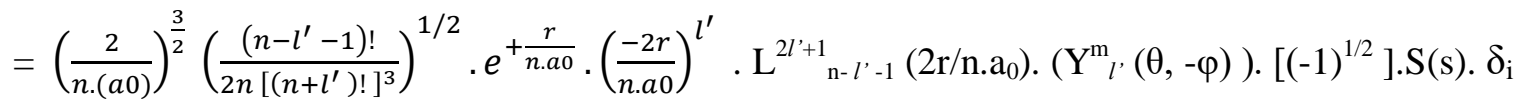

$=\left(\frac{2}{n \cdot(a 0)}\right)^{\frac{3}{2}}\left(\frac{\left(n-l^{\prime}-1\right) !}{2 n\left[\left(n+l^{\prime}\right) !\right]^{3}}\right)^{1 / 2} \cdot e^{+\frac{r}{n \cdot a 0}} \cdot\left(\frac{-2 r}{n \cdot a 0}\right)^{l^{\prime}} \cdot \mathrm{L}_{\mathrm{n}-l^{\prime}-1}^{2 l^{\prime}+1}\left(2 \mathrm{r} / \mathrm{n} \cdot \mathrm{a}_{0}\right) \cdot\left(\mathrm{Y}^{\mathrm{m}} l^{\prime}(\theta,-\varphi)\right) \cdot[\mathrm{i}] \cdot \mathrm{S}(\mathrm{s}) \cdot \delta_{\mathrm{i}}$

$\operatorname{But}\left(\mathrm{Y}^{\mathrm{m}}{ }_{l},(\theta,-\varphi)\right)=\alpha \cdot \frac{\sqrt{\left(2 l^{\prime}+1\right)\left(l^{\prime}-|\mathrm{m}|\right) !}}{2\left(l^{\prime}+|m|\right) !} \cdot \mathrm{e}^{\mathrm{im}(-1 \cdot \varphi)} \cdot \mathrm{P}_{l^{\prime}}{ }^{\mathrm{m}}(\cos (\theta))$

where $\mathrm{P}_{l^{\prime}}(\mathrm{x})=\frac{1}{2^{l^{\prime}} l^{\prime} !}\left(\frac{d}{d x}\right)^{l^{\prime}}\left(x^{2}-1\right)^{l^{\prime}}$

where $\alpha=(-1)^{\mathrm{m}}$ for $\mathrm{m} \geq 0$ and $\alpha=1$ for $\mathrm{m}<0$

Thus $\left(\mathrm{Y}^{\mathrm{m}}{ }_{l},(\theta,-\varphi)\right)=\alpha \cdot \frac{\sqrt{\left(2 l^{\prime}+1\right)\left(l^{\prime}-|\mathrm{m}|\right) !}}{2\left(l^{\prime}+|m|\right) !} \cdot \mathrm{e}^{-\mathrm{im} \cdot \varphi} \cdot \mathrm{P}_{l^{\prime}}{ }^{\mathrm{m}}(\cos \theta)$ 
Thus $\left(\Psi_{\mathrm{n}, l, \mathrm{~m}, \mathrm{~s}}(\mathrm{r}, \theta,-\varphi)\right)^{*}=$

$\left\{\left(\frac{2}{n \cdot(a 0)}\right)^{\frac{3}{2}}\left(\frac{\left(n-l^{\prime}-1\right) !}{2 n\left[\left(n+l^{\prime}\right) !\right]^{3}}\right)^{1 / 2} \cdot e^{+\frac{r}{n \cdot a 0}} \cdot\left(\frac{-2 r}{n \cdot a 0}\right)^{l^{\prime}} \cdot \mathrm{L}^{2 l^{\prime}+1}{ }_{\mathrm{n}-l^{\prime}-1}\left(2 \mathrm{r} / \mathrm{n} \cdot \mathrm{a}_{0}\right)\right\} *$

$\left\{\alpha \cdot \frac{\sqrt{\left(2 l^{\prime}+1\right)\left(l^{\prime}-|\mathrm{m}|\right) !}}{2\left(l^{\prime}+|m|\right) !} \cdot \mathrm{e}^{+\mathrm{im} \cdot \varphi} \cdot \mathrm{P}_{l^{\prime}}{ }^{\mathrm{m}}(\cos \theta)[-\mathrm{i}] \cdot \mathrm{S}(\mathrm{s})\right\} . \delta_{\mathrm{i}}$

Thus $\left(\Psi_{\mathrm{n}, l^{\prime}, \mathrm{ms}}(\mathrm{r}, \theta,-\varphi)\right)^{*}\left(\Psi_{\mathrm{n}, l}, \mathrm{~ms}(\mathrm{r}, \theta,-\varphi)\right)=$

$\left\{\left(\frac{2}{n \cdot(a 0)}\right)^{\frac{3}{2}}\left(\frac{\left(n-l^{\prime}-1\right) !}{2 n\left[\left(n+l^{\prime}\right) !\right]^{3}}\right)^{1 / 2} \cdot e^{+\frac{r}{n \cdot a 0}} \cdot\left(\frac{-2 r}{n \cdot a 0}\right)^{l^{\prime}} \cdot \mathrm{L}^{2 l^{\prime}+1}{ }_{\mathrm{n}-l^{\prime}-1}\left(2 \mathrm{r} / \mathrm{n} \cdot \mathrm{a}_{0}\right)\right\}$

$\left.\left\{\alpha \cdot \frac{\sqrt{\left(2 l^{\prime}+1\right)\left(l^{\prime}-|\mathrm{m}|\right) !}}{2\left(l^{\prime}+|m|\right) !} \cdot \mathrm{e}^{+\mathrm{im} \cdot \varphi} \cdot \mathrm{P}_{l^{\prime}}{ }^{\mathrm{m}}(\cos \theta)[-\mathrm{i}]\right\} \cdot \mathrm{S}(\mathrm{s})\right\} * \delta_{\mathrm{i}} *$

$\left\{\left(\frac{2}{n \cdot(a 0)}\right)^{\frac{3}{2}}\left(\frac{\left(n-l^{\prime}-1\right) !}{2 n\left[\left(n+l^{\prime}\right) !\right]^{3}}\right)^{1 / 2} \cdot e^{+\frac{r}{n \cdot a 0}} \cdot\left(\frac{-2 r}{n \cdot a 0}\right)^{l^{\prime}} \cdot \mathrm{L}^{2 l^{\prime}+1}{ }_{\mathrm{n}-l^{\prime}-1}\left(2 \mathrm{r} / \mathrm{n} \cdot \mathrm{a}_{0}\right)\right\} *$

$\left\{\alpha \cdot \frac{\sqrt{\left(2 l^{\prime}+1\right)\left(l^{\prime}-|\mathrm{m}|\right) !}}{2\left(l^{\prime}+|m|\right) !} \cdot \mathrm{e}^{-\mathrm{im} \cdot \varphi} \cdot \mathrm{P}_{l^{\prime}}{ }^{\mathrm{m}}(\cos \theta)[\mathrm{i}]\right\} . \mathrm{S}(\mathrm{s}) * \delta_{\mathrm{i}}$

$=\left\{\left(\frac{2}{n \cdot(a 0)}\right)^{3}\left(\frac{\left(n-l^{\prime}-1\right) !}{2 n\left[\left(n+l^{\prime}\right) !\right]^{3}}\right) \cdot e^{+\frac{2 r}{n \cdot a 0}} \cdot\left(\frac{-2 r}{n \cdot a 0}\right)^{2 l^{\prime}} \cdot\left[\mathrm{L}^{2 l^{\prime}+1} \mathrm{n}-l^{\prime}-1\left(2 \mathrm{r} / \mathrm{n} \cdot \mathrm{a}_{0}\right)\right]^{2}\right\} *$

$\left\{\frac{\left(2 l^{\prime}+1\right)\left(l^{\prime}-|\mathrm{m}|\right) !}{\left[2\left(l^{\prime}+|m|\right) !\right]^{2}} \cdot\left[\mathrm{P}_{l^{\prime}}{ }^{\mathrm{m}}(\cos \theta)\right]^{2} \cdot\left[-\mathrm{i}^{2}\right] \cdot[\mathrm{S}(\mathrm{s})]^{2}\right\}$

$=\left\{\left(\frac{2}{n \cdot(a 0)}\right)^{3}\left(\frac{\left(n-l^{\prime}-1\right) !}{2 n\left[\left(n+l^{\prime}\right) !\right]^{3}}\right) \cdot e^{+\frac{2 r}{n \cdot a 0}} \cdot\left(\frac{2 r}{n \cdot a 0}\right)^{2 l^{\prime}} \cdot\left[\mathrm{L}^{2 l^{\prime}+1}{ }_{\mathrm{n}-l^{\prime}-1}\left(2 \mathrm{r} / \mathrm{n} \cdot \mathrm{a}_{0}\right)\right]^{2}\right\} *$

$\left\{\frac{\left(2 l^{\prime}+1\right)\left(l^{\prime}-|\mathrm{m}|\right) !}{\left[2\left(l^{\prime}+|m|\right) !\right]^{2}} \cdot\left[\mathrm{P}_{l}{ }^{\mathrm{m}}(\cos \theta)\right]^{2} \cdot[\mathrm{S}(\mathrm{s})]^{2}\right\}$ 
Thus

$\left(\Psi_{\mathrm{n}, l, \mathrm{~m}}(\mathrm{r}, \theta,-\varphi)\right)^{*} \cdot\left(\Psi_{\mathrm{n}, l^{\prime}, \mathrm{m}}(\mathrm{r}, \theta,-\varphi)\right)=$

$\left.\left(\frac{2}{n \cdot a 0}\right)^{3}\left(\frac{\left(n-l^{\prime}-1\right) !}{2 n\left[\left(n+l^{\prime}\right) !\right]^{3}}\right) \cdot e^{+\frac{2 r}{n \cdot a 0}} \cdot\left(\frac{2 r}{n \cdot a 0}\right)^{2 l^{\prime}} \cdot\left[\mathrm{L}^{2 l^{\prime}+1}{ }_{\mathrm{n}-l^{\prime}-1}\left(2 \mathrm{r} / \mathrm{n} \cdot \mathrm{a}_{0}\right)\right]^{2}\right\} \cdot\left\{\frac{\left(2 l^{\prime}+1\right)\left(l^{\prime}-|\mathrm{m}|\right) !}{\left[2\left(l^{\prime}+|m|\right) !\right]^{2}}\right\} *$

$\left[\mathrm{P}_{l}{ }^{\mathrm{m}}(\cos \theta)\right]^{2} \cdot[\mathrm{S}(\mathrm{s})]^{2}$

$=\left|\Psi_{\mathrm{n}, l}, \mathrm{~ms}(\mathrm{r}, \theta,-\varphi)\right|^{2}=$ probability of the existence of $\mathrm{P}$ at point $01=\mathrm{A}_{1}$

By (14),

$\left[\left(\frac{2}{n \cdot a 0}\right)^{3}\left(\frac{(n-l-1) !}{2 n[(n+l) !]^{3}}\right) \cdot e^{-\frac{2 r}{n \cdot a 0}} \cdot\left(\frac{2 r}{n \cdot a 0}\right)^{2 l} \cdot\left(\mathrm{L}_{\mathrm{n}-l-1}^{21+1}\left(2 \mathrm{r} / \mathrm{n} \cdot \mathrm{a}_{0}\right)\right)^{2} \cdot \frac{(2 l+1)(l-|m|) !}{[2(l+|m|) !]^{2}} \cdot\left[\mathrm{P}_{l}^{\mathrm{m}}(\cos \theta)\right]^{2} \cdot[\mathrm{S}(\mathrm{s})]^{2}\right.$

$=\left|\Psi_{\mathrm{n} l \mathrm{~ms}}(\mathrm{r}, \theta, \varphi)\right|^{2}=$ probability of the existence of $\mathrm{P}^{\prime}$ at point $02=\mathrm{A}_{2}$

Where

$$
L_{n-l-1}^{2 l+1}(0)=\sum_{i=0}^{n-i-1} \frac{(-1)^{i}[(n+l)]^{2} \rho^{i}}{i !(n-l-1-i) !(2 l+1+i) !}
$$

and

$\mathrm{P}_{l}^{\mathrm{m}}=(-1)^{\mathrm{m}} \cdot\left(1-\mathrm{x}^{2}\right)^{\mathrm{m} / 2}\left(\frac{d}{d x}\right)^{|m|} \cdot \mathrm{P}_{l}(\mathrm{x})$

where $\mathrm{P}_{l}(\mathrm{x})=\frac{1}{2^{l} l !}\left(\frac{d}{d x}\right)^{l}\left(x^{2}-1\right)^{l}$

The difference between (14) and (15) is due to the value ' $l$ ' and ' $l$ ' ' also.

Вy (3.1); $\frac{1}{R} \frac{d}{d r}\left(r^{2} \frac{d R}{d r}\right)-\left(2 . \mathrm{M} \cdot \frac{\mathrm{r}^{2}}{\hbar^{2}}\right) \cdot\left[\mathrm{V}-\mathrm{E}^{\prime}\right]=l(l+1) \ldots \ldots \ldots \ldots \ldots \ldots \ldots \ldots \ldots \ldots \ldots$

But $E^{\prime}=\left(E-2 \cdot \mu_{B} \cdot B \cdot m_{s}-\sqrt{ }(3 / 4) . \hbar\right)$

But for $\mathrm{P}^{\prime}$ the value of $\mathrm{V}$ is a positive value. But for $\mathrm{P}, \mathrm{V}<0$.

Because for $\mathrm{P},\left.\mathrm{V}(\mathrm{r})\right|_{\mathrm{p}}=-\mathrm{V}(\mathrm{r})=-\mathrm{q}^{2} / \mathrm{r}$. And $\mathrm{V}(\mathrm{r})_{\mid \mathrm{P}},=\mathrm{q}^{2} / \mathrm{r}$ 
Thus by (3.1) by considering $\mathrm{P}: \frac{1}{R} \frac{d}{d r}\left(r^{2} \frac{d R}{d r}\right)-\left(2 \cdot \mathrm{M} \cdot \frac{\mathrm{r}^{2}}{\hbar^{2}}\right) \cdot\left[-\mathrm{V}-\left(\mathrm{E}^{\prime}\right) \mid \mathrm{p}\right]=l^{\prime}\left(l^{\prime}+1\right)$

$\frac{1}{R} \frac{d}{d r}\left(r^{2} \frac{d R}{d r}\right)+\left(2 \cdot \mathrm{M} \cdot \frac{\mathrm{r}^{2}}{\hbar^{2}}\right) \cdot\left[\mathrm{V}+\mathrm{E}^{\prime} \mid p\right]=l^{\prime}\left(l^{\prime}+1\right)$

But for $\mathrm{P}^{\prime}, \mathrm{V}(\mathrm{r})=\mathrm{q}^{2} / \mathrm{r}>0$;

Thus $\frac{1}{R} \frac{d}{d r}\left(r^{2} \frac{d R}{d r}\right)-\left(2 \cdot \mathrm{M} \cdot \frac{\mathrm{r}^{2}}{\hbar^{2}}\right) \cdot\left[\mathrm{V}-\mathrm{E}^{\prime} \mid p^{\prime}\right]=l(l+1)$

Therefore for $\mathrm{P}^{\prime}$ :

Thus $\frac{1}{R} \frac{d}{d r}\left(r^{2} \frac{d R}{d r}\right)+\left(2 \cdot \mathrm{M} \cdot \frac{\mathrm{r}^{2}}{\hbar^{2}}\right) \cdot\left[\mathrm{E}^{\prime} \mid p^{\prime}-V\right]=l(l+1)$

By (17) and (18);

$l(l+1)-l^{\prime}(l+1)=\left(2 \cdot \mathrm{M} \cdot \frac{\mathrm{r}^{2}}{\hbar^{2}}\right) \cdot\left[\mathrm{E}^{\prime}\left|p^{\prime}-2 V-\mathrm{E}^{\prime}\right| p\right]$

But $\left(\left.E^{\prime}\right|_{p}\right)^{\prime}=\left(E-2 \cdot \mu_{B} \cdot B \cdot m_{s}-\sqrt{ }(3 / 4) \cdot \hbar\right)$

$\left(\left.E^{\prime}\right|_{p}\right)=\left(E_{-}-2 \cdot \mu_{B} \cdot B \cdot\left(m_{s}\right)_{P}-\sqrt{ }(3 / 4) \cdot \hbar\right)$

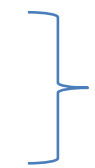

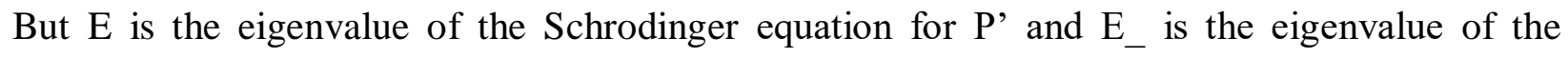
Schrodinger equation for the particle P. And in (19.1), we keep the external magnetic field that let $m_{s}=\left(m_{s}\right)_{P}$

The Schrodinger equation for $\mathrm{P}$ ' contains a positive electric potential term ( V(r) ). But the Schrodinger equation for $\mathrm{P}$ contains a negative electric potential term ( $-\mathrm{V}(\mathrm{r}))$.

And the difference between $\mathrm{E}$ and $\mathrm{E}_{-}$occurred due to the sign of $\mathrm{V}(\mathrm{r})$. Thus under the conditions (C) above and by (i) :

$\mathrm{E}-\mathrm{E}_{-}=2 \mathrm{~V}-\left(\hbar^{2} / 2 \mathrm{M}\right) \cdot \frac{1}{r^{2} \sin ^{2} \theta}\left[-m^{2} \cdot e^{i m \varphi}-\left(-m^{2} \cdot e^{-i m \varphi}\right)\right]$

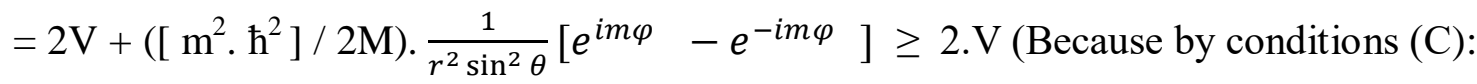

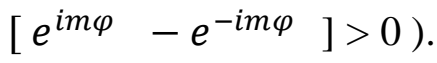


Therefore $\left(E^{-}-E_{-}\right) \geq 2 \mathrm{~V}$. Thus by $19.1:\left(\left.\mathrm{E}^{\prime}\right|_{\mathrm{p}}{ }^{\prime}\right)-\left(\left.\mathrm{E}^{\prime}\right|_{\mathrm{p}}\right) \geq 2 \mathrm{~V}$

Thus

$\left[\mathrm{E}^{\prime}\left|p^{\prime}-2 V-\mathrm{E}^{\prime}\right| p\right] \geq 0$. By (19), $l(l+1) \geq l^{\prime}\left(l^{\prime}+1\right)$.

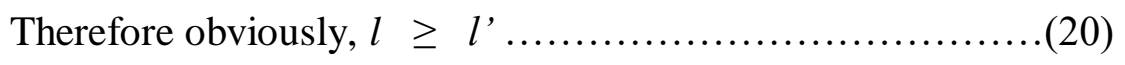

By (14) and (15) :

$\mathrm{A}_{1} / \mathrm{A}_{2}=$

$\left.\left(\frac{\left(n-l^{\prime}-1\right) !}{2 n\left[\left(n+l^{\prime}\right) !\right]^{3}}\right) \cdot e^{+\frac{2 r}{n \cdot a 0}} \cdot\left(\frac{2 r}{n \cdot a 0}\right)^{2 l^{\prime}} \cdot\left[\mathrm{L}^{2 l^{\prime}+1}{ }_{\mathrm{n}-l^{\prime}-1}\left(2 \mathrm{r} / \mathrm{n} \cdot \mathrm{a}_{0}\right)\right]^{2}\right\} \cdot\left\{\frac{\left(2 l^{\prime}+1\right)\left(l^{\prime}-|\mathrm{m}|\right) !}{\left[2\left(l^{\prime}+|m|\right) !\right]^{2}}\right\} \cdot\left[\mathrm{P}_{l^{\prime}}{ }^{\mathrm{m}}(\cos \theta)\right]^{2}$

$\left(\frac{(n-l-1) !}{2 n[(n+l) !]^{3}}\right) \cdot e^{-\frac{2 r}{n \cdot a 0}} \cdot\left(\frac{2 r}{n \cdot a 0}\right)^{2 l} \cdot\left(\mathrm{L}^{2 l+1}{ }_{\mathrm{n}-l-1}\left(2 \mathrm{r} / \mathrm{n} \cdot \mathrm{a}_{0}\right)\right)^{2} \cdot \frac{(2 l+1)(l-|m|) !}{[2(l+|m|) !]^{2}} \cdot\left[\mathrm{P}_{l}^{\mathrm{m}}(\cos \theta)\right]^{2}$

Thus $\mathrm{A}_{1} / \mathrm{A}_{2}=$

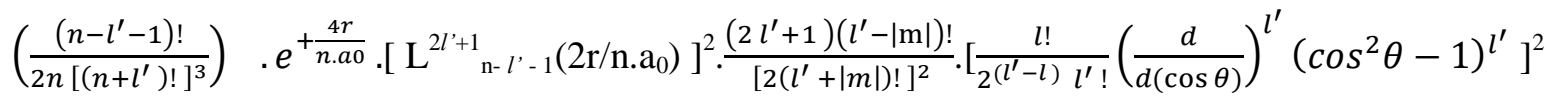

$\left.\left(\frac{(n-l-1) !}{2 n[(n+l) !]^{3}}\right) \cdot\left(\frac{2 r}{n \cdot a 0}\right)^{2\left(l-l^{\prime}\right)}\left[\mathrm{L}^{2 l+1}{ }_{\mathrm{n}-l-1}\left(2 \mathrm{r} / \mathrm{n} \cdot \mathrm{a}_{0}\right)\right]^{2}\right\} \cdot\left\{\frac{(2 l+1)(l-|\mathrm{m}|) !}{[2(l+|m|) !]^{2}}\right\} \cdot\left[\left(\frac{d}{d(\cos \theta)}\right)^{l}\left(\cos ^{2} \theta-1\right)^{l}\right]^{2}$

We know that according to quantum mechanics, $l \geq l$ ' 
But,

$\left[\frac{\left(n-l^{\prime}-1\right) !}{2 n\left[\left(n+l^{\prime}\right) !\right]^{3}} * \frac{2 n[(n+l) !]^{3}}{(n-l-1) !}\right]=$

$\left[(n+l) \cdot(\mathrm{n}+l-1) \ldots \ldots\left(\mathrm{n}+l^{\prime}+1\right)\right]^{3} /\left[(\mathrm{n}-l-1) .(\mathrm{n}-l-2) \ldots \ldots \ldots .\left(\mathrm{n}-l^{\prime}\right)\right]>1$

$\operatorname{But}\left(l^{\prime}-|m|\right) ! \cdot\left[(l+|\mathrm{m}|) !^{2} /\left[\left(l^{\prime}+|\mathrm{m}|\right) !\right]^{2}\{(l-|\mathrm{m}|) !]=\right.$

$\left[(l+|\mathrm{m}|) .(l+|\mathrm{m}|-1) \ldots\left(l^{\prime}+|\mathrm{m}|+1\right)\right]^{2} /\left[(l-|\mathrm{m}|) .(l-|\mathrm{m}|-1) \ldots\left(l^{\prime}+1-|\mathrm{m}|\right)\right]$.

But $[(l+|\mathrm{m}|-\mathrm{i})]^{2} /(l-|\mathrm{m}|-\mathrm{i})>1$ for each $\mathrm{i} \geq 0$. And similar to that $\left(l^{\prime}+|\mathrm{m}|+1\right)^{2} /\left(l^{\prime}+1-|\mathrm{m}|\right)>1$

Thus $\left[(l+|\mathrm{m}|) \cdot(l+|\mathrm{m}|-1) \ldots\left(l^{\prime}+|\mathrm{m}|+1\right)\right]^{2} /\left[(l-|\mathrm{m}|) .(l-|\mathrm{m}|-1) \ldots\left(l^{\prime}+1-|\mathrm{m}|\right)\right]>1$

Thus $\left[(l+|\mathrm{m}|) ! /\left(l^{\prime}+|\mathrm{m}|\right) !\right]^{2} /\left\{(l-|\mathrm{m}|) ! /\left(l^{\prime}-|m|\right) !>1 \ldots \ldots \ldots \ldots . . .(20.1 .0)\right.$

Then $\left(2 l^{\prime}+1\right) /(2 l+1)=\left[1+\left(1 / 2 l^{\prime}\right)\right] /\left[\left(l / l^{\prime}\right)+\left(1 / 2 . l^{\prime}\right)\right]>1 /\left[\left(l / l l^{\prime}\right)+1\right]\left(\right.$ because $\left.l^{\prime}>1\right)$

Then $\left(2 l^{\prime}+1\right) /(2 l+1)>l^{\prime} /\left[l+l^{\prime}\right]>1 /\left[l+l^{\prime}\right]>1 /[2 . l]$ ( because $l^{\prime}>1$ and $\left.l \geq l^{\prime}\right)$.

Thus by (20.1.1) and (20.1.0):

$\left(l^{\prime}-|m|\right) ! .\left[(l+|\mathrm{m}|) !^{2} /\left[\left(l^{\prime}+|\mathrm{m}|\right) !\right]^{2}\{(l-|\mathrm{m}|) !]^{*}\left[\left(2 l l^{\prime}+1\right) /(2 l+1)\right]>(1 / 2 . l)\right.$

Thus $\left[\frac{\left(2 l^{\prime}+1\right)\left(l^{\prime}-|\mathrm{m}|\right) !}{\left[\left(l^{\prime}+|m|\right) !\right]^{2}} * \frac{[(l+|m|) !]^{2}}{(2 l+1)(l-|\mathrm{m}|) !}\right]>(1 / 2 . l)>0 \ldots \ldots \ldots \ldots . . .(20.2)$

for $l^{\prime}=4 ;\left[\left(\frac{d}{d(\cos \theta)}\right)^{l^{\prime}}\left(\cos ^{2} \theta-1\right)^{l^{\prime}}\right]^{2}=\left[1680 \cdot \cos ^{4} \theta+144-1440 \cdot \cos ^{2} \theta\right]^{2}$,

for $l^{\prime}=3 ;\left[\left(\frac{d}{d(\cos \theta)}\right)^{l^{\prime}}\left(\cos ^{2} \theta-1\right)^{l^{\prime}}\right]^{2}=\left[72 \cdot \cos \theta-120 \cdot \cos ^{3} \theta\right]^{2}$

for $l^{\prime}=2 ; \quad\left[\left(\frac{d}{d(\cos \theta)}\right)^{l^{\prime}}\left(\cos ^{2} \theta-1\right)^{l^{\prime}}\right]^{2}=\left[4-12 \cdot \cos ^{2} \theta\right]^{2}=16+144 \cdot \cos ^{4} \theta-96 \cdot \cos ^{2} \theta$

for $l^{\prime}=1 ;\left[\left(\frac{d}{d(\cos \theta)}\right)^{l^{\prime}}\left(\cos ^{2} \theta-1\right)^{l^{\prime}}\right]^{2}=4 \cdot \cos ^{2} \theta$ 
By considering above sequence it is obvious that when the value $l$ ' increases, the value of $\left[\left(\frac{d}{d(\cos \theta)}\right)^{l^{\prime}}\left(\cos ^{2} \theta-1\right)^{l^{\prime}}\right]^{2}$ increases. But, we locate $\mathbf{P}$ and $\mathbf{P}^{\prime}$ such that $\cos \boldsymbol{\theta}>(\mathbf{1} / \mathbf{2})$

Then all $\left[\left(\frac{d}{d(\cos \theta)}\right)^{l}\left(\cos ^{2} \theta-1\right)^{l} \geq 1\right.$ and $\left[\left(\frac{d}{d(\cos \theta)}\right)^{l^{\prime}}\left(\cos ^{2} \theta-1\right)^{l^{\prime}}\right] \geq 1$

(By considering above calculations for $\left[\left(\frac{d}{d(\cos \theta)}\right)^{l^{\prime}}\left(\cos ^{2} \theta-1\right)^{l^{\prime}}\right]^{2}$ ).

Thus $\left[\left(\frac{d}{d(\cos \theta)}\right)^{l^{\prime}}\left(\cos ^{2} \theta-1\right)^{l^{\prime}}\right]^{2} /\left[\left(\frac{d}{d(\cos \theta)}\right)^{l}\left(\cos ^{2} \theta-1\right)^{l}\right]^{2} \leq 1$

And $\left[\frac{l !}{2^{\left(l^{\prime}-l\right)} l^{\prime} !}\right]^{2}=\left[l \cdot(l-1) .(l-2) \ldots \ldots \ldots . .\left(l^{\prime}+1\right) \cdot 2^{\left(l-l^{\prime}\right)}\right]^{2}>2$ Therefore,

$$
\left[\frac{l !}{2^{\left(l^{\prime}-l\right)} l^{\prime} !}\right]^{2}>\left\{\left[\left(\frac{d}{d(\cos \theta)}\right)^{l^{\prime}}\left(\cos ^{2} \theta-1\right)^{l^{\prime}}\right] /\left[\left(\frac{d}{d(\cos \theta)}\right)^{l}\left(\cos ^{2} \theta-1\right)^{l}\right] .\left[\frac{l !}{2^{\left(l^{\prime}-l\right)} l^{\prime} !}\right]\right\}^{2}
$$

Thus

$\left[\frac{l !}{2^{\left(l^{\prime}-l\right)} l^{\prime} !}\right]^{2}>\left\{\left[\left(\frac{d}{d(\cos \theta)}\right)^{l^{\prime}}\left(\cos ^{2} \theta-1\right)^{l^{\prime}}\right] /\left[\left(\frac{d}{d(\cos \theta)}\right)^{l}\left(\cos ^{2} \theta-1\right)^{l}\right]\right\}^{2} \cdot\left[\frac{l !}{2^{\left(l^{\prime}-l\right)} l^{\prime} !}\right]^{2}$

But

$$
L_{n-l-1}^{2 i+1}(\rho)=\sum_{i=0}^{n-i-1} \frac{(-1)^{i}[(n+l) !]^{2} \rho^{i}}{i !(n-l-1-i) !(2 l+1+i) !}
$$

And $\left[e^{+\frac{4 r}{n . a 0}} /\left(\frac{2 r}{n . a 0}\right)^{2\left(l-l^{\prime}\right)}\right]=1+\left(\frac{4 r}{n . a 0}\right)+\frac{\left(\frac{4 r}{n . a 0}\right)}{2 !}+\frac{\left.\left(\frac{4 r}{n a 0}\right)^{2}\right)}{3 !}+\ldots \ldots \ldots \ldots \ldots+\frac{\left.\left(\frac{4 r}{n a 0}\right)^{x}\right)}{x !}+\ldots \ldots \ldots \ldots$

$$
\left(\frac{2 r}{n . a 0}\right)^{2\left(l-l^{\prime}\right)}
$$

(22); $\mathrm{x}$ is a natural number

$\operatorname{But}\left(4 \mathrm{r} / \mathrm{na}_{0}\right)>0$. Thus

$\left[e^{+\frac{4 r}{n . a 0}} /\left(\frac{2 r}{n . a 0}\right)^{2\left(l-l^{\prime}\right)}\right]>\left(\frac{n \cdot a 0}{2 r}\right)^{2\left(l-l^{\prime}\right)} \geq 0$ 
$\left.\left(\frac{\left(n-l^{\prime}-1\right) !}{2 n\left[\left(n+l^{\prime}\right) !\right]^{3}}\right) \cdot e^{+\frac{4 r}{n \cdot a 0}} \cdot\left[\mathrm{L}^{2 l^{\prime}+1}{ }_{\mathrm{n}-l^{\prime}-1}\left(2 \mathrm{r} / \mathrm{n} \cdot \mathrm{a}_{0}\right)\right]^{2}\right\} \cdot\left\{\frac{\left(2 l^{\prime}+1\right)\left(l^{\prime}-|\mathrm{m}|\right) !}{\left[2\left(l^{\prime}+|m|\right) !\right]^{2}}\right\} \quad=\mathrm{F}$

$\overline{\left(\frac{(n-l-1) !}{2 n[(n+l) !]^{3}}\right) \cdot\left(\frac{2 r}{n \cdot a 0}\right)^{2\left(l-l^{\prime}\right)}\left[\mathrm{L}^{2 l+1}{ }_{\mathrm{n}-l-1}\left(2 \mathrm{r} / \mathrm{n} \cdot \mathrm{a}_{0}\right)\right]^{2} \cdot\left\{\frac{(2 l+1)(l-|\mathrm{m}|) !}{[2(l+|m|) !]^{2}}\right\}}$

By $(20.1),(20.2),(23)$ and since $\left[\mathrm{L}^{2 l^{\prime}+1}{ }_{\mathrm{n}-l^{\prime}-1}\left(2 \mathrm{r} / \mathrm{n} \cdot \mathrm{a}_{0}\right)\right]^{2 \mathrm{i}} \geq 0$ and since $\left[\mathrm{L}^{2 l+1}{ }_{\mathrm{n}-l-1}\left(2 \mathrm{r} / \mathrm{n} \cdot \mathrm{a}_{0}\right)\right]^{2} \geq 0$ :

$\mathrm{F} \geq 0$

By (21):

$\left[\frac{l !}{2^{\left(l^{\prime}-l\right)} l^{\prime} !}\right]^{2}>\left[\left[\left(\frac{d}{d(\cos \theta)}\right)^{l^{\prime}}\left(\cos ^{2} \theta-1\right)^{l^{\prime}}\right] /\left[\left(\frac{d}{d(\cos \theta)}\right)^{l}\left(\cos ^{2} \theta-1\right)^{l}\right]\right]^{2} \cdot\left[\frac{l !}{2^{\left(l^{\prime}-l\right)} l^{\prime} !}\right]^{2}=\mathrm{G}$

Thus, $\mathrm{G}<\left[\frac{l !}{2^{\left(l^{\prime}-l\right)} l^{\prime} !}\right]^{2}$

By (24) and (25):

$\mathrm{F} \geq 0$ and $\mathrm{G}<\left[\frac{l !}{2^{\left(l^{\prime}-l\right)} l^{\prime} !}\right]^{2}$. Thus $\mathrm{G} /\left[\frac{l !}{2^{\left(l^{\prime}-l\right)} l^{\prime} !}\right]^{2}<1$

Thus $\mathrm{F} \geq \mathrm{F} . \mathrm{G} /\left[\frac{l !}{2^{\left(l^{\prime}-l\right)} l^{\prime} !}\right]^{2}$

Thus F. $\left[\frac{l !}{2^{\left(l^{\prime}-l\right)} l^{\prime} !}\right]^{2} \geq$ F.G.

Thus, F. $2^{2(l+1) !} \geq$ F. $\left[\frac{l !}{2^{\left(l^{\prime}-l\right)} l^{\prime} !}\right]^{2} \geq$ F.G

Thus $1 / \mathrm{FG}=\mathrm{A}_{2} / \mathrm{A}_{1} \geq 1 /\left[\mathrm{F} \cdot 2^{2(l+1) !}\right]$

But for some $l_{\mathrm{g}}>l ;\left(l_{g}\right.$ is a very big number compare to $\left.l\right)$ :

F. $2^{2(l+1) !}<$ F. $2^{2(\lg +1) !}$ and for natural number $\mathrm{N}$ :

$2^{2(\lg +1) !} / \mathrm{N}>2^{2(l+1) !}$ and $1 /\left[\mathrm{F} .2^{2(\lg +1) !}\right]>(1 / \mathrm{N})$

***Here since there are infinite number of natural numbers and since $1 /\left[\mathrm{F} .2^{2(l g+1) !}\right]$ is a positive value, we can have such numbers $l_{\mathrm{g}}$ and $\mathrm{N}$ as in (28).

Then for the chosen $\mathrm{N}$ and $l_{\mathrm{g}}: 1 /\left[\mathrm{F} \cdot 2^{2(\lg +1) !}\right]>(1 / \mathrm{N})$. Thus $\mathrm{N} /\left[\mathrm{F} \cdot 2^{2(\lg +1) !}\right]>1$. 
$1 /\left\{\left[\right.\right.$ F. $\left.\left.2^{2(\lg +1) !}\right] / \mathrm{N}\right\}>1$. Thus $1 /\left[\right.$ F. $\left.2^{2(l+1) !}\right]>1$

By (27) and (29): $1 / \mathrm{FG}=\mathrm{A}_{2} / \mathrm{A}_{1}>1$

By (14) and (15): probability of the existence of $\mathrm{P}$ at point $01<$ probability of the existence of $\mathrm{P}$ ' at point 02

\subsection{Result Evaluation of Methodology part 1}

We can place any 3 arbitrary particles under the initially mentioned conditions. When we keep those particles under those conditions we can identify and observe the reality of the Universe !

According to (31), probability of the existence of $\mathrm{P}$ at point 01 (a random point) < probability of the existence of $\mathrm{P}^{\prime}$ at point 02 (another random point).

When consider the research environment system of all 3 particles ( $\mathrm{P}, \mathrm{P}^{\prime}, \mathrm{P}^{\prime}$ '): $\mathrm{P}$ is dealing with the rest of 2 particles, those have opposite charge sign and $\mathrm{P}$ has a negative electric potential energy.

But $\mathrm{P}^{\prime}$ is dealing with the rest of 2 particles, those have opposite charge sign and same charge sign and P' has a positive electric potential energy.

Therefore according to (31):

the probability of having a particle in the system with a positive electric potential energy $>$ the probability of having a particle in the system with a negative electric potential energy 


\section{Methodology part 2}

\subsection{Notations of Methodology part 2}

$\Psi_{1}=$ Wave function of the particle $\mathrm{P}_{1}$

$\mathrm{B}_{\mathrm{i}}=$ the total magnetic field that influences on ' $\mathrm{i}$ ' th particle

$\mathrm{q}_{\mathrm{i}}=$ the charge of the ' $\mathrm{i}$ 'th particle interact with the considering charged particle $\mathrm{P}_{1}$

$\mathrm{m}_{\mathrm{i}}=$ the mass of the ' $\mathrm{i}$ 'th particle interact with the considering charged particle $\mathrm{P}_{1}$.

$\mathrm{M}=$ the mass of the black hole

$\mathrm{c} \quad=$ speed of light

$r_{\mathrm{s}}=$ the Schwarzschild radius of the massive body

$r_{\mathrm{s}}=2 G M / \mathrm{c}^{2}$, where $G$ is the gravitational constant.

BUT DO NOT COMPARE THE EQUATION NUMBERS AND THE SYMBOLS OTHER PARTS IN THE RESEARCH METHODOLOGY AND IN THIS METHODOLOGY PART NUMBER 02.

\subsection{Content of Methodology part 2}

With this research part, I intend to explore how the supermassive black hole controls the solar winds of the nearby stars and how the supermassive black hole controls the orbiting velocity of nearby stars/planets (we know that most of the black holes create the whole galaxy to rotate around the center of the galaxy). That means with this research, I will explore the supermassive black holes in two sections.

$1^{\text {st }}$ section is : how the supermassive black hole controls the solar winds of the nearby stars 
$2^{\text {nd }}$ section is: how the supermassive black hole controls the orbiting velocity of nearby stars/planets

\subsubsection{Section 01: How the black hole controls the solar winds of the nearby stars}

We know that in our solar system, the main power source is the Sun. While the sun is radiating energy, it emits solar winds also towards the atmosphere. Our Earth also influenced by that wind which generates by the Sun. The solar wind contains highly energized charged particles those are harmful for the life.

Since the solar wind consists of charged particles, a high gravitational object (near to the exiting and propagating area of solar wind) can influence on the solar wind. In this case, I will study how the high gravitational force of the supermassive black hole influences on the particles of the solar wind of the nearby stars.

Since the particles those emitted by the solar wind which move though the free space, there is a magnetic field that induces near to those particles. Moreover rather than the magnetic fields induce due to the rest of the charged particles of the solar wind, there is another magnetic field that influences on the solar wind' particles. That is the magnetic field due to the black hole.

Let's consider the solar wind that emits by a star near to the supermassive black hole. But due to the gravitational field of the black hole, the potential energy of the solar wind particles changes with time. As well as the kinetic energy also varies. Moreover, there are electric and magnetic potential energy variations with the solar wind particles. Thus when the solar wind particles oscillate, high energy photons emit and those emitting photons are influenced by the high gravity field of the supermassive black hole.

Let's find the wave function for a charged particle $\left(\mathrm{P}_{1}\right)$ in the solar wind as below:

$\left(-\hbar^{2} / 2 \mathrm{M}_{1}\right) \cdot \nabla^{2} \Psi_{1}+\left\{\Sigma\left[\mathrm{q}_{1} \cdot \mathrm{q}_{\mathrm{i}}\right] / 4 \cdot \pi \cdot \mathrm{r}_{\mathrm{i}}-\Sigma \mathrm{GM}_{1} \mathrm{~m}_{\mathrm{i}} / \mathrm{r}_{\mathrm{i}}-\mathrm{GM}_{1} \cdot \mathrm{M} / \mathrm{R}_{1}-\Sigma \mu \cdot \mathrm{B}_{\mathrm{i}} \cdot \cos \theta_{\mathrm{i}}\right\} \Psi_{1}=\mathrm{E}_{1} \cdot \Psi_{1}$

Where $M_{1}$ is the mass of the considering charged particle of the solar wind, $q_{1}$ is the charge of the considering particle $\mathrm{P}_{1}$ of the solar wind, $\Psi_{1}$ is the wave function of $\mathrm{P}_{1}, \mathrm{E}_{1}$ is the eigenvalue for the charged particle, $B_{i}$ is the total magnetic field that influences on ' $i$ ' th particle (which interacts with the considering charged particle $\left.P_{1}\right), q_{i}$ is the charge of the ' $i$ 'th particle interact 
with the considering charged particle $\mathrm{P}_{1}, \mathrm{~m}_{\mathrm{i}}$ is the mass of the ' $\mathrm{i}$ 'th particle interact with the considering charged particle $\mathrm{P}_{1}, \mathrm{r}_{\mathrm{i}}$ is the distance between $\mathrm{P}_{1}$ and ' $\mathrm{i}$ 'th charged particle of the solar wind. $\mu$ is the Bohr Magneton. $M$ is the mass of the black hole, $R_{1}$ is the distance between the center of the black hole and $\mathrm{P}_{1}$.

Then $\left(-\hbar^{2} / 2 \mathrm{M}_{1}\right) . \nabla^{2} \Psi_{1}=\mathrm{E}_{1}^{\prime} \Psi_{1}$. Thus, $\nabla^{2} \Psi_{1}=\left[-2 \mathrm{M}_{1} \mathrm{E}_{1}{ }_{1} / \hbar^{2}\right] . \Psi_{1}$

where $\mathrm{E}_{1}^{\prime}=\mathrm{E}_{1}-\Sigma\left[\mathrm{q}_{1} \cdot \mathrm{q}_{\mathrm{i}}\right] / 4 \cdot \pi \cdot \mathrm{r}_{\mathrm{i}}+\Sigma \mathrm{GM}_{1} \mathrm{~m}_{\mathrm{i}} / \mathrm{r}_{\mathrm{i}}+\mathrm{GM}_{1} \cdot \mathrm{M} / \mathrm{R}_{1}+\Sigma \mu \cdot \mathrm{B}_{\mathrm{i}} \cdot \cos \theta_{\mathrm{i}}$

Then

$\nabla^{2} \Psi_{1}+\left[2 . \mathrm{E}_{1}^{\prime} . \mathrm{M}_{1} / \hbar^{2}\right] \Psi_{1}=0$

Then $\Psi_{1}=\mathrm{A} \cdot \cos \left(\mathrm{x}_{1}, \mathrm{r}_{1}\right)+\mathrm{B} \cdot \sin \left(\mathrm{x}_{1} \cdot \mathrm{r}_{1}\right)$ where $\mathrm{x}_{1}=\left[2 \cdot \mathrm{E}_{1} \cdot \mathrm{M}_{1} / \hbar^{2}\right], \mathrm{r}_{1}$ is the radial coordinate of the wave function $\Psi$ of $\mathrm{P}_{1}$. Here $\mathrm{r}_{1}>2 . \mathrm{r}_{\mathrm{s}}\left(\mathrm{r}_{\mathrm{s}}\right.$ is the Schwarzschild radius of the black hole). But we consider the center of the black hole as the origin. Then $r_{1}=R_{1}$ $(01)$

And A, B are complex constants.

But when $r_{1}=0, \Psi_{1}=0$ by $(01)$ (since at the singularity, there is no any particle as $P_{1}$ )

Thus $\mathrm{A}=0$. Thus $\Psi_{1}=\mathrm{B} \cdot \sin \left(\mathrm{x}_{1} \cdot \mathrm{r}_{1}\right)$. But at $\mathrm{r}_{1}=\mathrm{r}_{\mathrm{s}}, \Psi_{1}=0$ (at the event horizon also there is no a physical particle). Thus B. $\sin \left(\mathrm{x}_{1} \cdot \mathrm{r}_{\mathrm{s}}\right)=0$. Thus $\sin \left(\mathrm{x}_{1} \cdot \mathrm{r}_{\mathrm{s}}\right)=0$. Thus $\left(\mathrm{x}_{1} \cdot \mathrm{r}_{\mathrm{s}}\right)=\mathrm{n} \pi$.

Thus $\mathrm{x}_{1}=\mathrm{n} \pi / \mathrm{r}_{\mathrm{s}}$; where $\mathrm{n}$ is an integer (positive or negative).

Thus $\left[2 . E^{\prime}{ }_{1} \cdot M_{1} / \hbar^{2}\right]=n \pi / r_{s}$

$\mathrm{E}_{1}^{\prime}=\left[\mathrm{n} \hbar^{2} \pi / 2 \cdot \mathrm{M}_{1} \mathrm{r}_{\mathrm{s}}\right]$

Thus $\Psi_{1}=\mathrm{B} \cdot \sin \left(\left[2 \cdot \mathrm{E}^{\prime}{ }_{1} \cdot \mathrm{M}_{1} / \hbar^{2}\right] \cdot \mathrm{r}_{1}\right)$ 
By (02): $\left[\mathrm{E}_{1}-\Sigma\left[\mathrm{q}_{1} \cdot \mathrm{q}_{\mathrm{i}}\right] / 4 \cdot \pi \cdot \mathrm{r}_{\mathrm{i}}+\Sigma \mathrm{GM}_{1} \mathrm{~m}_{\mathrm{i}} / \mathrm{r}_{\mathrm{i}}+\mathrm{GM}_{1} \cdot \mathrm{M} / \mathrm{r}_{\mathrm{s}}+\Sigma \mu . \mathrm{B}_{\mathrm{i}} \cdot \cos \theta_{\mathrm{i}}\right]$

$=\left[\mathrm{n \hbar}^{2} \pi / 2 \cdot \mathrm{M}_{1} \mathrm{r}_{\mathrm{s}}\right]$

But Time dependent wave function can be written as: $\Psi_{1} \cdot \mathrm{e}^{-\mathrm{i}\left[\left(\mathrm{E} 1^{\prime} / \mathrm{h}\right)\right] \mathrm{t}}=\Psi^{(\mathrm{t})}{ }_{1}$

Thus $\partial \Psi^{(\mathrm{t})}{ }_{1} / \partial \mathrm{t}=\left(-\mathrm{i} \cdot \mathrm{E}_{1}{ }_{1} / \hbar\right) . \Psi^{(\mathrm{t})}{ }_{1}$.

Then $\partial^{2} \Psi^{(\mathrm{t})}{ }_{1} / \partial \mathrm{t}^{2}=\left(-\mathrm{i} \cdot \mathrm{E}^{\prime}{ }_{1} / \hbar\right)^{2} \cdot \Psi_{1}{ }^{(\mathrm{t})}=-\left(\mathrm{E}^{\prime}{ }_{1} / \hbar\right)^{2} \cdot \Psi^{(\mathrm{t})}{ }_{1}$

By (02):

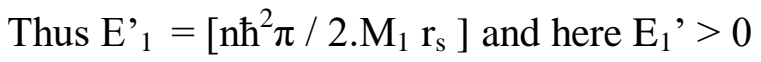

By (05) and (06):

$\partial^{2} \Psi^{(\mathrm{t})}{ }_{1} / \partial \mathrm{t}^{2}=-\left[\mathrm{n} \pi \hbar / 2 \cdot \mathrm{M}_{1} \mathrm{r}_{\mathrm{s}}\right]^{2} \cdot \Psi^{(\mathrm{t})}{ }_{1}=\mathrm{a}(\mathrm{t})=$ the linear acceleration of $\mathrm{P}_{1}$

Equation (07) indicates the acceleration of $P_{1}$ (a particle from the solar wind) towards the black hole.

But the particle $\mathrm{P}_{1}$ attracts towards the black hole in a spiral manner.

But the angular acceleration of $\mathrm{P}_{1}$ at time $\mathrm{t}$ (time $\mathrm{t}$ is the moment which the particle completes one orbit along the spiral motion path. i.e $\left[t_{i}=t-0\right]$ is the orbital time of $\left.P_{1}\right)=a(t) / d(t)$ $=\left(\Delta \omega / \Delta t_{i}\right)$. But the acceleration of $P_{1}$ towards the black hole changes with time. And $d(t)$ is the radius of one circle of motion of spiral motion (towards the black hole) at time ' $t$ '.

Here $\Delta t_{i}\left(=\left[t_{2}-0\right]\right)$ is an arbitrary time duration starting from the beginning of time (i.e. starting from $\mathrm{t}=0$. i.e. $\mathrm{t}_{1}=0$.

But we choose the $\mathrm{t}_{1}$ (the beginning of the time counting of the journey of $\mathrm{P}_{1}$ towards the black hole) such that $\mathrm{d}\left(\mathrm{t}_{1}\right)$ creates $\mathrm{k} \cdot \mathrm{e}^{\mathrm{i}\left[\left(\mathrm{E} 1^{\prime} / \mathrm{h}\right)\right] \mathrm{t} 2}<1$; where $\mathrm{k}=\mathrm{d}\left(\mathrm{t}_{2}\right) / \mathrm{d}\left(\mathrm{t}_{1}\right)<1$ (because $\mathrm{t}_{2}>\mathrm{t}_{1}$ and since the gravitational field on the solar wind particle is getting stronger when the particle approach towards the black hole. Then the radius of one circle of motion of spiral motion of $\mathrm{P}_{1}$ (towards the black hole) is reducing with the time flow. Then $d\left(t_{1}\right)>d\left(t_{2}\right)$. 
Then $\Delta \mathrm{t}_{\mathrm{i}}=[\mathrm{d}(\mathrm{t}) \cdot \Delta \omega] / \mathrm{a}(\mathrm{t})=\left[\left(\mathrm{d}(\mathrm{t}) \cdot \mathrm{v}_{\mathrm{t} 2} / \mathrm{d}\left(\mathrm{t}_{2}\right)\right)-\left(\mathrm{d}(\mathrm{t}) \cdot \mathrm{v}_{\mathrm{t} 1} / \mathrm{d}\left(\mathrm{t}_{1}\right)\right)\right] / \mathrm{a}(\mathrm{t})$

$\left.=\left[\mathrm{d}\left(\mathrm{t}_{2}\right) / \mathrm{a}\left(\mathrm{t}_{2}\right)\right] *\left[\mathrm{v}_{\mathrm{t} 2} / \mathrm{d}\left(\mathrm{t}_{2}\right)\right)-\mathrm{v}_{\mathrm{t} 1} / \mathrm{d}\left(\mathrm{t}_{1}\right)\right]$

Where $d\left(t_{2}\right)$ is the radius of one circle of motion of spiral motion of $\mathrm{P}_{1}$ (towards the black hole) at time ' $\mathrm{t}_{2}$ '.

$\mathrm{d}\left(\mathrm{t}_{1}\right)$ is the radius of one circle of motion of spiral motion of $\mathrm{P}_{1}$ (towards the black hole) at time ' $t_{1}$ '.

$v_{t 2}$ is the linear velocity of of $P_{1}$ at time $t_{2}$ and $v_{t 1}$ is the linear velocity of of $P_{1}$ at time $t_{1}$.

Here $\Delta t_{i}\left(=\left[t_{2}-0\right]\right)$ is an arbitrary time duration starting from the beginning of time (i.e. starting from $t=0$. i.e. $t_{1}=0$

But $\mathrm{v}\left(\mathrm{t}_{1}\right)=\partial \Psi^{(\mathrm{t})}{ }_{1} /\left.\partial \mathrm{t}\right|_{\mathrm{t}=\mathrm{t} 1}=\left(-\mathrm{i} \cdot \mathrm{E}^{\prime}{ }_{1} / \mathrm{h}\right) .\left.\Psi^{(\mathrm{t})}{ }_{1}\right|_{\mathrm{t}=\mathrm{t} 1}=$

$\left(-\mathrm{i} \cdot \mathrm{E}^{\prime}{ }_{1} / \hbar\right) \cdot \mathrm{B}_{0} \cdot$ i. $\sin \left(\left[2 \cdot \mathrm{E}^{\prime}{ }_{1} \cdot \mathrm{M}_{1} / \hbar^{2}\right] \cdot \mathrm{r}_{1}\right) \cdot \mathrm{e}^{-\mathrm{i}\left[\left(\mathrm{E} 1^{\prime} / \hbar\right)\right] \mathrm{t} 1}\left(\right.$ Where $\left.\left(\mathrm{B}_{0} \cdot \mathrm{i}\right)=\mathrm{B}\right)$.

and $\mathrm{v}\left(\mathrm{t}_{2}\right)=\partial \Psi^{(\mathrm{t})}{ }_{1} /\left.\partial \mathrm{t}\right|_{\mathrm{t}=\mathrm{t} 2}=\left.\left(-\mathrm{i} \cdot \mathrm{E}^{\prime}{ }_{1} / \mathrm{h}\right) \cdot \Psi^{(\mathrm{t})}{ }_{1}\right|_{\mathrm{t}=\mathrm{t} 2}=$

$\left(-\mathrm{i} \cdot \mathrm{E}^{\prime}{ }_{1} / \hbar\right) \cdot \mathrm{B}_{0} \cdot \mathrm{i} \cdot \sin \left(\left[2 \cdot \mathrm{E}^{\prime}{ }_{1} \cdot \mathrm{M}_{1} / \hbar^{2}\right] \cdot \mathrm{r}_{1}\right) \cdot \mathrm{e}^{-\mathrm{i}\left[\left(\mathrm{E} 1^{\prime} / \hbar\right)\right] \mathrm{t} 2}\left(\right.$ Where $\left.\left(\mathrm{B}_{0} \cdot \mathrm{i}\right)=\mathrm{B}\right)$.

Thus $v\left(t_{1}\right)=\left(E^{\prime}{ }_{1} / \hbar\right) \cdot B_{0} \cdot \sin \left(\left[2 \cdot E^{\prime}{ }_{1} \cdot M_{1} / \hbar^{2}\right] \cdot r_{1}\right) \cdot e^{-i\left[\left(E 1^{\prime} / \hbar\right)\right] t 1}$

and

$v\left(t_{2}\right)=\left(E^{\prime}{ }_{1} / \hbar\right) \cdot B_{0} \cdot \sin \left(\left[2 \cdot E^{\prime}{ }_{1} \cdot M_{1} / \hbar^{2}\right] \cdot r_{1}\right) \cdot e^{-i\left[\left(E 1^{\prime} / \hbar\right)\right] t 2}$

By (7.1):

$\left.\Delta \mathrm{t}_{\mathrm{i}}=\left[\mathrm{d}\left(\mathrm{t}_{2}\right) / \mathrm{a}\left(\mathrm{t}_{2}\right)\right] *\left[\mathrm{v}_{\mathrm{t} 2} / \mathrm{d}\left(\mathrm{t}_{2}\right)\right)-\mathrm{v}_{\mathrm{t} 1} / \mathrm{d}\left(\mathrm{t}_{1}\right)\right]=\left[\mathrm{v}\left(\mathrm{t}_{2}\right) / \mathrm{a}\left(\mathrm{t}_{2}\right)\right]-\left[\mathrm{v}\left(\mathrm{t}_{1}\right) \cdot \mathrm{d}\left(\mathrm{t}_{2}\right) /\left(\mathrm{d}\left(\mathrm{t}_{1}\right) \cdot \mathrm{a}\left(\mathrm{t}_{2}\right)\right)\right]$ ...(10)

But $t_{1}$ is consider as the beginning of the motion of the particle $\mathrm{P}_{1}$ towards the black hole. Therefore $\mathrm{I}$ consider $\mathrm{t}_{1}$ as 0 . Thus by (08):

$\left.v\left(t_{1}\right)\right|_{t 1=0}=\left(E^{\prime}{ }_{1} / \hbar\right) \cdot B_{0} \cdot \sin \left(\left[2 \cdot E^{\prime}{ }_{1} \cdot M_{1} / \hbar^{2}\right] \cdot r_{1}\right)$ 
By (08), (09) and (10) :

$\Delta \mathrm{t}_{\mathrm{i}}=\left[\mathrm{v}\left(\mathrm{t}_{2}\right) / \mathrm{a}\left(\mathrm{t}_{2}\right)\right]-\left[\mathrm{v}\left(\mathrm{t}_{1}\right) \cdot \mathrm{d}\left(\mathrm{t}_{2}\right) /\left(\mathrm{d}\left(\mathrm{t}_{1}\right) \cdot \mathrm{a}\left(\mathrm{t}_{2}\right)\right)\right]$

But (07) and (09): [ $\left.\mathrm{v}\left(\mathrm{t}_{2}\right) / \mathrm{a}\left(\mathrm{t}_{2}\right)\right]=$

$\left.\left(\mathrm{E}_{1}{ }_{1} / \hbar\right) \cdot \mathrm{B}_{0} \cdot \sin \left(\left[2 \cdot \mathrm{E}_{1}{ }_{1} \cdot \mathrm{M}_{1} / \hbar^{2}\right] \cdot \mathrm{r}_{1}\right) \cdot \mathrm{e}^{-\mathrm{i}\left[\left(\mathrm{El}^{1} / \mathrm{h}\right)\right] \mathrm{t} 2} /\left.\left\{-\left[\mathrm{n} \pi \cdot \hbar / 2 \cdot \mathrm{M}_{1} \mathrm{r}_{\mathrm{s}}\right]^{2}\right\} \cdot \Psi^{(\mathrm{t})}{ }_{1}\right|_{\mathrm{t}=\mathrm{t} 2}\right\}$

$=\left(E_{1}^{\prime} / \hbar\right) \cdot B_{0} \cdot \sin \left(\left[2 \cdot E_{1}^{\prime} \cdot M_{1} / \hbar^{2}\right] \cdot r_{1}\right) \cdot e^{-i\left[\left(E 1^{\prime} / \hbar\right)\right] t 2} /\left\{-\left[n \pi \hbar / 2 \cdot M_{1} r_{s}\right]^{2}\right\} \cdot B$ $\left.\cdot \sin \left(\left[2 \cdot \mathrm{E}_{1}{ }_{1} \cdot \mathrm{M}_{1} / \hbar^{2}\right] \cdot \mathrm{r}_{1}\right) \cdot \mathrm{e}^{-\mathrm{i}\left[\left(\mathrm{E} 1^{\prime} / \hbar\right)\right] \mathrm{t} 2}\right\}$

$=\left(E_{1}^{\prime} / i . \hbar\right) . /-\left[n \pi \hbar / 2 \cdot M_{1} r_{s}\right]^{2}=\left(i . E_{1}^{\prime}\right) /\left[\left\{\hbar \cdot\left[n \pi \hbar / 2 \cdot M_{1} r_{s}\right]^{2}\right\}\right.$

By (07) and (08): $\left.\left[v\left(t_{1}\right) / a\left(t_{2}\right)\right)\right]=$

$\left(E^{\prime}{ }_{1} / \hbar\right) \cdot B_{0} \cdot \sin \left(\left[2 \cdot E^{\prime}{ }_{1} \cdot M_{1} / \hbar^{2}\right] \cdot r_{1}\right) /\left\{-\left[n \pi \hbar / 2 \cdot M_{1} r_{s}\right]^{2}\right\}$.

B. $\left.\sin \left(\left[2 \cdot \mathrm{E}_{1}, \mathrm{M}_{1} / \hbar^{2}\right] \cdot \mathrm{r}_{1}\right) \cdot \mathrm{e}^{-\mathrm{i}\left[\left(\mathrm{El}^{1} / \hbar\right)\right] \mathrm{t2}}\right\}$

$\left.=\left(E^{\prime}{ }_{1} / \mathrm{i} \hbar\right) /\left\{-\left[n \pi \hbar / 2 \cdot M_{1} r_{s}\right]^{2}\right\} \cdot e^{-i\left[\left(E 1^{\prime} / \hbar\right)\right]+2}\right\}=\left(E_{1}^{\prime} \cdot i\right) /\left\{\hbar\left[n \pi \hbar / 2 \cdot M_{1} r_{s}\right]^{2} \cdot e^{-i\left[\left(E 1^{\prime} / \hbar\right)\right]+2}\right\}$

Thus by (11.1), (12) and (13): $\Delta \mathrm{t}_{\mathrm{i}}=\left(\mathrm{i} . \mathrm{E}_{1}{ }_{1}\right) /\left[\left\{\hbar \cdot\left[\mathrm{n} \pi \hbar / 2 . \mathrm{M}_{1} \mathrm{r}_{\mathrm{s}}\right]^{2}\right\}\right.$

$-\left(\right.$ k. $\left.\left.\left(E_{1}^{\prime}, i\right) /\left\{\hbar\left[n \pi \hbar / 2 \cdot M_{1} r_{s}\right]\right\}^{2} \cdot e^{-i\left[\left(E^{\prime} / \hbar\right)\right] t 2}\right\}\right\}$

where $\mathrm{k}=\mathrm{d}\left(\mathrm{t}_{2}\right) / \mathrm{d}\left(\mathrm{t}_{1}\right)<1$ (because $\mathrm{t}_{2}>\mathrm{t}_{1}$ and since the gravitational field on the solar wind particle is getting stronger when the particle approach towards the supermassive black hole. Then the radius of one circle of motion of spiral motion of $\mathrm{P}_{1}$ (towards the black hole) is reducing with the time flow. Then $d\left(t_{1}\right)>d\left(t_{2}\right)$. Where we choose the $t_{1}$ (the beginning of the time counting of the journey of $\mathrm{P}_{1}$ towards the black hole) such that $\mathrm{d}\left(\mathrm{t}_{1}\right)$ creates $1>\mathrm{ke}^{\mathrm{i}\left[\left(\mathrm{El}^{\prime} / \mathrm{h}\right)\right] \text { t2 }}$ ..(13.1)

$\mathrm{k}=\mathrm{d}\left(\mathrm{t}_{2}\right) / \mathrm{d}\left(\mathrm{t}_{1}\right)<<<1$.

Then $\Delta \mathrm{t}_{\mathrm{i}}=\left(\mathrm{E}_{1}^{\prime} \cdot \mathrm{i} / \hbar\right) \cdot\left\{\left[1 /\left\{\left[\mathrm{n} \pi \hbar / 2 \cdot \mathrm{M}_{1} \mathrm{r}_{\mathrm{s}}\right]\right\}^{2}-\left(\mathrm{E}_{1}, \mathrm{i} / \hbar\right) \cdot \mathrm{k} \mathrm{e}^{\mathrm{i}\left[\left(\mathrm{E}^{1} / \mathrm{h}\right)\right] \mathrm{t} 2} /\left[\left[\mathrm{n} \pi \hbar / 2 \cdot \mathrm{M}_{1} \mathrm{r}_{\mathrm{s}}\right]\right\}^{2}\right\}\right.$

Then $\Delta \mathrm{t}_{\mathrm{i}}=\mathrm{E}_{1}{ }_{1} . \mathrm{i}\left(1-\mathrm{ke} \mathrm{e}^{\mathrm{i}\left[\left(\mathrm{E} 1^{\prime} / \hbar\right)\right] \mathrm{t} 2}\right) /\left[\hbar .\left\{\left(\mathrm{n} \pi \hbar / 2 \cdot \mathrm{M}_{1} \mathrm{r}_{\mathrm{s}}\right)\right\}^{2}\right]$ 
$* * *$ DO NOT confuse on ' $i$ ' term in $\Delta t_{i}$ and ' $i$ ' term in (ih). ' $i$ ' term in (ih) is $\sqrt{ }(-1)$. And ' $i$ ' term in $\Delta t_{i}$ is just the order number.

Then $\Delta t_{i}=E^{\prime}{ }_{1}$.i. $\left(1-k \cdot e^{i .\left(E 1^{\prime} / \hbar\right) \cdot t 2}\right) /\left[\hbar .\left\{\left(n \pi \hbar / 2 \cdot M_{1} r_{s}\right\}^{2}\right]>0(\right.$ by $(13.1))$

Then $\Delta \mathrm{t}_{\mathrm{i}}=$

$\left\{\left(1-\left\{k+k \cdot \text { i. }\left(E_{1}^{\prime} / \hbar\right) \cdot t_{2}\right]+k \cdot\left[i \cdot\left(E_{1}^{\prime} / \hbar\right) \cdot t_{2}\right]^{2} / 2 !+\ldots+k \cdot\left[i \cdot\left(E_{1} / \hbar\right) \cdot t_{2}\right]^{n} / n !\right)\right\}^{*}$

[ $\mathrm{E}_{1}^{\prime}$.i. $/\left[\right.$ h. $\left.\left.\left\{\left(\mathrm{n} \pi \hbar / 2 \cdot \mathrm{M}_{1} \mathrm{r}_{\mathrm{s}}\right)\right\}^{2}\right]\right]$

Thus $\Delta \mathrm{t}_{\mathrm{i}}=\left(\mathrm{E}^{\prime}{ }_{1} / \hbar\right) *\left[1 /\left\{\left(\mathrm{n} \pi \hbar / 2 \cdot \mathrm{M}_{1} \mathrm{r}_{\mathrm{s}}\right)\right\}^{2}\right] * \sum_{j=1}^{\infty} k \cdot\left(\frac{\mathrm{E}^{\prime} 1 \mathrm{t} 2}{\hbar}\right)^{j} \cdot\left(\frac{\delta \mathrm{j}}{j !}\right)$

$+(1-\mathrm{k}) \cdot\left[\mathrm{E}^{\prime}\right.$. i. $/\left[\right.$ h. $\left.\left.\left\{\left(\mathrm{n} \pi \hbar / 2 \cdot \mathrm{M}_{1} \mathrm{r}_{\mathrm{s}}\right)\right\}^{2}\right]\right]$

$=\left(\mathrm{E}^{\prime}{ }_{1} / \hbar\right) *\left[1 /\left\{\left(\mathrm{n} \pi \hbar / 2 \cdot \mathrm{M}_{1} \mathrm{r}_{\mathrm{s}}\right)\right\}^{2}\right] * \mathrm{k} \cdot e^{\left(E 1^{\prime} \cdot \frac{t 2}{\hbar}\right) * \delta_{\mathrm{j}}}$

$+(1-\mathrm{k}) \cdot\left[\mathrm{E}_{1}{ }_{1}\right.$.i. $/\left[\right.$ h. $\left.\left.\left\{\left(\mathrm{n} \pi \hbar / 2 \cdot \mathrm{M}_{1} \mathrm{r}_{\mathrm{s}}\right)\right\}^{2}\right]\right]-\left(-\mathrm{k} . \mathrm{E}_{1}{ }_{1}\right.$.i. $/\left[\right.$ [. $\left.\left.\left\{\left(\mathrm{n} \pi \hbar / 2 \cdot \mathrm{M}_{1} \mathrm{r}_{\mathrm{s}}\right)\right\}^{2}\right]\right]$

$=\left(\mathrm{E}_{1}^{\prime} / \hbar\right) *\left[1 /\left\{\left(\mathrm{n} \pi / 2 \cdot \mathrm{M}_{1} \mathrm{r}_{\mathrm{s}}\right)\right\}^{2}\right] *\left[i+k \cdot e^{\left(E 1^{\prime} \cdot \frac{t 2}{\hbar}\right) *} \delta_{\mathrm{j}}\right]$

Where $\delta_{\mathrm{j}}=1,-1, \mathrm{i}$ or $-\mathrm{i}$;

$\left(\delta_{\mathrm{j}}\right)=-\mathrm{i} \quad$; if $\quad \mathrm{j}-1=4 . \mathrm{b}, \mathrm{b}$ is an integer number

$\left(\delta_{\mathrm{j}}\right)=\mathrm{i} \quad$; if $\quad \mathrm{j}-1=2 . \mathrm{b}, \quad \mathrm{b}$ is a natural number

$\left(\delta_{\mathrm{j}}\right)=1 \quad$; if $\quad \mathrm{j}-1=1+4 \mathrm{~b}, \mathrm{~b}$ is 0 or a natural number

$\left(\delta_{\mathrm{j}}\right)=-1 \quad$; if $\quad \mathrm{j}-1=3+4 \mathrm{~b}, \mathrm{~b}$ is 0 or a natural number

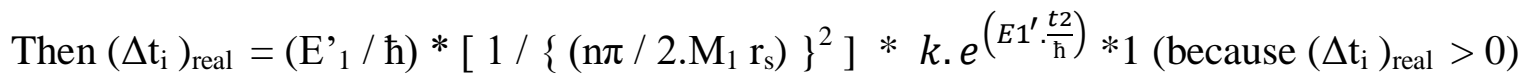

Thus $\left(\Delta \mathrm{t}_{\mathrm{i}}\right)_{\text {real }}=\mathrm{E}^{\prime}{ }_{1} * \mathrm{k} \cdot e^{\left(E 1^{\prime} \cdot \frac{t 2}{\hbar}\right) /\left[\hbar\left\{\left(\mathrm{n} \pi / 2 \cdot \mathrm{M}_{1} \mathrm{r}_{\mathrm{s}}\right)\right\}^{2}\right]}$

$\operatorname{By~(06):~} \mathrm{E}_{1}=\left[\mathrm{n \hbar} \hbar^{2} \pi / 2 \cdot \mathrm{M}_{1} \mathrm{r}_{\mathrm{s}}\right]$. Then

Thus $\left\{\left[\mathrm{n} \pi / 2 . \mathrm{M}_{1} \mathrm{r}_{\mathrm{s}}\right]\right\}^{2}=\left[\mathrm{E}_{1}{ }_{1} / \hbar^{2}\right]^{2}$ 
$\operatorname{By}(14):\left(\Delta \mathrm{t}_{\mathrm{i}}\right)_{\mathrm{real}}=\left(\mathrm{E}_{1}^{\prime} / \hbar\right)^{*}\left[\hbar^{4} /\left(\mathrm{E}_{1}^{\prime}\right)^{2}\right] * \mathrm{k} \cdot e^{\left(E^{\prime} 1 \cdot \frac{t 2}{\hbar}\right)}$

Thus $\left(\Delta \mathrm{t}_{\mathrm{i}}\right)_{\text {real }}=\left[\hbar^{3} / \mathrm{E}_{1}^{\prime}\right]^{*} k \cdot e^{\left(E^{\prime} 1 \cdot \frac{t 2}{\mathrm{~h}}\right)}$

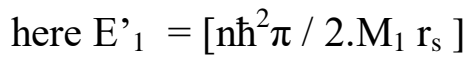

But $\Delta \mathrm{t}_{\mathrm{i}}=\mathrm{t}_{2}-0=\left(\Delta \mathrm{t}_{\mathrm{i}}\right)$. But $\mathrm{t}_{2}$ is an arbitrary moment from the beginning $\mathrm{t}=0$. Thus let's denote $\mathrm{t}_{2} \equiv \mathrm{t}$. Then $\left(\Delta \mathrm{t}_{\mathrm{i}}\right) \equiv \mathrm{t}$.

Then by $(15)$ and $(16): \mathrm{t}_{2}=\left[\hbar^{3} / \mathrm{E}_{1}{ }_{1}\right]^{*} k \cdot e^{\left(E^{\prime} 1 \cdot \frac{t 2}{\hbar}\right)} \cdot$ Then $\left[\mathrm{E}^{\prime}{ }_{1} / \hbar^{3}\right]=\left(\mathrm{k} / \mathrm{t}_{2}\right) \cdot e^{\left(E^{\prime} 1 \cdot \frac{t 2}{\hbar}\right)} \rightarrow$

$\mathrm{t}_{2} \cdot e^{-\left(E^{\prime} \cdot \frac{t 2}{\hbar}\right)}=\left[\mathrm{k} \cdot \hbar^{3} / \mathrm{E}_{1}^{\prime}\right]$. Then by the notation as in (16):

$$
\mathrm{t}=\mathrm{T} \quad \mathrm{t}=\mathrm{T}
$$

Then $\quad \int e^{-E l^{\prime} \cdot t / \hbar} \cdot t \cdot d t=\left[k \cdot \hbar^{3} / E_{1}^{\prime}\right] \int d t$

$$
\mathrm{t}=0 \quad \mathrm{t}=0
$$

Where we consider $\mathrm{T}$ as the orbital time period of the particle $\mathrm{P}_{1}$ (arbitrary taken from the solar wind particle soup) of one complete oscillation, while moving towards the supermassive Black hole.

$$
\mathrm{t}=\mathrm{T}
$$

Then by (17): [t. $\left.\left(-\hbar / \mathrm{E}_{1}{ }^{\prime}\right) \cdot \mathrm{e}^{-\mathrm{E} 1^{\prime} \cdot \mathrm{t} / \hbar}\right]^{\mathrm{t}=\mathrm{T}}{ }_{\mathrm{t}=0}-\int\left(-\hbar / \mathrm{E}_{1}{ }^{\prime}\right) \cdot \mathrm{e}^{-\mathrm{E}{ }^{\prime} \cdot \mathrm{t} / \hbar} \cdot 1 \mathrm{dt}=\left[\mathrm{k} \cdot \hbar^{3} / \mathrm{E}_{1}{ }^{\prime}\right] \cdot \mathrm{T}$

$$
\mathrm{t}=0
$$

Then $\quad t=T$

$-\left[T \cdot\left(\hbar / E_{1}^{\prime}\right)\right] \cdot e^{-E 1^{\prime} \cdot T / \hbar}+\int\left(\hbar / E_{1}^{\prime}\right) \cdot e^{-E 1^{\prime} \cdot t / \hbar} d t=\left[k \cdot \hbar^{3} / E_{1}^{\prime}\right] \cdot T$

$$
t=0
$$


Then -[T. $\left.\left(\hbar / \mathrm{E}_{1}{ }^{\prime}\right)\right] \cdot \mathrm{e}^{-\mathrm{E} 1^{\prime} \cdot \mathrm{T} / \hbar}+\left(\hbar / \mathrm{E}_{1}{ }^{\prime}\right) \cdot\left(-\hbar / \mathrm{E}_{1}{ }^{\prime}\right)\left[\mathrm{e}^{\mathrm{E} \mathrm{I}^{\prime} \cdot \mathrm{t} / \hbar}\right]^{\mathrm{t}=\mathrm{T}}{ }_{\mathrm{t}=0}=\left[\mathrm{k} \cdot \hbar^{3} / \mathrm{E}_{1}{ }^{\prime}\right] \cdot \mathrm{T}$

Then $-\left[\mathrm{T} \cdot\left(\hbar / \mathrm{E}_{1}{ }^{\prime}\right)\right] \cdot \mathrm{e}^{-\mathrm{E} 1^{\prime} \cdot \mathrm{T} / \hbar}-\left(\hbar / \mathrm{E}_{1}{ }^{\prime}\right)^{2} \cdot\left[\mathrm{e}^{-\mathrm{E}^{\prime} \cdot \mathrm{T} / \hbar}-1\right]=\left[\mathrm{k} \cdot \hbar^{3} / \mathrm{E}_{1}{ }^{\prime}\right] \cdot \mathrm{T}$

Then $\left(\hbar / E_{1}\right)^{2}-\left[T \cdot\left(\hbar / E_{1}{ }^{\prime}\right)\right] \cdot e^{-E 1^{\prime} \cdot T / \hbar}-\left(\hbar / E_{1}{ }^{\prime}\right)^{2} \cdot e^{-E 1^{\prime} \cdot T / \hbar}=\left[k \cdot \hbar^{3} / E_{1}^{\prime}\right] \cdot T$

Then $\left(\hbar / E_{1}{ }^{\prime}\right)-T \cdot e^{-E 1^{\prime} \cdot T / \hbar}-\left(\hbar / E_{1}{ }^{\prime}\right) \cdot e^{-E 1^{\prime} \cdot T / \hbar}=k \cdot \hbar^{2} \cdot T$

Then $\left(\hbar / \mathrm{E}_{1}{ }^{\prime}\right)=\mathrm{T} \cdot \mathrm{e}^{-\mathrm{E} 1^{\prime} \cdot \mathrm{T} / \hbar}+\left(\hbar / \mathrm{E}_{1}{ }^{\prime}\right) \cdot \mathrm{e}^{-\mathrm{E}^{\prime} \cdot \mathrm{T} / \hbar}+\mathrm{k} \cdot \hbar^{2} \cdot \mathrm{T}$

$=\mathrm{T} \cdot\left[\mathrm{k} \cdot \hbar^{2}+\mathrm{e}^{-\mathrm{E} 1^{\prime} \cdot \mathrm{T} / \hbar}\right]+\left(\hbar / \mathrm{E}_{1}{ }^{\prime}\right) \cdot \mathrm{e}^{-\mathrm{E} 1^{\prime} \cdot \mathrm{T} / \hbar}$

But by (15) and (16) $: \mathrm{t}_{2}=\left[\hbar^{3} / \mathrm{E}_{1}^{\prime}\right] * \mathrm{k} \cdot e^{\left(E^{\prime} 1 \cdot \frac{t 2}{\hbar}\right)}$. Then $\mathrm{T}=\left.\left[\hbar^{3} / \mathrm{E}^{\prime}{ }_{1}\right] * k \cdot e^{\left(E^{\prime} 1 \cdot \frac{T}{\mathrm{~h}}\right)}\right|_{\mathrm{t} 2=\mathrm{T}}$

Then $\mathrm{e}^{-\mathrm{E} 1^{\prime} \cdot \mathrm{T} / \hbar}=\left[\hbar^{3} \cdot \mathrm{k} /\left(\mathrm{E}_{1}^{\prime} \cdot \mathrm{T}\right)\right]$

Thus by (18) and (19): $\left(\hbar / \mathrm{E}_{1}{ }^{\prime}\right)=\mathrm{T} \cdot\left[\mathrm{k} \cdot \hbar^{2}+\left[\hbar^{3} \mathrm{k} /\left(\mathrm{E}^{\prime}{ }_{1} . \mathrm{T}\right)\right]\right]+\left(\hbar / \mathrm{E}_{1}{ }^{\prime}\right) \cdot\left[\hbar^{3} \mathrm{k} /\left(\mathrm{E}_{1}{ }_{1} . \mathrm{T}\right)\right]$

Then $\left(\hbar / E_{1}{ }^{\prime}\right) \cdot E_{1}{ }^{\prime} \cdot T=T \cdot\left[E_{1}{ }^{\prime} \cdot T \cdot k \cdot \hbar^{2}+k \cdot \hbar^{3}\right]+\left(\hbar^{4} k / E_{1}{ }^{\prime}\right)$

Then $\mathrm{T}=\mathrm{T} \cdot\left[\left(\mathrm{E}_{1}{ }^{\prime} \cdot \mathrm{T} \cdot \mathrm{k} \cdot \hbar+\mathrm{k} \cdot \hbar^{2}\right)\right]+\left(\hbar^{3} \mathrm{k} / \mathrm{E}_{1}{ }^{\prime}\right)$

Then $T=E_{1}{ }^{\prime} \cdot T^{2} \cdot k \cdot \hbar+k \cdot T \cdot \hbar^{2}+\left(\hbar^{3} k / E_{1}{ }^{\prime}\right)$.

Then $E_{1}{ }^{\prime} \cdot T^{2} \cdot \hbar \cdot k-T \cdot\left(1-k \cdot \hbar^{2}\right)+\left(\hbar^{3} \cdot k / E_{1}{ }^{\prime}\right)=0$

Then $T^{2}-T \cdot\left[(1 / k)-\hbar^{2}\right] /\left(E_{1}^{\prime} \cdot \hbar\right)+\left(\hbar / E_{1}^{\prime}\right)^{2}=0$

But by (06): $\mathrm{E}_{1}^{\prime}=\left[\mathrm{n \hbar}{ }^{2} \pi / 2 \cdot \mathrm{M}_{1} \mathrm{r}_{\mathrm{s}}\right]$

By (06) and (20): $\mathrm{T}^{2}-\mathrm{T} \cdot\left[(1 / \mathrm{k})-\hbar^{2}\right] /\left(\mathrm{n} \hbar^{3} \pi / 2 \cdot \mathrm{M}_{1} \mathrm{r}_{\mathrm{s}}\right)+\left(2 \cdot \mathrm{M}_{1} \mathrm{r}_{\mathrm{s}} / \mathrm{n \hbar \pi}\right)^{2}=0$

Then $\mathrm{T}^{2}$ - T. $\left[(1 / \mathrm{k})-\hbar^{2}\right]$. $\left[2 \cdot \mathrm{M}_{1} \mathrm{r}_{\mathrm{s}} /\left(\mathrm{n} \hbar^{3} \pi\right)\right]+\left(2 \cdot \mathrm{M}_{1} \mathrm{r}_{\mathrm{s}} / \mathrm{n} \hbar \pi\right)^{2}=0$

$\operatorname{But}\left(2 \cdot \mathrm{M}_{1} \mathrm{r}_{\mathrm{s}} / \mathrm{n \hbar \pi}\right)^{2}>0$ and $\left[\mathrm{T} . \hbar^{2} \cdot\left[2 \cdot \mathrm{M}_{1} \mathrm{r}_{\mathrm{s}} /\left(\mathrm{n} \hbar^{3} \pi\right)\right]>0\right.$

Thus by (21): $\left.\mathrm{T}^{2}-\mathrm{T} \cdot 2 \cdot \mathrm{M}_{1} \mathrm{r}_{\mathrm{s}} /\left(\mathrm{k} \cdot \mathrm{nh} \hbar^{3} \pi\right)\right]<0$.

Thus $\mathrm{T}<2 . \mathrm{M}_{1} \mathrm{r}_{\mathrm{s}} /\left(\mathrm{k} \cdot \mathrm{n \hbar ^{3 }} \pi\right)$

But $1>\mathrm{ke}^{\mathrm{i}\left[\left(\mathrm{E} 1^{\prime} / \mathrm{h}\right)\right] \mathrm{T}}$. Then $\mathrm{e}^{-\mathrm{i}\left[\left(\mathrm{El}^{1} / \mathrm{h}\right)\right] \mathrm{T}}>\mathrm{k}$. But real part of $\left(\mathrm{e}^{-\mathrm{i}\left[\left(\mathrm{El}^{\prime} / \mathrm{h}\right)\right] \mathrm{T}}\right)=\cos \left(\mathrm{E}_{1}\right.$ '. $\left.\mathrm{T} / \hbar\right)$ 
Thus $\cos \left(\mathrm{E}_{1}{ }^{\prime} \cdot \mathrm{T} / \hbar\right)>\mathrm{k}$. Then $\left(\mathrm{E}_{1}{ }^{\prime} \cdot \mathrm{T} / \hbar\right)>\cos \left(\mathrm{E}_{1}{ }^{\prime} \cdot \mathrm{T} / \hbar\right)>\mathrm{k}$.

Then $(1 / \mathrm{k})>\left[\hbar /\left(\mathrm{E}_{1} \cdot \mathrm{T}\right)\right]$

But by (06): $\mathrm{E}_{1}{ }_{1}=\left[\mathrm{n \hbar ^{2 }} \pi / 2 \cdot \mathrm{M}_{1} \mathrm{r}_{\mathrm{s}}\right]$

Thus by (23) and (06): (1/ k) > 2.M $\mathrm{M}_{\mathrm{s}} /(\mathrm{n} . \hbar . \pi . \mathrm{T})$

But $\hbar<1$. And $(1 / \mathrm{k})>1$. Thus for some positive integer number $(\mathrm{w}-3)$, where $(\mathrm{w}-3) \geq 1$ and w $>2$ :

$(1 / \mathrm{k})<2 . \mathrm{M}_{1} \mathrm{r}_{\mathrm{s}} /\left(\mathrm{n} . \mathrm{h}^{\mathrm{w}-3} \cdot \pi . \mathrm{T}\right) \ldots \ldots \ldots \ldots \ldots \ldots(25)$ for some integer number $\mathrm{w}$, where $\mathrm{w}-3 \geq 1$.

By (22) and by (25): $\mathrm{T}<2 \cdot \mathrm{M}_{1} \mathrm{r}_{\mathrm{s}} /\left(\mathrm{k} \cdot \mathrm{n \hbar ^{3 }} \pi\right)<\left[2 \cdot \mathrm{M}_{1} \mathrm{r}_{\mathrm{s}} /\left(\mathrm{n \hbar}^{3} \pi\right)\right] .2 \cdot \mathrm{M}_{1} \mathrm{r}_{\mathrm{s}} /\left(\mathrm{n} \cdot \hbar^{\mathrm{w}-3} \cdot \pi \cdot \mathrm{T}\right)$

$=\left[\left(2 \cdot M_{1} r_{s}\right)^{2} /\left(n^{2} \cdot \hbar^{w} \cdot \pi^{2} \cdot T\right)\right.$. Then $T^{2}<\left[\left(2 \cdot M_{1} r_{s}\right)^{2} /\left(n^{2} \cdot \hbar^{w} \cdot \pi^{2}\right)\right.$

Then $\mathrm{T}<\left[2 . \mathrm{M}_{1} \mathrm{r}_{\mathrm{s}}\right] /\left[\mathrm{n} . \mathrm{h}^{\mathrm{w} / 2} \cdot \pi\right] \ldots \ldots \ldots \ldots \ldots \ldots . . .(26)$ But $(\mathrm{w} / 2)>1$. But $\mathrm{M}_{1}<1$ in SI units.

Thus by (26): $\mathrm{T}<\left[2 . \mathrm{M}_{1} \mathrm{r}_{\mathrm{s}}\right] /\left[\mathrm{n} \cdot \hbar^{\mathrm{w} / 2} \cdot \pi\right]<2 . \mathrm{r}_{\mathrm{s}} \cdot\left[\left(\mathrm{M}_{1}\right)^{\mathrm{p}} . \hbar^{-\mathrm{q}}\right] /[\mathrm{n} . \pi] \ldots \ldots \ldots \ldots . . .(26.0)$

\{ Because for some natural numbers $\mathrm{p}, \mathrm{q}$ and $\mathrm{w}$ : we can write $(\mathrm{p}-1)<\mathrm{q}-(\mathrm{w} / 2)$. Then we have the capability to write $\mathrm{M}_{1}{ }^{\mathrm{p}-1}>\hbar^{\mathrm{q}-[\mathrm{w} / 2]}$ for some natural numbers $\mathrm{p}, \mathrm{q}$ and $\mathrm{w}$. Because $\mathrm{M}_{1}>\hbar$, $\mathrm{M}_{1}<1, \hbar<1$ and $\mathrm{w}>2$. Then we can write $1<\left[\mathrm{M}_{1} / \hbar^{\mathrm{w} / 2}\right]<\left[\left(\mathrm{M}_{1}\right)^{\mathrm{p}} \cdot \hbar^{-\mathrm{q}}\right] \ldots \ldots . . .(26)^{\prime}$; for some natural number $\mathrm{p}$ and $\mathrm{q}$ and $\mathrm{w}$ \}

Thus by (26)': $\mathrm{M}_{1}^{\mathrm{p}} / \hbar^{\mathrm{q}}>1 \ldots \ldots \ldots \ldots \ldots \ldots(26.0 .1)$

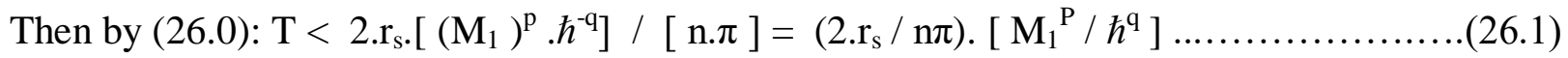

Thus $\mathrm{T}<\left[2 . \mathrm{M}_{1}^{\mathrm{p}} \cdot \mathrm{r}_{\mathrm{s}} /\left(\mathrm{n} \pi \cdot \hbar^{\mathrm{q}}\right)\right] \ldots \ldots \ldots \ldots \ldots(26.2)$

Let $\mathrm{f}$ is the frequency of oscillation of the particle that has been released from the solar wind and which is moving towards the supermassive black hole. Here $\mathrm{T}$ is the Orbital Time period for one complete oscillation of the considered solar wind particle, while moving towards the supermassive Black hole. Here $\mathrm{f}$ is the frequency of electromagnetic waves emits by the solar wind particle (that is accelerating towards the supermassive black hole).

Then $\mathrm{f}=(1 / \mathrm{T})$. Then by $(26.2): \mathrm{f}=(1 / \mathrm{T})>\left[\mathrm{n} \pi \cdot \hbar^{\mathrm{q}}\right] /\left(2 \cdot \mathrm{M}_{1}{ }^{\mathrm{p}} \cdot \mathrm{r}_{\mathrm{s}}\right)$ 
By (26.0.1): $\mathrm{M}_{1}^{\mathrm{p}} / \hbar^{\mathrm{q}}>1$. If $\hbar<\mathrm{M}_{1}$ : we have the capability to choose $\mathrm{q}>\mathrm{p}$.

Then we are responsible to choose natural numbers ' $\mathrm{a}$ ', $\mathrm{p}$, w and $\mathrm{q}$ such that:

$q>p,(p-1)<q-(w / 2), \underline{w \geq 2}, \underline{2 q+6<(p+a)}$ and $\underline{p}>a$.

(Since $q>p, 2 p-6<2 q-6<2 q+6<(p+a)$. Then $2 p-6<p+a$. Then $p<a+6$ )

That means we are responsible to choose the values of a, p, w and q such that those values obey above relationships. Here we considered that $\hbar<\mathrm{M}_{1}$.

Then by (26.0.1): $\mathrm{M}_{1}{ }^{\mathrm{p}}>\hbar^{\mathrm{q}}>\hbar^{\mathrm{q}+1}$. Then $\mathrm{M}_{1}{ }^{\mathrm{p}-1}>\mathrm{M}_{1}{ }^{\mathrm{p}}>\hbar^{\mathrm{q}}>\hbar^{\mathrm{q}+1}$ (because $\mathrm{M}_{1}<1$ and $\hbar<1$ )

Then $\mathrm{M}_{1}^{\mathrm{p}-1} \cdot\left(\hbar^{\mathrm{q}} / \mathrm{M}_{1}^{\mathrm{p}}\right)>\hbar^{\mathrm{q}+1} \cdot\left(\hbar^{\mathrm{q}} / \mathrm{M}_{1}^{\mathrm{p}}\right)$.

Then $\left(\hbar^{\mathrm{q}} / \mathrm{M}_{1}^{\mathrm{p}}\right)>\hbar^{2 \mathrm{q}+1} / \mathrm{M}_{1}^{2 \mathrm{p}-1}>\left(\mathrm{M}_{1}^{\mathrm{a}-\mathrm{p}} / \hbar^{4}\right) ;$ where $\left.\mathrm{p}>\mathrm{a} \ldots \ldots \ldots \ldots \ldots \ldots . . . . . . . .26 .3 .1\right)$

(Because although $\hbar<\mathrm{M}_{1}$, there exist natural numbers $\mathrm{q}$, p and 'a' $: 2 \mathrm{q}+5<(\mathrm{p}+\mathrm{a}-1)$ such that $\hbar^{2 \mathrm{q}+5}>\mathrm{M}_{1}{ }^{2 \mathrm{p}-1+\mathrm{a}-\mathrm{p}}$, since $\hbar<\mathrm{M}_{1}$. Then $\left.\hbar^{2 \mathrm{q}+1} / \mathrm{M}_{1}{ }^{2 \mathrm{p}-1}>\left[\mathrm{M}_{1}^{\mathrm{a}-\mathrm{p}} / \hbar^{4}\right]\right)$

Thus by (26.3.1): $\left(\hbar^{\mathrm{q}} / \mathrm{M}_{1}^{\mathrm{p}}\right)>\left(\mathrm{M}_{1}^{\mathrm{a}-\mathrm{p}} / \hbar^{4}\right) \ldots \ldots \ldots \ldots . .(26.4)$ where $\mathrm{p}>\mathrm{a}$.

By (26.3) and (26.4): $\mathrm{f}=(1 / \mathrm{T})>\left[\mathrm{n} \pi \cdot \mathrm{M}_{1}^{\mathrm{a}-\mathrm{p}} / 2 \cdot \mathrm{r}_{\mathrm{s}}\right] *\left[1 / \hbar^{4}\right]>\left[\mathrm{n} \pi \cdot \mathrm{M}_{1} / 2 \cdot \mathrm{r}_{\mathrm{s}}\right] *\left[1 / \hbar^{4}\right]$ (because $\mathrm{p}>\mathrm{a}$ and since $\left.\mathrm{M}_{1}<1\right)$.

Then $\mathrm{f}>\left[\mathrm{n} \cdot \pi \cdot \mathrm{M}_{1} /\left(2 \cdot \mathrm{r}_{\mathrm{s}}\right)\right]^{*}\left\{1 / \hbar^{4}\right\}>\mathrm{f}>\left[\mathrm{n} \cdot \pi \cdot \mathrm{M}_{1} /\left(2 . \mathrm{r}_{\mathrm{s}}\right)\right]^{*}\left\{1 / \hbar^{3}\right\}$ Because $\hbar<1$.

Then $\mathrm{f}>\left[\mathrm{n} \cdot \pi \cdot \mathrm{M}_{1} /\left(2 \cdot \mathrm{r}_{\mathrm{s}}\right)\right]^{*}\left\{1 / \hbar^{3}\right\}$

But the usual mass of a Supermassive black hole is

$\mathrm{M}=\left(1.989 \times 10^{30} * 16 * 10^{9}\right)=31.824 * 10^{39} \mathrm{~kg}$

But $\mathrm{r}_{\mathrm{s}}=2 G M / \mathrm{c}^{2}=2 * 6.754 \times 10^{-11} * 31.824 * 10^{39} /\left(2.998 * 10^{8}\right)^{2}=47.82 * 10^{12}$ meters 


\section{$\underline{\text { (Case 1: Consider } \mathbf{P}_{1} \text { as an electron) }}$}

Then Then $\mathrm{M}_{1}=9.11 * 10^{-31} \mathrm{~kg}$. But $\mathrm{r}_{\mathrm{s}}=47.82 * 10^{12}$ meters according to above calculations with regards of a supermassive black hole. Then $\hbar<\mathrm{M}_{1}$

But by (27): $\mathrm{f}>\left[\mathrm{n} \cdot \pi \cdot \mathrm{M}_{1} /\left(2 . \mathrm{r}_{\mathrm{s}}\right)\right] *\left\{1 / \hbar^{3}\right\}$

Then by $(28): \mathrm{f}>\left\{\left(\mathrm{n} * 3.14 * 9.11 * 10^{-31}\right) /\left(2 * 47.82 * 10^{12}\right)\right\} *\left\{1 /\left[6.63 * 10^{-34}\right]^{3}\right\}$

But $\left\{\left(\mathrm{n} * 3.14 * 9.11 * 10^{-31}\right) /\left(2 * 47.82 * 10^{12}\right)\right\}$

$\geq\left\{\left(3.14 * 9.11 * 10^{-31}\right) /\left(2 * 47.82 * 10^{12}\right)\right\}$ (because $\mathrm{n}$ is the principle quantum number of the considered solar wind particle. Then $\mathrm{n} \geq 1$ ).

Thus $\mathrm{f}>\left\{\left(3.14 * 9.11 * 10^{-31}\right) /\left(2 * 47.82 * 10^{12}\right)\right\} *\left\{1 /\left[6.63 * 10^{-34}\right]^{3}\right\}=0.00103 * 10^{59}=$ $1.03 * 10^{56} \mathrm{~Hz}$

Thus f $>1.03 * 10^{56} \mathrm{~Hz}$

But maximum frequency of an electromagnetic wave is $<10^{30} \mathrm{~Hz}$

But $\mathrm{f}>1.03 * 10^{56} \mathrm{~Hz}>10^{30}>$ frequency of an electromagnetic wave

Thus the electrons of solar wind, which are moving towards the supermassive black hole, do not emit any electromagnetic radiations, due to their oscillations.

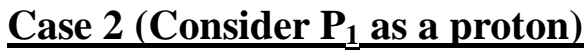

Then $\mathrm{M}_{1}=1.67 * 10^{-27} \mathrm{~kg}$. But $\mathrm{r}_{\mathrm{s}}=47.82 * 10^{12}$ meters according to above calculations with regards of a supermassive black hole. Then $\hbar<\mathrm{M}_{1}$

But by (27): $\mathrm{f}>\left[\mathrm{n} \cdot \pi \cdot \mathrm{M}_{1} /\left(2 . \mathrm{r}_{\mathrm{s}}\right)\right] *\left\{1 / \hbar^{3}\right\} \ldots \ldots \ldots \ldots \ldots(28)$

Then by $(28)$ : $\mathrm{f}>\left\{\left(\mathrm{n} * 3.14 * 1.67 * 10^{-27}\right) /\left(2 * 47.82 * 10^{12}\right)\right\} *\left\{1 /\left[6.63 * 10^{-34}\right]^{3}\right\}$

But $\left\{\left(\mathrm{n} * 3.14 * 1.67 * 10^{-27}\right) /\left(2 * 47.82 * 10^{12}\right)\right\}$

$\geq\left\{\left(3.14 * 1.67 * 10^{-27}\right) /\left(2 * 47.82 * 10^{12}\right)\right\}$ (because $\mathrm{n}$ is the principle quantum number of the considered solar wind particle. Then $n \geq 1$ ). 
Thus $\mathrm{f}>\left\{\left(3.14 * 1.67 * 10^{-27}\right) /\left(2 * 47.82 * 10^{12}\right)\right\}^{*}\left\{1 /\left[6.63 * 10^{-34}\right]^{3}\right\}$

Thus by (30): f $>1.88133 * 10^{-4} * 10^{63}=1.88133 * 10^{59} \mathrm{~Hz}$. Thus f $>1.88133 * 10^{59} \mathrm{~Hz}$

But maximum frequency of an electromagnetic wave is $<10^{30} \mathrm{~Hz}$

But by $(31), \mathrm{f}>1.88133 * 10^{59} \mathrm{~Hz}>10^{30}>$ frequency of an electromagnetic wave

Thus the protons of solar wind, which are moving towards the supermassive black hole, do not emit any electromagnetic radiations, due to their oscillations.

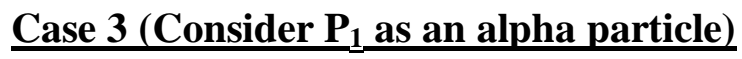

Then $\mathrm{M}_{1}=1.65 * 10^{-27} \mathrm{~kg}$. But $\mathrm{r}_{\mathrm{s}}=47.82 * 10^{12}$ meters according to above calculations with regards of a supermassive black hole. Then $\hbar<\mathrm{M}_{1}$.

But by (27): $\mathrm{f}>\left[\mathrm{n} . \pi \cdot \mathrm{M}_{1} /\left(2 . \mathrm{r}_{\mathrm{s}}\right)\right] *\left\{1 / \hbar^{3}\right\} \ldots \ldots \ldots \ldots \ldots(28)$

Then by $(28): \mathrm{f}>\left\{\left(\mathrm{n} * 3.14 * 1.65 * 10^{-27}\right) /\left(2 * 47.82 * 10^{12}\right)\right\} *\left\{1 /\left[6.63 * 10^{-34}\right]^{3}\right\}$

But $\left\{\left(\mathrm{n} * 3.14 * 1.65 * 10^{-27}\right) /\left(2 * 47.82 * 10^{12}\right)\right\} \geq\left\{\left(3.14 * 1.65 * 10^{-27}\right) /\left(2 * 47.82 * 10^{12}\right)\right\}$ (because $\mathrm{n}$ is the principle quantum number of the considered solar wind particle. Then $\mathrm{n} \geq 1$ ).

Thus $\mathrm{f}>\left\{\left(3.14 * 1.65 * 10^{-27}\right) /\left(2 * 47.82 * 10^{12}\right)\right\}^{*}\left\{1 /\left[6.63 * 10^{-34}\right]^{3}\right\} \ldots \ldots . . .(32)$ Thus by (32): $\mathrm{f}>1.8588 * 10^{-4} * 10^{63}=1.8588 * 10^{59} \mathrm{~Hz}$. Thus $\mathrm{f}>1.8588 * 10^{59}$ Hz............................ (32.1)

But maximum frequency of an electromagnetic wave is $\left\langle 10^{30} \mathrm{~Hz}\right.$. But f $>1.8588 * 10^{59} \mathrm{~Hz}>$ $10^{30}>$ frequency of an electromagnetic wave. Thus the alpha particles of the solar wind, which are moving towards the supermassive black hole, do not emit any electromagnetic radiations, due to their oscillations.

Therefore the particles of solar wind (electrons, protons and alpha particles), those move towards the supermassive black hole do not emit any electromagnetic waves to the outer space. (32.2) 


\subsubsection{Section 2 : How the supermassive black hole controls the orbiting velocity of nearby stars/planets}

According to the well-known knowledge, GMM' $/ \mathrm{r}^{2}=\mathrm{M}^{\prime} \cdot \mathrm{V}^{2} / \mathrm{r}$

$\mathrm{M}=$ mass of the supermassive black hole according to planet's reference frame

$\mathrm{M}^{\prime}$ = mass of the considering planet according to planet's reference frame

$r(t)=$ the distance between supermassive black hole and the planet at time ' $t$ ' according to the planet's reference frame

$\mathrm{V}=$ the orbiting linear velocity of the planet around the central object

Then $\mathrm{V}=\sqrt{ }(\mathrm{GM} / \mathrm{r})$

But the equation (33) is valid only according to classical physics theories. We know that there is a magnetic field that is spreading from the supermassive black hole's magnetic axis, towards the space. But usually there is another magnetic field that is due to the magnetic field of the planet (which orbits around the black hole).Also there are some other magnetic fields that is existing in that system. Those are the magnetic fields due to the magnetic fields of other planets/stars near to the considering main planet.

Then there is a magnetic attraction/repulsion among those magnetic fields. Depending on the direction of the considering main planet's magnetic axis and the total equivalent magnetic axis of rest of the matters nearby to the main planet, the velocity of the main planet $\left(\mathrm{A}_{1}\right)$ changes.

Then let's try to find the total equivalent magnetic force $\left(\mathbf{F}_{1}\right)$ that acts on $\mathbf{A}_{1}$ (due to the total magnetic field because of the black hole and the magnetic fields of rest of other planets/stars nearby to $A_{1}$ ) as below.

$\mathrm{F}_{1}=\left(\pi \mu_{0} / 4\right)^{*}\left(\mathrm{M}_{1} \cdot \mathrm{M}_{2} \cdot \mathrm{R}_{1}{ }^{2} \cdot \mathrm{R}_{2}^{2}\right) *\left[\frac{1}{x^{2}}+\frac{1}{(x+L 1+L 2)^{2}}-\frac{1}{(x+L 1)^{2}}-\frac{1}{(x+L 2)^{2}}\right]$

$\mu_{0}$ is the permeability of space, which equals to $4 \pi^{*} 10^{-7} \mathrm{~T} \cdot \mathrm{m} / \mathrm{A}$ 
$\mathrm{M}_{1}, \mathrm{M}_{2}$ identified as the magnetization of the magnet in $\mathrm{A}_{1}$ and the magnetization of the total equivalent magnet of the host planets/black hole respectively (the virtual magnets which produced by the magnetic field of the black hole/ host planets of $\mathrm{A}_{1}$ )

$\mathrm{x}$ is the distance between the two virtual magnets in meters (in the black hole/nearby planets/ nearby stars) - identified as the distance between magnet in $\mathrm{A}_{1}$ and the equivalent magnet of the host planets/ black hole.

$R_{1}, R_{2}$ are the radiuses of two magnets in meters - identified as the radius of the magnet in $\mathrm{A}_{1}$ and the radius of the total equivalent magnet of the host planets/black hole respectively (the virtual magnets which produced by the magnetic field of the black hole/ host planets of $\mathrm{A}_{1}$ )

$L_{1}, L_{2}$ are the lengths of two magnets in meters- identified as the lengths of the magnet in $\mathrm{A}_{1}$ and the length of the total equivalent magnet of the host planets/black hole respectively (the virtual magnets which produced by the magnetic field of the black hole/host planets of $\mathrm{A}_{1}$ ).

But we know that the magnetization of $\mathrm{A}_{1}\left(=\mathrm{M}_{1}\right)<$ magnetization of the supermassive black hole/host planets $\left(=\mathrm{M}_{2}\right)$.

And radius of the magnet in $A_{1}$ (virtual magnet that causes $A_{1}$ 's magnetic field) $\left(=R_{1}\right)<$

radius of the total equivalent magnet of the host planets/supermassive black hole $\left(=\mathrm{R}_{2}\right)$ ............(35)

But the gravitational force acting on $\mathrm{A}_{1}$, due to other host planets and host star of it $\left(\mathrm{F}_{2}\right)$ at time $\mathrm{t}$ $=\mathrm{GmM} / \mathrm{L}^{2}(\mathrm{t})_{-}$. But $\mathrm{F}_{2}>0$.

Here $\mathrm{L}(\mathrm{t})$ is the distance between $\mathrm{A}_{1}$ and the gravitational center of the host planets and the host star of $A_{1}$ at time t. $m$ is the total mass of the of the host planets and the host star of $A_{1}$.

The gravitational force acting on $A_{1}$ due to the supermassive black hole $\left(F_{3}\right)$ (supermassive black hole has located at the center of the galaxy which the $A_{1}$ has located) $=G M M^{\prime} / r^{2}(t)$

Here $r(t)$ is the distance between $A_{1}$ and the supermassive black hole at time $t$.

Here $\mathrm{L}^{2}(\mathrm{t})_{-}$means that $\mathrm{L}^{2}(\mathrm{t})$ is a vector. And $\mathrm{r}^{2}(\mathrm{t})_{-}$means $\mathrm{r}^{2}(\mathrm{t})$ is a vector. 
Then the projection of $F_{2}$ on the direction of $F_{1}=\left[\mathrm{GmM}^{\prime} / \mathrm{L}^{2}(\mathrm{t})\right] \cdot \cos \theta>0$

And the projection of $F_{3}$ on the direction of $F_{1}=\left[G M M^{\prime} / r^{2}(t)\right] \cdot \cos \phi$

Here $\theta$ is the angle between the direction of $F_{1}$ and $F_{2}$ and $\phi$ is the angle between the direction of $F_{3}$ and $F_{1}$.

But $A_{1}$ is orbiting around its host star. As well as $A_{1}$ and its solar system is revolving around the supermassive black hole (Supermassive black hole is at the center of the galaxy which $\mathrm{A}_{1}$ has located). Then let $F_{4}$ is the total centrifugal force acting on $A_{1}$. Then $F_{4}=M^{\prime} . V^{2}{ }_{0} / D$

The projection of $F_{4}$ on the direction of $F_{1}=\left[M^{\prime} \cdot\left(V_{0}^{2} / D\right) \cdot \cos \delta\right]$ for some $V_{0}$ and $D$.

Here $\delta$ is the angle between the direction of $F_{1}$ and $F_{4}$.

Here $\mathrm{V}_{0}$ is the total equivalent linear velocity of $\mathrm{A}_{1}$ (along the direction which is perpendicular to the total centrifugal force acting direction at time $t$ ). And $D$ is the distance between $A_{1}$ and total centrifugal force acting center.

Thus total external force acting on $\mathbf{A}_{\mathbf{1}}$ (due to the supermassive black hole/host objects) at time $\mathrm{t}=$ $\mathbf{F}=\mathrm{F}_{1}+\mathrm{F}_{2}+\mathrm{F}_{3}-\mathrm{F}_{4}$ (Because the total centrifugal force acting in the opposite direction of rest of the forces acting on $A_{1}$ ).

$=\mathrm{F}_{1}+\left[\mathrm{GmM}^{\prime} / \mathrm{L}^{2}(\mathrm{t})\right] \cdot \cos \theta+\left[\mathrm{GMM}^{\prime} / \mathrm{r}^{2}(\mathrm{t})\right] \cdot \cos \phi-\left[\left(\mathrm{M}^{\prime} \cdot \mathrm{V}^{2}{ }_{0} / \mathrm{D}\right) \cdot \cos \delta\right]$

But $A_{1}$ is stable in the system at time t. Thus $F=0$.

Thus $\mathrm{F}_{1}+\left[\mathrm{GmM} \mathrm{G}^{\prime} / \mathrm{L}^{2}(\mathrm{t})\right] \cdot \cos \theta+\left[\mathrm{GMM}^{\prime} / \mathrm{r}^{2}(\mathrm{t})\right] \cdot \cos \phi-\left[\left(\mathrm{M}^{\prime} \cdot \mathrm{V}^{2}{ }_{0} / \mathrm{D}\right) \cdot \cos \delta\right]=0$.

Thus $\mathrm{F}_{1}+\left[\mathrm{GmM} / \mathrm{L}^{2}(\mathrm{t})\right] \cdot \cos \theta+\left[\mathrm{GMM}^{\prime} / \mathrm{r}^{2}(\mathrm{t})\right] \cdot \cos \phi=\left[\left(\mathrm{M}^{\prime} \cdot \mathrm{V}^{2}{ }_{0} / \mathrm{D}\right) \cdot \cos \delta\right]$ ..(36)

By (34): $\mathrm{F}_{1}=\left(\pi \mu_{0} / 4\right) *\left(\mathrm{M}_{1} \cdot \mathrm{M}_{2} \cdot \mathrm{R}_{1}^{2} \cdot \mathrm{R}_{2}^{2}\right) *\left[\frac{1}{x^{2}}+\frac{1}{(x+L 1+L 2)^{2}}-\frac{1}{(x+L 1)^{2}}-\frac{1}{(x+L 2)^{2}}\right]$ 
Consider

$$
\frac{1}{x^{2}}+\frac{1}{(x+L 1+L 2)^{2}}=\left[2 x^{2}+(L 1)^{2}+(L 2)^{2}+2 \cdot L 1 \cdot L 2+2 x \cdot L 1+2 \cdot x \cdot L 2\right] \frac{1}{x^{2}(x+L 1+L 2)^{2}}
$$

$\frac{1}{(x+L 1)^{2}}+\frac{1}{(x+L 2)^{2}}=\left[2 x^{2}+(L 1)^{2}+(L 2)^{2}+2 L 1 \cdot x+2 \cdot L 2 \cdot x\right] \frac{1}{(x+L 1)^{2} \cdot(x+L 2)^{2}}$

But $x^{2}(x+L 1+L 2)^{2}=\mathrm{x}^{2}\left[\mathrm{x}^{2}+\mathrm{L}_{1}^{2}+\mathrm{L}_{2}^{2}+2 \cdot \mathrm{L}_{1} \cdot \mathrm{L}_{2}+2 \mathrm{x} . \mathrm{L}_{1}+2 \mathrm{x} \cdot \mathrm{L}_{2}\right]$

$=x^{4}+x^{2} L^{2}{ }_{1}+x^{2} L^{2}{ }_{2}+2 \cdot x^{2} L_{1} \cdot L_{2}+2 x^{3} \cdot L_{1}+2 x^{3} L_{2}$

And $(x+L 1)^{2} \cdot(x+L 2)^{2}=\left(\mathrm{x}^{2}+\mathrm{L}_{1}^{2}+2 \cdot \mathrm{x} . \mathrm{L}_{1}\right)^{*}\left(\mathrm{x}^{2}+\mathrm{L}_{2}{ }_{2}+2 \cdot \mathrm{x} . \mathrm{L}_{2}\right)$

Thus obviously, $x^{2}(x+L 1+L 2)^{2}<(x+L 1)^{2} \cdot(x+L 2)^{2}$

Thus obviously by (37), (38) and (39): $\frac{1}{x^{2}}+\frac{1}{(x+L 1+L 2)^{2}}>\frac{1}{(x+L 1)^{2}}+\frac{1}{(x+L 2)^{2}}$

Thus by (34), $\mathrm{F}_{1}>0$.

By (36), since $\mathrm{F}_{1}+\left[\mathrm{GmM} / \mathrm{L}^{2}(\mathrm{t})\right] \cdot \cos \theta>0$ (Because $\left.\mathrm{F}_{1}>0\right)$ :

$\left[\mathrm{GMM}^{\prime} / \mathrm{r}^{2}(\mathrm{t})\right] \cdot \cos \phi<\left[\left(\mathrm{M}^{\prime} \cdot \mathrm{V}_{0}{ }^{2} / \mathrm{D}\right) \cdot \cos \delta\right]<\left(\mathrm{M}^{\prime} \cdot \mathrm{V}^{2}{ }_{0} / \mathrm{D}\right)\left(\right.$ Since $\left.\mathrm{F}_{2}>0\right)$

Thus $\mathrm{GM} * \mathrm{D} *[1 / \mathrm{r}]^{2} *[\cos \phi]<\mathrm{V}^{2}{ }_{0}$

$\mathrm{GM} *\left[\cos \phi / \mathrm{r}^{2}\right]<\mathrm{GM} * \mathrm{D} *[1 / \mathrm{r}]^{2} *[\cos \phi]<\mathrm{V}_{0}^{2}$ (Because $\mathrm{D}>1$ in SI units)

Thus GM* $\left[\cos \phi / \mathrm{r}^{2}\right]<\mathrm{V}^{2}{ }_{0}$

By (36): $\mathrm{F}_{1}+\left[\mathrm{GmM}^{\prime} / \mathrm{L}^{2}(\mathrm{t})\right] \cdot \cos \theta+\left[\mathrm{GMM}^{\prime} / \mathrm{r}^{2}(\mathrm{t})\right] \cdot \cos \phi=\left[\left(\mathrm{M}^{\prime} \cdot \mathrm{V}^{2}{ }_{0} / \mathrm{D}\right) \cdot \cos \delta\right]$

Then $\mathrm{F}_{1}+\left[\mathrm{GmM}^{\prime} / \mathrm{L}^{2}(\mathrm{t})\right] \cdot \cos \theta+\left[\mathrm{GMM}^{\prime} / \mathrm{r}^{2}(\mathrm{t})\right] \cdot \cos \phi<\mathrm{F}_{1}+\mathrm{GmM}^{\prime} / \mathrm{L}^{2}(\mathrm{t})+\mathrm{GMM}^{\prime}$ (Because $r^{2}(t)>1$ in SI units and $\cos \theta<1$ and $\cos \phi<1$ )

Thus $\left(\mathrm{M}^{\prime} \cdot \mathrm{V}_{0}^{2} / \mathrm{D}\right) \cdot \cos \delta<\mathrm{F}_{1}+\mathrm{GmM}^{\prime} / \mathrm{L}^{2}(\mathrm{t})+\mathrm{GMM}$ ' 
Then $\mathrm{V}_{0}^{2}<\left\{\left(\mathrm{D} / \mathrm{M}^{\prime}\right) . \mathrm{F}_{1}+\mathrm{Gm}^{*}[\mathrm{D} / \mathrm{L}(\mathrm{t})]+\right.$ G.M. D $\} / \cos \delta$ (Because L (t) $>1$ in SI units) $<\left\{\left(\mathrm{D} . \mathrm{F}_{1}\right)+\mathrm{Gm}^{*}[\mathrm{D} / \mathrm{L}(\mathrm{t})]+\mathrm{G} \cdot \mathrm{M} \cdot \mathrm{D}\right\} / \cos \delta=\mathrm{D}\left[\mathrm{F}_{1}+(\mathrm{Gm} / \mathrm{L}(\mathrm{t}))+\mathrm{GM}\right] / \cos \delta$ (Because $\mathrm{M}^{\prime}>1$ )

Thus $\mathrm{V}_{0}^{2}<\mathrm{D}\left[\mathrm{F}_{1}+(\mathrm{Gm} / \mathrm{L}(\mathrm{t}))+\mathrm{GM}\right] / \cos \delta$

By (40) and (41): GM* $\left[\cos \phi / \mathrm{r}^{2}\right]<\mathrm{V}_{0}^{2}<\mathrm{D}\left[\mathrm{F}_{1}+(\mathrm{Gm} / \mathrm{L}(\mathrm{t}))+\mathrm{GM}\right] / \cos \delta$

Here $V_{0}$ is the total equivalent linear velocity of $A_{1}$ along its path of orbiting, $M$ is the mass of the supermassive black hole, $\mathrm{D}$ is the distance between $\mathrm{A}_{1}$ and total centrifugal force acting center, $r(t)$ is the distance between $A_{1}$ and the supermassive black hole at time $t, F_{1}$ is the total equivalent magnetic force that acts on $\mathrm{A}_{1}, \mathrm{~m}$ is the total mass of the of the host planets and the host star of $A_{1}, L(t)$ is the distance between $A_{1}$ and the gravitational center of the host planets and the host star of $A_{1}$ at time $t, \phi$ is the angle between the direction of $F_{3}$ and $F_{1}, \delta$ is the angle between the direction of $\mathrm{F}_{1}$ and $\mathrm{F}_{4}$.

\subsection{Result Evaluation of Methodology part 2}

According to (32): All the above considered particles of solar wind, those move towards the supermassive black hole do not emit any electromagnetic waves to the outer space. Therefore the nearby area of a supermassive black hole is dark since the above considered solar wind particles do not emit any electromagnetic waves to the outer space. Therefore no one can see any electromagnetic waves emitting due oscillation of the solar wind particles, when those solar wind particles in the sky are accelerating towards the supermassive black hole. And there is a range for the orbital velocity of a planet if that planet is considerably influenced by a supermassive black hole.

According to (42): $\mathrm{GM} *\left[\cos \phi / \mathrm{r}^{2}\right]<\mathrm{V}_{0}^{2}<\mathrm{D}\left[\mathrm{F}_{1}+(\mathrm{Gm} / \mathrm{L}(\mathrm{t}))+\mathrm{GM}\right] / \cos \delta$

That implies that there is a range for the total equivalent linear velocity of a planet which is along its path of orbiting. And that limit of the linear velocity depends on the mass of the host supermassive black hole as well. 


\section{Methodology part 3}

\subsection{Notations of Methodology part 3}

$\psi=$ wave function

$\mathrm{G}=$ universal gravitational constant

$E_{i}=$ energy eigenvalue of the wave function $\psi_{i}$

$\mathrm{m}_{\mathrm{i}}=$ the mass of the matter particle ' $\mathrm{i}$ '

$\left(V_{0}\right)_{i}=$ the electric potential energy associated with the matter particle ' $\mathrm{i}$ '

$r_{i}=$ the radial coordinate to the matter particle ' $i$ '.

$\theta_{\mathrm{i}}=$ the polar coordinate to the particle ' $\mathrm{i}$ '

$\phi_{\mathrm{i}}=$ the azimuthal angel to particle ' $\mathrm{i}$ '

$\mathrm{M}_{\mathrm{i}}=$ the total mass of the rest of the gravitationally repulsive matters with respect to the matter particle ' $i$ '

$\mathrm{M}=$ the total mass of the gravitationally attractive matters in the considering space volume

$\mathrm{R}_{\mathrm{i}}=$ the distance between $\mathrm{m}_{\mathrm{i}}$ and gravitational center of the gravitationally attractive matters in the considering space volume

$\Omega=$ the vacuum energy of the considering space volume

$S_{i}=$ the spin operator of the particle ' $i$ '

$E^{\prime}=$ the eigenvalue of the quantum vacuum system

$\mathrm{v}=$ the number of matter/wave particles in the considering quantum vacuum states

$\mathrm{a}=$ number of matter particles in the considering space volume of the ordinary universe 
$\Sigma \mathrm{m}_{\mathrm{i}}=\mathrm{M}_{0}, \Sigma \mathrm{r}_{\mathrm{i}}=\mathrm{D}, \Sigma \psi_{\mathrm{i}}\left(\mathrm{r}_{\mathrm{i}}, \theta_{\mathrm{i}}, \phi_{\mathrm{i}}\right)=\Psi, \Sigma \mathrm{E}_{\mathrm{i}}=\mathrm{E}_{0}, \Sigma\left(\mathrm{V}_{0}\right)_{\mathrm{i}}=\mathrm{V}_{1}$ and $\Sigma\left(\Delta \mathrm{H}_{\mathrm{i}}\right)=\mathrm{H}_{1}$

$\Sigma \mathrm{m}_{\mathrm{j}}=\mathrm{M}^{\prime}, \Sigma \mathrm{r}_{\mathrm{j}}=\mathrm{D}^{\prime}, \Sigma \psi_{\mathrm{j}}\left(\mathrm{r}_{\mathrm{j}}, \theta_{\mathrm{j}}, \phi_{\mathrm{j}}\right)=\Psi^{\prime}, \Sigma \mathrm{E}_{\mathrm{j}}^{\prime}=\mathrm{E}^{\prime}{ }_{0}, \Sigma\left(\mathrm{V}_{0}\right)_{\mathrm{j}}=\mathrm{V}_{2}$ and $\Sigma\left(\Delta \mathrm{H}_{\mathrm{j}}\right)=\mathrm{H}_{2}$

$\Delta \mathrm{H}_{\mathrm{i}}=$ the potential energy (potential energy of ' $\mathrm{i}$ ' th matter particle) associated with the external magnetic field $B_{i}$ plus the potential energy associated with the interaction of the charged matter's spin magnetic moment with the magnetic fields induced due to other charges around the original charged matter $\mathrm{m}_{\mathrm{Bi}}=$ the magnetic moment of ' $\mathrm{i}$ ' particle due to the external magnetic field $\mathrm{B}_{\mathrm{i}}$

$\mathrm{B}_{\mathrm{i}}{ }_{\mathrm{i}}=$ the magnetic field induced due to other charges around the original charged matter

$\mathrm{B}_{\mathrm{i}}=$ external magnetic field that influences on ' $\mathrm{i}$ ' th matter, $\mu_{\mathrm{B}}=$ The Bohr Magneton

$\left(\mathrm{m}_{\mathrm{s}}\right)_{\mathrm{i}}=$ the spin magnetic moment associated with the interaction of the charged matter's spin magnetic field with the magnetic fields induced due to other charges around the original charged matter ' $i$ '

\subsection{Content of the Methodology part 3}

We know that the universe is expanding with an acceleration rate. Now let's explore about the contribution of predicted mass of the quantum vacuum on the expansion of the Universe.

In the space, the contribution to the accelerating expansion of the universe by the quantum vacuum is much bit than the contribution by other matters in the universe to the accelerating expansion of the universe.

Through this below content, I am intending to explain the reasons for the above fact using theories in quantum mechanics.

But the space all over the universe is not empty at all. The space we identify as 'Empty' is filled with an energy called as 'Vacuum Energy'. Vacuum energy lasts usually all across the universe.

Moreover, scientists are dealing with a term 'Quantum Vacuum' currently. But what is the meaning of a 'Quantum Vacuum'? 
Quantum Vacuum is the quantum state with the lowest possible energy. For the quantum vacuum, we should tend to lower the temperature to absolute zero. In the space, the contribution to the accelerating expansion of the universe by the quantum vacuum is much bit/null than the contribution by other ordinary matters in the universe. But why the quantum vacuum has little effect on the expansion of the universe? That is the question that we should answer through this research part.

\section{BUT DO NOT COMPARE THE EQUATION NUMBERS AND THE SYMBOLS OTHER PARTS IN THE RESEARCH METHODOLOGY AND IN THIS METHODOLOGY PART NUMBER 03.}

Let's consider some space volume of the universe. That space volume we consider should be at least the order of $10^{\sigma}$ light years as the radius. Where $\sigma$ is a considerably large natural number. We already know that there are two types of matters. First type is the matters which are gravitationally attractive with each other. Other type is the matter which gravitationally repulsive with respect to each other.

Let's consider all the matters which are gravitationally repulsive with respect to each other. i.e. let's consider all the gravitationally repulsive matters in the considering space volume (the space of at least $10^{\sigma}$ light years in radius) as below:

Let there are ' $a$ ' number of matters those are gravitationally repulsive (in the space volume that we consider) with respect to each other. Those 'matters' are fundamental particles or solid blocks.

Then the total wave function $\left(\psi_{1}, 2, \ldots . ., \mathrm{a}(\mathrm{r}, \theta, \phi)\right)$ for the all 'a' number of gravitationally repulsive matters can be written as:

$\psi_{1,2, \ldots, \mathrm{a}}(\mathrm{r}, \theta, \phi)=\mathrm{c}_{1 .} \psi_{1}\left(\mathrm{r}_{1}, \theta_{1}, \phi_{1}\right)+\mathrm{c}_{2} \psi_{2}\left(\mathrm{r}_{2}, \theta_{2}, \phi_{2}\right)+\ldots \ldots \ldots . \mathrm{c}_{\mathrm{a}} \cdot \psi_{\mathrm{a}}\left(\mathrm{r}_{\mathrm{a}}, \theta_{\mathrm{a}}, \phi_{\mathrm{a}}\right) \ldots \ldots \ldots \ldots \ldots$ (1.01) where $c_{i}$ are complex constants.

$\mathrm{E}=\mathrm{E}_{1}+\mathrm{E}_{2}+\ldots \ldots \ldots+\mathrm{E}_{\mathrm{i}}+\ldots \ldots \ldots+\mathrm{E}_{\mathrm{a}}$

Here $\mathrm{H}_{\mathrm{i}}$ the Hamiltonian operator of ' $\mathrm{i}$ ' th matter particle in the repulsive gravitational system. 
***And when we identify the matter particle's location system for each cases (each cases means each order number ' $\mathrm{i}$ ' of each particle), we should consider the origin as the location of the $\mathrm{M}_{\mathrm{i}}$ (location of the $\mathrm{M}_{\mathrm{i}}$ is the gravitational center of the total mass of the rest of the gravitationally repulsive matters except the matter particle ' $i$ ').

Here, $H_{i}=-\left(\hbar^{2} / 2 m_{i}\right) \cdot \nabla_{i}^{2}+\left(V_{0}\right)_{i}+G \cdot m_{i} \cdot M_{i} / r_{i}-\left[G \cdot m_{i} \cdot M / R_{i}\right]+\Omega+\Delta H_{i}+S_{i} \ldots \ldots(01)$

Here the gravitational potential energy associated with the term $\left[G \cdot m_{i} \cdot M_{i} / r_{i}\right]$ is a positive term since that term is regarding the repulsive gravitational potential energy.

Here,

$$
\nabla^{2}=\frac{1}{r^{2}} \frac{\partial}{\partial}\left(r^{2} \frac{\partial}{\partial}\right)+\frac{1}{r^{2} \sin \theta} \frac{\partial}{\partial \theta}\left(\sin \theta \frac{\partial}{\partial \theta}\right)+\frac{1}{r^{2} \sin ^{2} \theta}\left(\frac{\partial^{2}}{\partial \phi^{2}}\right)
$$

Where $\psi_{i}\left(r_{i}, \theta_{i}, \phi_{i}\right)$ is the wave function of the ' $i$ ' th gravitationally repulsive matter. $i$ belongs to $\{1,2, \ldots \ldots \ldots \ldots, a\}$.

And $E_{i}$ is the eigenvalue of the wave function $\psi_{i}\left(r_{i}, \theta_{i}, \phi_{i}\right) . m_{i}$ is the mass of the matter particle ' $\mathrm{i}$ '. $\left(\mathrm{V}_{0}\right)_{\mathrm{i}}$ is the electric potential energy associated with the matter particle ' $\mathrm{i}$ '. $\mathrm{r}_{\mathrm{i}}$ is the radial coordinate to the matter particle ' $i$ ' from the gravitational center. $\theta_{i}$ is the polar coordinate to the particle ' $\mathrm{i}$ '. $\phi_{\mathrm{i}}$ is the azimuthal angel to the particle ' $\mathrm{i}$ '. $\mathrm{M}_{\mathrm{i}}$ is the total mass of the rest of the gravitationally repulsive matters except the matter particle ' $i$ '. $M$ is the total mass of the gravitationally attractive matters in the considering space volume. $R_{i}$ is the distance between $m_{i}$ and gravitational center of the gravitationally attractive matters in the considering space volume.

Here $\Delta \mathrm{H}_{\mathrm{i}}$ is the potential energy (potential energy of ' $\mathrm{i}$ ' th matter particle) associated with the external magnetic field $\mathrm{B}_{\mathrm{i}}$ and the potential energy associated with the interaction of the charged matter's spin magnetic moment with the magnetic fields induced due to other charges around the original charged matter. $m_{B i}$ is the magnetic moment of ' $i$ ' th particle due to the external magnetic field $\mathrm{B}_{\mathrm{i}} . \mathrm{B}_{\mathrm{i}}{ }_{\mathrm{i}}$ is the magnetic field induced due to other charges around the original charged matter. 
And $\left(m_{s}\right)_{i}$ is the spin magnetic moment quantum number associated with the interaction of the charged matter's spin magnetic field with the magnetic fields induced due to other charges around the original charged matter ' $i$ '.

Here $\Delta H_{i}=2 \cdot \mu_{B} \cdot B_{i} \cdot\left(m_{s}\right)_{i}-m_{B i} \cdot B_{i}$

And $\Omega$ is the vacuum energy operator of the considering space volume. $S_{i}$ is the spin operator of the particle 'i'.

Now let's consider the wave function, Hamiltonian and the eigenvalue for the quantum vacuum as below.

$\Upsilon\left(r^{\prime}, \theta^{\prime}, \phi^{\prime}\right)=c_{1}{ }^{\prime} \Upsilon_{1}\left(r^{\prime}{ }_{1}, \theta^{\prime}{ }_{1}, \phi^{\prime}{ }_{1}\right)+c_{2}{ }^{\prime} \cdot \Upsilon_{2}\left(r^{\prime}{ }_{2}, \theta^{\prime}{ }_{2}, \phi^{\prime}{ }_{2}\right)+\ldots \ldots . .+c_{v}{ }^{\prime} . \Upsilon_{v}\left(r^{\prime}{ }_{v}, \theta^{\prime}{ }_{v}, \phi^{\prime}{ }_{v}\right)$ ..(2.01) where $\mathrm{c}_{\mathrm{i}}^{\prime}$ are complex constants.

$\mathrm{E}^{\prime}=$ the eigenvalue of the quantum vacuum system

Since $E^{\prime}$ is the total energy of the quantum vacuum, $E^{\prime}$ is less than $E$ (which is mentioned above) Where each i belongs to $\{1,2,3, \ldots \ldots \ldots$, a $\}$ according to the definition of quantum vacuum.

Let ' $v$ ' is the number of matter/wave particles in the considering quantum vacuum states volume. $\Upsilon_{j}\left(r^{\prime}{ }_{j}, \theta{ }_{j}, \phi_{j}\right)$ is the wave function of the ' $j$ ' th matter/wave in the quantum vacuum of the considering space volume. $r^{\prime}{ }_{j}$ is the radial component of the wave function $\Upsilon_{j} . \theta^{\prime}$ is the polar coordinate to the ' $j$ ' th matter/wave in the quantum vacuum. $\phi{ }_{j}$ is the azimuthal coordinate to the ' $\mathrm{j}$ ' th matter/wave in the quantum vacuum.

The Hamiltonian $\left(\mathrm{H}_{\mathrm{j}}{ }^{\prime}\right)$ of the matter/wave in the quantum vacuum is:

$H_{j}{ }^{\prime}=-\left(\hbar^{2} / 2 m_{j}\right) \cdot \nabla_{j}{ }^{2}+\left(V_{0}\right)_{j}+G \cdot m_{j} \cdot M_{j} / r_{j}{ }_{j}-\left[G \cdot m_{j} \cdot M / R_{j}\right]+\Omega+\Delta H_{j}+S_{j}$ (02)

The meanings of the symbols of (02) are similar to the symbols of (01). 
By considering (01):

$\left[-\left(\hbar^{2} / 2 m_{i}\right) \cdot \nabla_{i}^{2}+\left(V_{0}\right)_{i}+G \cdot m_{i} \cdot M_{i} / r_{i}-\left[G \cdot m_{i} \cdot M / R_{i}\right]+\Omega+\Delta H_{i}+S_{i}\right] \cdot\left[\psi_{i}\left(r_{i}, \theta_{i}, \phi_{i}\right)\right]$

$=\mathrm{E}_{\mathrm{i}} \cdot \psi_{\mathrm{i}}\left(\mathrm{r}_{\mathrm{i}}, \theta_{\mathrm{i}}, \phi_{\mathrm{i}}\right)$

Here,

$\nabla^{2}=\frac{1}{r^{2} \sin \theta}\left[\sin \theta \frac{\partial}{\partial r}\left(r^{2} \frac{\partial \psi}{\partial r}\right)+\frac{\partial}{\partial \theta}\left(\sin \theta \frac{\partial \psi}{\partial \theta}\right)+\frac{1}{\sin \theta} \frac{\partial^{2} \psi}{\partial \varphi^{2}}\right]$

By considering (02):

$\left[-\left(\hbar^{2} / 2 m_{j}\right) \cdot \nabla_{j}{ }^{2}+\left(V_{0}\right)_{j}+G \cdot m_{j} \cdot M_{j} / r_{j}{ }_{j}-\left[G \cdot m_{j} \cdot M / R_{j}\right]+\Omega+\Delta H_{j}+S_{j}\right] . Y_{j}\left(r_{j}, \theta_{j}{ }^{\prime}, \phi_{j}{ }^{\prime}\right)$

$=E_{j}{ }^{\prime} \Upsilon_{j}\left(r_{j}{ }^{\prime}, \theta_{j}{ }^{\prime}, \phi_{j}{ }^{\prime}\right)$

Where, $E_{1}, E_{2}, \ldots \ldots \ldots . . . E_{a}>E_{j}^{\prime}$

By (03), $\Sigma\left[-\left(\hbar^{2} / 2 m_{i}\right) \cdot \nabla_{i}^{2}+\left(V_{0}\right)_{i}+G \cdot m_{i} \cdot M_{i} / r_{i}-\left[G \cdot m_{i} \cdot M / R_{i}\right]+\Omega+\Delta H_{i}+S_{i}\right] .\left[\psi_{i}\left(r_{i}, \theta_{i}, \phi_{i}\right)\right]$

$=\Sigma \mathrm{E}_{\mathrm{i}} \cdot \psi_{\mathrm{i}}\left(\mathrm{r}_{\mathrm{i}}, \theta_{\mathrm{i}}, \phi_{\mathrm{i}}\right)$

Let's consider two positive real numbers $x_{i}$ and $y_{i}$. Then

$\Sigma\left(\mathrm{x}_{\mathrm{i}} / \mathrm{y}_{\mathrm{i}}\right)=\left(\mathrm{x}_{1} / \mathrm{y}_{1}\right)+\left(\mathrm{x}_{2} / \mathrm{y}_{2}\right)+$ $+\left(x_{n} / y_{n}\right)$

But $\left(\mathrm{x}_{\mathrm{i}} / \mathrm{y}_{\mathrm{i}}\right)>\mathrm{x}_{\mathrm{i}} / \Sigma \mathrm{y}_{\mathrm{i}}$ for each $\mathrm{i}$ belongs to $\{1,2,3, \ldots \ldots \ldots \ldots \ldots, \mathrm{a}\}$

Thus $\left(\mathrm{x}_{1} / \mathrm{y}_{1}\right)+\left(\mathrm{x}_{2} / \mathrm{y}_{2}\right)+\ldots \ldots \ldots \ldots . .\left(\mathrm{x}_{\mathrm{n}} / \mathrm{y}_{\mathrm{n}}\right)>\left(\mathrm{x}_{1} / \Sigma \mathrm{y}_{\mathrm{i}}\right)+\left(\mathrm{x}_{2} / \Sigma \mathrm{y}_{\mathrm{i}}\right)+\ldots+\left(\mathrm{x}_{\mathrm{n}} / \Sigma \mathrm{y}_{\mathrm{i}}\right)$

i.e. $\Sigma\left(\mathrm{x}_{\mathrm{i}} / \mathrm{y}_{\mathrm{i}}\right)>\Sigma \mathrm{x}_{\mathrm{i}} / \Sigma \mathrm{y}_{\mathrm{i}}$ for $\mathrm{x}_{\mathrm{i}}, \mathrm{y}_{\mathrm{i}}>0$

Let's consider :

$\Sigma\left[-\left(\hbar^{2} / 2 m_{i}\right) \cdot \nabla_{i}^{2}+\left(V_{0}\right)_{i}+G \cdot m_{i} \cdot M_{i} / r_{i}-\left[G \cdot m_{i} \cdot M / R_{i}\right]+\Omega+\Delta H_{i}+S_{i}\right]$

$>\left(-\hbar^{2} / 2\right) \cdot\left[\Sigma\left(\nabla_{\mathrm{i}}^{2} / \mathrm{m}_{\mathrm{i}}\right)\right]+\Sigma\left(\mathrm{V}_{0}\right)_{\mathrm{i}}+\mathrm{G} \cdot\left[\Sigma\left(\mathrm{m}_{\mathrm{i}} \cdot \mathrm{M}_{\mathrm{i}}\right) / \Sigma \mathrm{r}_{\mathrm{i}}\right]-$ G.M. $\left[\Sigma \mathrm{m}_{\mathrm{i}} / \mathrm{R}_{\mathrm{i}}\right]+\Omega \cdot \mathrm{a}+\Sigma\left(\Delta \mathrm{H}_{\mathrm{i}}\right)+\Sigma \mathrm{S}_{\mathrm{i}}$

$>\left(-\hbar^{2} / 2\right) \cdot\left[\Sigma\left(\nabla_{\mathrm{i}}^{2} / \mathrm{m}_{\mathrm{i}}\right)\right]+\Sigma\left(\mathrm{V}_{0}\right)_{\mathrm{i}}+\mathrm{G}\left[\Sigma \mathrm{m}_{\mathrm{i}}^{2} / \Sigma \mathrm{r}_{\mathrm{i}}\right]-$ G.M. $\left[\Sigma\left(\mathrm{m}_{\mathrm{i}} / \mathrm{R}_{\mathrm{i}}\right)\right]+\Omega \cdot \mathrm{a}+\Sigma\left(\Delta \mathrm{H}_{\mathrm{i}}\right)+\Sigma \mathrm{S}_{\mathrm{i}}$ 
(By considering (06)). Also $\mathrm{m}_{\mathrm{i}}<\mathrm{M}_{\mathrm{i}}$ for each ' $\mathrm{i}$ ' belongs to $\{1,2, \ldots \ldots \ldots \ldots, \mathrm{a}\}$. Because the mass of one single particle $\left(=\mathrm{m}_{\mathrm{i}}\right)$ is less than the addition of all masses of the rest of the matters $\left(\mathrm{M}_{\mathrm{i}}\right)$ in the universe.

$\Sigma \mathrm{S}_{\mathrm{i}}>0$ and $\Omega . \mathrm{a}>0$

Thus

$\left[\left(-\hbar^{2} / 2\right) \cdot\left[\Sigma\left(\nabla_{\mathrm{i}}{ }^{2} / \mathrm{m}_{\mathrm{i}}\right)\right]+\Sigma\left(\mathrm{V}_{0}\right)_{\mathrm{i}}+\mathrm{G}\left[\Sigma \mathrm{m}_{\mathrm{i}}^{2} / \Sigma \mathrm{r}_{\mathrm{i}}\right]-\right.$ G.M. $\left.\left[\Sigma\left(\mathrm{m}_{\mathrm{i}} / \mathrm{R}_{\mathrm{i}}\right)\right]+\Omega \cdot \mathrm{a}+\Sigma\left(\Delta \mathrm{H}_{\mathrm{i}}\right)+\Sigma \mathrm{S}_{\mathrm{i}}\right] \psi_{\mathrm{i}}$ $>\left[\left(-\hbar^{2} / 2\right) \cdot\left[\Sigma\left(\nabla_{\mathrm{i}}^{2} / \mathrm{m}_{\mathrm{i}}\right)\right]+\Sigma\left(\mathrm{V}_{0}\right)_{\mathrm{i}}+\mathrm{G}\left[\Sigma \mathrm{m}_{\mathrm{i}}^{2} / \Sigma \mathrm{r}_{\mathrm{i}}\right]-\mathrm{G} \cdot \mathrm{M} \cdot\left[\Sigma\left(\mathrm{m}_{\mathrm{i}} / \mathrm{R}_{\mathrm{i}}\right)\right]+\Sigma\left(\Delta \mathrm{H}_{\mathrm{i}}\right)\right] \cdot \psi_{\mathrm{i}}$ $=\left[\left(-\hbar^{2} / 2\right) \cdot\left[\Sigma\left(\nabla_{\mathrm{i}}^{2} / \mathrm{m}_{\mathrm{i}}\right)\right]+\Sigma\left(\mathrm{V}_{0}\right)_{\mathrm{i}}+[\mathrm{G} / \mathrm{D}] \cdot\left[\Sigma \mathrm{m}_{\mathrm{i}}^{2}\right]-\mathrm{G} \cdot \mathrm{M} \cdot\left[\Sigma\left(\mathrm{m}_{\mathrm{i}} / \mathrm{R}_{\mathrm{i}}\right)\right]+\Sigma\left(\Delta \mathrm{H}_{\mathrm{i}}\right)\right] \cdot \psi_{\mathrm{i}}$ where $\Sigma \mathrm{m}_{\mathrm{i}}=\mathrm{M}_{0}$ and $\Sigma \mathrm{r}_{\mathrm{i}}=\mathrm{D}$

Therefore by (03):

$\Sigma \mathrm{E}_{\mathrm{i}} \cdot \psi_{\mathrm{i}}\left(\mathrm{r}_{\mathrm{i}}, \theta_{\mathrm{i}}, \phi_{\mathrm{i}}\right)>$

$\Sigma\left\{\left(-\hbar^{2} / 2\right) \cdot\left[\Sigma\left(\nabla_{\mathrm{i}}^{2} / \mathrm{m}_{\mathrm{i}}\right)\right]+\Sigma\left(\mathrm{V}_{0}\right)_{\mathrm{i}}+[\mathrm{G} / \mathrm{D}] \cdot\left[\Sigma \mathrm{m}_{\mathrm{i}}^{2}\right]-\mathrm{G} \cdot \mathrm{M} \cdot\left[\Sigma\left(\mathrm{m}_{\mathrm{i}} / \mathrm{R}_{\mathrm{i}}\right)\right]+\Sigma\left(\Delta \mathrm{H}_{\mathrm{i}}\right)\right\} \cdot \psi_{\mathrm{i}}\left(\mathrm{r}_{\mathrm{i}}, \theta_{\mathrm{i}}, \phi_{\mathrm{i}}\right)$

But the operator term $\left\{\left(-\hbar^{2} / 2\right) \cdot\left[\Sigma\left(\nabla_{\mathrm{i}}^{2} / \mathrm{m}_{\mathrm{i}}\right)\right]+\Sigma\left(\mathrm{V}_{0}\right)_{\mathrm{i}}+[\mathrm{G} / \mathrm{D}] \cdot\left[\Sigma \mathrm{m}_{\mathrm{i}}^{2}\right]-\right.$ G.M. $\left[\Sigma\left(\mathrm{m}_{\mathrm{i}} / \mathrm{R}_{\mathrm{i}}\right)\right]+$ $\left.\Sigma\left(\Delta \mathrm{H}_{\mathrm{i}}\right)\right\}$ is independent from ' $\mathrm{i}$ '. Here $\mathrm{i}$ belongs to $\{1,2,3, \ldots \ldots \ldots \mathrm{a}\}$. Thus,

$\Sigma \mathrm{E}_{\mathrm{i}} . \Sigma \psi_{\mathrm{i}}\left(\mathrm{r}_{\mathrm{i}}, \theta_{\mathrm{i}}, \phi_{\mathrm{i}}\right)>\Sigma \mathrm{E}_{\mathrm{i}} \cdot \psi_{\mathrm{i}}\left(\mathrm{r}_{\mathrm{i}}, \theta_{\mathrm{i}}, \phi_{\mathrm{i}}\right)>$

$\left\{\left(-\hbar^{2} / 2\right) \cdot\left[\Sigma\left(\nabla_{\mathrm{i}}^{2} / \mathrm{m}_{\mathrm{i}}\right)\right]+\Sigma\left(\mathrm{V}_{0}\right)_{\mathrm{i}}+[\mathrm{G} / \mathrm{D}] .\left[\Sigma \mathrm{m}_{\mathrm{i}}^{2}\right]-\right.$ G.M. $\left.\left[\Sigma\left(\mathrm{m}_{\mathrm{i}} / \mathrm{R}_{\mathrm{i}}\right)\right]+\Sigma\left(\Delta \mathrm{H}_{\mathrm{i}}\right)\right\} . \Sigma \psi_{\mathrm{i}}\left(\mathrm{r}_{\mathrm{i}}, \theta_{\mathrm{i}}, \phi_{\mathrm{i}}\right)$

Because $\Sigma\left(\mathrm{x}_{\mathrm{i}} \cdot \mathrm{y}_{\mathrm{i}}\right)<\Sigma \mathrm{x}_{\mathrm{i}} \cdot \Sigma \mathrm{y}_{\mathrm{i}}$ for positive $\mathrm{x}_{\mathrm{i}}$ and $\mathrm{y}_{\mathrm{i}}$.

Let $\Sigma \psi_{\mathrm{i}}\left(\mathrm{r}_{\mathrm{i}}, \theta_{\mathrm{i}}, \phi_{\mathrm{i}}\right)=\Psi, \Sigma \mathbf{E}_{\mathbf{i}}=\mathbf{E}_{\mathbf{0}}$

Let $\Sigma\left(\mathrm{V}_{0}\right)_{\mathrm{i}}=\mathrm{V}_{1}$ and $\Sigma\left(\Delta \mathrm{H}_{\mathrm{i}}\right)=\mathrm{H}_{1}$

Then $\left\{\left(-\hbar^{2} / 2\right) \cdot\left[\Sigma\left(\nabla_{\mathrm{i}}^{2} / \mathrm{m}_{\mathrm{i}}\right)\right]+\mathrm{V}_{1}+[\mathrm{G} / \mathrm{D}] .\left[\Sigma \mathrm{m}_{\mathrm{i}}^{2}\right]-\right.$ G.M. $\left.\left[\Sigma\left(\mathrm{m}_{\mathrm{i}} / \mathrm{R}_{\mathrm{i}}\right)\right]+\mathrm{H}_{1}\right\} \cdot \Psi<\mathrm{E}_{0} \cdot \Psi$ ..(07)

Where $\Sigma \mathrm{m}_{\mathrm{j}}=\mathrm{M}^{\prime}, \Sigma \mathrm{r}_{\mathrm{i}}=\mathrm{D}, \Sigma \psi_{\mathrm{i}}\left(\mathrm{r}_{\mathrm{i}}, \theta_{\mathrm{i}}, \phi_{\mathrm{i}}\right)=\Psi, \Sigma \mathrm{E}_{\mathrm{i}}=\mathrm{E}_{0}, \Sigma\left(\mathrm{V}_{0}\right)_{\mathrm{i}}=\mathrm{V}_{1}$ and $\Sigma\left(\Delta \mathrm{H}_{\mathrm{i}}\right)=\mathrm{H}_{1}$ 
By (04):

$\left[-\left(\hbar^{2} / 2 m_{j}\right) \cdot \nabla_{j}^{2}+\left(V_{0}\right)_{j}+G \cdot m_{j} \cdot M_{j} / r_{j}-\left[G \cdot m_{j} \cdot M / R_{j}\right]+\Omega+\Delta H_{j}+S_{j}\right] \cdot \Upsilon_{j}\left(r_{j}^{\prime}, \theta_{j}{ }^{\prime}, \phi_{j}{ }^{\prime}\right)$

$=E_{j}^{\prime} \Upsilon_{j}\left(r_{j}^{\prime}, \theta_{j}{ }^{\prime}, \phi_{j}{ }^{\prime}\right)$

Similar to (07),

$\left\{\left(-\hbar^{2} / 2\right) \cdot\left[\Sigma\left(\nabla_{\mathrm{j}}{ }^{2} / \mathrm{m}_{\mathrm{j}}\right)\right]+\mathrm{V}_{2}+\left[\mathrm{G} / \mathrm{D}^{\prime}\right] .\left[\Sigma \mathrm{m}_{\mathrm{j}}^{2}\right]-\right.$ G.M. $\left.\left[\Sigma\left(\mathrm{m}_{\mathrm{j}} / \mathrm{R}_{\mathrm{j}}\right)\right]+\mathrm{H}_{2}\right\} . \Psi^{\prime}<\mathrm{E}_{0}^{\prime} . \Psi^{\prime}$ (08)

Where $\Sigma \mathrm{r}_{\mathrm{j}}=\mathrm{D}^{\prime}, \Sigma \psi_{\mathrm{j}}\left(\mathrm{r}_{\mathrm{j}}, \theta_{\mathrm{j}}, \phi_{\mathrm{j}}\right)=\Psi^{\prime}, \boldsymbol{\Sigma} \mathbf{E}_{\mathbf{j}} \mathbf{j}^{\prime} \mathbf{E}^{\prime}{ }_{\mathbf{0}}, \Sigma\left(\mathrm{V}_{0}\right)_{\mathrm{j}}=\mathrm{V}_{2}$ and $\Sigma\left(\Delta \mathrm{H}_{\mathrm{j}}\right)=\mathrm{H}_{2}$

And $E_{i}>E_{j}$ for all $i$ belongs to $\{1,2, \ldots . . a\}$ and for all $j$ belongs to $\{1,2, \ldots \ldots . . v\}$

Since in quantum vacuum, the energy of each quantum level < energy of other (excited) quantum levels.

Here $\mathrm{M}^{\prime}$ is the total mass of the quantum vacuum.

By (07): $\left\{\left(-\hbar^{2} / 2\right) \cdot\left[\Sigma\left(\nabla_{\mathrm{i}}{ }^{2} / \mathrm{m}_{\mathrm{i}}\right)\right]+\mathrm{V}_{1}+[\mathrm{G} / \mathrm{D}] \cdot\left[\Sigma \mathrm{m}_{\mathrm{i}}^{2}\right]-\right.$ G.M. $\left.\left[\Sigma\left(\mathrm{m}_{\mathrm{i}} / \mathrm{R}_{\mathrm{i}}\right)\right]+\mathrm{H}_{1}\right\} \cdot \Psi<\mathrm{E}_{0} \cdot \Psi$

But - G.M. $\left[\Sigma\left(\mathrm{m}_{\mathrm{i}} / \mathrm{R}_{\mathrm{i}}\right)\right]>$ - G.M. $\left[\Sigma \mathrm{m}_{\mathrm{i}} . \Sigma\left(1 / \mathrm{R}_{\mathrm{i}}\right)\right]$ since $\mathrm{G}, \mathrm{M}, \mathrm{m}_{\mathrm{i}}, \mathrm{R}_{\mathrm{i}}>0$.

Thus

$\left\{\left(-\hbar^{2} / 2\right) \cdot\left[\Sigma\left(\nabla_{\mathrm{i}}^{2} / \mathrm{m}_{\mathrm{i}}\right)\right]+\mathrm{V}_{1}+[\mathrm{G} / \mathrm{D}] \cdot\left[\Sigma \mathrm{m}_{\mathrm{i}}^{2}\right]-\left[\mathrm{G} \cdot \mathrm{M}^{\mathrm{M}} \cdot \mathrm{M}_{0} / \mathrm{D}_{1}\right]+\mathrm{H}_{1}\right\} . \Psi<\mathrm{E}_{0} . \Psi$

By (08):

$\left\{\left(-\hbar^{2} / 2\right) \cdot\left[\Sigma\left(\nabla_{\mathrm{j}}{ }^{2} / \mathrm{m}_{\mathrm{j}}\right)\right]+\mathrm{V}_{2}+\left[\mathrm{G} / \mathrm{D}^{\prime}\right] .\left[\Sigma \mathrm{m}_{\mathrm{j}}^{2}\right]-\left[\right.\right.$ G.M.M'/ $\left.\left.\mathrm{D}_{2}\right]+\mathrm{H}_{2}\right\} \cdot \Psi^{\prime}<\mathrm{E}^{\prime}{ }_{0} . \Psi^{\prime}$ ..(08)

Where $1 / D_{1}=\Sigma\left(1 / R_{i}\right)$ and $1 / D_{2}=\Sigma\left(1 / R_{j}\right)$

By (07)':

$\left\{\left(-\hbar^{2} / 2\right) \cdot\left[\Sigma\left(\nabla_{\mathrm{i}}^{2} / \mathrm{m}_{\mathrm{i}}\right)\right]+\mathrm{V}_{1}+[\mathrm{G} / \mathrm{D}] \cdot\left[\Sigma \mathrm{m}_{\mathrm{i}}^{2}\right]-\left[\mathrm{G} \cdot \mathrm{M}^{\mathrm{M}} \mathrm{M}_{0} / \mathrm{D}_{1}\right]+\mathrm{H}_{1}\right\} \cdot \Psi<\mathrm{E}_{0} \cdot \Psi$ 
and by (08)' :

$\left\{\left(-\hbar^{2} / 2\right) \cdot\left[\Sigma\left(\nabla_{j}^{2} / m_{j}\right)\right]+V_{2}+\left[G / D^{\prime}\right] \cdot\left[\Sigma m_{j}^{2}\right]-[\right.$ G.M.M'/ D $\left.]+H_{2}\right\} . \Psi ' /\left[E_{0}^{\prime} . \Psi^{\prime}\right]<1$ But $\mathrm{E}_{0}>0$. Thus

$\left\{\left\{\left(-\hbar^{2} / 2\right) \cdot\left[\Sigma\left(\nabla_{\mathrm{j}}^{2} / \mathrm{m}_{\mathrm{j}}\right)\right]+\mathrm{V}_{2}+\left[\mathrm{G} / \mathrm{D}^{\prime}\right] \cdot\left[\Sigma \mathrm{m}_{\mathrm{j}}^{2}\right]-\left[\mathrm{G} \cdot \mathrm{M} \cdot \mathrm{M}^{\prime} / \mathrm{D}_{2}\right]+\mathrm{H}_{2}\right\} . \Psi^{\prime} /\left[\mathrm{E}_{0}^{\prime} . \Psi^{\prime}\right]\right\} .\left[\mathrm{E}_{0} . \Psi\right]$

$<\mathrm{E}_{0} \cdot \Psi$ (10) But $_{0}>\mathrm{E}_{0}{ }_{0}$ (by the result (05))

(Since $E_{i}>E_{j}$, and $\mathrm{a}>\mathrm{v}$; where $\mathrm{i}$ can get any natural number up to ' $\mathrm{a}$ '. And $\mathrm{j}$ can get any natural number up to $\mathrm{v}$. Therefore by (10):

$\left\{\left\{\left(-\hbar^{2} / 2\right) \cdot\left[\Sigma\left(\nabla_{\mathrm{j}}^{2} / \mathrm{m}_{\mathrm{j}}\right)\right]+\mathrm{V}_{2}+\left[\mathrm{G} / \mathrm{D}^{\prime}\right] \cdot\left[\Sigma \mathrm{m}_{\mathrm{j}}^{2}\right]-\left[\mathrm{G} \cdot \mathrm{M} \cdot \mathrm{M}^{\prime} / \mathrm{D}_{2}\right]+\mathrm{H}_{2}\right\}\right\} \cdot \Psi<\mathrm{E}_{0} \cdot \Psi$ (11)

(Because $\left.\left(\mathrm{E}_{0} / \mathrm{E}_{0}{ }_{0}\right)>1\right)$.

By (07)' :

$\left\{\left(-\hbar^{2} / 2\right) \cdot\left[\Sigma\left(\nabla_{\mathrm{i}}^{2} / \mathrm{m}_{\mathrm{i}}\right)\right]+\mathrm{V}_{1}+[\mathrm{G} / \mathrm{D}] \cdot\left[\Sigma \mathrm{m}_{\mathrm{i}}^{2}\right]-\left[\mathrm{G} \cdot \mathrm{M} \cdot \mathrm{M}_{0} / \mathrm{D}_{1}\right]+\mathrm{H}_{1}\right\} \cdot \Psi<\mathrm{E}_{0} \cdot \Psi$ ..(07)

For some operator $\mathrm{K}_{1}$, by (07)':

$\left\{\left(-\hbar^{2} / 2\right) \cdot\left[\Sigma\left(\nabla_{\mathrm{i}}^{2} / \mathrm{m}_{\mathrm{i}}\right)\right]+\mathrm{V}_{1}+[\mathrm{G} / \mathrm{D}] \cdot\left[\Sigma \mathrm{m}_{\mathrm{i}}^{2}\right]-\left[\mathrm{G} \cdot \mathrm{M} \cdot \mathrm{M}_{0} / \mathrm{D}_{1}\right]+\mathrm{H}_{1}+\mathrm{K}_{1}\right\} \cdot \Psi=\mathrm{E}_{0} \cdot \Psi$ (12)

For some operator $\mathrm{K}_{2}$, by (11):

$\left\{\left(-\hbar^{2} / 2\right) \cdot\left[\Sigma\left(\nabla_{\mathrm{j}}^{2} / \mathrm{m}_{\mathrm{j}}\right)\right]+\mathrm{V}_{2}+\left[\mathrm{G} / \mathrm{D}^{\prime}\right] \cdot\left[\Sigma \mathrm{m}_{\mathrm{j}}^{2}\right]-\left[\mathrm{G} \cdot \mathrm{M} \cdot \mathrm{M}^{\prime} / \mathrm{D}_{2}\right]+\mathrm{H}_{2}+\mathrm{K}_{2}\right\} \cdot \Psi=\mathrm{E}_{0} \cdot \Psi$ (13) 


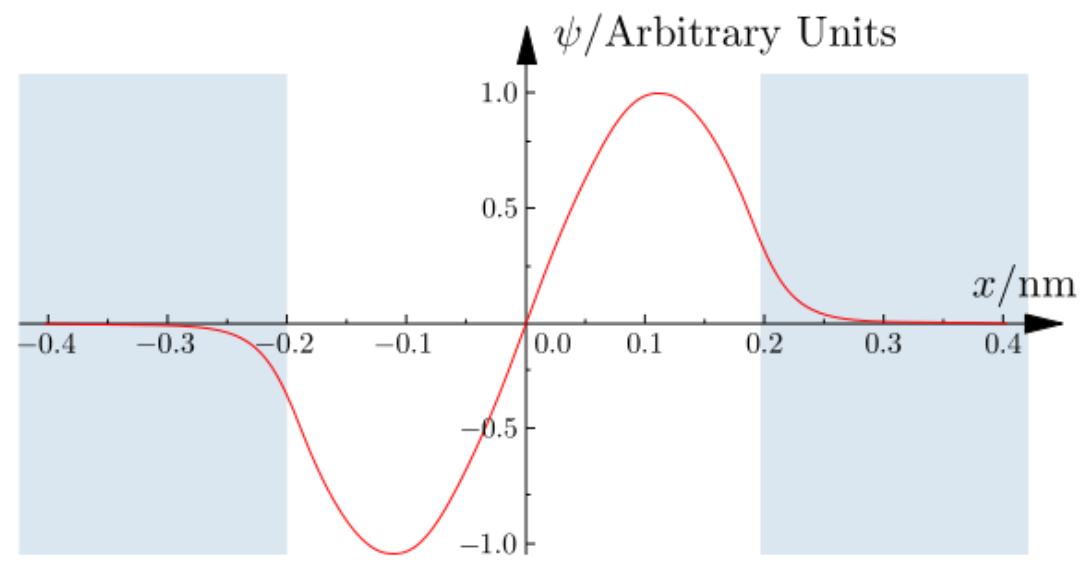

Figure 02: Behavior of the wave function in 2-D

\subsection{Result Evaluation of Methodology part 3}

By (12) and (13):

The Hamiltonian (kinetic energy + potential energy operators) of the quantum vacuum becomes the Hamiltonian of the ordinary matters in the universe. That means the kinetic energy + potential energy of the particles of quantum vacuum becomes the kinetic energy + potential energy of the ordinary matter in the universe. In another words, just after some matter/waves became the members of the quantum vacuum, right after that and by an instant, those matters/waves become the virtual members of the ordinary matters/waves in the universe. I use a word 'virtual', because the ordinary matters system already have a definite kinetic + potential energy values. Because simultaneously, the ordinary matters system in the considering space volume cannot have two different kinetic + potential energy values. 


\section{Methodology part 4}

\subsection{Notations of Methodology part 4}

$\mathrm{M}_{\mathrm{i}}=$ the mass of the particle ' $\mathrm{i}$ '

$\psi_{i}\left(r_{i}, \theta_{i}, \varphi_{i}\right)=$ the wave function of ' $i$ ' th particle

$V_{i}\left(r_{i}\right)=$ the electric potential energy of the particle ' $i$ ' in the vacuum space

$\Delta \mathrm{H}_{\mathrm{i}}=$ the magnetic potential energy associated with the ' $\mathrm{i}$ ' th particle

$E_{i}=$ the eigenvalue of the wave equation for ' $i$ ' th particle in the quantum vacuum

$\Lambda=$ the cosmological constant

$\mathrm{v}=$ the volume of the considering space

$S_{i}=$ the spin operator of the ' $i$ 'th particle in the quantum vacuum

$\mu_{\mathrm{B}}=$ the Bohr Magneton

$r \equiv r_{i}=$ the radial coordinate to the ' $\mathrm{i}$ ' th particle in the quantum vacuum

$\theta \equiv \theta_{\mathrm{i}}=$ the polar coordinate to the ' $\mathrm{i}$ ' th particle

$\phi \equiv \phi_{\mathrm{i}}=$ the azimuthal coordinate of the ' $\mathrm{i}$ ' th particle in the quantum vacuum

$\mathrm{E}_{0}=$ the total energy in the quantum vacuum of the considering space volume

$\Sigma \psi_{\mathrm{i}}=\Psi, \Sigma \mathrm{E}_{\mathrm{i}}=\mathrm{E}_{0}$

$\mathrm{n}, l, \mathrm{~m}, \mathrm{~s}$ are quantum numbers of the wave function $\psi$

$\mathrm{e} \quad=$ Exponential function

$\mathrm{L}^{2 l+1} \mathrm{n}-l-1(\mathrm{x})=$ Lagrangian function of $\mathrm{x}$

$a_{0}=\mid\left(\hbar^{2} /\left[M .\left(q_{1} \cdot q_{2}\right)\right] \mid, \hbar=\right.$ plank constant $, q_{1}, q_{2}=$ electric charges of two particles 
BUT DO NOT COMPARE THE EQUATION NUMBERS AND THE SYMBOLS OTHER PARTS IN THE RESEARCH METHODOLOGY AND IN THIS METHODOLOGY PART NUMBER 04.

\subsection{Content of the Methodology part 4}

Since several centuries, scientists are exploring the universe. Although some of theoretical concepts are talking about the perfect vacuum, a perfect vacuum is not real. That means there is a non-zero vacuum energy in the vacuum space all across the universe. And cosmological vacuum contains the cosmological vacuum energy density called as 'cosmological constant'.

And the minimum possible energy of a quantum state called as 'zero-point energy' or 'quantum vacuum'.

But scientists are confused on why the energy of the zero-point energy (quantum vacuum) state, does not contribute to the cosmological vacuum energy (cosmological constant) much. The goal of this research part is to investigate a solution to that particular problem.

Scientists are arguing that the contribution from the zero-point energy to the cosmological constant is not considerably large. The purpose of this methodology part number 04, is to provide an explanation that would be able to explain why is the contribution from the zero-point energy (or in another words, minimum possible energy of the quantum vacuum) to the cosmological constant is not considerably large.

Let's consider a space volume in the universe with $10^{\sigma}$ as the radius. Where $\sigma$ is a comparably large natural number. And consider the quantum vacuum (or in another words, zero-point energy states) in that considering space volume.

The 3 dimensional time independent Schrodinger equation for a particle is written as follows:

$-\left(\hbar^{2} / 2 \mathrm{M}\right) \nabla^{2} \psi+\mathrm{V} \psi=\mathrm{E} \psi$

Here $\mathrm{M}$ is the mass of the particle, $\mathrm{V}$ is the potential energy of the considering particle.

So, that the equation is rewritten in spherical coordinates where, 
$\nabla^{2}=\frac{1}{r^{2}} \frac{\partial}{\partial}\left(r^{2} \frac{\partial}{\partial}\right)+\frac{1}{r^{2} \sin \theta} \frac{\partial}{\partial \theta}\left(\sin \theta \frac{\partial}{\partial \theta}\right)+\frac{1}{r^{2} \sin ^{2} \theta}\left(\frac{\partial^{2}}{\partial \phi^{2}}\right)$

Let's consider the matter particles in the quantum vacuum- in another words, zero-point energy states as $\mathrm{P} 1, \mathrm{P}_{2}, \ldots \ldots, \mathrm{P}_{\mathrm{a}}$. Where there are 'a' number of matter particles in that considering space volume at the considering instant. I use the word 'instant', because the particles in the zero point energy states are not steady.

Where $\psi_{i}\left(r_{i}, \theta_{i}, \varphi_{i}\right)$ : the wave function of ' $i$ ' th particle in the considering quantum vacuum space. Let, $\mathrm{V}_{\mathrm{i}}\left(\mathrm{r}_{\mathrm{i}}\right)$ is the electric potential energy of the particle ' $\mathrm{i}$ ' in the vacuum space. $\Delta \mathrm{H}_{\mathrm{i}}$ is the magnetic potential energy associated with the ' $i$ ' th particle in the considering vacuum space.

$E_{i}=[$ the eigenvalue of the wave equation for ' $i$ ' th particle $-(\Lambda . v)]$

Resulting in the following form of the Schrodinger equation:

$\left(-\hbar^{2} / 2 \mathrm{M}_{\mathrm{i}}\right) \cdot \frac{1}{r^{2} \sin \theta}\left[\sin \theta \frac{\partial}{\partial r}\left(r^{2} \frac{\partial \psi}{\partial r}\right)+\frac{\partial}{\partial \theta}\left(\sin \theta \frac{\partial \psi}{\partial \theta}\right)+\frac{1}{\sin \theta} \frac{\partial^{2} \psi}{\partial \varphi^{2}}\right] \mathrm{r}, \theta, \phi=($ ri, $\theta \mathrm{i}, \phi \mathrm{i})+\mathrm{V}_{\mathrm{i}}\left(\mathrm{r}_{\mathrm{i}}\right) \psi_{\mathrm{i}}$

$+\mathrm{S}_{\mathrm{i}} \cdot \psi_{\mathrm{i}}+\Delta \mathrm{H}_{\mathrm{i}} \cdot \psi_{\mathrm{i}}=\left[\mathrm{E}_{\mathrm{i}}-(\Lambda . v)\right] \psi_{\mathrm{i}}$

Then $\left(-\hbar^{2} / 2 \mathrm{M}_{\mathrm{i}}\right) \cdot \frac{1}{r^{2} \sin \theta}\left[\sin \theta \frac{\partial}{\partial r}\left(r^{2} \frac{\partial \psi}{\partial r}\right)+\frac{\partial}{\partial \theta}\left(\sin \theta \frac{\partial \psi}{\partial \theta}\right)+\frac{1}{\sin \theta} \frac{\partial^{2} \psi}{\partial \varphi^{2}}\right] \mathrm{r}, \theta, \phi=(\mathrm{ri}, \theta \mathrm{i}, \phi \mathrm{i})+\mathrm{V}_{\mathrm{i}}\left(\mathrm{r}_{\mathrm{i}}\right) \psi_{\mathrm{i}}$

$+\mathrm{S}_{\mathrm{i} \cdot \psi_{\mathrm{i}}}+\Delta \mathrm{H}_{\mathrm{i}} \cdot \psi_{\mathrm{i}}+(\Lambda . \mathrm{v}) \psi_{\mathrm{i}}=\mathrm{E}_{\mathrm{i}} \psi_{\mathrm{i}}$

Here $\Lambda$ is the cosmological constant, $\mathrm{v}$ is the volume of the considering space. $\mathrm{S}_{\mathrm{i}}$ is the spin operator of the ' $i$ 'th particle in the quantum vacuum.

Here $\Delta \mathrm{H}_{\mathrm{i}}=2 \cdot \mu_{\mathrm{B}} \cdot \mathrm{B}_{\mathrm{i}} \cdot \mathrm{m}_{\mathrm{S}}$, Here $\mu_{\mathrm{B}}$ is the Bohr Magneton

With: $\psi_{\mathrm{i}}=\psi_{\mathrm{i}}\left(\mathrm{r}_{\mathrm{i}}, \theta_{\mathrm{i}}, \varphi_{\mathrm{i}}\right)$ and

here $\Delta \mathrm{H}_{\mathrm{i}}$ is the potential energy associated with the interaction of the charged particle's ( 'i' ) spin magnetic moment with the magnetic field induced due to the magnetic field $\mathrm{B}_{\mathrm{i}}$ (induced due to the total magnetic moment of the reference frame) 
By $(01)$,

$[(\Lambda . v)] . \psi_{\mathrm{i}}=\mathrm{E}_{\mathrm{i}} \psi_{\mathrm{i}}-\left(-\hbar^{2} / 2 \mathrm{M}_{\mathrm{i}}\right) \cdot \frac{1}{r i^{2} \sin \theta i}\left[\sin \theta i \frac{\partial}{\partial r i}\left(r i^{2} \frac{\partial \psi i}{\partial r i}\right)+\frac{\partial}{\partial \theta i}\left(\sin \theta i \frac{\partial \psi i}{\partial \theta i}\right)+\frac{1}{\sin \theta i} \frac{\partial^{2} \psi i}{\partial \varphi i^{2}}\right]$

$-\mathrm{V}_{\mathrm{i}}\left(\mathrm{r}_{\mathrm{i}}\right) \psi_{\mathrm{i}}-\mathrm{S}_{\mathrm{i}} \psi_{\mathrm{i}}-\Delta \mathrm{H}_{\mathrm{i}} \cdot \psi_{\mathrm{i}}$. Thus

$[(\Lambda . v)] \cdot \psi_{i}+V_{i}\left(r_{i}\right) \psi_{i}+\hbar\left(V_{s} \cdot(s+1)\right) \cdot \psi_{i}+2 \cdot \mu_{B} \cdot B_{i} \cdot m_{s} \cdot \psi_{i}=$

$\mathrm{E}_{\mathrm{i}} \psi_{\mathrm{i}}+\left(\hbar^{2} / 2 \mathrm{M}_{\mathrm{i}}\right) \cdot \frac{1}{r i^{2} \sin \theta i}\left[\sin \theta i \frac{\partial}{\partial r i}\left(r i^{2} \frac{\partial \psi i}{\partial r i}\right)+\frac{\partial}{\partial \theta i}\left(\sin \theta i \frac{\partial \psi i}{\partial \theta i}\right)+\frac{1}{\sin \theta i} \frac{\partial^{2} \psi i}{\partial \varphi i^{2}}\right]$

By considering all 'a' number of particles in the quantum vacuum (i.e. in the zero-point energy states), I can write:

$\Sigma[(\Lambda . v)] \cdot \psi_{\mathrm{i}}+\Sigma \mathrm{V}_{\mathrm{i}}\left(\mathrm{r}_{\mathrm{i}}\right) \psi_{\mathrm{i}}+\Sigma \hbar\left(V_{\mathrm{s}} \cdot(\mathrm{s}+1)\right) \cdot \psi_{\mathrm{i}}+\Sigma 2 \cdot \mu_{\mathrm{B}} \cdot \mathrm{B}_{\mathrm{i}} \cdot \mathrm{m}_{\mathrm{s}} \cdot \psi_{\mathrm{i}}=$

$\Sigma \mathrm{E}_{\mathrm{i}} \psi_{\mathrm{i}}+\Sigma\left(\hbar^{2} / 2 \mathrm{M}_{\mathrm{i}}\right) \cdot \frac{1}{r i^{2} \sin \theta i}\left[\sin \theta i \frac{\partial}{\partial r i}\left(r i^{2} \frac{\partial \psi i}{\partial r i}\right)+\frac{\partial}{\partial \theta i}\left(\sin \theta i \frac{\partial \psi i}{\partial \theta i}\right)+\frac{1}{\sin \theta i} \frac{\partial^{2} \psi i}{\partial \varphi i^{2}}\right]$

Thus, $\left[(\Lambda . v)+\hbar\left(V_{s} .(\mathrm{s}+1)\right)\right] . \Sigma \psi_{\mathrm{i}}+2 \cdot \mu_{\mathrm{B}} \cdot \mathrm{m}_{\mathrm{s}} \cdot \Sigma\left(\mathrm{B}_{\mathrm{i}} \psi_{\mathrm{i}}\right)+\Sigma\left(\mathrm{V}_{\mathrm{i}}\left(\mathrm{r}_{\mathrm{i}}\right) \psi_{\mathrm{i}}\right)<$

$\Sigma \mathrm{E}_{\mathrm{i}} \Sigma \psi_{\mathrm{i}}+\Sigma\left(\hbar^{2} / 2 \mathrm{M}_{\mathrm{i}}\right) \cdot \frac{1}{r i^{2} \sin \theta i}\left[\sin \theta i \frac{\partial}{\partial r i}\left(r i^{2} \frac{\partial \psi i}{\partial r i}\right)+\frac{\partial}{\partial \theta i}\left(\sin \theta i \frac{\partial \psi i}{\partial \theta i}\right)+\frac{1}{\sin \theta i} \frac{\partial^{2} \psi i}{\partial \varphi i^{2}}\right]$

(because for positive $\mathrm{x}_{\mathrm{i}}$ and positive $\mathrm{y}_{\mathrm{i}}, \Sigma\left(\mathrm{x}_{\mathrm{i}}, \mathrm{y}_{\mathrm{i}}\right)<\Sigma \mathrm{x}_{\mathrm{i}}, \Sigma \mathrm{y}_{\mathrm{i}}$ and since $\mathrm{E}_{\mathrm{i}}>0$ )

Here $E_{i}$ is the zero point energy for each ' $i$ 'th particle in the quantum vacuum.

Thus, $\left[\hbar\left(V_{\mathrm{s} .}(\mathrm{s}+1)\right)\right] . \Sigma \psi_{\mathrm{i}}+2 \cdot \mu_{\mathrm{B}} \cdot \mathrm{m}_{\mathrm{s}} \cdot \Sigma\left(\mathrm{B}_{\mathrm{i}} \psi_{\mathrm{i}}\right)+\Sigma\left(\mathrm{V}_{\mathrm{i}}\left(\mathrm{r}_{\mathrm{i}}\right) \psi_{\mathrm{i}}\right)$

$$
-\left(\hbar^{2} / 2\right) . \Sigma\left[\frac{1}{M i \cdot r i^{2} \sin \theta i}\left[\sin \theta i \frac{\partial}{\partial r i}\left(r i^{2} \frac{\partial \psi i}{\partial r i}\right)+\frac{\partial}{\partial \theta i}\left(\sin \theta i \frac{\partial \psi i}{\partial \theta i}\right)+\frac{1}{\sin \theta i} \frac{\partial^{2} \psi i}{\partial \varphi i^{2}}\right]\right]
$$

$<\Sigma \mathrm{E}_{\mathrm{i}} \Sigma \psi_{\mathrm{i}}-(\Lambda . \mathrm{v}) \Sigma \psi_{\mathrm{i}}=\left[\mathrm{E}_{0}-(\Lambda . \mathrm{v})\right] . \Psi$ (where $\mathrm{E}_{0}$ is the total energy of the zero-point energy levels in the considering space volume). And $\Sigma \psi_{\mathrm{i}}=\Psi$

Thus $\left[\mathrm{E}_{0}-(\Lambda . \mathrm{v})\right] . \Psi>\left[\hbar\left(V_{\mathrm{s} .}(\mathrm{s}+1)\right)\right] . \Psi+2 \cdot \mu_{\mathrm{B}} \cdot \mathrm{m}_{\mathrm{s}} \cdot \Sigma\left(\mathrm{B}_{\mathrm{i}} \psi_{\mathrm{i}}\right)+\Sigma\left(\mathrm{V}_{\mathrm{i}}\left(\mathrm{r}_{\mathrm{i}}\right) \psi_{\mathrm{i}}\right)$

$-\left(\hbar^{2} / 2\right) . \Sigma\left[\frac{1}{M i . r i^{2} \sin \theta i}\left[\sin \theta i \frac{\partial}{\partial r i}\left(r i^{2} \frac{\partial \psi i}{\partial r i}\right)+\frac{\partial}{\partial \theta i}\left(\sin \theta i \frac{\partial \psi i}{\partial \theta i}\right)+\frac{1}{\sin \theta i} \frac{\partial^{2} \psi i}{\partial \varphi i^{2}}\right]\right] \ldots$ 
But using the procedures those scientists already have done, I can state the expression for $\left(\psi_{\mathrm{i}}\right)_{\mathrm{n} 1 \mathrm{~m}}\left(\mathrm{r}_{\mathrm{i}}, \theta_{\mathrm{i}}, \varphi_{\mathrm{i}}\right)$ as below:

$\left(\psi_{\mathrm{i}}\right)_{\mathrm{n} 1 \mathrm{~m} \mathrm{~s}}\left(\mathrm{r}_{\mathrm{i}}, \theta_{\mathrm{i}}, \varphi_{\mathrm{i}}\right)=\left(\frac{2}{n \cdot a 0}\right)^{\frac{3}{2}}\left(\frac{(n-l-1) !}{2 n[(n+l) !]^{3}}\right)^{1 / 2} \cdot e^{-\frac{r}{n \cdot a 0}} \cdot\left(\frac{2 r}{n \cdot a 0}\right)^{l} \cdot \mathrm{L}^{2 \mathrm{l}+1}{ }_{\mathrm{n}-l-1}\left(2 \mathrm{r} / \mathrm{n} \cdot \mathrm{a}_{0}\right) \cdot\left(\mathrm{Y}^{\mathrm{m}}{ }_{l}(\theta, \varphi)\right) \cdot \mathrm{S}(\mathrm{s})$

Where $\quad L_{n-i-1}^{2 l+1}(\rho)=\sum_{i=0}^{n-i-1} \frac{(-1)^{i}[(n+l)]^{2} \rho^{i}}{i !(n-l-1-i) !(2 l+1+i) !} \quad$ and $\mathrm{a}_{0}$ is the Bohr radius.

$\mathrm{Y}_{l}^{\mathrm{m}}(\theta, \varphi)=\alpha \cdot \frac{\sqrt{(2 l+1)(l-|\mathrm{m}|) !}}{2(l+|m|) !} \cdot \mathrm{e}^{\mathrm{i} \mathrm{m} \varphi} \cdot \mathrm{P}_{l}^{\mathrm{m}}(\cos \theta)$

where $\mathrm{P}_{l}^{\mathrm{m}}=\mathrm{P}_{l^{\prime}}(\cos \theta)=\frac{1}{2^{l^{\prime}} l^{\prime} !}\left(\frac{d}{d \cos \theta}\right)^{l^{\prime}}\left(\cos \theta^{2}-1\right)^{l^{\prime}}=\frac{1}{2^{l^{\prime}} l^{\prime} !}\left(\frac{d}{d \cos \theta}\right)^{l^{\prime}}\left(\sin ^{2} \theta\right)^{l^{\prime}}$

Then $\left[\frac{1}{r i^{2} \sin \theta i}\left[\sin \theta i \frac{\partial}{\partial r i}\left(r i^{2} \frac{\partial \psi i}{\partial r i}\right)+\frac{\partial}{\partial \theta i}\left(\sin \theta i \frac{\partial \psi i}{\partial \theta i}\right)+\frac{1}{\sin \theta i} \frac{\partial^{2} \psi i}{\partial \varphi i^{2}}\right]\right.$

$=\frac{1}{r i^{2} \sin \theta i}\left\{\left[\sin \theta_{\mathrm{i}} \cdot\left(2 \cdot \mathrm{r}_{\mathrm{i}} \cdot \frac{\partial \psi i}{\partial r i}+\mathrm{r}_{\mathrm{i}}^{2} \cdot \frac{\partial^{2} \psi i}{\partial r i^{2}}\right)\right]+\left[\left(\cos \theta_{\mathrm{i}} \cdot \frac{\partial \psi i}{\partial \theta i}\right)+\sin \theta_{\mathrm{i}} \cdot \frac{\partial^{2} \psi i}{\partial \theta i^{2}}\right]+\left[\left(1 / \sin \theta_{\mathrm{i}}\right) \frac{\partial^{2} \psi i}{\partial \varphi i^{2}}\right]\right\}$ .$(05)$

But now let's find an expression for $(1 / \mathrm{S}) \frac{\partial \psi i}{\partial r i}$ by (04) as below:

$(1 / \mathrm{S}) \frac{\partial \psi i}{\partial r i}=\left(\frac{2}{n \cdot a 0}\right)^{\frac{3}{2}}\left(\frac{(n-l-1) !}{2 n[(n+l) !]^{3}}\right)^{1 / 2} \cdot e^{-\frac{r}{n \cdot a 0}} \cdot\left(\frac{2 r}{n \cdot a 0}\right)^{l} \cdot \mathrm{L}_{\mathrm{n}-l-1}^{21+1}\left(2 \mathrm{r} / \mathrm{n} \cdot \mathrm{a}_{0}\right) \cdot\left(\mathrm{Y}_{l}^{\mathrm{m}}(\theta, \varphi)\right) \cdot\left[-1 / \mathrm{na}_{0}\right]$

$+\left(\frac{2}{n \cdot a 0}\right)^{\frac{3}{2}}\left(\frac{(n-l-1) !}{2 n[(n+l) !]^{3}}\right)^{1 / 2} \cdot e^{-\frac{r}{n \cdot a 0}} \cdot\left(\frac{2 r}{n \cdot a 0}\right)^{l} *$

$\mathrm{n}-l-1$

$\left[(1 / \mathrm{r}) \cdot \sum_{\mathrm{i}=1}\left[(-1)^{1} \cdot[(\mathrm{n}+l) !]^{2}\left(2 \cdot \mathrm{r} / \mathrm{na}_{0}\right)^{\mathrm{i}} . . \mathrm{i} /(\mathrm{i} ! .(\mathrm{n}-l-1-\mathrm{i}) ! .(2 l+1+\mathrm{i}) !) *\left(\mathrm{Y}^{\mathrm{m}}{ }_{l}(\theta, \varphi)\right)+\right.\right.$ $\left(\frac{2}{n \cdot a 0}\right)^{\frac{3}{2}}\left(\frac{(n-l-1) !}{2 n[(n+l) !]^{3}}\right)^{1 / 2} \cdot e^{-\frac{r}{n \cdot a 0}} \cdot\left(\frac{2}{n \cdot a 0}\right)^{l} \cdot \mathrm{r}^{l-1} \cdot l \cdot \mathrm{L}^{21+1}{ }_{\mathrm{n}-l-1}\left(2 \mathrm{r} / \mathrm{n} \cdot \mathrm{a}_{0}\right) \cdot\left(\mathrm{Y}^{\mathrm{m}_{l}}(\theta, \varphi)\right)$ 
Now let's find an expression for $(1 / \mathrm{S}) \cdot \frac{\partial^{2} \psi i}{\partial r i^{2}}$ by (04) as below:

$$
\begin{aligned}
& (1 / \mathrm{S}) \cdot \frac{\partial^{2} \psi i}{\partial r i^{2}}=\left(\frac{2}{n \cdot a 0}\right)^{\frac{3}{2}}\left(\frac{(n-l-1) !}{2 n[(n+l) !]^{3}}\right)^{1 / 2} \cdot e^{-\frac{r}{n \cdot a 0}} \cdot\left(\frac{2 r}{n \cdot a 0}\right)^{l} \cdot \mathrm{L}_{\mathrm{n}-l-1}^{21+1}\left(2 \mathrm{r} / \mathrm{n} \cdot \mathrm{a}_{0}\right) \cdot\left(\mathrm{Y}^{\mathrm{m}}{ }_{l}(\theta, \varphi)\right) \cdot\left[1 / \mathrm{na}_{0}\right]^{2} \\
& +\left(\frac{2}{n \cdot a 0}\right)^{\frac{3}{2}}\left(\frac{(n-l-1) !}{2 n[(n+l) !]^{3}}\right)^{1 / 2} \cdot e^{-\frac{r}{n \cdot a 0}} \cdot\left(\frac{2}{n \cdot a 0}\right)^{l} \cdot \mathrm{r}^{l-1} \cdot l \cdot \mathrm{L}_{\mathrm{n}-l-1}^{21+1}\left(2 \mathrm{r} / \mathrm{n} \cdot \mathrm{a}_{0}\right) \cdot\left(\mathrm{Y}_{l}{ }_{l}(\theta, \varphi)\right) \cdot\left[-1 / \mathrm{na}_{0}\right]+ \\
& \left\{\left(\frac{2}{n \cdot a 0}\right)^{\frac{3}{2}}\left(\frac{(n-l-1) !}{2 n[(n+l) !]^{3}}\right)^{1 / 2} \cdot e^{-\frac{r}{n \cdot a 0}} \cdot\left(\frac{2 r}{n \cdot a 0}\right)^{l} *\right.
\end{aligned}
$$

$\left[(1 / \mathrm{r}) \cdot \sum_{\mathrm{i}=1}\left[(-1){ }^{\mathrm{i}} \cdot[(\mathrm{n}+l) !]^{2} \cdot\right.\right.$ i. $\left.\left(2 \cdot \mathrm{r} / \mathrm{na}_{0}\right)^{\mathrm{i}} /(\mathrm{i} ! \cdot(\mathrm{n}-l-1-\mathrm{i}) ! \cdot(2 l+1+\mathrm{i}) !) *\left(\mathrm{Y}^{\mathrm{m}}{ }_{l}(\theta, \varphi)\right) \cdot\left[-1 / \mathrm{na}_{0}\right]\right\}$

$$
+\left(\frac{2}{n \cdot a 0}\right)^{\frac{3}{2}}\left(\frac{(n-l-1) !}{2 n[(n+l) !]^{3}}\right)^{1 / 2} \cdot e^{-\frac{r}{n \cdot a 0}} \cdot\left(\frac{2 r}{n \cdot a 0}\right)^{l} *
$$

$\left[(1 / \mathrm{r}) \cdot \sum_{\mathrm{i}=1}\left[(-1) \cdot{ }^{\mathrm{i}} \cdot[(\mathrm{n}+l) !]^{2}\left(2 \cdot \mathrm{r} / \mathrm{na}_{0}\right)^{\mathrm{i}} \cdot \mathrm{i} /(\mathrm{i} ! .(\mathrm{n}-l-1-\mathrm{i}) ! \cdot(2 l+1+\mathrm{i}) !) *\left(\mathrm{Y}^{\mathrm{m}}{ }_{l}(\theta, \varphi)\right)\left[-1 / \mathrm{na}_{0}\right]\right.\right.$

$$
+\left(\frac{2}{n \cdot a 0}\right)^{\frac{3}{2}}\left(\frac{(n-l-1) !}{2 n[(n+l) !]^{3}}\right)^{1 / 2} \cdot e^{-\frac{r}{n \cdot a 0}} \cdot\left(\frac{2 r}{n \cdot a 0}\right)^{l} *
$$

$\left[\left(1 / \mathrm{r}^{2}\right) \cdot \sum_{\mathrm{i}=1}\left[(-1) \cdot{ }^{\mathrm{i}} \cdot[(\mathrm{n}+l) !]^{2}\left(2 \cdot \mathrm{r} / \mathrm{na}_{0}\right)^{\mathrm{i}} \cdot\right.\right.$ i. $\left.(\mathrm{i}-1) /(\mathrm{i} ! \cdot(\mathrm{n}-l-1-\mathrm{i}) ! .(2 l+1+\mathrm{i}) !) \mathrm{Y}^{\mathrm{m}}{ }_{l}(\theta, \varphi)\right)$

$$
\begin{aligned}
& +\left(\frac{2}{n \cdot a 0}\right)^{\frac{3}{2}}\left(\frac{(n-l-1) !}{2 n[(n+l) !]^{3}}\right)^{1 / 2} \cdot e^{-\frac{r}{n \cdot a 0}} \cdot\left(\frac{2}{n \cdot a 0}\right)^{l} \cdot \mathrm{r}^{l-l} \cdot l . \\
& \left(1 / \mathrm{r}^{2}\right) * \sum_{\mathrm{i}=1}\left[(-1){ }^{\mathrm{i}} \cdot[(\mathrm{n}+l) !]^{2}\left(2 \cdot \mathrm{r} / \mathrm{na}_{0}\right)^{\mathrm{i}} \cdot \mathrm{i}(\mathrm{i}-1) /(\mathrm{i} ! .(\mathrm{n}-l-1-\mathrm{i}) ! \cdot(2 l+1+\mathrm{i}) !)\left(\mathrm{Y}^{\mathrm{m}}{ }_{l}(\theta, \varphi)\right)\right. \\
& +\left(\frac{2}{n \cdot a 0}\right)^{\frac{3}{2}}\left(\frac{(n-l-1) !}{2 n[(n+l) !]^{3}}\right)^{1 / 2} \cdot e^{-\frac{r}{n \cdot a 0}} \cdot\left(\frac{2}{n \cdot a 0}\right)^{l} \cdot \mathrm{r}^{l-1} \cdot l \cdot \mathrm{L}_{\mathrm{n}-l-1}^{21+1}\left(2 \mathrm{r} / \mathrm{n} \cdot \mathrm{a}_{0}\right) \cdot\left(\mathrm{Y}_{l}^{\mathrm{m}}(\theta, \varphi)\right) \cdot\left[-1 / \mathrm{na}_{0}\right] \\
& +\left(\frac{2}{n \cdot a 0}\right)^{\frac{3}{2}}\left(\frac{(n-l-1) !}{2 n[(n+l) !]^{3}}\right)^{1 / 2} \cdot e^{-\frac{r}{n \cdot a 0}} \cdot\left(\frac{2}{n \cdot a 0}\right)^{l} \cdot r^{l-2} \cdot \mathrm{L}^{21+1} \mathrm{n}-l-1\left(2 \mathrm{r} / \mathrm{n} \cdot \mathrm{a}_{0}\right) \cdot\left(\mathrm{Y}_{l}^{\mathrm{m}_{l}}(\theta, \varphi)\right) \cdot(l-1) \cdot l \\
& +\left(\frac{2}{n \cdot a 0}\right)^{\frac{3}{2}}\left(\frac{(n-l-1) !}{2 n[(n+l) !]^{3}}\right)^{1 / 2} \cdot e^{-\frac{r}{n \cdot a 0}} \cdot\left(\frac{2}{n \cdot a 0}\right)^{l} \cdot r^{l-l} \cdot l * \\
& {\left[( 1 / \mathrm { r } ) \cdot \sum _ { \mathrm { i } = 1 } \left[(-1){ }^{\mathrm{i}} \cdot[(\mathrm{n}+l) !]^{2}\left(2 \cdot \mathrm{r} / \mathrm{na}_{0}\right)^{\mathrm{i}} \cdot \mathrm{i} /(\mathrm{i} ! .(\mathrm{n}-l-1-\mathrm{i}) ! .(2 l+1+\mathrm{i}) !)\left(\mathrm{Y}_{l}^{\mathrm{m}}(\theta, \varphi)\right)\right.\right.}
\end{aligned}
$$


Let's find $\partial\left[\mathrm{P}_{l}^{\mathrm{m}}\left(\cos \theta_{\mathrm{i}}\right)\right] / \partial \theta_{\mathrm{i}}$ by (4.1) as below:

$\partial\left[\mathrm{P}_{l}^{\mathrm{m}}\left(\cos \theta_{\mathrm{i}}\right)\right] / \partial \theta_{\mathrm{i}}=\partial\left[\frac{1}{2^{l^{\prime}} l^{\prime} !}\left(\frac{d}{d \cos \theta}\right)^{l^{\prime}}\left(\sin ^{2} \theta\right)^{l^{\prime}}\right] / \partial \theta_{\mathrm{i}}=-\left[\frac{1}{2^{l^{\prime}} l^{\prime} !}\left(\frac{d}{d \cos \theta}\right)^{l^{\prime}+1}(\sin \theta)^{2 l^{\prime}}\right] \cdot \sin \theta$

( Because $\left.d / d \theta_{i}\left(d / d \operatorname{Cos} \theta_{i}\right)=-\left(d^{2} / d \operatorname{Cos} \theta_{i}^{2}\right) \cdot \sin \theta_{i}\right)$

But by using (04): (1/S) $\frac{\partial \psi i}{\partial \theta i}=$

$$
\begin{gathered}
-\left(\frac{2}{n \cdot a 0}\right)^{\frac{3}{2}}\left(\frac{(n-l-1) !}{2 n[(n+l) !]^{3}}\right)^{1 / 2} \cdot e^{-\frac{r}{n \cdot a 0}} \cdot\left(\frac{2 r}{n \cdot a 0}\right)^{l} \cdot \mathrm{L}_{\mathrm{n}-l-1}^{2 l+1}\left(2 \mathrm{r} / \mathrm{n} \cdot \mathrm{a}_{0}\right) . \alpha . \\
\frac{\sqrt{(2 l+1)(l-|\mathrm{m}|) !}}{2(l+|m|) !} \cdot \mathrm{e}^{\mathrm{i} \varphi} \cdot\left[\frac{1}{2^{l^{\prime}} l^{\prime} !}\left(\frac{d}{d \cos \theta}\right)^{l^{\prime}+1}(\sin \theta)^{2 l^{\prime}}\right] \cdot \sin \theta \quad \ldots \ldots \ldots \ldots \ldots \ldots \ldots \ldots \ldots \ldots
\end{gathered}
$$

But by (4.1):

$\partial^{2}\left[\mathrm{P}_{l}^{\mathrm{m}}\left(\cos \theta_{\mathrm{i}}\right)\right] / \partial \theta_{\mathrm{i}}{ }^{2}=$

$-\left[\frac{1}{2^{l^{\prime}} l^{\prime} !}\left(\frac{d}{d \cos \theta}\right)^{l^{\prime}+1}(\sin \theta)^{2 l^{\prime}}\right] \cdot \cos \theta-\left[(\sin \theta) \cdot(-\sin \theta) \cdot \frac{1}{2^{l^{\prime}} l^{\prime} !}\left(\frac{d}{d \cos \theta}\right)^{l^{\prime}+2}(\sin \theta)^{2 l^{\prime}}\right.$

$=(\sin \theta)^{2} \cdot \frac{1}{2^{l^{\prime}} l^{\prime} !}\left(\frac{d}{d \cos \theta}\right)^{l^{\prime}+2}(\sin \theta)^{2 l^{\prime}}-\cos \theta \cdot\left[\frac{1}{2^{l^{\prime}} l^{\prime} !}\left(\frac{d}{d \cos \theta}\right)^{l^{\prime}+1}(\sin \theta)^{2 l^{\prime}}\right.$

Thus

$\left(\frac{2}{n \cdot a 0}\right)^{\frac{3}{2}}\left(\frac{(n-l-1) !}{2 n[(n+l) !]^{3}}\right)^{1 / 2} \cdot e^{-\frac{r}{n \cdot a 0}} \cdot\left(\frac{2 r}{n \cdot a 0}\right)^{l} \cdot \mathrm{L}^{21+1} \mathrm{n}-l-1\left(2 \mathrm{r} / \mathrm{n} \cdot \mathrm{a}_{0}\right) \cdot \alpha \cdot \frac{\sqrt{(2 l+1)(l-|\mathrm{m}|) !}}{2(l+|m|) !} \cdot \mathrm{e}^{\mathrm{im} \varphi} \cdot$

$\left\{(\sin \theta)^{2} \cdot \frac{1}{2^{l^{\prime}} l^{\prime} !}\left(\frac{d}{d \cos \theta}\right)^{l^{\prime}+2}(\sin \theta)^{2 l^{\prime}}-\cos \theta \cdot\left[\frac{1}{2^{l^{\prime}} l^{\prime} !}\left(\frac{d}{d \cos \theta}\right)^{l^{\prime}+1}(\sin \theta)^{2 l^{\prime}}\right\}=(1 / \mathrm{S}) \frac{\partial^{2} \psi i}{\partial \theta i^{2}}\right.$

$\ldots \ldots \ldots \ldots \ldots \ldots \ldots . . . . . . . . . . . .3)$ But by $(04):(1 / \mathrm{S}) \frac{\partial^{2} \psi i}{\partial \varphi i^{2}}=$

$\left(\frac{2}{n \cdot a 0}\right)^{\frac{3}{2}}\left(\frac{(n-l-1) !}{2 n[(n+l) !]^{3}}\right)^{1 / 2} \cdot e^{-\frac{r}{n \cdot a 0}} \cdot\left(\frac{2 r}{n \cdot a 0}\right)^{l} \cdot \mathrm{L}^{21+1}{ }_{\mathrm{n}-l-1}\left(2 \mathrm{r} / \mathrm{n} \cdot \mathrm{a}_{0}\right) \cdot \alpha \cdot \frac{\sqrt{(2 l+1)(l-|\mathrm{m}|) !}}{2(l+|m|) !} \cdot \mathrm{e}^{\mathrm{im} \varphi} \cdot \mathrm{P}_{l}^{\mathrm{m}}(\cos \theta) \cdot(\mathrm{im})^{2}$

$=-\mathrm{m}^{2}\left(\frac{2}{n \cdot a 0}\right)^{\frac{3}{2}}\left(\frac{(n-l-1) !}{2 n[(n+l) !]^{3}}\right)^{1 / 2} \cdot e^{-\frac{r}{n \cdot a 0}} \cdot\left(\frac{2 r}{n \cdot a 0}\right)^{l} \mathrm{~L}_{\mathrm{n}-l-1}^{2 l+1}\left(2 \mathrm{r} / \mathrm{n} \cdot \mathrm{a}_{0}\right) \cdot \alpha \cdot \frac{\sqrt{(2 l+1)(l-|\mathrm{m}|) !}}{2(l+|m|) !} \cdot \mathrm{e}^{\mathrm{im} \varphi} \cdot \mathrm{P}_{l}^{\mathrm{m}}(\cos \theta)$ 
By $(05), \quad\left[\frac{1}{r i^{2} \sin \theta i}\left[\sin \theta i \frac{\partial}{\partial r i}\left(r i^{2} \frac{\partial \psi i}{\partial r i}\right)+\frac{\partial}{\partial \theta i}\left(\sin \theta i \frac{\partial \psi i}{\partial \theta i}\right)+\frac{1}{\sin \theta i} \frac{\partial^{2} \psi i}{\partial \varphi i^{2}}\right]=\right.$

$\frac{1}{r i^{2} \sin \theta i}\left\{\left[\sin \theta_{\mathrm{i}} \cdot\left(2 \cdot \mathrm{r}_{\mathrm{i}} \cdot \frac{\partial \psi i}{\partial r i}+\mathrm{r}_{\mathrm{i}}^{2} \cdot \frac{\partial^{2} \psi i}{\partial r i^{2}}\right)\right]+\left[\left(\cos \theta_{\mathrm{i}} \cdot \frac{\partial \psi i}{\partial \theta i}\right)+\sin \theta_{\mathrm{i}} \cdot \frac{\partial^{2} \psi i}{\partial \theta i^{2}}\right]+\left[\frac{1}{\sin \theta i} \frac{\partial^{2} \psi i}{\partial \varphi i^{2}}\right]\right\}$

But by (5.1):

$2 \cdot \mathrm{r}_{\mathrm{i}} \cdot \sin \theta_{\mathrm{i}} \cdot \frac{\partial \psi i}{\partial r i}=\left\{\left(\frac{2}{n \cdot a 0}\right)^{\frac{3}{2}}\left(\frac{(n-l-1) !}{2 n[(n+l) !]^{3}}\right)^{1 / 2} \cdot e^{-\frac{r i}{n \cdot a 0}} \cdot\left(\frac{2 r i}{n \cdot a 0}\right)^{l} \cdot \mathrm{L}^{2 \mathrm{l}+1}{ }_{\mathrm{n}-l-1}\left(2 \mathrm{r}_{\mathrm{i}} / \mathrm{n} \cdot \mathrm{a}_{0}\right)^{*}\left\{\left(\mathrm{Y}_{l}^{\mathrm{m}}(\theta, \varphi) \cdot\left[-1 / \mathrm{na}_{0}\right]\right\}\right.\right.$

$+\left(\frac{2}{n \cdot a 0}\right)^{\frac{3}{2}}\left(\frac{(n-l-1) !}{2 n[(n+l) !]^{3}}\right)^{1 / 2} \cdot e^{-\frac{r i}{n \cdot a 0}} \cdot\left(\frac{2 r i}{n \cdot a 0}\right)^{l} *$

$\left[(1 / \mathrm{r}) \cdot \sum_{\mathrm{i}=1}\left[(-1) \cdot[(\mathrm{n}+l) !]^{2}\left(2 \cdot \mathrm{r} / \mathrm{na}_{0}\right)^{\mathrm{i}} . . \mathrm{i} /(\mathrm{i} ! \cdot(\mathrm{n}-l-1-\mathrm{i}) ! \cdot(2 l+1+\mathrm{i}) !) \cdot\left(\mathrm{Y}^{\mathrm{m}}{ }_{l}(\theta, \varphi)\right)+\right.\right.$

$\left(\frac{2}{n \cdot a 0}\right)^{\frac{3}{2}}\left(\frac{(n-l-1) !}{2 n[(n+l) !]^{3}}\right)^{1 / 2} \cdot e^{-\frac{r i}{n \cdot a 0}} \cdot\left(\frac{2}{n \cdot a 0}\right)^{l} \cdot \mathrm{r}_{\mathrm{i}}^{l-1} \cdot l \cdot \mathrm{L}_{\mathrm{n}-l-1}^{21+1}\left(2 \mathrm{r}_{\mathrm{i}} / \mathrm{n} \cdot \mathrm{a}_{0}\right) \cdot\left(\mathrm{Y}^{\mathrm{m}}{ }_{l}(\theta, \varphi)\right)$ \}. S. $2 \cdot \mathrm{r}_{\mathrm{i}} \cdot \sin \theta_{\mathrm{i}}$

By (5.2):

$(1 / \mathrm{S}) \cdot \sin \theta_{\mathrm{i}} \cdot \mathrm{r}_{\mathrm{i}}^{2} \frac{\partial^{2} \psi i}{\partial r i^{2}}=\sin \theta_{\mathrm{i}} \cdot \mathrm{r}_{\mathrm{i}}^{2} *\{$

$\left(\frac{2}{n \cdot a 0}\right)^{\frac{3}{2}}\left(\frac{(n-l-1) !}{2 n[(n+l) !]^{3}}\right)^{1 / 2} \cdot e^{-\frac{r}{n \cdot a 0}} \cdot\left(\frac{2 r}{n \cdot a 0}\right)^{l} \cdot \mathrm{L}^{21+1}{ }_{\mathrm{n}-l-1}\left(2 \mathrm{r} / \mathrm{n} \cdot \mathrm{a}_{0}\right) \cdot\left(\mathrm{Y}_{l}^{\mathrm{m}}(\theta, \varphi)\right) \cdot\left[1 / \mathrm{na}_{0}\right]^{2}$

$+\left(\frac{2}{n \cdot a 0}\right)^{\frac{3}{2}}\left(\frac{(n-l-1) !}{2 n[(n+l) !]^{3}}\right)^{1 / 2} \cdot e^{-\frac{r}{n \cdot a 0}} \cdot\left(\frac{2}{n \cdot a 0}\right)^{l} \cdot \mathrm{r}^{l-1} \cdot l . \mathrm{L}_{\mathrm{n}-l-1}^{2 \mathrm{l}+1}\left(2 \mathrm{r} / \mathrm{n} \cdot \mathrm{a}_{0}\right) \cdot\left(\mathrm{Y}_{l}^{\mathrm{m}}(\theta, \varphi)\right) \cdot\left[-1 / \mathrm{na}_{0}\right]+$ $\left\{\left(\frac{2}{n \cdot a 0}\right)^{\frac{3}{2}}\left(\frac{(n-l-1) !}{2 n[(n+l) !]^{3}}\right)^{1 / 2} \cdot e^{-\frac{r}{n \cdot a 0}} \cdot\left(\frac{2 r}{n \cdot a 0}\right)^{l} *\right.$

$\left[(1 / \mathrm{r}) \cdot \sum_{\mathrm{i}=1}\left[(-1){ }^{\mathrm{i}} \cdot[(\mathrm{n}+l) !]^{2} \cdot\right.\right.$ i. $\left.\left(2 \cdot r / \mathrm{na}_{0}\right)^{\mathrm{i}} \cdot /(\mathrm{i} ! .(\mathrm{n}-l-1-\mathrm{i}) ! \cdot(2 l+1+\mathrm{i}) !) *\left(\mathrm{Y}_{l}^{\mathrm{m}}(\theta, \varphi)\right) \cdot\left[-1 / \mathrm{na}_{0}\right]\right\}$

$+\left(\frac{2}{n \cdot a 0}\right)^{\frac{3}{2}}\left(\frac{(n-l-1) !}{2 n[(n+l) !]^{3}}\right)^{1 / 2} \cdot e^{-\frac{r}{n \cdot a 0}} \cdot\left(\frac{2 r}{n \cdot a 0}\right)^{l} *$

$\left[(1 / \mathrm{r}) \cdot \sum_{\mathrm{i}=1}\left[(-1) \cdot{ }^{\mathrm{i}} \cdot[(\mathrm{n}+l) !]^{2}\left(2 \cdot \mathrm{r} / \mathrm{na}_{0}\right)^{\mathrm{i}} \cdot \mathrm{i} /(\mathrm{i} ! \cdot(\mathrm{n}-l-1-\mathrm{i}) ! \cdot(2 l+1+\mathrm{i}) !) *\left(\mathrm{Y}^{\mathrm{m}}{ }_{l}(\theta, \varphi)\right)\left[-1 / \mathrm{na}_{0}\right]\right.\right.$ 
$+\left(\frac{2}{n \cdot a 0}\right)^{\frac{3}{2}}\left(\frac{(n-l-1) !}{2 n[(n+l) !]^{3}}\right)^{1 / 2} \cdot e^{-\frac{r}{n \cdot a 0}} \cdot\left(\frac{2 r}{n \cdot a 0}\right)^{l} *$

$\left[\left(1 / \mathrm{r}^{2}\right) \cdot \sum_{\mathrm{i}=1}\left[(-1) \cdot[(\mathrm{n}+l) !]^{2}\left(2 \cdot \mathrm{r} / \mathrm{na}_{0}\right)^{\mathrm{i}} \cdot\right.\right.$ i. $\left.(\mathrm{i}-1) /(\mathrm{i} ! \cdot(\mathrm{n}-l-1-\mathrm{i}) ! \cdot(2 l+1+\mathrm{i}) !) \mathrm{Y}^{\mathrm{m}}{ }_{l}(\theta, \varphi)\right)$

$+\left(\frac{2}{n \cdot a 0}\right)^{\frac{3}{2}}\left(\frac{(n-l-1) !}{2 n[(n+l) !]^{3}}\right)^{1 / 2} \cdot e^{-\frac{r}{n \cdot a 0}} \cdot\left(\frac{2}{n \cdot a 0}\right)^{l} \cdot \mathrm{r}^{l-1} \cdot l *$

$\left[(1 / \mathrm{r}) * \sum_{\mathrm{i}=1}\left[(-1) \cdot[(\mathrm{n}+l) !]^{2}\left(2 \cdot \mathrm{r} / \mathrm{na}_{0}\right)^{\mathrm{i}} . \mathrm{i} /(\mathrm{i} ! .(\mathrm{n}-l-1-\mathrm{i}) ! .(2 l+1+\mathrm{i}) !)\left(\mathrm{Y}^{\mathrm{m}}{ }_{l}(\theta, \varphi)\right)\right.\right.$

$+\left(\frac{2}{n \cdot a 0}\right)^{\frac{3}{2}}\left(\frac{(n-l-1) !}{2 n[(n+l) !]^{3}}\right)^{1 / 2} \cdot e^{-\frac{r}{n \cdot a 0}} \cdot\left(\frac{2}{n \cdot a 0}\right)^{l} \cdot \mathrm{r}^{l-1} \cdot l \cdot \mathrm{L}_{\mathrm{n}-l-1}^{21+1}\left(2 \mathrm{r} / \mathrm{n} \cdot \mathrm{a}_{0}\right) \cdot\left(\mathrm{Y}_{l}^{\mathrm{m}}(\theta, \varphi)\right) \cdot\left[-1 / \mathrm{na}_{0}\right]$

$+\left(\frac{2}{n \cdot a 0}\right)^{\frac{3}{2}}\left(\frac{(n-l-1) !}{2 n[(n+l) !]^{3}}\right)^{1 / 2} \cdot e^{-\frac{r}{n \cdot a 0}} \cdot\left(\frac{2}{n \cdot a 0}\right)^{l} \cdot r^{l-2} \cdot \mathrm{L}_{\mathrm{n}-l-1}^{21+1}\left(2 \mathrm{r} / \mathrm{n} \cdot \mathrm{a}_{0}\right) \cdot\left(\mathrm{Y}_{l}^{\mathrm{m}}(\theta, \varphi)\right) \cdot(l-1) \cdot l$

$+\left(\frac{2}{n \cdot a 0}\right)^{\frac{3}{2}}\left(\frac{(n-l-1) !}{2 n[(n+l) !]^{3}}\right)^{1 / 2} \cdot e^{-\frac{r}{n \cdot a 0}} \cdot\left(\frac{2}{n \cdot a 0}\right)^{l} \cdot \mathrm{r}^{l-l} \cdot l *$

$\left[(1 / \mathrm{r}) \cdot \sum_{\mathrm{i}=1}\left[(-1) \cdot[(\mathrm{n}+l) !]^{2}\left(2 \cdot \mathrm{r} / \mathrm{na}_{0}\right)^{\mathrm{i}} \cdot \mathrm{i} /(\mathrm{i} ! .(\mathrm{n}-l-1-\mathrm{i}) ! \cdot(2 l+1+\mathrm{i}) !)\left(\mathrm{Y}^{\mathrm{m}}{ }_{l}(\theta, \varphi)\right) \quad\right\}\right.$

$\leq\left(\mathrm{r}_{\mathrm{i}}^{2}\right) \cdot\left\{\left(\frac{2}{n \cdot a 0}\right)^{\frac{3}{2}}\left(\frac{(n-l-1) !}{2 n[(n+l) !]^{3}}\right)^{1 / 2} \cdot e^{-\frac{r}{n \cdot a 0}} \cdot\left(\frac{2 r}{n \cdot a 0}\right)^{l} \cdot \mathrm{L}_{\mathrm{n}-l-1}^{2 \mathrm{l}+1}\left(2 \mathrm{r} / \mathrm{n} \cdot \mathrm{a}_{0}\right) \cdot\left(\mathrm{Y}_{l}^{\mathrm{m}}(\theta, \varphi)\right) \cdot\left[1 / \mathrm{na}_{0}\right]^{2}\right.$

$+\left(\frac{2}{n \cdot a 0}\right)^{\frac{3}{2}}\left(\frac{(n-l-1) !}{2 n[(n+l) !]^{3}}\right)^{1 / 2} \cdot e^{-\frac{r}{n \cdot a 0}} \cdot\left(\frac{2}{n \cdot a 0}\right)^{l} \cdot \mathrm{r}^{l-1} \cdot l \cdot \mathrm{L}_{\mathrm{n}-l-1}^{2 \mathrm{l}+1}\left(2 \mathrm{r} / \mathrm{n} \cdot \mathrm{a}_{0}\right) \cdot\left(\mathrm{Y}_{l}^{\mathrm{m}}(\theta, \varphi)\right) \cdot\left[-1 / \mathrm{na}_{0}\right]+$

$\left\{\left(\frac{2}{n \cdot a 0}\right)^{\frac{3}{2}}\left(\frac{(n-l-1) !}{2 n[(n+l) !]^{3}}\right)^{1 / 2} \cdot e^{-\frac{r}{n \cdot a 0}} \cdot\left(\frac{2 r}{n \cdot a 0}\right)^{l} *\left\{\mathrm{~L}\left(2 \mathrm{r} / \mathrm{na}_{0}\right)+\mathrm{n}^{2}\right\} *\left(\mathrm{Y}_{l}^{\mathrm{m}}(\theta, \varphi)\right) \cdot\left[-1 / \mathrm{na}_{0}\right]\right\}$

$+\left(\frac{2}{n \cdot a 0}\right)^{\frac{3}{2}}\left(\frac{(n-l-1) !}{2 n[(n+l) !]^{3}}\right)^{1 / 2} \cdot e^{-\frac{r}{n \cdot a 0}} \cdot\left(\frac{2 r}{n \cdot a 0}\right)^{l} *\left\{\mathrm{~L}\left(2 \mathrm{r} / \mathrm{na}_{0}\right)+\mathrm{n}^{2}\right\} *\left(\mathrm{Y}_{l}^{\mathrm{m}}(\theta, \varphi)\right)\left[-1 / \mathrm{na}_{0}\right]$

$+\left(\frac{2}{n \cdot a 0}\right)^{\frac{3}{2}}\left(\frac{(n-l-1) !}{2 n[(n+l) !]^{3}}\right)^{1 / 2} \cdot e^{-\frac{r}{n \cdot a 0}} \cdot\left(\frac{2 r}{n \cdot a 0}\right)^{l} *$

$\left.\left\{\mathrm{L}\left(2 \mathrm{r} / \mathrm{na}_{0}\right)+2 \cdot \mathrm{n}^{3}+[(2 \mathrm{n}) !]^{2}\left(2 \mathrm{r} / \mathrm{a}_{0}\right) /[(\mathrm{n}-l-2) !(2 . l) !]\right\} . \mathrm{Y}^{\mathrm{m}}{ }_{l}(\theta, \varphi)\right)$

$$
\begin{aligned}
& +\left(\frac{2}{n \cdot a 0}\right)^{\frac{3}{2}}\left(\frac{(n-l-1) !}{2 n[(n+l) !]^{3}}\right)^{1 / 2} \cdot e^{-\frac{r}{n \cdot a 0}} \cdot\left(\frac{2}{n \cdot a 0}\right)^{l} \cdot \mathrm{r}^{l-1} \cdot l *\left\{\mathrm{~L}\left(2 \mathrm{r} / \mathrm{na}_{0}\right)+\mathrm{n}^{2}\right\}\left(\mathrm{Y}_{l}^{\mathrm{m}}(\theta, \varphi)\right) \\
& +\left(\frac{2}{n \cdot a 0}\right)^{\frac{3}{2}}\left(\frac{(n-l-1) !}{2 n[(n+l) !]^{3}}\right)^{1 / 2} \cdot e^{-\frac{r}{n \cdot a 0}} \cdot\left(\frac{2}{n \cdot a 0}\right)^{l} \cdot \mathrm{r}^{l-l} \cdot l \cdot \mathrm{L}_{\mathrm{n}-l-1}^{2 l+1}\left(2 \mathrm{r} / \mathrm{n} \cdot \mathrm{a}_{0}\right) \cdot\left(\mathrm{Y}_{l}^{\mathrm{m}}(\theta, \varphi)\right) \cdot\left[-1 / \mathrm{na}_{0}\right]
\end{aligned}
$$




$$
\begin{aligned}
& +\left(\frac{2}{n \cdot a 0}\right)^{\frac{3}{2}}\left(\frac{(n-l-1) !}{2 n[(n+l) !]^{3}}\right)^{1 / 2} \cdot e^{-\frac{r}{n \cdot a 0}} \cdot\left(\frac{2}{n \cdot a 0}\right)^{l} \cdot r^{l-2} \cdot \mathrm{L}_{\mathrm{n}-l-1}^{21+1}\left(2 \mathrm{r} / \mathrm{n}^{2} \mathrm{a}_{0}\right) \cdot\left(\mathrm{Y}_{l}^{\mathrm{m}}(\theta, \varphi)\right) \cdot(l-1) \cdot l \\
& \left.+\left(\frac{2}{n \cdot a 0}\right)^{\frac{3}{2}}\left(\frac{(n-l-1) !}{2 n[(n+l) !]^{3}}\right)^{1 / 2} \cdot e^{-\frac{r}{n \cdot a 0}} \cdot\left(\frac{2}{n \cdot a 0}\right)^{l} \cdot \mathrm{r}^{l-l} \cdot l *\left\{\mathrm{~L}\left(2 \mathrm{r} / \mathrm{na}_{0}\right)+\mathrm{n}^{2}\right\}\left(\mathrm{Y}_{l}{ }_{l}(\theta, \varphi)\right) \quad\right\}
\end{aligned}
$$

(Because due to the below results of (8.1.2) and (8.1.3))

Because $\partial \mathrm{L} / \partial \mathrm{r}=\left|\partial \sum_{\mathrm{i}}(-1)^{\mathrm{i}} .[(\mathrm{n}+l) !]^{2} .\left(2 \mathrm{r} / \mathrm{na}_{0}\right)^{\mathrm{i}} /[\mathrm{i} ! .(\mathrm{n}-l-1-\mathrm{i}) !(2 . l+1+\mathrm{i}) !] / \partial \mathrm{r}\right|$

$=\left|\sum_{\mathrm{i}=1}(-1)^{\mathrm{i}} \cdot[(\mathrm{n}+l) !]^{2} \cdot\left(2 \mathrm{r} / \mathrm{na}_{0}\right)^{\mathrm{i}} \cdot \mathrm{i} /[\mathrm{r} . \mathrm{i} ! .(\mathrm{n}-l-1-\mathrm{i}) !(2 \cdot l+1+\mathrm{i}) !]\right|$

$\leq\left|\sum_{\mathrm{i}=1}(-1)^{\mathrm{i}} \cdot[(\mathrm{n}+l) !]^{2} \cdot\left(2 \mathrm{r} / \mathrm{na}_{0}\right)^{\mathrm{i}} /[\mathrm{r} \cdot \mathrm{i} ! \cdot(\mathrm{n}-l-1-\mathrm{i}) !(2 \cdot l+1+\mathrm{i}) !]\right|+\mid \sum_{\mathrm{i}=1}(\mathrm{i})$

(because $\mid \sum_{\mathrm{i}}(-1)^{\mathrm{i}} \cdot[(\mathrm{n}+l) !]^{2} \cdot\left(2 \mathrm{r} / \mathrm{na}_{0}\right)^{\mathrm{i}} /[$ r. i $! .(\mathrm{n}-l-1-\mathrm{i}) !(2 \cdot l+1+\mathrm{i}) !] \mid>0$ and $\mathrm{i}>0$.

And because $\sum_{\mathrm{i}}\left(\mathrm{x}_{\mathrm{i}} \cdot \mathrm{y}_{\mathrm{i}}\right) \leq \sum_{\mathrm{i}} \mathrm{x}_{\mathrm{i}}+\sum_{\mathrm{i}} \mathrm{y}_{\mathrm{i}}$ for positive $\mathrm{x}_{\mathrm{i}}$ and $\mathrm{y}_{\mathrm{i}}$.

Then $\partial \mathrm{L} / \partial \mathrm{r} \leq\left|(1 / \mathrm{r}) \sum_{\mathrm{i}=0}(-1)^{\mathrm{i}} \cdot[(\mathrm{n}+l) !]^{2} \cdot\left(2 \mathrm{r} / \mathrm{na}_{0}\right)^{\mathrm{i}} /[\mathrm{i} ! \cdot(\mathrm{n}-l-1-\mathrm{i}) !(2 \cdot l+1+\mathrm{i}) !]\right|$

$+\left[(1 / \mathrm{r}) \cdot \mid \sum_{\mathrm{i}}(\mathrm{i})\right]-[(\mathrm{n}+l) !]^{2} /[\mathrm{r} .(\mathrm{n}-l-1) !(2 . l+1) !] \mid$

$\leq(1 / \mathrm{r}) . \mathrm{L}\left(2 \mathrm{r} / \mathrm{na}_{0}\right)+(\mathrm{n}-l-1)(\mathrm{n}-l) / 2 . \mathrm{r} \leq\left\{\mathrm{L}\left(2 \mathrm{r} / \mathrm{na}_{0}\right)+\mathrm{n}^{2}\right\} \ldots \ldots \ldots \ldots \ldots \ldots . .(8.1 .2)($ because $\mathrm{r}>1)$

And $\partial^{2} \mathrm{~L} / \partial \mathrm{r}^{2}=\left|\partial \sum_{\mathrm{i}=1}(-1)^{\mathrm{i}} \cdot[(\mathrm{n}+l) !]^{2} \cdot\left(2 \mathrm{r} / \mathrm{na}_{0}\right)^{\mathrm{i}} . \mathrm{i} /[\mathrm{r} . \mathrm{i} ! .(\mathrm{n}-l-1-\mathrm{i}) !(2 \cdot l+1+\mathrm{i}) !] / \partial \mathrm{r}\right|$

$=\left|\partial \sum_{\mathrm{i}=1}(-1)^{\mathrm{i}} \cdot[(\mathrm{n}+l) !]^{2} \cdot\left(2 / \mathrm{na}_{0}\right)^{\mathrm{i}} \cdot \mathrm{i} \cdot \mathrm{r}^{\mathrm{i}-1} /[\mathrm{i} ! \cdot(\mathrm{n}-l-1-\mathrm{i}) !(2 \cdot l+1+\mathrm{i}) !] / \partial \mathrm{r}\right|$

$=\left|\sum_{\mathrm{i}=2}(-1)^{\mathrm{i}} \cdot[(\mathrm{n}+l) !]^{2} \cdot\left(2 / \mathrm{na}_{0}\right)^{\mathrm{i}} \cdot \mathrm{i} \cdot(\mathrm{i}-1) \mathrm{r}^{\mathrm{i}-2} /[\mathrm{i} ! .(\mathrm{n}-l-1-\mathrm{i}) !(2 \cdot l+1+\mathrm{i}) !]\right|$

$=\left|\sum_{\mathrm{i}=2}(-1)^{\mathrm{i}} \cdot[(\mathrm{n}+l) !]^{2} \cdot\left(2 \mathrm{r} / \mathrm{na}_{0}\right)^{\mathrm{i}} \cdot \mathrm{i} \cdot(\mathrm{i}-1) /\left[\mathrm{r}^{2} . \mathrm{i} ! \cdot(\mathrm{n}-l-1-\mathrm{i}) !(2 \cdot l+1+\mathrm{i}) !\right]\right|$

$\leq\left|\sum_{\mathrm{i}=2}(-1)^{\mathrm{i}} \cdot[(\mathrm{n}+l) !]^{2} \cdot\left(2 \mathrm{r} / \mathrm{na}_{0}\right)^{\mathrm{i}} /\left[\mathrm{r}^{2} \cdot \mathrm{i} ! \cdot(\mathrm{n}-l-1-\mathrm{i}) !(2 \cdot l+1+\mathrm{i}) !\right]\right|+\left|\sum_{\mathrm{i}=1} \mathrm{i} \cdot(\mathrm{i}-1)\right|$

$=\left|\sum_{\mathrm{i}=0}(-1)^{\mathrm{i}} \cdot[(\mathrm{n}+l) !]^{2} \cdot\left(2 \mathrm{r} / \mathrm{na}_{0}\right)^{\mathrm{i}} /\left[\mathrm{r}^{2} \cdot \mathrm{i} ! .(\mathrm{n}-l-1-\mathrm{i}) !(2 \cdot l+1+\mathrm{i}) !\right]\right|+\left|\sum_{\mathrm{i}=1} \mathrm{i} \cdot(\mathrm{i}-1)\right|$

$-[(\mathrm{n}+l) !]^{2} /\left[\mathrm{r}^{2} .(\mathrm{n}-l-1) !(2 . l+1) !\right]+[(\mathrm{n}+l) !]^{2}\left(2 \mathrm{r} / \mathrm{na}_{0}\right) /\left[\mathrm{r}^{2} .(\mathrm{n}-l-2) !(2 . l+2) !\right]$

$\leq\left(1 / \mathrm{r}^{2}\right) . \mathrm{L}\left(2 \mathrm{r} / \mathrm{na}_{0}\right)+\mid\left(1 / \mathrm{r}^{2}\right) \cdot \sum_{\mathrm{i}=1} \mathrm{i}^{2}+[(\mathrm{n}+l) !]^{2}\left(2 \mathrm{r} / \mathrm{na}_{0}\right) /\left[\mathrm{r}^{2} .(\mathrm{n}-l-2) !(2 \cdot l+2) !\right]$ 
$=\left(1 / \mathrm{r}^{2}\right) \cdot \mathrm{L}\left(2 \mathrm{r} / \mathrm{na}_{0}\right)+(\mathrm{n}-l-1) \cdot(\mathrm{n}-l) \cdot\left[(2 \mathrm{n}-2 \cdot l-1) / 6 \cdot \mathrm{r}^{2}\right]$

$+[(\mathrm{n}+l) !]^{2}\left(2 \mathrm{r} / \mathrm{na}_{0}\right) /\left[\mathrm{r}^{2} .(\mathrm{n}-l-2) !(2 . l+2) !\right]$

$\leq \mathrm{L}\left(2 \mathrm{r} / \mathrm{na}_{0}\right)+2 \cdot \mathrm{n}^{3}+[(2 \mathrm{n}) !]^{2} \cdot\left(2 \mathrm{r} / \mathrm{a}_{0}\right) \quad$ (because $l>1, \mathrm{n}>l$ and $\left.\mathrm{n}>1\right)$

Thus $\partial^{2} \mathrm{~L} / \partial \mathrm{r}^{2} \leq \mathrm{L}\left(2 \mathrm{r} / \mathrm{na}_{0}\right)+2 \cdot \mathrm{n}^{3}+[(2 \mathrm{n}) !]^{2}\left(2 \mathrm{r} / \mathrm{a}_{0}\right)$

Thus by above inequalities: (1/S). $\sin \theta_{\mathrm{i}} \cdot \mathrm{r}_{\mathrm{i}}^{2} \frac{\partial^{2} \psi i}{\partial r i^{2}}$

$\leq\left(\mathrm{r}_{\mathrm{i}}^{2}\right) \cdot\left\{\left(\frac{2}{n \cdot a 0}\right)^{\frac{3}{2}}\left(\frac{(n-l-1) !}{2 n[(n+l) !]^{3}}\right)^{1 / 2} \cdot e^{-\frac{r}{n \cdot a 0}} \cdot\left(\frac{2 r}{n \cdot a 0}\right)^{l} \cdot \mathrm{L}_{\mathrm{n}-l-1}^{21+1}\left(2 \mathrm{r} / \mathrm{n} \cdot \mathrm{a}_{0}\right) \cdot\left(\mathrm{Y}^{\mathrm{m}}{ }_{l}(\theta, \varphi)\right)^{*}\right.$

$\left\{\left[1 / \mathrm{na}_{0}\right]^{2}-\left(l / \mathrm{r} \cdot \mathrm{na}_{0}\right)-\left[\mathrm{L}\left(2 \mathrm{r} / \mathrm{na}_{0}\right)+\mathrm{n}^{2}\right] / \mathrm{na}_{0}-\left[\mathrm{L}\left(2 \mathrm{r} / \mathrm{na}_{0}\right)+\mathrm{n}^{2}\right] / \mathrm{na}_{0}+\mathrm{L}\left(2 \mathrm{r} / \mathrm{na}_{0}\right)+2 \cdot \mathrm{n}^{3}+\right.$ $\left.[(2 \mathrm{n}) !]^{2} \cdot\left(2 \mathrm{r} / \mathrm{a}_{0}\right)+(l / \mathrm{r}) \cdot *\left[\mathrm{~L}\left(2 \mathrm{r} / \mathrm{na}_{0}\right)+\mathrm{n}^{2}\right]-l /\left(\mathrm{r} \cdot \mathrm{na}_{0}\right)+l \cdot(l-1) / \mathrm{r}^{2}+(l / \mathrm{r}) \cdot *\left[\mathrm{~L}\left(2 \mathrm{r} / \mathrm{na}_{0}\right)+\mathrm{n}^{2}\right]\right\}$

$=\left(\mathrm{r}_{\mathrm{i}}^{2}\right) \cdot\left\{\left(\frac{2}{n \cdot a 0}\right)^{\frac{3}{2}}\left(\frac{(n-l-1) !}{2 n[(n+l) !]^{3}}\right)^{1 / 2} \cdot e^{-\frac{r}{n \cdot a 0}} \cdot\left(\frac{2 r}{n \cdot a 0}\right)^{l} \cdot \mathrm{L}_{\mathrm{n}-l-1}^{21+1}\left(2 \mathrm{r} / \mathrm{n} \cdot \mathrm{a}_{0}\right) \cdot\left(\mathrm{Y}^{\mathrm{m}}{ }_{l}(\theta, \varphi)\right)^{*}\right.$

$\left\{\left[1 / \mathrm{na}_{0}\right]^{2}-\left(2 l / \mathrm{r} \cdot \mathrm{na}_{0}\right)-\left[2 \cdot \mathrm{L}\left(2 \mathrm{r} / \mathrm{na}_{0}\right)+\mathrm{n}^{2}\right] / \mathrm{na}_{0}+2 .(l / \mathrm{r}) \cdot *\left[\mathrm{~L}\left(2 \mathrm{r} / \mathrm{na}_{0}\right)+\mathrm{n}^{2}\right]+\mathrm{L}\left(2 \mathrm{r} / \mathrm{na}_{0}\right)+2 \cdot \mathrm{n}^{3}\right.$

$\left.+[(2 \mathrm{n}) !]^{2}\left(2 \mathrm{r} / \mathrm{a}_{0}\right)+l \cdot(l-1) / \mathrm{r}^{2}\right\}$

$\leq\left(\mathrm{r}_{\mathrm{i}}^{2}\right) \cdot\left\{\left(\frac{2}{n \cdot a 0}\right)^{\frac{3}{2}}\left(\frac{(n-l-1) !}{2 n[(n+l) !]^{3}}\right)^{1 / 2} \cdot e^{-\frac{r}{n \cdot a 0}} \cdot\left(\frac{2 r}{n \cdot a 0}\right)^{l} \cdot \mathrm{L}_{\mathrm{n}-l-1}^{21+1}\left(2 \mathrm{r} / \mathrm{n} \cdot \mathrm{a}_{0}\right) \cdot\left(\mathrm{Y}_{l}^{\mathrm{m}}(\theta, \varphi)\right)^{*}\right.$

$\left\{\left[1 / \mathrm{na}_{0}\right]^{2}-\left[2 . \mathrm{L}\left(2 \mathrm{r} / \mathrm{na}_{0}\right)\right] / \mathrm{na}_{0}+2 . l *\left[\mathrm{~L}\left(2 \mathrm{r} / \mathrm{na}_{0}\right)+\mathrm{n}^{2}\right]+\mathrm{L}\left(2 \mathrm{r} / \mathrm{na}_{0}\right)+2 \cdot \mathrm{n}^{3}+[(2 \mathrm{n}) !]^{2}\left(2 \mathrm{r} / \mathrm{a}_{0}\right)\right.$

$+l .(l-1)\}$ (because $\mathrm{r}>1$ and $\mathrm{n}>1)$

And by (8.1): $2 \cdot \mathrm{r}_{\mathrm{i}} \cdot \sin \theta_{\mathrm{i}} \cdot \frac{\partial \psi i}{\partial r i} \leq\left\{\left(\frac{2}{n \cdot a 0}\right)^{\frac{3}{2}}\left(\frac{(n-l-1) !}{2 n[(n+l) !]^{3}}\right)^{1 / 2} \cdot e^{-\frac{r i}{n \cdot a 0}} \cdot\left(\frac{2 r i}{n \cdot a 0}\right)^{l} \cdot \mathrm{L}^{21+1} \mathrm{n}-l-1\left(2 \mathrm{r}_{\mathrm{i}} / \mathrm{n} \cdot \mathrm{a}_{0}\right)^{*}\right.$

$\left\{\left(\mathrm{Y}_{l}^{\mathrm{m}}(\theta, \varphi) \cdot\left[-1 / \mathrm{na}_{0}\right]\right\}\right.$

$+\left(\frac{2}{n \cdot a 0}\right)^{\frac{3}{2}}\left(\frac{(n-l-1) !}{2 n[(n+l) !]^{3}}\right)^{1 / 2} \cdot e^{-\frac{r i}{n \cdot a 0}} \cdot\left(\frac{2 r i}{n \cdot a 0}\right)^{l} *(1 / \mathrm{r})\left[\mathrm{L}\left(2 \mathrm{r} / \mathrm{na}_{0}\right)+\mathrm{n}^{2}\right] \cdot\left(\mathrm{Y}^{\mathrm{m}}{ }_{l}(\theta, \varphi)\right)$

$\left.+\left(\frac{2}{n \cdot a 0}\right)^{\frac{3}{2}}\left(\frac{(n-l-1) !}{2 n[(n+l) !]^{3}}\right)^{1 / 2} \cdot e^{-\frac{r i}{n \cdot a 0}} \cdot\left(\frac{2}{n \cdot a 0}\right)^{l} \cdot \mathrm{r}_{\mathrm{i}}^{l-1} \cdot l \cdot \mathrm{L}^{21+1}{ }_{\mathrm{n}-l-1}\left(2 \mathrm{r}_{\mathrm{i}} / \mathrm{n} \cdot \mathrm{a}_{0}\right) \cdot\left(\mathrm{Y}^{\mathrm{m}}{ }_{l}(\theta, \varphi)\right)\right\} \cdot \mathrm{S} \cdot 2 \cdot \mathrm{r}_{\mathrm{i}} \cdot \sin \theta_{\mathrm{i}}$ 
$\leq\left\{\left(\frac{2}{n \cdot a 0}\right)^{\frac{3}{2}}\left(\frac{(n-l-1) !}{2 n[(n+l) !]^{3}}\right)^{1 / 2} \cdot e^{-\frac{r i}{n \cdot a 0}} \cdot\left(\frac{2 r i}{n \cdot a 0}\right)^{l} \cdot \mathrm{L}^{21+1}{ }_{\mathrm{n}-l-1}\left(2 \mathrm{r}_{\mathrm{i}} / \mathrm{n} \cdot \mathrm{a}_{0}\right) *\left(\mathrm{Y}^{\mathrm{m}}{ }_{l}(\theta, \varphi)^{*}\right.\right.$

$\left\{\left[-1 / \mathrm{na}_{0}\right]+(1 / \mathrm{r}) \cdot\left[\mathrm{L}\left(2 \mathrm{r} / \mathrm{na}_{0}\right)+\mathrm{n}^{2}\right]+(l / \mathrm{r})\right\} .2 . \mathrm{S} . \mathrm{r}_{\mathrm{i}}\left(\right.$ since $\left.\sin \theta_{\mathrm{i}}<1\right)$

Thus 2.r. $\mathrm{r}_{\mathrm{i}} \cdot \sin \theta_{\mathrm{i}} \cdot \frac{\partial \psi i}{\partial r i} \leq\left\{\left(\frac{2}{n \cdot a 0}\right)^{\frac{3}{2}}\left(\frac{(n-l-1) !}{2 n[(n+l) !]^{3}}\right)^{1 / 2} \cdot e^{-\frac{r i}{n \cdot a 0}} \cdot\left(\frac{2 r i}{n \cdot a 0}\right)^{l} \cdot \mathrm{L}^{21+1}{ }_{\mathrm{n}-l-1}\left(2 \mathrm{r}_{\mathrm{i}} / \mathrm{n} \cdot \mathrm{a}_{0}\right) *\left(\mathrm{Y}^{\mathrm{m}}{ }_{l}(\theta, \varphi)^{*}\right.\right.$

$\left\{\left[\mathrm{L}\left(2 \mathrm{r} / \mathrm{na}_{0}\right)+\mathrm{n}^{2}\right]+l\right\} .2 . \mathrm{S} . \mathrm{r}_{\mathrm{i}} \ldots \ldots \ldots \ldots \ldots \ldots \ldots(8.1 .5)\left(\right.$ Because $\mathrm{n}>0, \mathrm{r}>1$ and $\left.\mathrm{a}_{0}>0\right)$

And by (5.2.1)

$(1 / \mathrm{S}) \cdot \cos \theta_{\mathrm{i}} \cdot \frac{\partial \psi i}{\partial \theta i}=$

$-\left[\cos \theta_{\mathrm{i}}\right] \cdot\left(\frac{2}{n \cdot a 0}\right)^{\frac{3}{2}}\left(\frac{(n-l-1) !}{2 n[(n+l) !]^{3}}\right)^{1 / 2} \cdot e^{-\frac{r}{n \cdot a 0}} \cdot\left(\frac{2 r}{n \cdot a 0}\right)^{l} \cdot \mathrm{L}_{\mathrm{n}-l-1}^{21+1}\left(2 \mathrm{r} / \mathrm{n} \cdot \mathrm{a}_{0}\right) \cdot \alpha \cdot \frac{\sqrt{(2 l+1)(l-|\mathrm{m}|) !}}{2(l+|m|) !} \cdot \mathrm{e}^{\mathrm{im} \varphi}$.

$\left[\frac{1}{2^{l^{\prime}} l^{\prime} !}\left(\frac{d}{d \cos \theta}\right)^{l^{\prime}+1}(\sin \theta)^{2 l^{\prime}}\right] \cdot \sin \theta_{\mathrm{i}}$

But by (5.3): (1/S).sin $\theta i \frac{\partial^{2} \psi i}{\partial \theta i^{2}}=$

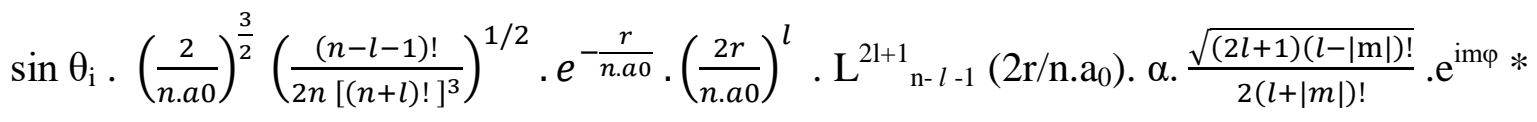

$\left\{\left(\sin \theta_{\mathrm{i}}\right)^{2} \cdot \frac{1}{2^{l^{\prime}} l^{\prime} !}\left(\frac{d}{d \cos \theta i}\right)^{l^{\prime}+2}(\sin \theta i)^{2 l^{\prime}}-\cos \theta_{\mathrm{i}} \cdot\left[\frac{1}{2^{l^{\prime}} l^{\prime} !}\left(\frac{d}{d \cos \theta i}\right)^{l^{\prime}+1}(\sin \theta i)^{2 l^{\prime}}\right\}\right.$

And by (5.4):

$\left(1 /\left[\mathrm{S} \cdot \sin \theta_{\mathrm{i}}\right]\right) \frac{\partial^{2} \psi i}{\partial \varphi i^{2}}=-\left(1 / \sin \theta_{\mathrm{i}}\right) \cdot \mathrm{m}^{2}\left(\frac{2}{n \cdot a 0}\right)^{\frac{3}{2}}\left(\frac{(n-l-1) !}{2 n[(n+l) !]^{3}}\right)^{1 / 2} \cdot e^{-\frac{r}{n \cdot a 0}} \cdot\left(\frac{2 r}{n \cdot a 0}\right)^{l} \mathrm{~L}^{2 \mathrm{l}+1}{ }_{\mathrm{n}-l-1}\left(2 \mathrm{r} / \mathrm{n} \cdot \mathrm{a}_{0}\right)$

$\alpha \cdot \frac{\sqrt{(2 l+1)(l-|\mathrm{m}|) !}}{2(l+|m|) !} \cdot \mathrm{e}^{\mathrm{im} \varphi} \cdot \mathrm{P}_{l}^{\mathrm{m}}\left(\cos \theta_{\mathrm{i}}\right)$

But $e^{-\frac{r}{n \cdot a 0}} \cdot\left(\frac{2 r i}{n \cdot a 0}\right)^{l}=\left(\frac{2 r i}{n \cdot a 0}\right)^{l} /\left[1+\left(\mathrm{r}_{\mathrm{i}} / \mathrm{na}_{0}\right)+\left(\mathrm{r}_{\mathrm{i}} / \mathrm{na}_{0}\right)^{2} / 2 !+\ldots \ldots \ldots+\left(\mathrm{r}_{\mathrm{i}} / \mathrm{na}_{0}\right)^{\mathrm{k}} / \mathrm{k} !\right]<\left(\frac{2 r i}{n \cdot a 0}\right)^{l}$ 
By (03), (8.1.4), (8.1.5), (8.3), (8.4) and (8.5):

$\left[\mathrm{E}_{0}-(\Lambda . v)\right] . \Psi>[\hbar(\sqrt{s} .(\mathrm{s}+1))] . \Psi+2 \cdot \mu_{\mathrm{B}} \cdot \mathrm{m}_{\mathrm{s}} \cdot \Sigma\left(\mathrm{B}_{\mathrm{i}} \psi_{\mathrm{i}}\right)+\Sigma\left(\mathrm{V}_{\mathrm{i}}\left(\mathrm{r}_{\mathrm{i}}\right) \psi_{\mathrm{i}}\right)$

$-\left(\hbar^{2} / 2 \mathrm{M}_{\mathrm{i}}\right) \cdot \Sigma\left[\frac{1}{r i^{2} \sin \theta i}\left[\sin \theta i \frac{\partial}{\partial r i}\left(r i^{2} \frac{\partial \psi i}{\partial r i}\right)+\frac{\partial}{\partial \theta i}\left(\sin \theta i \frac{\partial \psi i}{\partial \theta i}\right)+\frac{1}{\sin \theta i} \frac{\partial^{2} \psi i}{\partial \varphi i^{2}}\right]\right.$

$>\left[\hbar\left(V_{\mathrm{s}} \cdot(\mathrm{s}+1)\right)\right] \cdot \Psi+2 \cdot \mu_{\mathrm{B}} \cdot \mathrm{m}_{\mathrm{s}} \cdot \Sigma\left(\mathrm{B}_{\mathrm{i}} \psi_{\mathrm{i}}\right)+\Sigma\left(\mathrm{V}_{\mathrm{i}}\left(\mathrm{r}_{\mathrm{i}}\right) \psi_{\mathrm{i}}\right)$

$-\mid\left(\hbar^{2} / 2 \mathrm{M}_{\mathrm{i}}\right) \cdot \Sigma\left[\frac{1}{r^{2} \sin \theta i}\left[\sin \theta i \frac{\partial}{\partial r i}\left(r i^{2} \frac{\partial \psi i}{\partial r i}\right)+\frac{\partial}{\partial \theta i}\left(\sin \theta i \frac{\partial \psi i}{\partial \theta i}\right)+\frac{1}{\sin \theta i} \frac{\partial^{2} \psi i}{\partial \varphi i^{2}}\right] \mid\right.$

$=\left[\hbar\left(V_{\mathrm{s}} \cdot(\mathrm{s}+1)\right)\right] \cdot \Psi+2 \cdot \mu_{\mathrm{B}} \cdot \mathrm{m}_{\mathrm{s}} \cdot \Sigma\left(\mathrm{B}_{\mathrm{i}} \psi_{\mathrm{i}}\right)+\Sigma\left(\mathrm{V}_{\mathrm{i}}\left(\mathrm{r}_{\mathrm{i}}\right) \psi_{\mathrm{i}}\right)$

$-\mid\left(\hbar^{2} / 2 \mathrm{M}_{\mathrm{i}}\right) \cdot \Sigma\left[\frac{1}{r i^{2} \sin \theta i}\left[\sin \theta_{\mathrm{i}} \cdot\left(2 \cdot \mathrm{r}_{\mathrm{i}} \cdot \frac{\partial \psi i}{\partial r i}+\mathrm{r}_{\mathrm{i}}^{2} \cdot \frac{\partial^{2} \psi i}{\partial r i^{2}}\right)\right]+\left[\left(\cos \theta_{\mathrm{i}} \cdot \frac{\partial \psi i}{\partial \theta i}\right)+\sin \theta_{\mathrm{i}} \cdot \frac{\partial^{2} \psi i}{\partial \theta i^{2}}\right]+\left[\frac{1}{\sin \theta i} \frac{\partial^{2} \psi i}{\partial \varphi i^{2}}\right]\right]$

Because $(x-y) \geq x-|y|$ for all real $x$ and real $y$.

Therefore,

$\left[\mathrm{E}_{0}-(\Lambda . v)\right] . \Psi>2 \cdot \mu_{\mathrm{B}} \cdot \mathrm{m}_{\mathrm{s}} \cdot \Sigma\left(\mathrm{B}_{\mathrm{i}} \psi_{\mathrm{i}}\right)+\Sigma\left(\mathrm{V}_{\mathrm{i}}\left(\mathrm{r}_{\mathrm{i}}\right) \psi_{\mathrm{i}}\right)$

$-\Sigma\left(\hbar^{2} /\left[2 \mathrm{M}_{\mathrm{i}} \mathrm{r}_{\mathrm{i}}{ }^{2} \cdot \sin \theta_{\mathrm{i}}\right]\right) \mid\left\{\left(\frac{2}{n \cdot a 0}\right)^{\frac{3}{2}}\left(\frac{(n-l-1) !}{2 n[(n+l) !]^{3}}\right)^{1 / 2} \cdot e^{-\frac{r i}{n \cdot a 0}} \cdot\left(\frac{2 r i}{n \cdot a 0}\right)^{l} \cdot \mathrm{L}^{21+1}{ }_{\mathrm{n}-l-1}\left(2 \mathrm{r}_{\mathrm{i}} / \mathrm{n} \cdot \mathrm{a}_{0}\right)^{*}\left(\mathrm{Y}^{\mathrm{m}}{ }_{l}(\theta, \varphi)^{*}\right.\right.$

$\left.\left[\mathrm{L}\left(2 \mathrm{r} / \mathrm{na}_{0}\right)+\mathrm{n}^{2}\right]+l\right\} \cdot 2 \cdot \mathrm{S} \cdot \mathrm{r}_{\mathrm{i}}$

$+\left(\mathrm{r}_{\mathrm{i}}^{2}\right) \cdot\left\{\left(\frac{2}{n \cdot a 0}\right)^{\frac{3}{2}}\left(\frac{(n-l-1) !}{2 n[(n+l) !]^{3}}\right)^{1 / 2} \cdot e^{-\frac{r}{n \cdot a 0}} \cdot\left(\frac{2 r}{n \cdot a 0}\right)^{l} \cdot \mathrm{L}^{21+1}{ }_{\mathrm{n}-l-1}\left(2 \mathrm{r} / \mathrm{n} \cdot \mathrm{a}_{0}\right) \cdot\left(\mathrm{Y}_{l}^{\mathrm{m}_{l}}(\theta, \varphi)\right)^{*}\right.$

$\left\{\left[1 / \mathrm{na}_{0}\right]^{2}-\left[2 . \mathrm{L}\left(2 \mathrm{r} / \mathrm{na}_{0}\right)\right] / \mathrm{na}_{0}+2 . l *\left[\mathrm{~L}\left(2 \mathrm{r} / \mathrm{na}_{0}\right)+\mathrm{n}^{2}\right]+\mathrm{L}\left(2 \mathrm{r} / \mathrm{na}_{0}\right)+2 \cdot \mathrm{n}^{3}+[(2 \mathrm{n}) !]^{2}\left(2 \mathrm{r} / \mathrm{a}_{0}\right)\right.$

$+l \cdot(l-1)\}$ 
$-\left[\cos \theta_{\mathrm{i}}\right] \cdot\left(\frac{2}{n \cdot a 0}\right)^{\frac{3}{2}}\left(\frac{(n-l-1) !}{2 n[(n+l) !]^{3}}\right)^{1 / 2} \cdot e^{-\frac{r}{n \cdot a 0}} \cdot\left(\frac{2 r}{n \cdot a 0}\right)^{l} \cdot \mathrm{L}_{\mathrm{n}-l-1}^{2 l+1}\left(2 \mathrm{r} / \mathrm{n} \cdot \mathrm{a}_{0}\right) \cdot \alpha \cdot \frac{\sqrt{(2 l+1)(l-|\mathrm{m}|) !}}{2(l+|m|) !} \cdot \mathrm{e}^{\mathrm{im} \varphi}$.

$\left[\frac{1}{2^{l^{\prime}} l^{\prime} !}\left(\frac{d}{d \cos \theta}\right)^{l^{\prime}+1}(\sin \theta)^{2 l^{\prime}}\right]$ S. $\sin \theta_{\mathrm{i}}+$

$\mathrm{S} \cdot \sin \theta_{\mathrm{i}} \cdot\left(\frac{2}{n \cdot a 0}\right)^{\frac{3}{2}}\left(\frac{(n-l-1) !}{2 n[(n+l) !]^{3}}\right)^{1 / 2} \cdot e^{-\frac{r}{n \cdot a 0}} \cdot\left(\frac{2 r}{n \cdot a 0}\right)^{l} \cdot \mathrm{L}_{\mathrm{n}-l-1}^{21+1}\left(2 \mathrm{r} / \mathrm{n} \cdot \mathrm{a}_{0}\right) \cdot \alpha \cdot \frac{\sqrt{(2 l+1)(l-|\mathrm{m}|) !}}{2(l+|m|) !} \cdot \mathrm{e}^{\mathrm{im} \varphi} *$

$\left\{\left(\sin \theta_{\mathrm{i}}\right)^{2} \cdot \frac{1}{2^{l^{\prime}} l^{\prime} !}\left(\frac{d}{d \cos \theta i}\right)^{l^{\prime}+2}(\sin \theta i)^{2 l^{\prime}}-\cos \theta_{\mathrm{i}} \cdot\left[\frac{1}{2^{l^{\prime}} l^{\prime} !}\left(\frac{d}{d \cos \theta i}\right)^{l^{\prime}+1}(\sin \theta i)^{2 l^{\prime}}\right\}\right.$

$-\left(1 / \sin \theta_{\mathrm{i}}\right) \cdot \mathrm{S} \cdot \mathrm{m}^{2}\left(\frac{2}{n \cdot a 0}\right)^{\frac{3}{2}}\left(\frac{(n-l-1) !}{2 n[(n+l) !]^{3}}\right)^{1 / 2} \cdot e^{-\frac{r}{n \cdot a 0}} \cdot\left(\frac{2 r}{n \cdot a 0}\right)^{l} \mathrm{~L}_{\mathrm{n}-l-1}^{21+1}\left(2 \mathrm{r} / \mathrm{n} \cdot \mathrm{a}_{0}\right) \cdot \alpha \cdot \frac{\sqrt{(2 l+1)(l-|\mathrm{m}|) !}}{2(l+|m|) !}$

. $\mathrm{e}^{\mathrm{im} \varphi *} \mathrm{P}_{l}^{\mathrm{m}}\left(\cos \theta_{\mathrm{i}}\right)$

$* * *$ Above all $\mathrm{r} \equiv \mathrm{r}_{\mathrm{i}}, \theta \equiv \theta_{\mathrm{i}}, \phi \equiv \phi_{\mathrm{i}}$

Therefore, $\left[\mathrm{E}_{0}-(\Lambda . \mathrm{v})\right] . \Psi>2 \cdot \mu_{\mathrm{B}} \cdot \mathrm{m}_{\mathrm{s}} \cdot \Sigma\left(\mathrm{B}_{\mathrm{i}} \psi_{\mathrm{i}}\right)+\Sigma\left(\mathrm{V}_{\mathrm{i}}\left(\mathrm{r}_{\mathrm{i}}\right) \psi_{\mathrm{i}}\right)$

$-\Sigma\left(\hbar^{2} /\left[2 \mathrm{M}_{\mathrm{i}} \mathrm{r}_{\mathrm{i}}{ }^{2} \cdot \sin \theta_{\mathrm{i}}\right]\right) \cdot \mid\left\{\left(\frac{2}{n \cdot a 0}\right)^{\frac{3}{2}}\left(\frac{(n-l-1) !}{2 n[(n+l) !]^{3}}\right)^{1 / 2} \cdot e^{-\frac{r i}{n \cdot a 0}} \cdot\left(\frac{2 r i}{n \cdot a 0}\right)^{l} \cdot \mathrm{L}^{21+1}{ }_{\mathrm{n}-l-1}\left(2 \mathrm{r}_{\mathrm{i}} / \mathrm{n} \cdot \mathrm{a}_{0}\right)^{*}\left(\mathrm{Y}^{\mathrm{m}}{ }_{l}(\theta, \varphi)^{*}\right.\right.$

$\left.\left[\mathrm{L}\left(2 \mathrm{r} / \mathrm{na}_{0}\right)+\mathrm{n}^{2}\right]+l\right\} .2 \cdot \mathrm{S} \cdot \mathrm{r}_{\mathrm{i}}$

$-\left[\cos \theta_{\mathrm{i}}\right] \cdot\left(\frac{2}{n \cdot a 0}\right)^{\frac{3}{2}}\left(\frac{(n-l-1) !}{2 n[(n+l) !]^{3}}\right)^{1 / 2} \cdot e^{-\frac{r}{n \cdot a 0}} \cdot\left(\frac{2 r}{n \cdot a 0}\right)^{l} \cdot \mathrm{L}_{\mathrm{n}-l-1}^{21+1}\left(2 \mathrm{r} / \mathrm{n} \cdot \mathrm{a}_{0}\right)^{*}$

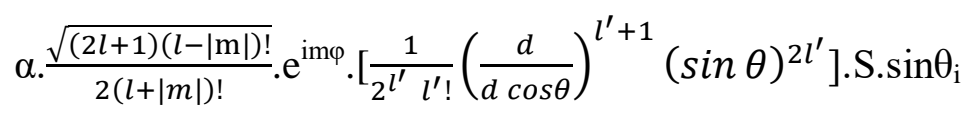

$-\left(1 / \sin \theta_{\mathrm{i}}\right) . \mathrm{S} \cdot \mathrm{m}^{2}\left(\frac{2}{n \cdot a 0}\right)^{\frac{3}{2}}\left(\frac{(n-l-1) !}{2 n[(n+l) !]^{3}}\right)^{1 / 2} \cdot e^{-\frac{r}{n \cdot a 0}} \cdot\left(\frac{2 r}{n \cdot a 0}\right)^{l} \mathrm{~L}^{21+1}{ }_{\mathrm{n}-l-1}\left(2 \mathrm{r} / \mathrm{n} \cdot \mathrm{a}_{0}\right) \cdot \alpha \cdot \frac{\sqrt{(2 l+1)(l-|\mathrm{m}|) !}}{2(l+|m|) !}$ $. \mathrm{e}^{\mathrm{im} \varphi *} \mathrm{P}_{l}^{\mathrm{m}}\left(\cos \theta_{\mathrm{i}}\right) \mid$ 
$-\mid \Sigma\left(\hbar^{2} /\left[2 \mathrm{M}_{\mathrm{i}} \mathrm{r}_{\mathrm{i}}^{2} \cdot \sin \theta_{\mathrm{i}}\right]\right)\left(\mathrm{r}_{\mathrm{i}}^{2}\right) \cdot\left\{\left(\frac{2}{n \cdot a 0}\right)^{\frac{3}{2}}\left(\frac{(n-l-1) !}{2 n[(n+l) !]^{3}}\right)^{1 / 2} \cdot e^{-\frac{r}{n \cdot a 0}} \cdot\left(\frac{2 r}{n \cdot a 0}\right)^{l} \cdot \mathrm{L}_{\mathrm{n}-l-1}^{2 \mathrm{l}+1}\left(2 \mathrm{r} / \mathrm{n} \cdot \mathrm{a}_{0}\right) \cdot\left(\mathrm{Y}_{l}^{\mathrm{m}}(\theta, \varphi)\right)^{*}\right.$

$\left\{\left[1 / \mathrm{na}_{0}\right]^{2}-\left[2 . \mathrm{L}\left(2 \mathrm{r} / \mathrm{na}_{0}\right)\right] / \mathrm{na}_{0}+2 . l *\left[\mathrm{~L}\left(2 \mathrm{r} / \mathrm{na}_{0}\right)+\mathrm{n}^{2}\right]+\mathrm{L}\left(2 \mathrm{r} / \mathrm{na}_{0}\right)+2 \cdot \mathrm{n}^{3}+[(2 \mathrm{n}) !]^{2}\left(2 \mathrm{r} / \mathrm{a}_{0}\right)\right.$

$+l \cdot(l-1)\} \mid$

- $\mid \Sigma\left(\hbar^{2} /\left[2 \mathrm{M}_{\mathrm{i}} \mathrm{r}_{\mathrm{i}}{ }^{2} \cdot \sin \theta_{\mathrm{i}}\right]\right) . \mathrm{S} \cdot \sin \theta_{\mathrm{i}} \cdot\left(\frac{2}{n \cdot a 0}\right)^{\frac{3}{2}}\left(\frac{(n-l-1) !}{2 n[(n+l) !]^{3}}\right)^{1 / 2} \cdot e^{-\frac{r}{n \cdot a 0}} \cdot\left(\frac{2 r}{n \cdot a 0}\right)^{l} \cdot \mathrm{L}_{\mathrm{n}-l-1}^{21+1}\left(2 \mathrm{r} / \mathrm{n} \cdot \mathrm{a}_{0}\right) \cdot \alpha$.

$\frac{\sqrt{(2 l+1)(l-|\mathrm{m}|) !}}{2(l+|m|) !} \cdot \mathrm{e}^{\mathrm{i} m \varphi} *\left\{\left(\sin \theta_{\mathrm{i}}\right)^{2} \cdot \frac{1}{2^{l^{\prime}} l^{\prime \prime} !}\left(\frac{d}{d \cos \theta i}\right)^{l^{\prime}+2}(\sin \theta i)^{2 l^{\prime}}-\cos \theta_{\mathrm{i}} \cdot\left[\frac{1}{2^{l^{\prime}} l^{\prime} !}\left(\frac{d}{d \cos \theta i}\right)^{l^{\prime}+1}(\sin \theta i)^{2 l^{\prime}}\right\}\right.$ । (09)

( Because $|X+Y| \leq|X|+|Y|$ for all real numbers $X$ and $Y$ )

We can substitute some parameters $\left(\mathrm{A}_{\mathrm{i}}, \mathrm{C}_{\mathrm{i}}\right.$ and $\left.\mathrm{D}_{\mathrm{i}}\right)$ to the above relationship (09) as below:

$\left[\mathrm{E}_{0}-(\Lambda . v)\right] . \Psi>$

$2 \cdot \mu_{\mathrm{B}} \cdot \mathrm{m}_{\mathrm{s}} \cdot \Sigma\left(\mathrm{B}_{\mathrm{i}} \psi_{\mathrm{i}}\right)+\Sigma\left(\mathrm{V}_{\mathrm{i}}\left(\mathrm{r}_{\mathrm{i}}\right) \psi_{\mathrm{i}}\right)-\Sigma \mathrm{A}_{\mathrm{i}} \cdot \psi_{\mathrm{i}}-\Sigma \mathrm{C}_{\mathrm{i}} \cdot \psi_{\mathrm{i}}-\Sigma \mathrm{D}_{\mathrm{i}} \cdot \psi_{\mathrm{i}}$

Where $\mathrm{A}_{\mathrm{i}}=$

$\left(\hbar^{2} /\left[2 \mathrm{M}_{\mathrm{i}} \mathrm{r}_{\mathrm{i}}{ }^{2} \cdot \sin \theta_{\mathrm{i}}\right]\right) \cdot \mid\left\{\left(\frac{2}{n \cdot a 0}\right)^{\frac{3}{2}}\left(\frac{(n-l-1) !}{2 n[(n+l) !]^{3}}\right)^{1 / 2} \cdot e^{-\frac{r i}{n \cdot a 0}} \cdot\left(\frac{2 r i}{n \cdot a 0}\right)^{l} \cdot \mathrm{L}^{2 \mathrm{l}+1}{ }_{\mathrm{n}-l-1}\left(2 \mathrm{r}_{\mathrm{i}} / \mathrm{n} \cdot \mathrm{a}_{0}\right)^{*}\left(\mathrm{Y}_{l}^{\mathrm{m}}(\theta, \varphi)^{*}\right.\right.$

$\left.\left[\mathrm{L}\left(2 \mathrm{r} / \mathrm{na}_{0}\right)+\mathrm{n}^{2}\right]+l\right\} \cdot 2 \cdot \mathrm{S} \cdot \mathrm{r}_{\mathrm{i}}$

$-\left[\cos \theta_{\mathrm{i}}\right] \cdot\left(\frac{2}{n \cdot a 0}\right)^{\frac{3}{2}}\left(\frac{(n-l-1) !}{2 n[(n+l) !]^{3}}\right)^{1 / 2} \cdot e^{-\frac{r}{n \cdot a 0}} \cdot\left(\frac{2 r}{n \cdot a 0}\right)^{l} \cdot \mathrm{L}_{\mathrm{n}-l-1}^{21+1}\left(2 \mathrm{r} / \mathrm{n} \cdot \mathrm{a}_{0}\right)$.

$\alpha \cdot \frac{\sqrt{(2 l+1)(l-|\mathrm{m}|) !}}{2(l+|m|) !} \cdot \mathrm{e}^{\mathrm{im} \varphi} \cdot\left[\frac{1}{2^{l^{\prime}} l^{\prime} !}\left(\frac{d}{d \cos \theta}\right)^{l^{\prime}+1}(\sin \theta)^{2 l^{\prime}}\right] . \mathrm{S} \cdot \sin \theta_{\mathrm{i}}$

$-\left(1 / \sin \theta_{\mathrm{i}}\right) \cdot \mathrm{S} \cdot \mathrm{m}^{2}\left(\frac{2}{n \cdot a 0}\right)^{\frac{3}{2}}\left(\frac{(n-l-1) !}{2 n[(n+l) !]^{3}}\right)^{1 / 2} \cdot e^{-\frac{r}{n \cdot a 0}} \cdot\left(\frac{2 r}{n \cdot a 0}\right)^{l} \mathrm{~L}^{2 l+1}{ }_{\mathrm{n}-l-1}\left(2 \mathrm{r} / \mathrm{n} \cdot \mathrm{a}_{0}\right) \cdot \alpha \cdot \frac{\sqrt{(2 l+1)(l-|\mathrm{m}|) !}}{2(l+|m|) !}$

$. \mathrm{e}^{\mathrm{im} \varphi} * \mathrm{P}_{l}^{\mathrm{m}}\left(\cos \theta_{\mathrm{i}}\right) \mid \geq 0$ 
And $\mathrm{C}_{\mathrm{i}}=$

$\mid \Sigma\left(\hbar^{2} /\left[2 \mathrm{M}_{\mathrm{i}} \mathrm{r}_{\mathrm{i}}^{2} \cdot \sin \theta_{\mathrm{i}}\right]\right)\left(\mathrm{r}_{\mathrm{i}}{ }^{2}\right) \cdot\left\{\left(\frac{2}{n \cdot a 0}\right)^{\frac{3}{2}}\left(\frac{(n-l-1) !}{2 n[(n+l) !]^{3}}\right)^{1 / 2} \cdot e^{-\frac{r}{n \cdot a 0}} \cdot\left(\frac{2 r}{n \cdot a 0}\right)^{l} \cdot \mathrm{L}^{2 \mathrm{l}+1}{ }_{\mathrm{n}-l-1}\left(2 \mathrm{r} / \mathrm{n} \cdot \mathrm{a}_{0}\right) \cdot\left(\mathrm{Y}^{\mathrm{m}}{ }_{l}(\theta, \varphi)\right)^{*}\right.$

$\left\{\left[1 / \mathrm{na}_{0}\right]^{2}-\left[2 . \mathrm{L}\left(2 \mathrm{r} / \mathrm{na}_{0}\right)\right] / \mathrm{na}_{0}+2 . l *\left[\mathrm{~L}\left(2 \mathrm{r} / \mathrm{na}_{0}\right)+\mathrm{n}^{2}\right]+\mathrm{L}\left(2 \mathrm{r} / \mathrm{na}_{0}\right)+2 \cdot \mathrm{n}^{3}+[(2 \mathrm{n}) !]^{2}\left(2 \mathrm{r} / \mathrm{a}_{0}\right)\right.$

$+l \cdot(l-1)\} \mid \geq 0$

And $\mathrm{D}_{\mathrm{i}}=\mid \Sigma\left(\hbar^{2} /\left[2 \mathrm{M}_{\mathrm{i}} \mathrm{r}_{\mathrm{i}}{ }^{2} \cdot \sin \theta_{\mathrm{i}}\right]\right) . \mathrm{S} \cdot \sin \theta_{\mathrm{i}} \cdot\left(\frac{2}{n \cdot a 0}\right)^{\frac{3}{2}}\left(\frac{(n-l-1) !}{2 n[(n+l) !]^{3}}\right)^{1 / 2} \cdot e^{-\frac{r}{n \cdot a 0}} \cdot\left(\frac{2 r}{n \cdot a 0}\right)^{l} \cdot \mathrm{L}_{\mathrm{n}-l-1}^{2 \mathrm{l}-1}\left(2 \mathrm{r} / \mathrm{n} \cdot \mathrm{a}_{0}\right)$.

a. $\frac{\sqrt{(2 l+1)(l-|\mathrm{m}|) !}}{2(l+|m|) !} \cdot \mathrm{e}^{\mathrm{i} m \varphi} *\left\{\left(\sin \theta_{\mathrm{i}}\right)^{2} \cdot \frac{1}{2^{l^{\prime}} l^{\prime} !}\left(\frac{d}{d \cos \theta i}\right)^{l^{\prime}+2}(\sin \theta i)^{2 l^{\prime}}-\cos \theta_{\mathrm{i}} \cdot\left[\frac{1}{2^{l^{\prime}} l^{\prime} !}\left(\frac{d}{d \cos \theta i}\right)^{l^{\prime}+1}(\sin \theta i)^{2 l^{\prime}}\right\}\right.$ |

$\geq 0$

All $\mathrm{A}_{\mathrm{i}}, \mathrm{C}_{\mathrm{i}}$ and $\mathrm{D}_{\mathrm{i}}$ are positive.

Then by (09):

$\left[\mathrm{E}_{0}-(\Lambda . v)\right] . \Psi>$

$2 \cdot \mu_{\mathrm{B}} \cdot \mathrm{m}_{\mathrm{s}} . \Sigma\left(\mathrm{B}_{\mathrm{i}} \psi_{\mathrm{i}}\right)+\Sigma\left(\mathrm{V}_{\mathrm{i}}\left(\mathrm{r}_{\mathrm{i}}\right) \psi_{\mathrm{i}}\right)-\Sigma \mathrm{A}_{\mathrm{i}} \cdot \psi_{\mathrm{i}}-\Sigma \mathrm{C}_{\mathrm{i}} \cdot \psi_{\mathrm{i}}-\Sigma \mathrm{D}_{\mathrm{i}} \cdot \psi_{\mathrm{i}}$

$=2 \cdot \mu_{\mathrm{B}} \cdot \mathrm{m}_{\mathrm{s}} \cdot \Sigma\left(\mathrm{B}_{\mathrm{i}} \psi_{\mathrm{i}}\right)+\Sigma\left(\mathrm{V}_{\mathrm{i}}\left(\mathrm{r}_{\mathrm{i}}\right) \psi_{\mathrm{i}}\right)-\mathrm{G} \cdot \Sigma \psi_{\mathrm{i}}$

(Since $\Sigma \mathrm{A}_{\mathrm{i}}>0, \Sigma \mathrm{C}_{\mathrm{i}}>0$ and $\Sigma \mathrm{D}_{\mathrm{i}}>0$ )

Where $\mathrm{G}=\Sigma \mathrm{A}_{\mathrm{i}}+\Sigma \mathrm{C}_{\mathrm{i}}+\Sigma \mathrm{D}_{\mathrm{i}}>0$

Then $\left[\mathrm{E}_{0}-(\Lambda . \mathrm{v})\right] . \Psi>2 . \mu_{\mathrm{B}} \cdot \mathrm{m}_{\mathrm{s}} \cdot \Sigma\left(\mathrm{B}_{\mathrm{i}} \psi_{\mathrm{i}}\right)+\Sigma\left(\mathrm{V}_{\mathrm{i}}\left(\mathrm{r}_{\mathrm{i}}\right) \psi_{\mathrm{i}}\right)-\mathrm{G} . \Psi$

Thus, $\left[\mathrm{E}_{0}-(\Lambda . v)\right] \Psi>2 \cdot \mu_{\mathrm{B}} \cdot \mathrm{m}_{\mathrm{s}} \cdot \Sigma\left(\mathrm{B}_{\mathrm{i}} \psi_{\mathrm{i}}\right)+\Sigma\left[\left(\mathrm{V}_{\mathrm{i}}\left(\mathrm{r}_{\mathrm{i}}\right) \psi_{\mathrm{i}}\right)-\mathrm{G}_{\mathrm{i}} \cdot \psi_{\mathrm{i}}\right]$

Where we arrange the terms $G_{i}$ such that each $G_{i}$ suits with the relationships in (13).

Then by (13): $\left[\mathrm{E}_{0}-(\Lambda . v)\right] \Psi>\Sigma\left[2 \cdot \mu_{\mathrm{B}} \cdot \mathrm{m}_{\mathrm{s}} \cdot \mathrm{B}_{\mathrm{i}}\right] \psi_{\mathrm{i}}+\Sigma\left[\left(\mathrm{V}_{\mathrm{i}}\left(\mathrm{r}_{\mathrm{i}}\right)-\mathrm{G}_{\mathrm{i}}\right] \psi_{\mathrm{i}}\right.$

$=\Sigma\left[2 \cdot \mu_{\mathrm{B}} \cdot \mathrm{m}_{\mathrm{s}} \cdot \mathrm{B}_{\mathrm{i}}+\mathrm{V}_{\mathrm{i}}\left(\mathrm{r}_{\mathrm{i}}\right)-\mathrm{G}_{\mathrm{i}}\right] \psi_{\mathrm{i}}$

Here $G_{i}=A_{i}+C_{i}+D_{i}$. Then each $G_{i} \neq 0$. 
But to achieve the required solution, there should be an external magnetic field $\left(\mathrm{B}_{\mathrm{i}}\right)$ that influences to the considering space volume such that $0<\left[2 \cdot \mu_{B} \cdot m_{s} \cdot B_{i}+V_{i}\left(r_{i}\right)-G_{i}\right]<1$ for each $\mathrm{i}$ belongs to $\{1,2, \ldots \ldots \ldots \ldots \ldots \ldots, \mathrm{a}\}$. Since $\mathrm{B}_{\mathrm{i}}>0$, by considering $\left[2 \cdot \mu_{\mathrm{B}} \cdot \mathrm{m}_{\mathrm{s}} \cdot \mathrm{B}_{\mathrm{i}}+\mathrm{V}_{\mathrm{i}}\left(\mathrm{r}_{\mathrm{i}}\right)\right]$, we can arrange $0<\left[2 \cdot \mu_{\mathrm{B}} \cdot \mathrm{m}_{\mathrm{s}} \cdot \mathrm{B}_{\mathrm{i}}+\mathrm{V}_{\mathrm{i}}\left(\mathrm{r}_{\mathrm{i}}\right)-\mathrm{G}_{\mathrm{i}}\right]<1$. Then let $\Sigma\left[2 \cdot \mu_{\mathrm{B}} \cdot \mathrm{m}_{\mathrm{s}} \cdot \mathrm{B}_{\mathrm{i}}+\mathrm{V}_{\mathrm{i}}\left(\mathrm{r}_{\mathrm{i}}\right)-\mathrm{G}_{\mathrm{i}}\right] \psi_{\mathrm{i}}=$ $\left[E^{\prime}, Y\right]$.

Then $\left[\mathrm{E}_{0}-(\Lambda . \mathrm{v})\right] \Psi>\left[\mathrm{E}^{\prime}, \mathrm{Y}\right]$.

Since we got the expression $\left[\mathrm{E}_{0}-(\Lambda . \mathrm{v})\right]$ and $\left[\mathrm{E}^{\prime} . \mathrm{Y}\right]$ as: $\left[\mathrm{E}_{0}-(\Lambda . \mathrm{v})\right] \Psi>\left[\mathrm{E}^{\prime} . \Upsilon\right]$ :

For some ' $u$ ' energy eigenvalue (positive real number) such that:

$\left[\mathrm{E}_{0}-(\Lambda . \mathrm{v})-\mathrm{u}\right] . \Psi=\left[\mathrm{E}^{\prime}, \mathrm{\Upsilon}\right]$; where $\mathrm{u}$ is a positive real number.

Then for some positive eigenvalue $\mathrm{E}^{*}$ and eigen function $\Psi$ :

$\left[\mathrm{E}_{0}-(\Lambda . \mathrm{v})-\mathrm{u}\right] \Psi=\left[\mathrm{E}^{\prime}, \mathrm{\Upsilon}\right]=\left(\mathrm{E}^{*}\right) \Psi$; with $\mathrm{E}^{*}>0$. Since $\mathrm{E}^{*}>0,\left[\mathrm{E}_{0}-(\Lambda . \mathrm{v})-\mathrm{u}\right]>0$. Since $\mathrm{u}$ is a positive real number, $\left[\mathrm{E}_{0}-(\Lambda . \mathrm{v})\right]>\mathrm{u}>0$. Then for some $\beta$ positive real number:

$\mathrm{E}_{0}=(\Lambda . v)+\beta$

\subsection{Result Evaluation of Methodology part 4}

Thus $\left(E_{0}-\beta\right) / v=\Lambda=$ cosmological constant. But ' $v$ ' (the space volume we consider in the units of meter cube) is greater than $1 \mathrm{~m}^{3}$. Here we measure and consider the space volume in the SI units (in the units of meter cube). Here $\mathrm{E}_{0}$ is the total energy of the zero point energy levels of the considering space volume. 


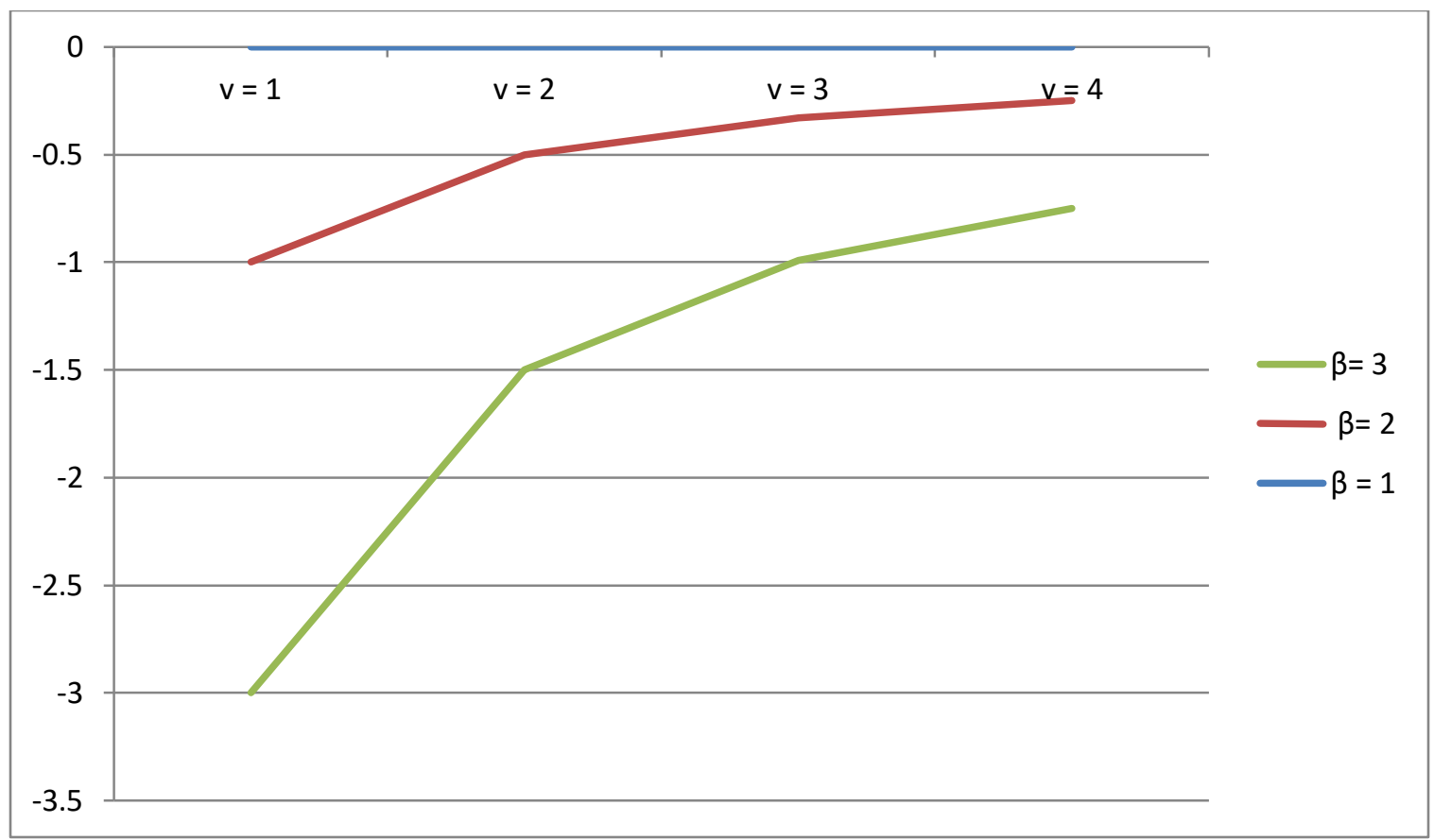

\section{Graph 03: graph of the variance of $\beta$ vs v}

Therefore we can observe that, the total energy of the zero point energy levels $\left(\mathrm{E}_{0}\right)$ can't cause a cosmological constant as much as big as the value of the total energy of the zero point energy levels. Because the values of surrounding energies of the matter/waves reduces the value of total energy of the zero-point energy levels $\left(\mathrm{E}_{0}\right)$ with respect to the value of cosmological constant $(\Lambda)$.

When there is a sufficient value of the external magnetic field, I can conclude that energy of the zero-point, can't cause a cosmological constant as much as big as the value of the total energy of the zero point energy levels. But to state that fact, there should be a sufficient value of the external magnetic field that creates $0<\left[2 \cdot \mu_{\mathrm{B}} \cdot \mathrm{m}_{\mathrm{S}} \cdot \mathrm{B}_{\mathrm{i}}+\mathrm{V}_{\mathrm{i}}\left(\mathrm{r}_{\mathrm{i}}\right)-\mathrm{G}_{\mathrm{i}}\right]<1$ to the considering space volume.

Therefore the external matter/waves creates the cosmological constant to be less than the value of the energy of the zero point energy levels.

Therefore the zero point energy (the quantum state with the lowest possible energy) of the vacuum does not cause a large cosmological constant (when the considering space volume contains the required value of the magnetic field). 


\section{Methodology part 5}

\subsection{Notations of Methodology part 5}

- $\tau$ is the proper time (time measured by a clock moving along the same world line with the test particle), measured by the clock at A

- $c$ is the speed of light

- $t$ is the improper time coordinate measured by $\mathrm{O}$ (measured by a stationary clock located far from the massive body A)

- $r$ is the radial coordinate from $\mathrm{A}$ to $\mathrm{O}$

- $\theta$ is the polar angle

- $\varphi$ is the azimuthal angle

- $r_{\mathrm{s}}$ is the Schwarzschild radius of the massive body, a scale factor which is related to its mass $M$ by $r_{\mathrm{s}}=2 G M / \mathrm{c}^{2}$, where $G$ is the gravitational constant.

\section{BUT DO NOT COMPARE THE EQUATION NUMBERS AND THE SYMBOLS OTHER PARTS IN THE RESEARCH METHODOLOGY AND IN THIS METHODOLOGY PART NUMBER 05.}

\subsection{Content of the Methodology part 5}

Usually satellites orbit around the Earth along the paths which are usually more than 1000 kilometers above the Earth's surface. Satellites are much valuable for communication, aircraft tracking, weather forecasting, astronomy fields and etc.

Satellites use the electromagnetic waves to send the signals and other necessary details towards a detector on the Earth.

But according to modern Astronomy/Cosmology theories, our universe is filled with an energy variety called as dark energy and gravitationally strong matter variety called as 'dark matter'. Our universe's observable matter percentage is less than $5 \%$ of total energy/matter amount. 
According to Einstein's General theory of Relativity, when an electromagnetic (EM) wave propagates near to gravitationally strong matter, the electromagnetic wave bends due to the strong gravitational field of the nearby matter object. Then due to the bending process of the electromagnetic wave, there is a shift of the wavelength of the electromagnetic wave. When the electromagnetic wave bends towards the gravitationally strong matter object, its wave length increases. But we know that, the wave length of 'red color' is greater than the wave length of other visible electromagnetic waves. Although the receiving electromagnetic wave is not a wave within the visible range of the EM radiations, we use the word 'gravitational redshift', since the strong gravitational field increases the wave length of the EM wave while it propagates away from the high gravity object.

Although the scientists those who are working with satellite technologies do not yet considered the influence to the EM waves (coming from the satellite) by the gravitational redshift, that fact plays a major role in the satellite communications.

By using the equations in the 'Gravitational Redshift', we can calculate the difference between the observed and theoretical wavelengths (and other measurements regarding the satellites orbiting around the Earth) of the EM waves coming from the Satellite that is above the Earth's surface. Then those calculations would provide us the real answer to the main problem of this research topic.

\subsection{Understand Gravitational Redshift}

Red shift is often denoted with the dimensionless variable $\mathrm{z}$, defined as the fractional change of the wave length.

$\mathrm{Z}=\left(\lambda_{0}-\lambda_{\mathrm{e}}\right) / \lambda_{\mathrm{e}}$

Where $\lambda_{0}$ is the wavelength of the electromagnetic radiation (photon) as measured by the observer. $\lambda_{\mathrm{e}}$ is the wavelength of the electromagnetic radiation (photon) when measured at the source of emission.

Gravitational red-shift or Einstein shift is the process by which electromagnetic radiation emitting from the source (that generates a strong gravitational field) towards the observer who is in a region of a weaker gravitational field. This is a direct result of gravitational time- dilation as 
one moves away from a source of gravitational field, the rate at which time passes is increased relative to the case when one is near to the source. We know that the frequency is the inverse of time (specifically, time required for completing one wave oscillation), and the frequency of the electromagnetic radiation is increased in an area of a higher gravitational potential (i.e. equivalently of lower gravitational field). There is a corresponding reduction in energy when electromagnetic radiation is red-shifted, according to Plank's relation (due to the electromagnetic radiation propagating in opposition to the gravitational gradient). There also exists a corresponding blue-shift when electromagnetic radiations propagating from an area of a weaker gravitational field to an area of a stronger gravitational field.

When we applied this to optical wavelengths, this manifests itself as a change in the color of visible light as the wavelength of the light is increased toward the red part of the light spectrum. Since frequency and wavelength are inversely proportional, this is equivalent to saying that the frequency of the light has reduced towards the red part of the light spectrum, giving this phenomenon the name 'red-shift'. When the light emitting star has attained the Schwarzschild radius, that gravitational red shift becomes infinite. That gravitational red shift is called as 'Infinite Gravitational red shift.

The gravitational red shift of a photon can be calculated in the framework of General Relativity (using Schwarzschild metric) as $\lim r_{\rightarrow}$ +infinity $z(r)=\left(1 / \sqrt{ }\left(1-r_{s} / R^{*}\right)\right)$

With the Schwarzschild radius $r_{s}=2 \mathrm{GM} / \mathrm{c}^{2}$

When $\mathrm{R}^{*}=\mathrm{r}_{\mathrm{s}}, \mathrm{z}(\mathrm{r})$ becomes infinity. That means when the radius of EM wave emitting object has attained Schwarzschild radius, the gravitational red shift becomes infinity. 


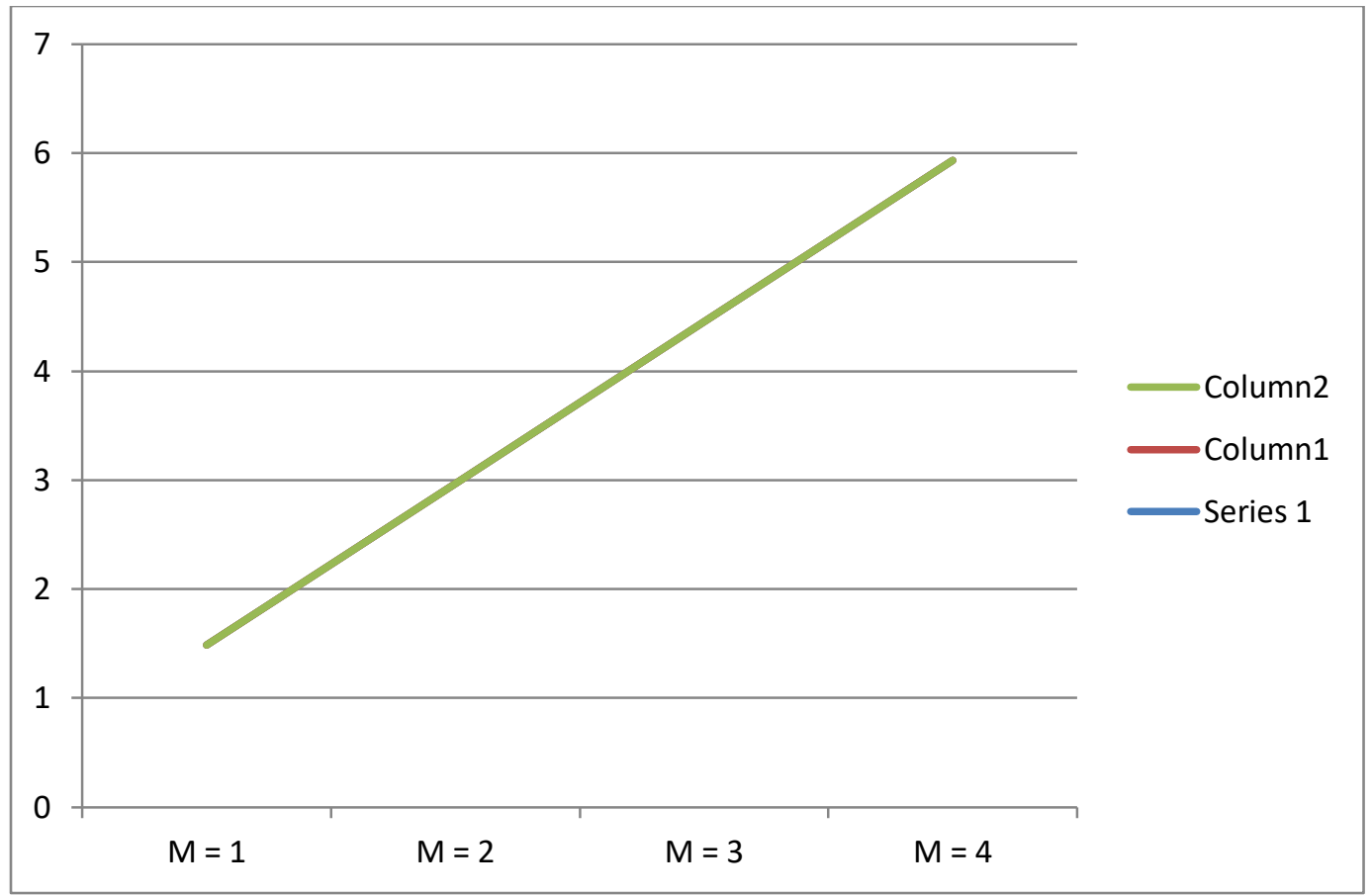

Graph 04: Variance of $r_{s}$ with respect to the mass $M$ of the gravitational object

Where $\mathrm{G}$ denotes Newton's gravitational constant, $\mathrm{M}$ the mass of the gravitating body, $\mathrm{C}$ is the speed of light, and the $\mathrm{R}^{*}$ the distance between the center of mass of the gravitating body and the point at which the photon is emitted. The red shift is not defined for photons those emitted inside the Schwarzschild radius, where the escape velocity is greater than the speed of light.

Therefore this formula only applies when $\mathrm{R}^{*}$ is at least as larger as $\mathrm{r}_{\mathrm{s}}$. When the photon is emitted at an infinitely large distance, there is no red shift. 


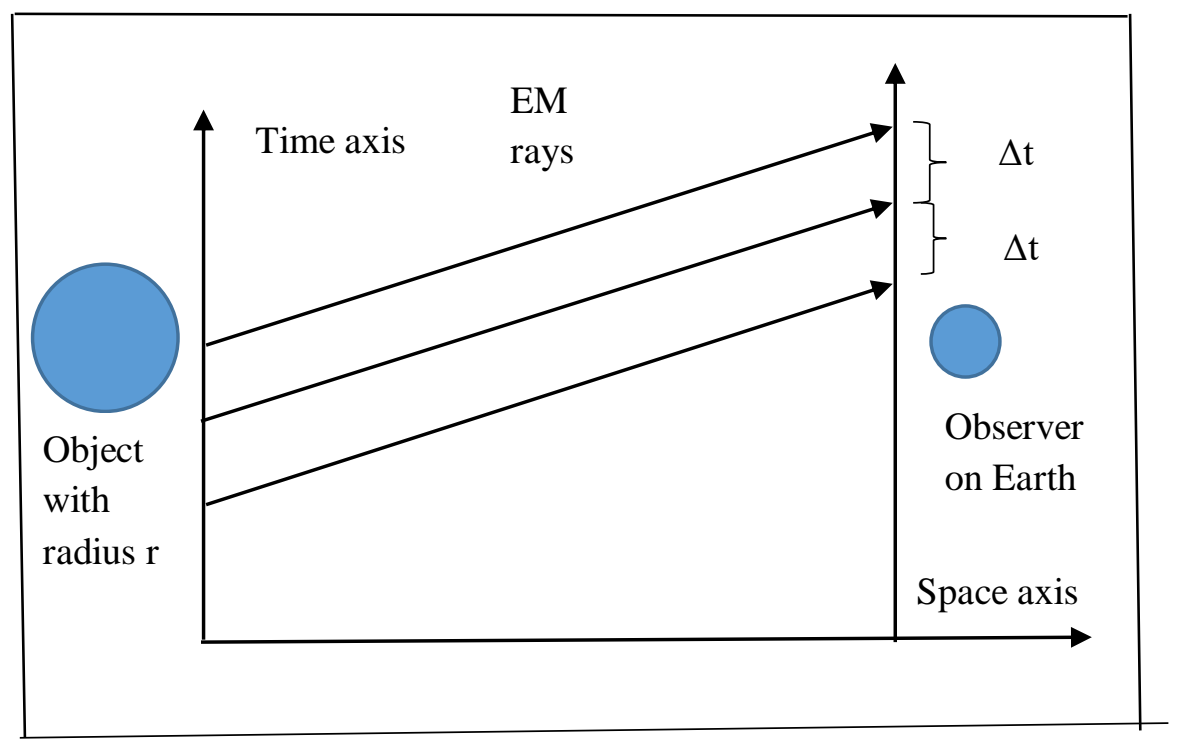

Figure 5: Gravitational red shift (zero for this case) VS radius of the object near to the satellite

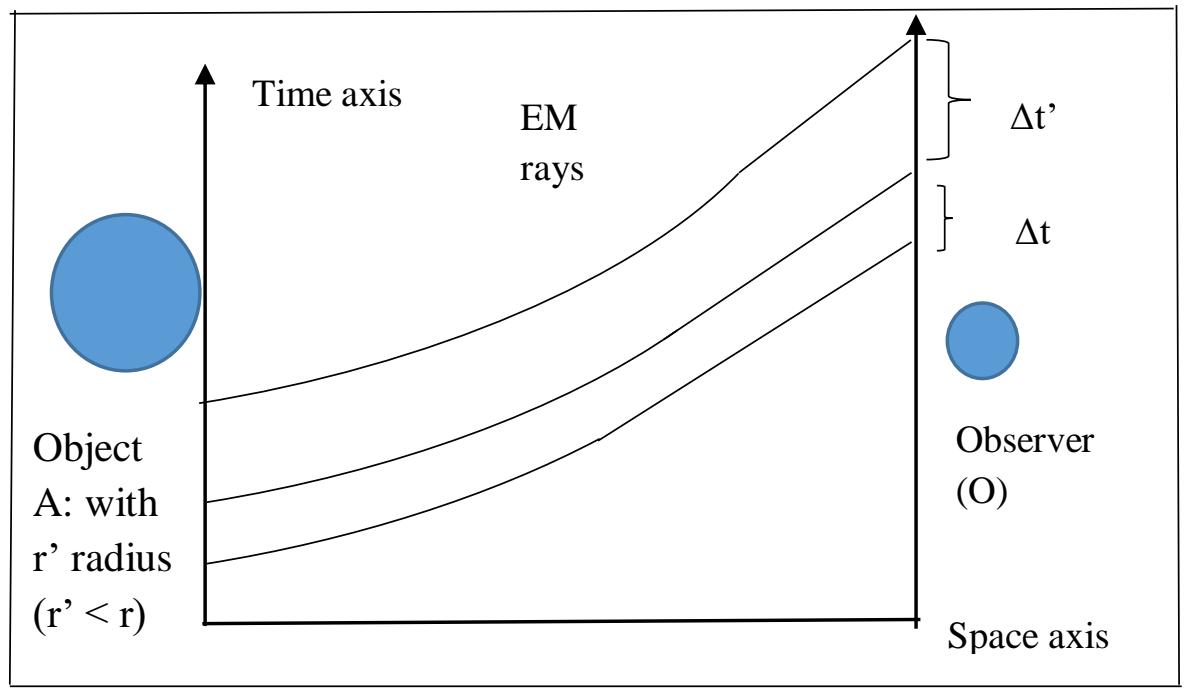

Here $\Delta \mathrm{t}^{\prime}>\Delta \mathrm{t}$

Figure 6: Gravitational red shift (positive) VS radius of the object near to satellite

In the above figure (03), the object A's radius is less than the radius of the object $A_{0}$ in the figure (02). The EM rays those shown in the figure (02) and figure (03), are the EM waves those emitted by the considering satellite. And the Object A is nearby to the satellite. i.e. the high gravity object influences to the space-time near to the satellite and the high gravity object curves 
the space-time near to the satellite. Then the EM waves those emits by the satellite bends. Then the frequency of receiving EM waves by the observer on the Earth, decreases, since the EM waves emitting by the satellite, take long time to propagate towards the Earth (due to the curvature of the space-time near to the satellite).

Consider the Schwarzschild equation related to the gravitational red shift:

$c^{2} d \tau^{2}=\left(1-\left(r_{s} / r\right)\right) c^{2} d t^{2}-\left(1-\left(r_{s} / r\right)\right)^{-1} d r^{2}-r^{2}\left(d \theta^{2}+\sin ^{2} \theta d \varphi^{2}\right)$

- $\tau$ is the proper time (time measured by a clock moving along the same world line with the test particle), measured by the clock at A

- $\quad c$ is the speed of light

- $t$ is the improper time coordinate measured by $\mathrm{O}$ (measured by a stationary clock located far from the massive body A)

- $\quad r$ is the radial coordinate from $\mathrm{A}$ to $\mathrm{O}$

- $\theta$ is the polar angle

- $\varphi$ is the azimuthal angle

- $\quad r_{\mathrm{s}}$ is the Schwarzschild radius of the massive body, a scale factor which is related to its mass $M$ by $r_{\mathrm{s}}=2 G M / \mathrm{c}^{2}$, where $G$ is the gravitational constant.

But first of all, we have to identify the meanings of ' $r$ ', $\theta$ and $\varphi$, when the dark matter strength bends the EM waves sending from the satellite.

r , $\theta$ and $\varphi$ are the spherical coordinates of the observer with respect to the high gravity body (here the dark matter/dark energy area).

But let us try to find the required input value as the M, for the dark energy that is nearby to the satellite that is orbiting around the Earth. i.e. try to find the value of $r_{s}$ for this situation.

Let's find the mass $\mathrm{M}$ of the dark energy volume (the mass of the dark energy within some certain volume near to the satellite) as below:

The dark energy density ( $\rho_{\mathrm{de}}$ ) of the Universe can be expressed as : 
$\rho_{\mathrm{de}}=(\mathrm{A} / 2 \pi) \cdot(\hbar / \mathrm{c}) \cdot\left(\ddot{\mathrm{X}} / \lambda^{3} \pi\right)$

where $\mathrm{A} \approx 2$ is a dimensionless constant; $\lambda_{\pi}=\left(\mathrm{h} / \mathrm{m}_{\pi} \mathrm{c}\right)$ is Compton wavelength of a pion and $\ddot{\mathrm{X}}$ the acceleration of the expansion of the Universe.

But the acceleration of the expansion of the Universe $(\ddot{\mathrm{X}})$ is:

$\ddot{X}=(-4 \pi G / 3) \cdot X\left(\rho+3 p / c^{2}\right)+X \cdot \Lambda c^{2} / 3$

Where $\rho$ and $\mathrm{P}$ are the density and pressure of the cosmological fluid respectively. And $\mathrm{X}$ is the scale factor in the Friedmann equations. $\mathrm{G}$ is the universal gravitation constant, $\mathrm{c}$ is the speed of light, $\Lambda$ is the cosmological constant.

But the equation of state of the cosmological fluid is: $P_{n}=w_{n} \cdot \rho_{n} \cdot c^{2}$

Where the equation-of state-parameter $\mathrm{w}_{\mathrm{n}}$ is a constant

Radiation, matter and dark energy (when identified with cosmological constant) are modeled respectively with $\mathrm{w}_{\mathrm{rad}}=(1 / 3), \mathrm{w}_{\text {matt }}=0, \mathrm{w}_{\mathrm{de}}=-1$.

By (05) and (06):

$\ddot{\mathrm{X}}=(-4 \pi \mathrm{G} / 3) \cdot \mathrm{X}\left(-\frac{P}{c^{2}}+\frac{3 \cdot P}{c^{2}}\right)+\mathrm{X} \cdot \Lambda \mathrm{c}^{2} / 3=(-8 \pi \mathrm{G} / 3) \cdot \mathrm{X} \cdot\left(\frac{P}{c^{2}}\right)+\mathrm{X} \cdot \Lambda \mathrm{c}^{2} / 3$

Where $\mathrm{X} s$ the scale factor of the universe.

By $(04): \rho_{\mathrm{de}}=(\mathrm{A} / 2 \pi) \cdot(\hbar / \mathrm{c}) \cdot\left(\ddot{\mathrm{X}} / \lambda^{3}{ }_{\pi}\right)$ where $\ddot{\mathrm{X}}=(-8 \pi \mathrm{G} / 3) \cdot \mathrm{X} \cdot\left(\frac{P}{c^{2}}\right)+\mathrm{X} \cdot \Lambda \mathrm{c}^{2} / 3$

Then $\rho_{\mathrm{de}}=(\mathrm{A} / 2 \pi) \cdot(\mathrm{h} / \mathrm{c}) \cdot\left(\ddot{\mathrm{X}} / \lambda^{3}\right)=(\mathrm{A} \cdot \hbar) /\left[2 \cdot \pi \cdot \mathrm{c} \cdot \lambda_{\pi}^{3}\right] \cdot\left[(-8 \pi \mathrm{G} / 3) \cdot \mathrm{X} \cdot\left(\frac{P}{c^{2}}\right)+\mathrm{X} \cdot \Lambda \mathrm{c}^{2} / 3\right]$

$=(-4 / 3) \cdot[$ A.h.G.P.X $] /\left[\mathrm{c}^{3} \cdot \lambda^{3}\right]+\left(\mathrm{A} \hbar \cdot \mathrm{X} /\left[2 \pi \mathrm{c} \cdot \lambda^{3} \pi\right]\right) \cdot \Lambda \mathrm{c}^{2} / 3=\rho_{\mathrm{de}}$

Where $\lambda_{\pi}=\left(\mathrm{h} / \mathrm{m}_{\pi} \mathrm{c}\right)=6.626 * 10^{-34} /\left(2.488 * 10^{-28} * 2.998 * 10^{8}\right)=.888 * 10^{-14}$

$\mathrm{P}=-5.2 * 10^{-10} \mathrm{~Pa}$

But for the present and recent universe, $\mathrm{X}=1$. 
Then by applying those numerical values, we get the value for $\rho_{\mathrm{de}}$ as below.

$$
\begin{aligned}
& \rho_{\mathrm{de}} \approx(-8 / 3) .\left(1.055^{*} 10^{-34}\right) *\left(6.674 * 10^{-11}\right) *\left(-5.2 * 10^{-10}\right) .1 /\left[\left(2.998 * 10^{8}\right)^{3 *}\left(.888 * 10^{-14}\right)^{3}\right] \\
& +2 * 1.055 * 10^{-34} * 1 * 2.998 * 10^{8} * 1.11 * 10^{-52} /\left[6 . \pi . *\left(.888 * 10^{-14}\right)^{3}\right] \\
& \approx\left[97.636 * 10^{-55} / 18.87 * 10^{-18}\right]+\left[7.022 * 10^{-78} / 6 * 3.142 * 7.002 * 10^{-43}\right] \\
& =5.174 * 10^{-37}+0.0530 * 10^{-35}=5.174 * 10^{-37}+5.30 * 10^{-37}=1.0474 * 10^{-36} \\
& \text { Thus } \rho_{\mathrm{de}} \approx 1.0474 * 10^{-36}
\end{aligned}
$$

Let's consider the volume of the dark energy content near to the satellite as ' $\mathrm{V}$ ' $\mathrm{m}^{3}$.

$$
\begin{aligned}
& \text { Then } \mathrm{M}=1.0474 * 10^{-36} . \mathrm{V} \ldots \ldots \ldots \ldots \ldots \ldots \ldots \ldots \ldots \ldots \ldots \ldots \ldots \ldots \ldots \ldots \ldots \ldots \ldots \ldots \ldots \ldots \ldots \ldots \ldots \ldots \\
& \text { then } \mathrm{r}_{\mathrm{s}}=2 \mathrm{GM} / \mathrm{c}^{2}=2 * 6.674 * 10^{-11} * 1.0474 * 10^{-36} * \mathrm{~V} /\left(2.998 * 10^{8}\right)^{2} \\
& =1.5555 * 10^{-63} * \mathrm{~V} . \text { Thus } \mathrm{r}_{\mathrm{s}}=1.5555 * 10^{-63} * \mathrm{~V} \ldots \ldots \ldots \ldots \ldots \ldots
\end{aligned}
$$

But we know that the line element in the spherical polar coordinates is:

$$
d s^{2}=d r^{2}+r^{2} \cdot d \theta^{2}+r^{2} \cdot \sin ^{2} \theta \cdot d \phi^{2} . \text { Then }\left[r^{2} \cdot d \theta^{2}+r^{2} \cdot \sin ^{2} \theta \cdot d \phi^{2}\right]=\left(d s^{2}-d r^{2}\right) .
$$

Then by (12) and (03):

$\mathrm{c}^{2} \mathrm{~d} \tau^{2}=\left(1-\left(\mathrm{r}_{\mathrm{s}} / \mathrm{r}\right)\right) \mathrm{c}^{2} \mathrm{dt}^{2}-\left(1-\left(\mathrm{r}_{\mathrm{s}} / \mathrm{r}\right)\right)^{-1} \mathrm{dr}^{2}-\mathrm{ds}^{2}+\mathrm{dr}^{2}$

But $\mathrm{U} . \mathrm{T}=\mathrm{s}$ Where $\mathrm{U}$ is the velocity of the satellite that is orbiting around the Earth. $\mathrm{T}$ is the orbital time period and $\mathrm{s}$ is the length of the orbital path of the satellite.

Then $\mathrm{ds}=\mathrm{T} . \mathrm{dU}+\mathrm{U} \cdot \mathrm{dT}$

Let's consider $\mathrm{dT}=1 \mathrm{~s}$. That means we consider a second, during the revolution of the satellite around the Earth.

Thus the gravitational force between the satellite and the Earth equals to the centrifugal force of the satellite. Thus, $\mathrm{mU}^{2} /(\mathrm{r}+6400000)=\mathrm{GmM}^{\prime} /(\mathrm{r}+6400000)^{2}$. Where $\mathrm{m}$ is the mass of the satellite. $\mathrm{M}^{\prime}$ is the mass of the Earth. G is the universal gravitational constant. $6400000 \mathrm{~m}$ is the radius of the Earth. 
*** Here we consider that the satellite and the gravitational center of the dark matter/energy (dark energy/matter near to the satellite) roughly coincide.

Then $U=\left(\mathrm{GM}^{\prime} / \mathrm{r}^{\prime}\right)^{1 / 2}$. Then $\mathrm{dU}=-\left(\mathrm{GM}^{\prime}\right)^{1 / 2} \cdot\left(\frac{1}{r^{\prime}}\right)^{\frac{3}{2}} \cdot(1 / 2) . \mathrm{dr} \mathrm{r}^{\prime}=-\left(\mathrm{dr} \mathrm{r}^{\prime} / 2\right) . \sqrt{ }\left(\mathrm{GM}^{\prime} / \mathrm{r}^{3}\right)$

Here $r^{\prime}=(r+6400000) ;$ here radius of the Earth $=6400 \mathrm{~km}$

For Low Earth Orbit (LEO) satellites usually, $U=7120 \mathrm{~m} / \mathrm{s}$ and $\mathrm{r}=1500 \mathrm{~km}=1.5 * 10^{6} \mathrm{~m}$

And r' $=7900000 \mathrm{~m}, 2 . \pi . \mathrm{r}=49612000 \mathrm{~m}=\mathrm{S}$. Then $\mathrm{T}=\mathrm{S} / \mathrm{U}=49612000 / 7120=7000$ seconds.

Then by (13): ds =

$-(7000) \cdot(\mathrm{dr} / 2) \cdot \sqrt{ }\left(\mathrm{GM}^{\prime} /(\mathrm{r}+6400000)^{3}\right)+7120 \cdot 1=7120-3500 \cdot \mathrm{dr} \cdot \sqrt{ }\left(\mathrm{GM} /(\mathrm{r}+6400000)^{3}\right)$

$\mathrm{G}=6.674 * 10^{-11}, \mathrm{M}^{\prime}=5.972 * 10^{24}, \mathrm{r}=1.5 * 10^{6}$

Thus $\left(\mathrm{GM} /(\mathrm{r}+6400000)^{3}\right)=39.857 * 10^{13} / 493.039 * 10^{18}=0.081 * 10^{-5}=0.81 * 10^{-6}$.

Thus $\sqrt{ }\left(\mathrm{GM}^{\prime} / \mathrm{r}^{\prime 3}\right)=0.9 * 10^{-3}$

Thus ds $=7120-\left(9.0 * 10^{-4}\right) * 3500 * \mathrm{dr}=7120-3.15 * \mathrm{dr}$

Then $\mathrm{ds}^{2}=50.6944 * 10^{6}-44856 * \mathrm{dr}+9.9225 * \mathrm{dr}^{2}$

By (12.1): $c^{2} d \tau^{2}=\left(1-\left(r_{s} / r\right)\right) c^{2}{d t^{2}}^{2}\left(1-\left(r_{s} / r\right)\right)^{-1} d r^{2}-d s^{2}+d r^{2}$

Thus

$c^{2} d \tau^{2}=\left(1-\left(r_{s} / r\right)\right) c^{2} d^{2}-\left(1-\left(r_{s} / r\right)\right)^{-1} d^{2}+d^{2}-50.6944 * 10^{6}+4.4856 * 10^{4} * d r-9.9225^{*} d^{2}$ $\mathrm{c}^{2} \mathrm{~d} \tau^{2}=\left(1-\left(\mathrm{r}_{\mathrm{s}} / \mathrm{r}\right)\right) \mathrm{c}^{2} \mathrm{dt}^{2}-\left(1-\left(\mathrm{r}_{\mathrm{s}} / \mathrm{r}\right)\right)^{-1} \mathrm{dr}^{2}-50.6944 * 10^{6}+4.4856 * 10^{4} * \mathrm{dr}-8.9225 * \mathrm{dr}^{2}$ .(15)

In (13.1): $\mathrm{dr} \neq 0$. 
But usually the change of the distance to the satellite from the Earth is around $1 \mathrm{~km}$ (due to the surrounding matters such as the gravitational attraction from the moon and etc). Then by assuming that fact, by (15): $\mathrm{dr}=1 \mathrm{~km}$.

Then $\mathrm{c}^{2} \mathrm{~d} \tau^{2}=\left(1-\left(\mathrm{r}_{\mathrm{s}} / \mathrm{r}\right)\right) \mathrm{c}^{2} \mathrm{dt}^{2}-\left(1-\left(\mathrm{r}_{\mathrm{s}} / \mathrm{r}\right)\right)^{-1} \mathrm{dr}^{2}-50.6944 * 10^{6}+4.4856^{*} 10^{4} * \mathrm{dr}-8.9225^{*} \mathrm{dr}^{2}$

$=\left(1-\left(1.5555 * 10^{-63} * \mathrm{~V} / 7.9 * 10^{6}\right)\right)\left(2.998 * 10^{8}\right)^{2} \mathrm{dt}^{2}$

$-\left(1-\left(1.5555 * 10^{-63} * \mathrm{~V} / 7.9 * 10^{6}\right)\right)^{-1} 1000^{2}-50.6944 * 10^{6}+4.4856^{*} 10^{4} * 1000-8.9225 *$ $1000^{2}$

But the volume of the dark energy content near to the satellite is V. Since the dark energy spreads all across the universe, it is strong. Therefore at least we want to consider $\mathrm{V}=\left(10^{10} \mathrm{~m}\right)^{3}$ $=10^{30} \mathrm{~m}^{3}$

By (16): $\mathrm{c}^{2} \mathrm{~d} \tau^{2}=\left(1-\left(1.5555 * 10^{-63} * 10^{30} / 7.9 * 10^{6}\right)\right) \mathrm{c}^{2} \mathrm{dt}^{2}-$

$\left(1-\left(1.5555 * 10^{-63} * 10^{30} / 7.9 * 10^{6}\right)\right)^{-1} * 1000^{2}-50.6944 * 10^{6}+4.4856^{*} 10^{4} * 1000-8.9225 *$ $1000^{2}$

$=\left(1-\left(1.969 * 10^{-40}\right)\right) \cdot \mathrm{c}^{2} \mathrm{dt}^{2}-\left(1-\left(1.969 * 10^{-40}\right)\right)^{-1} * 10^{6}+(-50.6944+44.856-8.9225)^{*}$ $10^{6}$

$=(0.99999999999999) \cdot \mathrm{c}^{2} \mathrm{dt}^{2}-(1 / 0.99999999999999) * 10^{6}-14.7609 * 10^{6}$

Thus, $\mathrm{c}^{2} \mathrm{~d} \tau^{2}=(0.99999999999999) . \mathrm{c}^{2} \mathrm{dt}^{2}-(1 / 0.99999999999999) * 10^{6}-14.7609 * 10^{6}$

$=(0.99999999999999) \cdot \mathrm{c}^{2} \mathrm{dt}^{2}-(1.00000000000000001) * 10^{6}-14.7609 * 10^{6}$

$=(0.99999999999999) \cdot \mathrm{c}^{2} \mathrm{dt}^{2}-\left(15.76090000000001 * 10^{6}\right)$

Thus $\mathrm{d} \tau^{2}=(0.99999999999999) . \mathrm{dt}^{2}-\left[0.157609 * 10^{8} /\left((2.998)^{2} * 10^{16}\right)\right]$

$\left.=(0.99999999999999) \cdot \mathrm{dt}^{2}-\left[0.01754 * 10^{-8}\right)\right]$

Thus $\left.\mathrm{d} \tau^{2}=(0.99999999999999) . \mathrm{dt}^{2}-\left[1.754 * 10^{-10}\right)\right]$

Thus $\mathrm{d} \tau^{2} / \mathrm{dt}^{2}=0.99999999999999-\left[1.754 * 10^{-10} / \mathrm{dt}^{2}\right]$ 
Then $\mathrm{d} \tau / \mathrm{dt}=(1 / \mathrm{dt}) * \sqrt{ }\left(0.999999999999 . \mathrm{dt}^{2}-1.754 * 10^{-10}\right)$

Here $\tau$ is the proper time measured by the clock at A (Clock located with the high gravity objecthigh gravity object is the content of dark matter/energy and near to that dark energy content, the satellite has located). And here $\mathrm{d} \tau$ is the time duration which the satellite emits two consecutive EM waves towards the Earth.

***But remember, high gravity object is the content of dark matter/energy and near to that dark energy content, the satellite has located.

And here, $\mathbf{t}$ is the improper time coordinate measured by $\mathrm{O}$ (measured by a stationary clock located far from the massive body A).

let's consider $\mathrm{d} \tau=10^{-4}$ (seconds)

Then by (17): $10^{-4} / \mathrm{dt}=(1 / \mathrm{dt}) * \sqrt{ }\left(0.999999999999 . \mathrm{dt}^{2}-1.754^{*} 10^{-10}\right)$

Then $1 / 10000=\sqrt{ }\left(0.999999999999 . \mathrm{dt}^{2}-1.754 * 10^{-10}\right)$

Then $(1 / 10000)^{2}=0.999999999999 . \mathrm{dt}^{2}-1.754 * 10^{-10}$

Then $10^{-8}+1.754 * 10^{-10}=0.999999999999 . \mathrm{dt}^{2}$

Then $\left[1.01754 * 10^{-8} / 0.999999999999\right]=\mathrm{dt}^{2}$

Then $1.01754 * 10^{-8}=\mathrm{dt}^{2}$

Thus $\mathrm{dt}=1.00873 * 10^{-4}$. Thus proper time $\mathrm{d} \tau=10^{-4} \mathrm{~s}$ and improper time $\mathrm{dt}=1.00873 * 10^{-4}$ (18)

Where $\mathrm{dt}$ is the time to receive two consecutive EM waves by $\mathrm{O}$ as measuring by $\mathrm{O}$.

Therefore the frequency $\left(\mathrm{f}_{1}\right)$ of sending EM waves by A towards $\mathrm{O}=1 / \mathrm{d} \tau=10^{4} \mathrm{~Hz}$

The frequency $\left(\mathrm{f}_{2}\right)$ of receiving the $\mathrm{EM}$ waves by $\mathrm{O}=1 / \mathrm{dt}=0.99135 * 10^{4} \mathrm{~Hz}$ 
Then by (19), wave length of sending EM waves by $\mathrm{A}=\lambda_{1}=2.998 * 10^{8} / 10^{4}=29980 \mathrm{~m} \ldots$..(21)

Then by (20) wave length of receiving EM waves by $\mathrm{O}=\lambda_{2}=2.998 * 10^{8} /\left(0.99135 * 10^{4}\right)=$ $30242 \mathrm{~m}$

Then the energy $\left(\mathrm{E}_{1}\right)$ of sending $\mathrm{EM}$ waves by $\mathrm{A}=\mathrm{hf}_{1}=6.626 * 10^{-34} * 10^{4}=6.626 * 10^{-30}$ ......(23)

The energy $\left(\mathrm{E}_{2}\right)$ of receiving $\mathrm{EM}$ waves by $\mathrm{O}=\mathrm{hf}_{2}=6.626^{*} 10^{-34} * 0.99135^{*} 10^{4}=6.5687 * 10^{-30}$ (24)

Then by (23), (24) energy difference of sending and receiving EM waves (due to the influence to the EM waves, sending by the satellite from the dark matter/energy nearby to the satellite) $=\left(\mathrm{E}_{1}-\mathrm{E}_{2}\right)=5.73 * 10^{-32}$ Jules

mass $\mathrm{m}$ of the satellite with orbiting velocity $7120 \mathrm{~m} / \mathrm{s}=\mathrm{m}_{0} / \sqrt{ }\left(1-\left(7120 / 2.998 * 10^{8}\right)\right)=$

$\mathrm{m}_{0} / \sqrt{ } 0.999762=\mathrm{m}_{0} / 0.999881=1.00012 \mathrm{~m}_{0}$. Thus $\mathrm{m}=1.00012 \mathrm{~m}_{0}$

Where $m_{0}$ is the rest mass of the satellite.

Then the gravitational potential energy of the satellite $=$

- GM'. m / r $=-\left[6.674 * 10^{-11} * 5.972 * 10^{24} * 1.00012 \mathrm{~m}_{0}\right] /(1.5+6.4) * 10^{6}=-5.052 * 10^{7} \mathrm{~J}$

Kinetic energy of the satellite $=\mathrm{m} . \mathrm{U}^{2} / 2=\left(1.00012 \mathrm{~m}_{0}\right) \cdot\left(7120^{2} / 2\right)=2.5350242 * 10^{7} \mathrm{~J}(\mathrm{By}$ 26)

Total THELORETICAL energy of the satellite $=-2.517 * 10^{7} \mathrm{~J}$

Let $\mathbf{E}_{1}{ }_{1}$ is the Observed energy of the satellite (that obtained by analyzing the EM waves coming and from the satellite). To calculate $\mathrm{E}_{1}{ }_{1}$, I used the EM waves received by $\mathrm{O}$.

Then for some $\mathrm{K}$ positive real number value, $\mathrm{E}^{\prime}{ }_{1}=\mathrm{E}_{1} * \mathrm{~K}=\left(\mathrm{E}_{2}+5.73 * 10^{-32}\right) * \mathrm{~K}$.

Where $E_{1}$ is the energy of the sending EM waves by the satellite. 
Then $\left(\mathrm{E}_{1}^{\prime} / \mathrm{K}\right)-5.73 * 10^{-32}=\mathrm{E}_{2}=6.5687 * 10^{-30}$

Then $\left(\mathrm{E}^{\prime}{ }_{1} / \mathrm{K}\right)=6.626 * 10^{-30}$.

Thus $\mathrm{E}_{1}{ }_{1}=6.626 * 10^{-30} * \mathrm{~K} ;$ Where $\mathrm{K}$ is a real number value

In order to know the value of $\mathrm{K}$, we have to consider a well-known and already calculated value of an energy of a planet/star and the detected energy of EM waves (those emitted by the planet/star and by considering that $\mathrm{K}$ is a constant).

Then for that planet/star, $\mathrm{K}=$

Observed energy of the planet / energy calculated by considering the sending EM waves by the planet

But we can theoretically calculate, the total energy at the surface of the Earth. But also we can measure the total energy at the surface of the Earth, by measuring the EM waves sending by the Earth by staying on the Earth. There should not be any considerable difference between those theoretically calculated value and measured value, since there is no any influence for the considering EM waves (those are sending by the Earth) by any dark energy (i.e. there is no any gravitational redshift that influences on the EM waves near to the surface of the Earth when the detector of EM wave also on the Earth, AS THE ASSUMPTION).

Therefore,

Theoretically calculated total energy of the surface of the Earth $=$ The observed total energy of the surface of the Earth

Theoretically calculated total energy of the surface of the Earth (that has been calculated by scientists before $)=174074$ terawatts $=174074 * 10^{12}=1.74 * 10^{17} \mathrm{~J} \mathrm{~s}^{-1}$ 
But the energy density (D) of an EM wave can be written as : (1/2).€. $E_{l}^{2}$. Where $\epsilon$ is the permittivity of the space near to the surface of the Earth. $\mathrm{E}_{l}$ is the electric field of the EM wave near to the surface of the Earth.

But the common EM waves in the Earth's surface should be infrared radiations. Average electric field of an (infrared) $\mathrm{EM}$ wave $=3.000 * 10^{-12} \mathrm{~N} / \mathrm{C}$

Thus the average energy density (D) of an EM wave near to the surface of the Earth can be written as:

$\mathrm{D}=(1 / 2) . \epsilon . \mathrm{E}_{l}^{2}=(1 / 2) * 8.85 * 10^{-12} *\left(3.000 * 10^{-12}\right)^{2}=39.825 * 10^{-36}$

Then the total average energy of the EM waves sending near to the surface of the Earth during a second $=$

$-39.825 * 10^{-36} * 4 * \pi *\left(6.4 * 10^{6}\right)^{2}=-20501 * 10^{-24}=-2.0501 * 10^{-20}$

By (30):

Then for the Earth, $\mathrm{K}=$

Observed energy of the Earth per second /energy of the sending EM waves by the Earth per second

$=$ Theoretically calculated total energy of the surface of the Earth / energy of the sending EM waves by the Earth (by 30.1)

Thus by considering the Earth; $\mathrm{K}=1.74 * 10^{17} \mathrm{~J} \mathrm{~s}^{-1} /\left(-2.0501 * 10^{-20}\right) \mathrm{J} \mathrm{s}^{-1}=-0.8487 * 10^{37}$ $=-8.487 * 10^{36}$

By (32) and (29): $\mathrm{E}^{\prime}{ }_{1}=-6.626 * 10^{-30} * 8.487 * 10^{36}=-5.624 * 10^{7}$

Thus $\mathrm{E}_{1}=-5.624 * 10^{7} \mathrm{~J}$ 


\subsection{Result Evaluation of Methodology part 5}

By (27) and (33):

Total THELORETICALLY calculated energy of the satellite $=-2.517 * 10^{7} \mathbf{J}$ ..............(27)

The Observed energy of the satellite $=-5.624 * 10^{7} \mathrm{~J}$

Therefore according to the above calculations as in (27) and (33), there is a difference between calculated energy of the satellite and the theoretical energy of the satellite. That causes by the dark energy/ dark matter near to the satellite that is orbiting around the Earth.

Although the satellite is orbiting near to the Earth compare to the other stellar objects in the Milky way, there is an influence to the light rays those are propagating near to the satellite by the dark energy/ dark matter those are surrounding to the satellite. But cosmological theories explain that the dark energy/dark matter content of the universe is more than $90 \%$ of the total energy/matter content of the whole universe.

Therefore we can apply this mathematical method to explain more observations in astrophysics/cosmology and in physics as well.

But I obtained the final result by considering LEO satellites. But by using similar calculation method, we can prove the result for any other satellite that is orbiting around the Earth.

The dark energy/dark matter causes a difference between the observed energy of satellites flying by Earth and the value predicted by the theory.

The strength of the considering dark matter/ dark energy amount near to the satellite may cause a large and much considerable difference between the observed energy of satellites and the value predicted by the theory. 


\section{Methodology part 6}

\subsection{Notations of Methodology part 6}

$\mathrm{G}=$ the Newton's universal gravitational constant

$\mathrm{m}=$ the mass of $\mathrm{S}$

$\mathrm{M}=$ the mass of the black hole of the galaxy which the star S has located

$\mathrm{D}=$ the distance between $\mathrm{S}$ and the black hole of the galaxy which the star $\mathrm{S}$ has located

$\mathrm{m}_{\mathrm{i}}=$ the mass of the ' $\mathrm{i}$ ' th object nearby to $\mathrm{S}$

$r_{i}=$ the distance between $S$ and ' $i$ ' th matter object at time $t$

$\mathrm{F}_{1}=$ the magnetic force acting between $\mathrm{S}$ and the black hole

$\mathrm{F}_{2}=$ the summation of magnetic forces those are acting between $\mathrm{S}$ and $\mathrm{m}_{\mathrm{i}}$ when there is an internal magnetic field with 'i'th object.

$\mu_{0}=$ the permeability of space, which equals to $4 \pi^{*} 10^{-7} \mathrm{~T} \cdot \mathrm{m} / \mathrm{A}$

$\mathrm{M}_{1}, \mathrm{M}_{2}=$ magnetization of the virtual equivalent magnets

$\mathrm{R}_{1}, \mathrm{R}_{2}=$ the radiuses of two magnets in meters

$\mathrm{x}=$ the distance between the two virtual magnets in meters

$L_{1}, L_{2}=$ the lengths of two magnets in meters

$X=$ scale factor of the universe

$\mathrm{M}_{\mathrm{de}}=$ mass of the dark matter in a considering volume of space

$\rho_{\mathrm{de}}=$ dark matter density 
BUT DO NOT COMPARE THE EQUATION NUMBERS AND THE SYMBOLS OTHER

PARTS IN THE RESEARCH METHODOLOGY AND IN THIS METHODOLOGY

PART NUMBER 06.

\subsection{Content of the Methodology part 6}

Dark matter is different from ordinary matter such as fermions and bosons in the universe.

Dark matter has never been directly observed; however, its existence would explain a number of astronomical observations. The name refers to the fact that it does not emit or interact with observable electromagnetic radiation, such as light, and thus invisible to the entire electromagnetic spectrum.

Although dark matter has not been directly observed, its existence and properties are inferred from unexplained mass in gravitational lensing calculations, which affects the motions of baryonic matter and light. It influences the universe's large-scale structure, the formation of galaxies, and affects of the cosmic microwave background.

The standard model of cosmology implies that the total mass-energy of the universe contains $4.9 \%$ ordinary matter, $26.8 \%$ dark matter and $68.3 \%$ dark energy.

Dark matter primarily consists of weakly interacting massive particles those interact only with weak and gravitational forces.

Since dark matter deals with the gravitational force, those dark matter is capable to control gravitational systems in the distant Universe. But according to the standard model of cosmology, dark matters spread all across the universe. But recently, scientists have discovered that the universe that we are currently living is expanding with an accelerating rate. But scientists are in the position that the accelerating expansion of the universe causes by the dark energy/dark matter. Therefore in general, dark matter is a form of matter that causes gravitational repulsion across the universe. 
Since the dark matters are almost everywhere in the universe, dark matter can affect to the motion of solar and planetary systems in the universe. Therefore there may be a difference between observed and theoretical speeds of the stars revolving around the centers of Galaxies.

Let's consider an arbitrary star (S) chosen from an arbitrary galaxy. Then there are large number of gravitational objects nearby to S. But scientists haven't discovered a direct evidence that confirms dark matter in the universe. As I previously mentioned, dark matters are repulsive gravity matter type while ordinary matters are attractive gravity matter type.

Let's try to find the total force (theoretically) acting on $\mathrm{S}$ without considering the dark matter/dark energy in the surrounding environment at time t. i.e. assume that there is no any influence from dark energy/dark matter on the star S.

Then the total force $(\mathrm{F})$ acting on $\mathrm{S}$ ( $\underline{\text { theoretically }})=$

$\mathrm{F}=\mathrm{GmM} / \mathrm{D}^{2}+\Sigma\left[\mathrm{Gm} \cdot \mathrm{m}_{\mathrm{i}} / \mathrm{r}_{\mathrm{i}}^{2}\right] \cdot \cos \phi+\mathrm{F}_{1}+\mathrm{F}_{2}$

Here let's denote $\mathrm{GmM} / \mathrm{D}^{2}=\mathrm{F}_{1}{ }_{1}$ and $\Sigma\left[\mathrm{Gm} . \mathrm{m}_{\mathrm{i}} / \mathrm{r}_{\mathrm{i}}{ }^{2}\right]=\mathrm{F}_{2}{ }_{2}$

Here $\phi$ is the angle between the direction of $\mathrm{F}_{1}{ }_{1}$ and $\mathrm{F}_{2}{ }_{2}$

Where $\mathrm{G}$ is the Newton's universal gravitational constant, $\mathrm{m}$ is the mass of $\mathrm{S}, \mathrm{M}$ is the mass of the black hole of the galaxy which the star S has located, D is the distance between $\mathrm{S}$ and the black hole of the galaxy which the star $\mathrm{S}$ has located, $\mathrm{m}_{\mathrm{i}}$ is the mass of the ' $\mathrm{i}$ ' th object nearby to S. i.e. ' $i$ ' th object is being gravitationally influence on $S$. $r_{i}$ is the distance between $S$ and ' $i$ ' th matter object at time t, $F_{1}$ is the magnetic force acting between $S$ and the black hole (because usually there is a magnetic field of a star in the universe and there is a magnetic field of a black hole also), $F_{2}$ is the summation of magnetic forces those are acting between $S$ and $m_{i}$ when there is an internal magnetic field with ' $i$ 'th object.

Thus $\mathrm{F}=\mathrm{GmM} / \mathrm{D}^{2}+\Sigma\left[\mathrm{Gm} \cdot \mathrm{m}_{\mathrm{i}} / \mathrm{r}_{\mathrm{i}}^{2}\right] \cdot \cos \phi+$

$\left(\pi \mu_{0} / 4\right)^{*}\left(\mathrm{M}_{1} \cdot \mathrm{M}_{2} \cdot \mathrm{R}_{1}^{2} \cdot \mathrm{R}_{2}^{2}\right) *\left[\frac{1}{x^{2}}+\frac{1}{(x+L 1+L 2)^{2}}-\frac{1}{(x+L 1)^{2}}-\frac{1}{(x+L 2)^{2}}\right] \cdot \cos \sigma+$

$\left(\pi \mu_{0} / 4\right)^{*} \Sigma\left(\mathrm{M}_{1} \cdot \mathrm{M}_{\mathrm{i}} \cdot \mathrm{R}_{1}{ }^{2} \cdot \mathrm{R}_{\mathrm{i}}^{2}\right) *\left[\frac{1}{x i^{2}}+\frac{1}{(x i+L 1+L i 2)^{2}}-\frac{1}{(x i+L 1)^{2}}-\frac{1}{(x i+L i 2)^{2}}\right] * \cdot \cos \theta_{\mathrm{i}}$ ...(01) 
Here $\mathrm{F}_{1}=\left(\pi \mu_{0} / 4\right)^{*}\left(\mathrm{M}_{1} \cdot \mathrm{M}_{2} \cdot \mathrm{R}_{1}^{2} \cdot \mathrm{R}_{2}^{2}\right) *\left[\frac{1}{x^{2}}+\frac{1}{(x+L 1+L 2)^{2}}-\frac{1}{(x+L 1)^{2}}-\frac{1}{(x+L 2)^{2}}\right]$

and $\mathrm{F}_{2}=\left(\pi \mu_{0} / 4\right)^{*} \Sigma\left(\mathrm{M}_{1} \cdot \mathrm{M}_{\mathrm{i}} \cdot \mathrm{R}_{1}{ }^{2} \cdot \mathrm{R}_{\mathrm{i}}^{2}\right) *\left[\frac{1}{x i^{2}}+\frac{1}{(x i+L 1+L i 2)^{2}}-\frac{1}{(x i+L 1)^{2}}-\frac{1}{(x i+L i 2)^{2}}\right]$

*** Refer the appendix

Here $\phi$ is the angle between the direction of $\mathrm{F}_{1}{ }_{1}$ and $\mathrm{F}_{2}{ }_{2}$

$\sigma$ is the angle between the direction of $\mathrm{F}^{\prime}{ }_{1}$ and $\mathrm{F}_{1}$

And $\theta_{\mathrm{i}}$ is the angle between the direction of $\mathrm{F}_{1}{ }_{1}$ and magnetic force acting direction between $\mathrm{S}$ and 'i' th object nearby to $\mathrm{S}$.

$M_{i}$ is the magnetization of $i$ ' th object nearby to $S . R_{i}$ is the radius of the equivalent magnet in ith object nearby to $\mathrm{S}$. Here we consider $\mathrm{M}_{\mathrm{i}}>0$ for each ' $\mathrm{i}$ '.

$\mu_{0}$ is the permeability of space, which equals to $4 \pi^{*} 10^{-7} \mathrm{~T} \cdot \mathrm{m} / \mathrm{A}$

Here $\mathrm{M}_{1}, \mathrm{M}_{2}$ are identified as the magnetization of the virtual equivalent magnet in $\mathrm{S}$ and the magnetization of the equivalent magnet of the black hole respectively (the virtual magnets which produced by the magnetic field of the black hole and $\mathrm{S}$ respectively).

$\mathrm{R}_{1}, \mathrm{R}_{2}$ are the radiuses of two magnets in meters - identified as the radius of the virtual magnet in $\mathrm{S}$ and the radius of the equivalent magnet of the black hole respectively (the virtual magnets which produced by the magnetic field of the black hole and S).

$\mathrm{x}$ is the distance between the two virtual magnets in meters - identified as the distance between virtual magnet in $\mathrm{S}$ and the equivalent virtual magnet of the black hole.

$\mathrm{X}_{\mathrm{i}}$ is the distance between the two virtual magnets in meters - identified as the distance between virtual magnet in $\mathrm{S}$ and the virtual magnet of the ' $i$ ' th object.

$L_{1}, L_{2}$ are the lengths of two magnets in meters- identified as the lengths of the magnet in $\mathrm{S}$ and the length of the virtual magnet of the black hole respectively (the virtual magnets which produced by the magnetic field of the black hole and S).

$\mathrm{L}_{\mathrm{i}, 2}$ is the length of two magnet in meters- identified as the length of the virtual magnet in 'i'th object. 
$R_{i}$ is the radius of the virtual magnet in the ' $i$ ' th object which is nearby to $S$.

$\mathrm{F}=\mathrm{GmM} / \mathrm{D}^{2}+\Sigma\left[\mathrm{Gm} \cdot \mathrm{m}_{\mathrm{i}} / \mathrm{r}_{\mathrm{i}}^{2}\right] \cdot \cos \phi+$

$\left(\pi \mu_{0} / 4\right) *\left(\mathrm{M}_{1} \cdot \mathrm{M}_{2} \cdot \mathrm{R}_{1}{ }^{2} \cdot \mathrm{R}_{2}^{2}\right) *\left[\frac{1}{x^{2}}+\frac{1}{(x+L 1+L 2)^{2}}-\frac{1}{(x+L 1)^{2}}-\frac{1}{(x+L 2)^{2}}\right] \cdot \cos \sigma$

$+\left(\pi \mu_{0} / 4\right)^{*} \Sigma\left(\mathrm{M}_{1} \cdot \mathrm{M}_{\mathrm{i}} \cdot \mathrm{R}_{1}{ }^{2} \cdot \mathrm{R}_{\mathrm{i}}^{2}\right) *\left[\frac{1}{x i^{2}}+\frac{1}{(x i+L 1+L i 2)^{2}}-\frac{1}{(x i+L 1)^{2}}-\frac{1}{(x i+L i 2)^{2}}\right] * \cdot \cos \theta_{\mathrm{i}}$

\section{Consider}

$$
\begin{aligned}
& \frac{1}{x^{2}}+\frac{1}{(x+L 1+L 2)^{2}}=\left[2 x^{2}+(L 1)^{2}+(L 2)^{2}+2 \cdot L 1 \cdot L 2+2 x \cdot L 1+2 \cdot x \cdot L 2\right] \frac{1}{x^{2}(x+L 1+L 2)^{2}} \\
& \frac{1}{(x+L 1)^{2}}+\frac{1}{(x+L 2)^{2}}=\left[2 x^{2}+(L 1)^{2}+(L 2)^{2}+2 L 1 \cdot x+2 \cdot L 2 \cdot x\right] \frac{1}{(x+L 1)^{2} \cdot(x+L 2)^{2}}
\end{aligned}
$$

But $x^{2}(x+L 1+L 2)^{2}=\mathrm{x}^{2}\left[\mathrm{x}^{2}+\mathrm{L}_{1}^{2}+\mathrm{L}_{2}^{2}+2 \cdot \mathrm{L}_{1} \cdot \mathrm{L}_{2}+2 \mathrm{x} \cdot \mathrm{L}_{1}+2 \mathrm{x} \cdot \mathrm{L}_{2}\right]$

$=x^{4}+x^{2} L_{1}^{2}+x^{2} L_{2}^{2}+2 \cdot x^{2} L_{1} \cdot L_{2}+2 x^{3} \cdot L_{1}+2 x^{3} L_{2}$

And $(x+L 1)^{2} \cdot(x+L 2)^{2}=\left(\mathrm{x}^{2}+\mathrm{L}_{1}^{2}+2 \cdot \mathrm{x} . \mathrm{L}_{1}\right)^{*}\left(\mathrm{x}^{2}+\mathrm{L}_{2}{ }_{2}+2 \cdot \mathrm{x} . \mathrm{L}_{2}\right)$

Thus obviously, $x^{2}(x+L 1+L 2)^{2}<(x+L 1)^{2} \cdot(x+L 2)^{2}$

Thus obviously $\frac{1}{x^{2}}+\frac{1}{(x+L 1+L 2)^{2}}-\left(\frac{1}{(x+L 1)^{2}}+\frac{1}{(x+L 2)^{2}}\right)>0$

Similarly, I can obtain, $\left[\frac{1}{x i^{2}}+\frac{1}{(x i+L 1+L i 2)^{2}}-\frac{1}{(x i+L 1)^{2}}-\frac{1}{(x i+L i 2)^{2}}\right]>0$.

But $\frac{1}{x i^{2}}<1$ in SI units and $\frac{1}{(x i+L 1+L i 2)^{2}}<1$ in SI units.

Thus By (01):

$\mathrm{F}=\mathrm{GmM} / \mathrm{D}^{2}+\Sigma\left[\mathrm{Gm} \cdot \mathrm{m}_{\mathrm{i}} / \mathrm{r}_{\mathrm{i}}^{2}\right] \cdot \cos \phi+$

$\left(\pi \mu_{0} / 4\right) *\left(\mathrm{M}_{1} \cdot \mathrm{M}_{2} \cdot \mathrm{R}_{1}{ }^{2} \cdot \mathrm{R}_{2}^{2}\right) *\left[\frac{1}{x^{2}}+\frac{1}{(x+L 1+L 2)^{2}}-\frac{1}{(x+L 1)^{2}}-\frac{1}{(x+L 2)^{2}}\right] \cdot \cos \sigma+$

$\left(\pi \mu_{0} / 4\right)^{*} \Sigma\left(\mathrm{M}_{1} \cdot \mathrm{M}_{\mathrm{i}} \cdot \mathrm{R}_{1}^{2} \cdot \mathrm{R}_{\mathrm{i}}^{2}\right) *\left[\frac{1}{x i^{2}}+\frac{1}{(x i+L 1+L i 2)^{2}}-\frac{1}{(x i+L 1)^{2}}-\frac{1}{(x i+L i 2)^{2}}\right] * \cdot \cos \theta_{\mathrm{i}}$ 
Thus by result (A):

$\mathrm{F}<\mathrm{GmM}+\Sigma\left[\mathrm{Gm} \cdot \mathrm{m}_{\mathrm{i}}\right]+\left(\mathrm{M}_{1} \cdot \mathrm{M}_{2} \cdot \mathrm{R}_{1}^{2} \cdot \mathrm{R}_{2}^{2}\right)+\Sigma\left(\mathrm{M}_{1} \cdot \mathrm{M}_{\mathrm{i}} \cdot \mathrm{R}_{1}{ }^{2} \cdot \mathrm{R}_{\mathrm{i}}^{2}\right)$

(Because $\cos \phi, \cos \sigma, \cos \theta_{i}<1$. And $r_{i}>1$ meter for all ' $i$ ' and $D>1$ meter and $\left(\pi \mu_{0} / 4\right)<$ 1) in SI units.

By (02): $\mathrm{F}<\mathrm{GmM}+\Sigma\left[\mathrm{Gm} \cdot \mathrm{m}_{\mathrm{i}}\right]+\left(\mathrm{M}_{1} \cdot \mathrm{M}_{2} \cdot \mathrm{R}_{1}{ }^{2} \cdot \mathrm{R}_{2}^{2}\right)+\Sigma\left(\mathrm{M}_{1} \cdot \mathrm{M}_{\mathrm{i}} \cdot \mathrm{R}_{1}{ }^{2} \cdot \mathrm{R}_{\mathrm{i}}^{2}\right)$

$=\mathrm{Gm}\left(\mathrm{M}+\Sigma \mathrm{m}_{\mathrm{i}}\right)+\mathrm{M}_{1} \cdot \mathrm{R}_{1}^{2}\left[\mathrm{M}_{2} \cdot \mathrm{R}_{2}{ }_{2}+\Sigma \mathrm{M}_{\mathrm{i}} \cdot \mathrm{R}_{\mathrm{i}}{ }\right]$

$=\mathrm{GmM}_{0}+\mathrm{M}_{1} \cdot \mathrm{R}_{1}^{2}\left[\mathrm{M}_{2} \cdot \mathrm{R}_{2}^{2}+\Sigma \mathrm{M}_{\mathrm{i}} \cdot \mathrm{R}_{\mathrm{i}}^{2}\right] ;$

where $\mathrm{M}_{0}=\left(\mathrm{M}+\Sigma \mathrm{m}_{\mathrm{i}}\right)=$ mass of the planetary objects nearby to $\mathrm{S}$, excluding $\mathrm{S}$.

Thus $\mathrm{F}<\mathrm{GmM}_{0}+\mathrm{M}_{1} \cdot \mathrm{R}^{2}{ }_{1}\left[\mathrm{M}_{2} \cdot \mathrm{R}_{2}^{2}+\Sigma \mathrm{M}_{\mathrm{i}} \cdot \mathrm{R}_{\mathrm{i}}^{2}\right]$

But $\mathrm{S}$ is stable along its path of orbiting. Therefore $\mathrm{F}=\mathrm{mU}^{2} / \mathrm{D}^{\prime}$

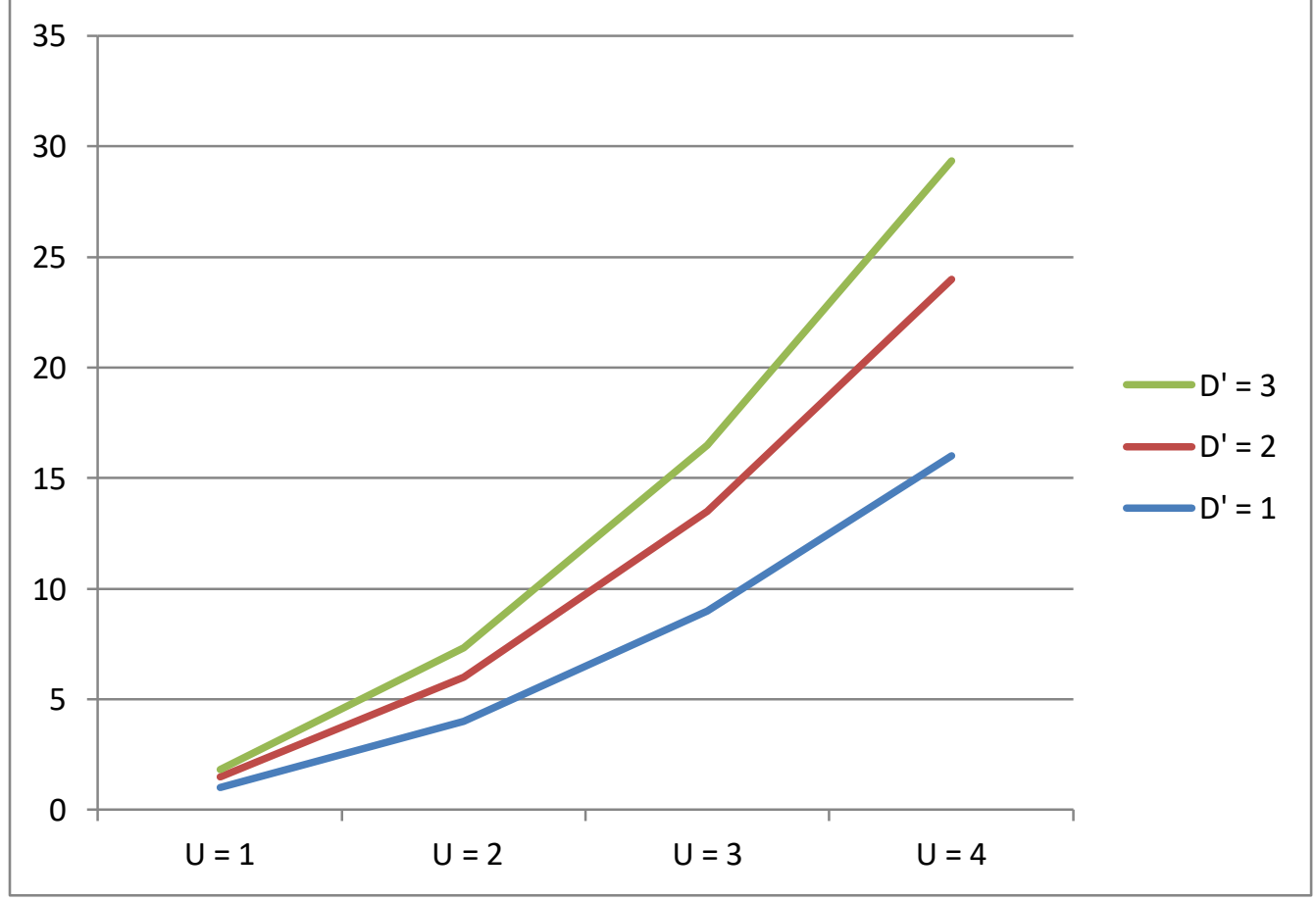

Graph 07: Variance of $F$ with respect to $U$ for different $D$ values 
$\mathrm{U}$ is the linear velocity of $\mathrm{S}$ that is theoretically calculated (along the orbital path of $\mathrm{S}$ ) with respect to the rest space within the galaxy which the star S has located. D' is the distance between $S$ and its total equivalent centrifugal force acting point in space ( $U$ is the velocity of $S$, when theoretically calculate the value of the star S's moving velocity- without considering the influence from the dark matter into account).

Then by (03): $\mathrm{mU}^{2} / \mathrm{D}^{\prime}<\mathrm{GmM}_{0}+\mathrm{M}_{1} \cdot \mathrm{R}^{2}{ }_{1}\left[\mathrm{M}_{2} \cdot \mathrm{R}_{2}{ }_{2}+\Sigma \mathrm{M}_{\mathrm{i}} \cdot \mathrm{R}_{\mathrm{i}}^{2}\right]$

Thus $\mathrm{U}^{2}<\left[\mathrm{GM}_{0} \cdot \mathrm{D}^{\prime}\right]+\left(\mathrm{D}^{\prime} / \mathrm{m}\right)^{*} \mathrm{M}_{1} \cdot \mathrm{R}_{1}^{2}\left[\mathrm{M}_{2} \cdot \mathrm{R}^{2}{ }_{2}+\Sigma \mathrm{M}_{\mathrm{i}} \cdot \mathrm{R}^{2}{ }_{\mathrm{i}}\right]$

$<\left[\mathrm{GM}_{0} \cdot \mathrm{D}^{\prime}\right]+\mathrm{D}^{\prime} * \mathrm{M}_{1} \cdot \mathrm{R}^{2}{ }_{1}\left[\mathrm{M}_{2} \cdot \mathrm{R}_{2}^{2}+\Sigma \mathrm{M}_{\mathrm{i}} \cdot \mathrm{R}_{\mathrm{i}}^{2}\right] \quad($ Because $\mathrm{m}>1 \mathrm{~kg})$

Thus $\mathrm{U}^{2}<\left\{\mathrm{GM}_{0}+\mathrm{M}_{1} \cdot \mathrm{R}_{1}^{2}\left[\mathrm{M}_{2} \cdot \mathrm{R}_{2}^{2}+\Sigma \mathrm{M}_{\mathrm{i}} \cdot \mathrm{R}_{\mathrm{i}}^{2}\right]\right\} . \mathrm{D}^{\prime}$

Here $\mathrm{U}$ is the theoretically calculated linear velocity of $\mathrm{S}$ without the consideration of dark matter / dark energy into account.

Now let's try to find the observable linear velocity of S by considering the electromagnetic radiations those detectable using a telescope. i.e. let's try to analyze the electromagnetic spectrum as below.

You all know that scientists able to use a spectrometer to analyze the electromagnetic waves coming from the distant universe. By using the resolution images, they are capable to identify the chemicals in the distant object's surface if they analyze the emission spectrum. Similar to that, after analyzing the emission spectrum of the star S, researcher is capable to calculate the wavelengths of two different regions of the emission spectrum. But according to the Doppler Effect, researchers cannot estimate the exact wavelengths of the chemicals of the star by neglecting the Doppler Effect. Thus we should take red shift due to the universal expansion plus the red shift/blue shift due to the star S's orbital velocity and the rotation along the axis of rotation.

Let's consider an emission spectrum of S's EM waves that has taken at time T. 
Let, $f_{1}$ is the frequency of emission line $L_{1}$ that has estimated using the emission spectrum taken at time $\mathrm{T}$. $\mathrm{f}_{0}$ is the relevant exact original frequency of that considered photon that has emitted by the star S.

Let, $\mathrm{f}_{2}$ is the frequency of emission line $\mathrm{L}_{2}$ that has estimated using the emission spectrum taken at time $\mathrm{T}$. $\mathrm{f}{ }^{\prime}{ }_{0}$ is the relevant exact original frequency of the considered photon (relevant to emission line $\mathrm{L}_{2}$ ) that has been emitted by the star $\mathrm{S}$.

But the photons associated with line $\mathrm{L}_{1}$ and $\mathrm{L}_{2}$ have received simultaneously. Then, according to the relativistic Doppler Effect:

$\mathrm{f}_{1}=\mathrm{f}_{0} * \sqrt{\frac{1-\frac{V b+V \cdot \cos \theta}{C}}{1+\frac{V b+V \cdot \cos \theta}{C}}}$

We place the telescope and other wave length measuring instruments in the rest space (within the galaxy which the star $\mathrm{S}$ has located).

Where, $\mathrm{V}_{\mathrm{b}}$ is the relative velocity of the stars with respect to the detector, due to the universal expansion that might caused by the Big Bang Explosion. Also, $\mathrm{V}$ is the moving (tangential) velocity of the star $\mathrm{S}$ when the detecting photon was emitting by the star $\mathrm{S}$. $\theta$ is the angle between the line joining the detector and the star $\mathrm{S}$ and the line parallel to the moving (tangential) velocity direction of the star $\mathrm{S}$ when the detecting photon was emitting. $\mathrm{C}$ is the speed of light.

Also,

$\mathrm{f}_{2}=\mathrm{f}^{\prime}{ }_{0} * \sqrt{\frac{1-\frac{V b+V \cdot \cos \theta}{C}}{1+\frac{V b+V \cdot \cos \theta}{C}}}$.

Depending on the detection of the photon at time $\mathrm{T}, \mathrm{V}$ may negative or positive.

By equation (05) and (06): $\mathrm{f}_{1} / \mathrm{f}_{2}=\mathrm{f}_{0} / \mathrm{f}{ }_{0}$

By analyzing the spectrum, we can calculate the value of $f_{1} / f_{2}$.

Let's consider $\mathrm{f}_{1} / \mathrm{f}_{2}=\mathrm{x}$

Then $\mathrm{f}_{0} / \mathrm{f}^{\prime}{ }_{0}=\mathrm{x}$. But $\mathrm{f}_{0}$ and $\mathrm{f}_{0}{ }_{0}$ are non-shifted frequency values. Then by comparing laboratory measurements of photon frequencies of various chemicals with the value $\mathrm{x}$; we can identify what 
should be the chemicals associated with the frequency $\mathrm{f}_{0}$ and $\mathrm{f}{ }^{\prime}{ }_{0}$. Then we can estimate the values of $\mathrm{f}_{0}$ and $\mathrm{f}_{0}$. Then by the equation (05), we can calculate the value of

$\sqrt{\frac{1-\frac{V b+V \cdot \cos \theta}{C}}{1+\frac{V b+V \cdot \cos \theta}{C}}}=\mathrm{y}$

But in order to calculate $\mathrm{V}_{\mathrm{b}}$, we should know the distance between the detector and the star $\mathrm{S}$ when the detecting photon (came from the star S) was emitting by the star S. There are several ways to calculate the distance to a faraway object.

Let's consider the below method: By using spectral classes, researcher has the capability to identify the color of the particular star S and then, they able to measure the surface temperature of the particular star S. By Hertzsprung-Russell diagram the researcher able to calculate the absolute brightness (M_) of the star S.

After measuring the apparent brightness (m') of the star $\mathrm{S}$, by using the equation $(5 . \log 10 \mathrm{~B}=$ m'-M_ -10 ) they able to calculate the distance to the star S (B) at the detecting photon emitted moment.

Especially this method is valid exactly only for the stars those are comparably closer to the detector. Then we can say the value of $\mathrm{V}_{\mathrm{b}}$, when the detected photon was emitting by the star $\mathrm{S}$ and the present moment are same. Also then only we can say the value of B, when the detected photon emitted by the star S and the value of B at the present moment are roughly same.

Then by the Hubble's equation for universal expansion, $V_{b}=H$. B, we can calculate the value $V_{b}$. 


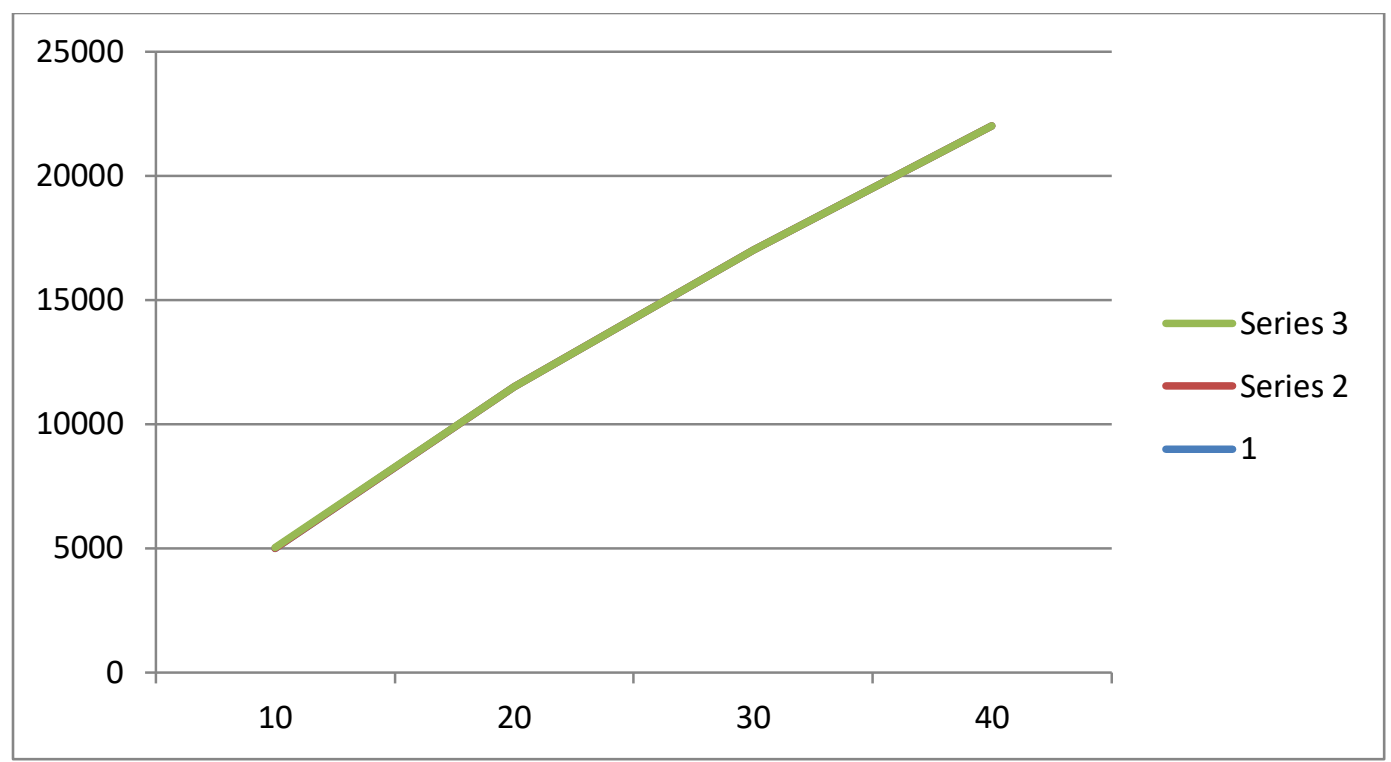

\section{Graph 08: Hubble's Equation of Universal Expansion plotting}

Then by equation (08), we can calculate the value $\mathrm{V} \cdot \cos \theta=\mathrm{k}$

Where $\theta$ is the angle between the line joining the detector and the star $\mathrm{S}$ and the line parallel to the (tangential) velocity direction of the star $S$ (the tangential velocity consists two different velocities: 1. the velocity of the star $S$ due to its motion through space-time 2. the tangential velocity due to the spinning of the star $\mathrm{S}$. i.e. the considering tangential velocity of the star $\mathrm{S}$ is a combination of those two tangential velocities of the star S) when the detecting photon was emitting. But we know that $\mathrm{V}$ is the moving (tangential) velocity of the star $\mathrm{S}$ when the detecting photon was emitting by the star S. But V is the observational moving (tangential) velocity of the star $\mathrm{S}$ when the detecting photon was emitting by the star S. Since I consider S as a star nearby to the detector, $\mathrm{V}$ is same as the observational moving (tangential) velocity of the star $\mathrm{S}$ at the moment of detecting the star S's electromagnetic waves.

But by (09), V. $\cos \theta=\mathrm{k}$ 
But we place the detector in the rest space in the galaxy that we consider. Then we can choose the place that we establish the detector as a place which gives us $\theta=0$. Because there are infinite number of places in the considering galaxy as which gives $\theta=0$.

Then for such situation, $\mathrm{k}=\mathrm{V}$. But we can calculate the value of $\mathrm{k}$ using the previous arguments and steps. Then we know the value of $\mathrm{V}$. Here $\mathrm{V}$ is the observational moving (tangential) velocity of the star $\mathrm{S}$ when the detecting photon was emitting by the star $\mathrm{S}$.

Now let's try to calculate the value of V practically as below:

By analyzing the spectrum, we can calculate the value of $x\left(=f_{1} / f_{2}\right)$.

Then $\mathrm{f}_{0} / \mathrm{f}^{\prime}{ }_{0}=\mathrm{x}$. But $\mathrm{f}_{0}$ and $\mathrm{f}_{0}$ are non-shifted frequency values. Then by comparing laboratory measurements of photon frequencies of various chemicals with the value $\mathrm{x}$; we can identify what should be the chemicals associated with the frequency $\mathrm{f}_{0}$ and $\mathrm{f}{ }^{\prime}{ }_{0}$. Then we can estimate the values of $\mathrm{f}_{0}$ and $\mathrm{f}^{\prime}{ }_{0}$. Then by the equation we know the value of $\sqrt{\frac{1-\frac{V b+V \cdot \cos \theta}{C}}{1+\frac{V b+V \cdot \cos \theta}{C}}}=\mathrm{y}$.

After measuring the apparent brightness (m') of the star $\mathrm{S}$, by using the equation $(5 \cdot \log 10 \mathrm{~B}=$ m'-M_ -10 ) it is capable to calculate the distance to the star S (B) at the detecting photon emitted moment. Then we know the value of $B$. Then by $V_{b}=H . B$, we know the value of $V_{b}$. Here $\mathrm{H}$ is the Hubble's constant of the universe at the time of emitting the considered electromagnetic waves by the star $\mathrm{S}$ (that is roughly same as the Hubble's constant of the universe at this moment also).

Thus $V_{b}=H . B$. Then by the definition of $y$ :

$\mathrm{y}=\sqrt{\frac{1-\frac{H B+V \cdot \cos \theta}{C}}{1+\frac{H B+V \cdot \cos \theta}{C}}}$

But we place our detector at a place such that as it gives $\theta=0$. Thus $y=\sqrt{\frac{1-\frac{H B+V}{C}}{1+\frac{H B+V}{C}}}$ 
Then, $\mathrm{y}^{2}\left[1+\frac{H B+V}{C}\right]=\left[1-\frac{(H B+V)}{C}\right]$

Then, $\mathrm{y}^{2}[\mathrm{C}+H B+V]=[\mathrm{C}-\mathrm{HB}-\mathrm{V}]$

Thus, $\mathrm{V}=\left[\mathrm{C}-\mathrm{HB}-\mathrm{y}^{2} \cdot \mathrm{C}-\mathrm{y}^{2}\right.$. HB $] /\left(\mathrm{y}^{2}+1\right)$

But we already know the values $\mathrm{C}, \mathrm{y}, \mathrm{H}, \mathrm{B}$.

Thus we know the observational velocity value (V) of the star $\mathbf{S}$ for the considering observable situation.

Now let's try to find the dark energy amount nearby with the star $\mathrm{S}$ as below (which is not accounted when we were calculating the velocity of motion of star $\mathrm{S}$ theoretically):

Let's find the mass ( $\mathrm{M}_{\mathrm{de}}$ ) of the dark energy volume (the mass of the dark energy within some certain volume near to the star S) as below:

The dark energy density ( $\rho_{\mathrm{de}}$ ) of the Universe can be express as :

$\rho_{\mathrm{de}}=(\mathrm{A} / 2 \pi) \cdot(\hbar / \mathrm{c}) \cdot\left(\ddot{\mathrm{X}} / \lambda_{\pi}^{3}\right)$

where $\mathrm{A} \approx 2$ is a dimensionless constant; $\lambda_{\pi}=\left(\mathrm{h} / \mathrm{m}_{\pi} \mathrm{c}\right)$ is Compton wavelength of a pion and $\ddot{\mathrm{X}}$ the acceleration of the expansion of the Universe.

But the acceleration of the expansion of the Universe $(\ddot{X})$ is:

$\ddot{X}=(-4 \pi \mathrm{G} / 3) \cdot \mathrm{X}\left(\rho+3 \mathrm{p} / \mathrm{c}^{2}\right)+\mathrm{X} \cdot \Lambda \cdot \mathrm{c}^{2} / 3$

Where $\rho$ and $\mathrm{P}$ are the density and pressure of the cosmological fluid respectively. And $\mathrm{X}$ is the scale factor in the Friedmann equations. $\mathrm{G}$ is the universal gravitation constant, $\mathrm{C}$ is the speed of light, $\Lambda$ is the cosmological constant.

But the equation of state of the cosmological fluid is: $P_{n}=w_{n} \cdot \rho_{n} \cdot c^{2}$

Where the equation-of state-parameter $\mathrm{w}_{\mathrm{n}}$ is a constant. 
Radiation, matter and dark energy (when identified with cosmological constant) are modeled respectively with $\mathrm{w}_{\mathrm{rad}}=(1 / 3), \mathrm{w}_{\text {matt }}=0, \mathrm{w}_{\mathrm{de}}=-1$.

By (12) and (13):

$\ddot{\mathrm{X}}=(-4 \pi \mathrm{G} / 3) \cdot \mathrm{X}\left(-\frac{P}{c^{2}}+\frac{3 \cdot P}{c^{2}}\right)=(-8 \pi \mathrm{G} / 3) \cdot \mathrm{X} \cdot\left(\frac{P}{c^{2}}\right)+\mathrm{X} \cdot \Lambda c^{2} / 3$

Where $\mathrm{X}$ s the scale factor of the universe.

By (11): $\rho_{\mathrm{de}}=(\mathrm{A} / 2 \pi) \cdot(\hbar / \mathrm{c}) \cdot\left(\ddot{\mathrm{X}} / \lambda^{3}{ }_{\pi}\right)$ where $\ddot{\mathrm{X}}=(-8 \pi \mathrm{G} / 3) \cdot \mathrm{X} \cdot\left(\frac{P}{c^{2}}\right)+\mathrm{X} \cdot \Lambda \mathrm{c}^{2} / 3$

Then $\rho_{\mathrm{de}}=(\mathrm{A} / 2 \pi) \cdot(\hbar / \mathrm{c}) \cdot\left(\ddot{\mathrm{X}} / \lambda^{3}{ }_{\pi}\right)=(\mathrm{A} \cdot \hbar) /\left[2 . \pi \cdot \mathrm{c} \cdot \lambda^{3}\right] \cdot\left[(-8 \pi \mathrm{G} / 3) \cdot \mathrm{X} \cdot\left(\frac{P}{c^{2}}\right)+\mathrm{X} \cdot \Lambda \mathrm{c}^{2} / 3\right]$

$=(-4 / 3) \cdot[$ A.h.G.P.X $] /\left[\mathrm{c}^{3} \cdot \lambda_{\pi}^{3}\right]+\left(\mathrm{A} \hbar \cdot X /\left[2 \pi \cdot \lambda_{\pi}^{3}\right]\right) \cdot \Lambda \mathrm{c} / 3=\rho_{\mathrm{de}}$

But for the present and recent universe, $\mathrm{X}=1$.

Thus $\rho_{\mathrm{de}}=\left(\mathrm{A} \hbar /\left[2 \pi \cdot \lambda_{\pi}^{3}\right]\right) \cdot \Lambda \mathrm{c} / 3-(4 / 3) .[$ A.h.G.P $] /\left[\mathrm{c}^{3} \cdot \lambda^{3}\right]$

Thus $\rho_{\mathrm{de}} \approx\left(\hbar /\left[\pi \cdot \lambda_{\pi}^{3}\right]\right) \cdot \Lambda \mathrm{c} / 3-(8 / 3) .[\hbar \cdot G \cdot P] /\left[\mathrm{c}^{3} \cdot \lambda^{3} \pi\right]$

(Since $\mathrm{A} \approx 2$ )

But now we want to find the volume that the dark energy content is existing nearby to the star S. But the surface area of $S$ is $=4 \pi . J^{2}$, where $J$ is the mean radius of the star $S$. But we have to consider dark matter influence on $\mathrm{S}$, at least $10^{7} \mathrm{~km}$ away from $\mathrm{S}$.

Then the volume that the dark energy content is existing nearby to the star $S=4 \pi . J^{2} * 10^{10}$ meter $^{3}$

Then the mass of the amount of the dark energy which is influenced on $\mathrm{S}=$

$\mathrm{M}_{\mathrm{de}}=\left[\left(\hbar /\left[\pi \cdot \lambda_{\pi}^{3}\right]\right) \cdot \Lambda \mathrm{c} / 3-(8 / 3) \cdot[\hbar \cdot \mathrm{G} \cdot \mathrm{P}] /\left[\mathrm{c}^{3} \cdot \lambda^{3}{ }_{\pi}\right]\right] * 4 \pi \cdot \mathrm{J}^{2} * 10^{10}$

Where $\lambda_{\pi}=\left(\mathrm{h} / \mathrm{m}_{\pi} \mathrm{c}\right)=6.626 * 10^{-34} /\left(2.488 * 10^{-28} * 2.998 * 10^{8}\right)=.888 * 10^{-14}$

$\mathrm{P}=-5.2 * 10^{-10} \mathrm{~Pa}, \mathrm{c}=2.998^{*} 10^{8} \mathrm{~m} / \mathrm{s}, \mathrm{h}=6.626^{*} 10^{-34}$ in SI units , $\mathrm{G}=6.67 * 10^{-11}$,

$\Lambda=1.11 * 10^{-52}$ SI units. Usually for a star of median size, $\mathrm{J}=10^{9}$ meters 
Thus by (16):

$$
\begin{aligned}
& \left.\mathrm{M}_{\mathrm{de}}=\left[\left(\hbar /\left[\pi . \lambda_{\pi}^{3}\right]\right) . \Lambda \mathrm{c} / 3-(8 / 3) .[\hbar . \mathrm{G} . \mathrm{P}] /\left[\mathrm{c}^{3} . \lambda^{3}\right]\right]\right]^{*} 4 \pi . \mathrm{J}^{2} * 10^{10} \\
& =6.626^{*} 10^{-34} * 1.11 * 10^{-52} * 2.998 * 10^{8} * 4 * 3.142 * 10^{10} * 10^{18} /\left[3 * 3.142^{*}\left(.888 * 10^{-14}\right)^{3}\right] \\
& -(32 / 3) * 6.626 * 10^{-34} * 6.67 * 10^{-11} *\left(-5.2 * 10^{-10}\right) * 3.142 * 10^{10} * 10^{18} /\left[\left(2.998 * 10^{8}\right)^{3} *\left(.888 * 10^{-14}\right)^{3}\right] \\
& =1.3189 * 10^{-6}+7702 * 10^{-27} / 18.9 * 10^{-18}=1.3189 * 10^{-6}+.4075 * 10^{-6}=1.7264 * 10^{-6} \mathrm{~kg}
\end{aligned}
$$

Thus $\mathrm{M}_{\mathrm{de}}=1.7264 * 10^{-6} \mathrm{~kg}$

But we know that dark matters are gravitationally repulsive.

Thus the real force acting on $\mathrm{S}$ should be $=\mathrm{F}-\left[\mathrm{G} . \mathrm{m} . \mathrm{M}_{\mathrm{de}} / \mathrm{r}_{\mathrm{de}}^{2}\right]$

Here $r_{d e}$ is the distance between $S$ and the gravitational center of total $M_{d e}$.

The equation (18) indicates the real force that should be acting on $S$ (It should be same as the observational force acting on $\mathrm{S}$ )

By considering (3.1) we can say similarly, $\quad \mathrm{F}-\left[\mathrm{G} . \mathrm{m} . \mathrm{M}_{\mathrm{de}} / \mathrm{r}_{\mathrm{de}}^{2}\right]=\mathrm{mV}^{2} / \mathrm{D}$,

(Because V should be the real velocity of the star. Because I added the influence of dark matter into account to get the real force acting on the star S. With the addition of the dark matter force acting on $S$, we get the observable real velocity of the star $S$ though the relationship similar to (3.1).

Thus $\mathrm{V}^{2}=\left(\mathrm{D}^{\prime} / \mathrm{m} \cdot \mathrm{r}_{\mathrm{de}}^{2}\right) *\left(\mathrm{~F} \cdot \mathrm{r}_{\mathrm{de}}^{2}-\left[\mathrm{G} \cdot \mathrm{m} \cdot \mathrm{M}_{\mathrm{de}}\right]\right)$

By (10):

$V^{2}=\left[C-H B-y^{2} \cdot C-y^{2} \cdot H B\right]^{2} /\left(y^{2}+1\right)^{2}=\left(D^{\prime} / m \cdot r_{d e}^{2}\right) *\left(F \cdot r_{d e}^{2}-\left[G \cdot m \cdot M_{d e}\right]\right)$

Thus $F=\left[\mathrm{m} / \mathrm{D}^{\prime}\right]^{*}\left[\mathrm{C}-\mathrm{HB}-\mathrm{y}^{2} \cdot \mathrm{C}-\mathrm{y}^{2} \cdot \mathrm{HB}\right]^{2} /\left(\mathrm{y}^{2}+1\right)^{2}+\left[\mathrm{G} \cdot \mathrm{m} \cdot \mathrm{M}_{\mathrm{de}}\right] / \mathrm{r}_{\mathrm{de}}^{2}$ (19)

But by (3.1): $\quad F=m U^{2} / D^{\prime}$ 
Thus by (19):

$\left\{\mathrm{m} /\left[\left(\mathrm{y}^{2}+1\right)^{2} \cdot \mathrm{D}^{\prime}\right]\right\} *\left[\mathrm{C}-\mathrm{HB}-\mathrm{y}^{2} \cdot \mathrm{C}-\mathrm{y}^{2} \cdot \mathrm{HB}\right]^{2}+\left[\mathrm{G} \cdot \mathrm{m} \cdot \mathrm{M}_{\mathrm{de}}\right] / \mathrm{r}_{\mathrm{de}}^{2}=\mathrm{mU}^{2} / \mathrm{D}^{\prime}$

Thus $\left[1 /\left(\mathrm{y}^{2}+1\right)^{2}\right] *\left[\mathrm{C}-\mathrm{HB}-\mathrm{y}^{2} \cdot \mathrm{C}-\mathrm{y}^{2} \cdot \mathrm{HB}\right]^{2}+\mathrm{G} \cdot \mathrm{M}_{\mathrm{de}} \cdot\left(\mathrm{D}^{\prime} / \mathrm{r}_{\mathrm{de}}^{2}\right)=\mathrm{U}^{2}$ ...(20)

But by (04):

$\mathrm{U}^{2}<\left\{\mathrm{GM}_{0}+\mathrm{M}_{1} \cdot \mathrm{R}_{1}^{2}\left[\mathrm{M}_{2} \cdot \mathrm{R}_{2}^{2}+\Sigma \mathrm{M}_{\mathrm{i}} \cdot \mathrm{R}_{\mathrm{i}}^{2}\right]\right\} \cdot \mathrm{D}^{\prime}$

But by (10), $\left[1 /\left(\mathrm{y}^{2}+1\right)\right] *\left[\mathrm{C}-\mathrm{HB}-\mathrm{y}^{2} . \mathrm{C}-\mathrm{y}^{2} . \mathrm{HB}\right]=\mathrm{V}>0$.

Thus, $\mathrm{U}^{2}>\mathrm{G} \cdot \mathrm{M}_{\mathrm{de}} \cdot\left(\mathrm{D}^{\prime} / \mathrm{r}_{\mathrm{de}}^{2}\right)$

Thus, $\left\{\mathrm{GM}_{0}+\mathrm{M}_{1} \cdot \mathrm{R}_{1}{ }_{1}\left[\mathrm{M}_{2} \cdot \mathrm{R}_{2}^{2}+\Sigma \mathrm{M}_{\mathrm{i}} \cdot \mathrm{R}_{\mathrm{i}}^{2}\right]\right\} \cdot \mathrm{D}^{\prime}>\mathrm{G} \cdot \mathrm{M}_{\mathrm{de}} \cdot\left(\mathrm{D}^{\prime} / \mathrm{r}_{\mathrm{de}}{ }^{2}\right)$

(Because by (20.1) and (04))

Thus $\mathrm{GM}_{0}+\mathrm{M}_{1} \cdot \mathrm{R}_{1}^{2}\left[\mathrm{M}_{2} \cdot \mathrm{R}_{2}^{2}+\Sigma \mathrm{M}_{\mathrm{i}} \cdot \mathrm{R}_{\mathrm{i}}^{2}\right]>\mathrm{G} \cdot \mathrm{M}_{\mathrm{de}} / \mathrm{r}_{\mathrm{de}}^{2}$

By (20) and (10): $\mathrm{U}^{2}=\mathrm{V}^{2}+\mathrm{G} \cdot \mathrm{M}_{\mathrm{de}} \cdot\left(\mathrm{D}^{\prime} / \mathrm{r}_{\mathrm{de}}{ }^{2}\right)$

Here in (22), $\mathrm{U}$ is the theoretically calculated moving velocity of the star $\mathrm{S}$. And $\mathrm{V}$ is the moving velocity of $\mathrm{S}$ that was observationally calculated.

$\mathrm{D}^{\prime}$ is the distance between $\mathrm{S}$ and its total equivalent centrifugal force acting point in space (when theoretically calculate the value of the star S's moving velocity $(\mathbf{U})$ - without considering the influence from the dark matter into account). Therefore D' is certain at some certain time.

But for the chosen star S, the amount of the rest of the masses (excluding dark matter) is certain at some certain moment. But we consider $\mathrm{V}$ as the observable velocity of the star $\mathrm{S}$ ( $\mathrm{V}$ is its observable velocity at some moment. But $\mathrm{U}$ is the theoretically calculated velocity of the star S at the same moment whenever star's observable velocity was V).

Thus by (22): $U^{2}=V^{2}+G \cdot M_{d e} \cdot\left(D^{\prime} / r_{d e}^{2}\right)$. Thus $U^{2}-V^{2}=G \cdot M_{d e} \cdot\left(D^{\prime} / r_{d e}^{2}\right)$

Thus $\mathrm{V}^{2}-\mathrm{U}^{2}=\mathrm{E}_{\mathrm{de}} * \mathrm{D}^{\prime}$ 
Where $E_{\mathrm{de}}=-\mathrm{G} \cdot \mathrm{M}_{\mathrm{de}} \cdot\left(1 / \mathrm{r}_{\mathrm{de}}{ }^{2}\right)=$ Gravitational field due to the dark matter content nearby to the star $\mathrm{S}$.

Thus by (23): the theoretical and observable difference of the moving velocity of the arbitrary chosen star $\mathrm{S}$ is due to the gravitational filed that caused by the dark matter that is nearby to the star S (Because D’ is certain at some certain moment).

By (21): $\quad \mathrm{GM}_{0}+\mathrm{M}_{1} \cdot \mathrm{R}_{1}^{2}\left[\mathrm{M}_{2} \cdot \mathrm{R}_{2}^{2}+\Sigma \mathrm{M}_{\mathrm{i}} \cdot \mathrm{R}_{\mathrm{i}}^{2}\right]>\mathrm{G} \cdot \mathrm{M}_{\mathrm{de}} / \mathrm{r}_{\mathrm{de}}^{2}$

Thus $\mathrm{M}_{0}>\left(\mathrm{M}_{\mathrm{de}} / \mathrm{r}_{\mathrm{de}}^{2}\right)-\left[\left\{\mathrm{M}_{1} \cdot \mathrm{R}_{1}^{2}\left[\mathrm{M}_{2} \cdot \mathrm{R}_{2}{ }^{2}+\Sigma \mathrm{M}_{\mathrm{i}} \cdot \mathrm{R}_{\mathrm{i}}^{2}\right]\right\} / \mathrm{G}\right]$.

Thus $\left\{\mathrm{M}_{0}+\left[\left\{\mathrm{M}_{1} \cdot \mathrm{R}_{1}^{2}\left[\mathrm{M}_{2} \cdot \mathrm{R}_{2}^{2}+\Sigma \mathrm{M}_{\mathrm{i}} \cdot \mathrm{R}_{\mathrm{i}}^{2}\right]\right\} / \mathrm{G}\right]\right\} / \mathrm{M}_{\mathrm{de}}>\left(1 / \mathrm{r}_{\mathrm{de}}^{2}\right)$

Thus $\mathrm{r}_{\text {de }}^{2}>\mathrm{G} . \mathrm{M}_{\mathrm{de}} /\left\{\mathrm{GM}_{0}+\left[\left\{\mathrm{M}_{1} \cdot \mathrm{R}_{1}^{2}\left[\mathrm{M}_{2} \cdot \mathrm{R}_{2}^{2}+\Sigma \mathrm{M}_{\mathrm{i}} \cdot \mathrm{R}_{\mathrm{i}}^{2}\right]\right\}\right]\right\}$

Here $\mathrm{M}_{0}=\left(\mathrm{M}+\Sigma \mathrm{m}_{\mathrm{i}}\right)=$ mass of the planetary objects nearby to $\mathrm{S}$, excluding $\mathrm{S}$.

But for some n positive real number parameter greater than 1:

G. $\mathrm{M}_{\mathrm{de}} /\left\{\mathrm{GM}_{0}+\left[\left\{\mathrm{M}_{1} \cdot \mathrm{R}^{2}{ }_{1}\left[\mathrm{M}_{2} \cdot \mathrm{R}_{2}^{2}+\Sigma \mathrm{M}_{\mathrm{i}} \cdot \mathrm{R}^{2}{ }_{\mathrm{i}}\right]\right\}\right]\right\}=$

G. $M_{\text {de }} /\left(\mathrm{GM}_{0}\right)\left\{1+\left[\left\{\mathrm{M}_{1} \cdot \mathrm{R}_{1}^{2}\left[\mathrm{M}_{2} \cdot \mathrm{R}_{2}^{2}+\Sigma \mathrm{M}_{\mathrm{i}} \cdot \mathrm{R}_{\mathrm{i}}^{2}\right]\right\}\right] /\left(\mathrm{GM}_{0}\right)\right\}$

$=\mathrm{G} \cdot \mathrm{M}_{\mathrm{de}} / \mathrm{n} \cdot \mathrm{G} \cdot \mathrm{M}_{0}=\mathrm{M}_{\mathrm{de}} /\left(\mathrm{n} \cdot \mathrm{M}_{0}\right)$

Where $n=1+\left[\left\{M_{1} \cdot R_{1}^{2}\left[M_{2} \cdot R_{2}^{2}+\Sigma M_{i} \cdot R_{i}^{2}\right]\right\}\right] /\left(G_{0}\right)>1$. Thus $n>1$.

But $\left[\mathrm{M}_{\mathrm{de}} / \mathrm{n} . \mathrm{M}_{0}\right]<\mathrm{M}_{\mathrm{de}} / \mathrm{M}_{0}$. Because $\mathrm{n}>1$.

Thus G. $\mathrm{M}_{\mathrm{de}} /\left\{\mathrm{GM}_{0}+\left[\left\{\mathrm{M}_{1} \cdot \mathrm{R}_{1}^{2}\left[\mathrm{M}_{2} \cdot \mathrm{R}_{2}^{2}+\Sigma \mathrm{M}_{\mathrm{i}} \cdot \mathrm{R}_{\mathrm{i}}^{2}\right]\right\}<\mathrm{M}_{\mathrm{de}} / \mathrm{M}_{0}<1\right.\right.$ (25)

(Because by (17): $\quad M_{\mathrm{de}}=1.7264 * 10^{-6} \mathrm{~kg}<1\left(1 \mathrm{unit}\right.$ in SI ) and since $\mathrm{M}_{0}>1 \mathrm{~kg}$ )

But G. $M_{\text {de }} /\left\{\mathrm{GM}_{0}+\left[\left\{\mathrm{M}_{1} \cdot \mathrm{R}^{2}{ }_{1}\left[\mathrm{M}_{2} \cdot \mathrm{R}_{2}^{2}+\Sigma \mathrm{M}_{\mathrm{i}} \cdot \mathrm{R}_{\mathrm{i}}^{2}\right]\right\}<\mathrm{G}^{*} \mathrm{M}_{0}\right.\right.$ (Since $\mathrm{G}$ is in the order of $10^{-11}$ and $\mathrm{M}_{0}$ is in the order of greater than $10^{11}$ and by 25 ).

Thus $1 /\left\{\mathrm{GM}_{0}+\left[\left\{\mathrm{M}_{1} \cdot \mathrm{R}_{1}^{2}\left[\mathrm{M}_{2} \cdot \mathrm{R}_{2}^{2}+\Sigma \mathrm{M}_{\mathrm{i}} \cdot \mathrm{R}_{\mathrm{i}}{ }\right]\right\}<\mathrm{M}_{0} / \mathrm{M}_{\mathrm{de}}\right.\right.$

But $M_{\text {de }} / M_{0}<\left\{\mathrm{GM}_{0}+\left[\left\{\mathrm{M}_{1} \cdot \mathrm{R}_{1}^{2}\left[\mathrm{M}_{2} \cdot \mathrm{R}_{2}{ }_{2}+\Sigma \mathrm{M}_{\mathrm{i}} \cdot \mathrm{R}_{\mathrm{i}}^{2}\right]\right\}\right.\right.$ 
But let's consider the whole universe.

Then $\Sigma \mathrm{M}_{\mathrm{de}}>\Sigma \mathrm{M}_{0}$ (Because there are dark matters in the universe than ordinary matter)......(26)

For the consideration of the whole universe (let's consider that there are ' $w$ ' number of objects in the whole universe for the consideration at this considered moment ). Then by (25.1):

$\Sigma\left[\mathrm{M}_{\mathrm{de}} / \mathrm{M}_{0}\right]<\Sigma \mathrm{GM}_{0}+\Sigma \mathrm{M}_{1} \cdot \mathrm{R}_{1}^{2}\left[\mathrm{M}_{2} \cdot \mathrm{R}_{2}^{2}+\Sigma \mathrm{M}_{\mathrm{i}} \cdot \mathrm{R}_{\mathrm{i}}^{2}\right]=$

$\mathrm{G} \mathrm{M}^{(1)}+\mathrm{w} \cdot \mathrm{M}_{1} \cdot \mathrm{R}^{2} \cdot \mathrm{M}_{2} \cdot \mathrm{R}_{2}{ }_{2}+\Sigma\left[\mathrm{M}_{1} * \mathrm{R}^{2}{ }_{1} * \mathrm{M}_{\mathrm{i}} \cdot \mathrm{R}_{\mathrm{i}}^{2}\right]$

Here $\mathrm{M}^{(1)}=\Sigma \mathrm{M}_{0}$ (By considering whole universe).

Then $\Sigma\left[\mathrm{M}_{\mathrm{de}} / \mathrm{M}_{0}\right]<\mathrm{G} \mathrm{M}^{(1)}+\mathrm{W} \cdot \mathrm{M}_{1} \cdot \mathrm{R}_{1}^{2} \cdot \mathrm{M}_{2} \cdot \mathrm{R}_{2}^{2}+\Sigma\left[\mathrm{M}_{1} * \mathrm{R}_{1}{ }_{1} * \mathrm{M}_{\mathrm{i}} \cdot \mathrm{R}_{\mathrm{i}}^{2}\right]$ (27)

But $\Sigma\left[\mathrm{M}_{\mathrm{de}} / \mathrm{M}_{0}\right]>\Sigma \mathrm{M}_{\mathrm{de}} / \Sigma \mathrm{M}_{0} \quad$.Thus

$1<\Sigma \mathrm{M}_{\mathrm{de}} / \Sigma \mathrm{M}_{0}<\mathrm{G} \mathrm{M}^{(1)}+\mathrm{w} \cdot \mathrm{M}_{1} \cdot \mathrm{R}_{1}^{2} \cdot \mathrm{M}_{2} \cdot \mathrm{R}_{2}{ }_{2}+\Sigma\left[\mathrm{M}_{1} * \mathrm{R}_{1}{ }_{1} * \mathrm{M}_{\mathrm{i}} \cdot \mathrm{R}_{\mathrm{i}}{ }\right]($ By 26 and 27)

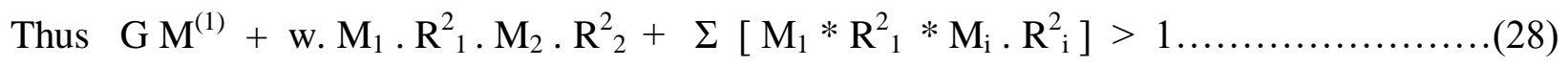

But in the term $\Sigma\left[\mathrm{M}_{1} * \mathrm{R}^{2}{ }_{1} * \mathrm{M}_{\mathrm{i}} \cdot \mathrm{R}_{\mathrm{i}}^{2}\right]$, there are some negative $\mathrm{M}_{\mathrm{i}}$ values also for some ' $\mathrm{i}$ ' th terms (since we consider the whole universe).

Therefore the universe is responsible naturally to have the term:

$\mathrm{G} \mathrm{M}^{(1)}+\mathrm{w} \cdot \mathrm{M}_{1} \cdot \mathrm{R}^{2}{ }_{1} \cdot \mathrm{M}_{2} \cdot \mathrm{R}_{2}^{2}+\Sigma\left[\mathrm{M}_{1} * \mathrm{R}_{1}^{2} * \mathrm{M}_{\mathrm{i}} \cdot \mathrm{R}_{\mathrm{i}}^{2}\right]>1$ (Although in the term $\Sigma\left[\mathrm{M}_{1} * \mathrm{R}^{2}{ }_{1} * \mathrm{M}_{\mathrm{i}} \cdot \mathrm{R}^{2}{ }_{\mathrm{i}}\right]$, there are some negative values ).

But by (23): $V^{2}-U^{2}=E_{d e} * D^{\prime}$, Here $V$ is the observable velocity of the star $S$. And $U$ is the theoretically calculated velocity of the star $\mathrm{S}$.

Thus the difference between

[ (Observable velocity of the star $S)^{2}$ - (theoretically calculated velocity of the star $\left.S\right)^{2}$ ] depends only on the dark matter's gravitational field. 
Moreover, the universe is responsible naturally to have the term:

By (28): $\mathrm{G} \mathrm{M}^{(1)}+\mathrm{w} \cdot \mathrm{M}_{1} \cdot \mathrm{R}^{2}{ }_{1} \cdot \mathrm{M}_{2} \cdot \mathrm{R}_{2}{ }_{2}+\Sigma\left[\mathrm{M}_{1} * \mathrm{R}^{2}{ }_{1} * \mathrm{M}_{\mathrm{i}} \cdot \mathrm{R}_{\mathrm{i}}{ }\right]>1$

(Although in the term $\Sigma\left[\mathrm{M}_{1} * \mathrm{R}_{1}^{2} * \mathrm{M}_{\mathrm{i}} \cdot \mathrm{R}_{\mathrm{i}}^{2}\right]$, there are some negative values for some ' $\mathrm{M}_{\mathrm{i}}$ ' 'i' th terms ).

\subsection{Result Evaluation of Methodology part 6}

Although the total mass of $M_{d e}$ is comparably small $\left(M_{d e}=1.7264 * 10^{-6} \mathrm{~kg}\right)$ within the considering space volume, that dark matter content able to cause a difference between the observable velocity and theoretical velocity of a star of any high masses.

Although among some of objects in the universe the magnetic force is repulsive, the whole universe is responsible to generate the term:

$\mathrm{G} \mathrm{M}^{(1)}+\mathrm{w} \cdot \mathrm{M}_{1} \cdot \mathrm{R}^{2} \cdot \mathrm{M}_{2} \cdot \mathrm{R}_{2}{ }_{2}+\Sigma\left[\mathrm{M}_{1} * \mathrm{R}_{1}^{2} * \mathrm{M}_{\mathrm{i}} \cdot \mathrm{R}_{\mathrm{i}}^{2}\right]>1$

(Although in the term $\Sigma\left[\mathrm{M}_{1} * \mathrm{R}_{1}^{2} * \mathrm{M}_{\mathrm{i}} \cdot \mathrm{R}_{\mathrm{i}}^{2}\right]$, there are some negative values for some $\mathrm{M}_{\mathrm{i}}$, ' $\mathrm{i}$ ' th terms ).

Then $\Sigma\left[\mathrm{M}_{1} * \mathrm{R}_{1}^{2} * \mathrm{M}_{\mathrm{j}} \cdot \mathrm{R}_{\mathrm{j}}{ }\right]-\Sigma\left[\mathrm{M}_{1} * \mathrm{R}_{1}^{2} * \mathrm{M}_{\mathrm{i}} \cdot \mathrm{R}_{\mathrm{i}}{ }\right]>1-\mathrm{G} \mathrm{M}^{(1)}-\mathrm{W} \cdot \mathrm{M}_{1} \cdot \mathrm{R}^{2} \cdot \mathrm{M}_{2} \cdot \mathrm{R}^{2}{ }_{2}$

Here ' $j$ ' th terms are indicating the magnetically attractive objects in the universe and ' $i$ ' th terms indicate magnetically repulsive objects in the universe.

Then $\Sigma\left[\mathrm{M}_{1} * \mathrm{R}_{1}{ }_{1} * \mathrm{M}_{\mathrm{i}} \cdot \mathrm{R}_{\mathrm{i}}^{2}\right]<\Sigma\left[\mathrm{M}_{1} * \mathrm{R}_{1}{ }_{1} * \mathrm{M}_{\mathrm{j}} \cdot \mathrm{R}_{\mathrm{j}}{ }_{\mathrm{j}}\right]+\mathrm{G} \mathrm{M}^{(1)}+\mathrm{w} \cdot \mathrm{M}_{1} \cdot \mathrm{R}^{2}{ }_{1} \cdot \mathrm{M}_{2} \cdot \mathrm{R}^{2}{ }_{2}-1$

Since I considered star S arbitrary from universe, I can state the below statement.

The dark matter in the universe is responsible for the difference between observed moving velocity of the stars and theoretically calculated moving velocity of the stars in the universe.

Also, $\Sigma\left[\mathrm{M}_{1} * \mathrm{R}^{2}{ }_{1} * \mathrm{M}_{\mathrm{i}} \cdot \mathrm{R}^{2}{ }_{\mathrm{i}}\right]<\Sigma\left[\mathrm{M}_{1} * \mathrm{R}^{2}{ }_{1} * \mathrm{M}_{\mathrm{j}} \cdot \mathrm{R}_{\mathrm{j}}{ }_{\mathrm{j}}\right]+\mathrm{G} \mathrm{M}^{(1)}+\mathrm{w} \cdot \mathrm{M}_{1} \cdot \mathrm{R}^{2}{ }_{1} \cdot \mathrm{M}_{2} \cdot \mathrm{R}^{2}{ }_{2}-1$

By considering the whole universe. Here ' $j$ ' th terms are indicating the magnetically attractive objects in the universe and ' $i$ ' th terms indicate magnetically repulsive objects in the universe. 


\section{Discussion}

\subsection{Discussion of Methodology part 1}

At this moment, there is no any significant explanation to explain why there are more matter particles rather than anti-matter particles in the Universe. But scientists have already investigated the concepts regarding the Anti-matter particles. But anti-matter particles are very rare according to recent experiments.

But this research explains why there are more matter particles in the universe rather than antimatter particles, in detail with the mathematical formulations.

We obtained the result by considering Fermions arbitrarily. But by considering arbitrary bosons also we can obtain the similar result.

\subsection{Discussion of Methodology part 2}

There are particles those eject by a solar surface (as the particles of the solar wind) and when those particles accelerate towards the supermassive black hole, those solar wind particles cannot emit any electromagnetic waves to the outer space. Therefore no one can detect any electromagnetic waves because of those solar wind particles in the sky, those are accelerating towards the supermassive black hole.

And there is a range for the orbital velocity of a planet if that planet is considerably influenced by a supermassive black hole. 


\subsection{Discussion of Methodology part 3}

When two different Hamiltonians become the Hamiltonian operators of a same wave function and the same eigenvalue, it is not a general and not a usual case. Then we have to explore the wave particle situation in depth to discover the reason to have such specific situation. In this particular situation, it is easy to predict the reason for that specific result as below.

And therefore I can conclude that the matters/waves of the quantum vacuum become the virtual member particles/waves of the ordinary matters/waves system of the universe. Therefore I can conclude that the matters/waves of the quantum vacuum are the virtual members of the ordinary matter system of the universe (the universe that seeks to expand with an accelerating rate). That means, in the real world, matters/waves of the quantum vacuum do not contribute to the processes and tasks taken by the ordinary matter system for the accelerating expansion of the universe. i.e. the matters/waves in the quantum vacuum do not deal with ordinary matters/waves really, to accelerate the expansion of the universe. But the ordinary matters/waves are the primary bodies that causes the gravitational repulsion of the universe in order to cause the accelerating expansion of the universe.

Therefore the matters/waves in the quantum vacuum do not contribute much to the expansion of the universe (done by the repulsive forces of the ordinary matters) in the real world.

\subsection{Discussion of Methodology part 4}

When there is a sufficient external magnetic field, I can conclude that energy of the zero-point, can't cause a cosmological constant as much as big as the value of the total energy of the zero point energy levels.

But to state that fact, there should be a sufficient external magnetic field that influences to the considering space volume. 


\subsection{Discussion of Methodology part 5}

Although the satellite is orbiting near to the Earth compare to the other stellar objects in the Milky way, there is an influence to the light rays those are propagating near to the satellite by the dark energy/ dark matter those are surrounding to the satellite. But cosmological theories explain that the dark energy/dark matter content of the universe is more than $90 \%$ of the total energy/matter content of the whole universe.

Therefore we can apply this mathematical method to explain more observations in astrophysics/cosmology and in physics as well.

But I obtained the final result by considering LEO satellites. But the by using similar calculation method, we can prove the result for any other satellite that is orbiting around the Earth.

\subsection{Discussion of Methodology part 6}

Although the total mass of $M_{d e}$ is comparably small $\left(M_{d e}=1.7264 * 10^{-6} \mathrm{~kg}\right)$ within the considering space volume, that dark matter content able to cause a difference between the observable velocity and theoretical velocity of a star of any high masses.

Although among some of objects in the universe the magnetic force is repulsive, the whole universe is responsible to generate the term:

$\mathrm{G} \mathrm{M}^{(1)}+\mathrm{w} \cdot \mathrm{M}_{1} \cdot \mathrm{R}_{1}^{2} \cdot \mathrm{M}_{2} \cdot \mathrm{R}_{2}^{2}+\Sigma\left[\mathrm{M}_{1} * \mathrm{R}_{1}^{2} * \mathrm{M}_{\mathrm{i}} \cdot \mathrm{R}_{\mathrm{i}}^{2}\right]>1$

(Although in the term $\Sigma\left[\mathrm{M}_{1} * \mathrm{R}^{2}{ }_{1} * \mathrm{M}_{\mathrm{i}} \cdot \mathrm{R}_{\mathrm{i}}^{2}\right]$, there are some negative values for some ' $\mathrm{i}$ ' th terms ).

Then $\Sigma\left[\mathrm{M}_{1} * \mathrm{R}_{1}^{2} * \mathrm{M}_{\mathrm{j}} \cdot \mathrm{R}_{\mathrm{j}}^{2}\right]-\Sigma\left[\mathrm{M}_{1} * \mathrm{R}_{1}^{2} * \mathrm{M}_{\mathrm{i}} \cdot \mathrm{R}_{\mathrm{i}}{ }^{2}\right]>1-\mathrm{G} \mathrm{M}^{(1)}-\mathrm{W} \cdot \mathrm{M}_{1} \cdot \mathrm{R}^{2} \cdot \mathrm{M}_{2} \cdot \mathrm{R}^{2}$

Here ' $j$ ' th terms are indicating the magnetically attractive objects in the universe and ' $i$ ' th terms indicate magnetically repulsive objects in the universe.

Then $\Sigma\left[\mathrm{M}_{1} * \mathrm{R}_{1}{ }_{1} * \mathrm{M}_{\mathrm{i}} \cdot \mathrm{R}_{\mathrm{i}}{ }_{\mathrm{i}}\right]<\Sigma\left[\mathrm{M}_{1} * \mathrm{R}_{1}{ }_{1} * \mathrm{M}_{\mathrm{j}} \cdot \mathrm{R}_{\mathrm{j}}{ }_{\mathrm{j}}\right]+\mathrm{G} \mathrm{M}^{(1)}+\mathrm{W} \cdot \mathrm{M}_{1} \cdot \mathrm{R}^{2} \cdot \mathrm{M}_{2} \cdot \mathrm{R}^{2}{ }_{2}-1$ 


\section{Conclusion}

\subsection{Conclusion of Methodology part 1}

According to (31):

The probability of having two particles in a system with the same sign of the electric charge (but with same mass, spin and other identities) > the probability of having two particles in a system with the opposite sign of the electric charge (but with same mass, spin and other identities)

But all those considering particles have same mass, spin and etc. i.e. those particles are matters and anti-matters.

But we choose P, P' and P" randomly from the Universe. And we brought those randomly chosen 3 particles to the research environment. And each two matters have same electric charge. And each two anti-matters also have same electric charge. But each two matter and anti-matter have opposite electric charge. But in the research environment, it is biased to have same type matters rather than opposite type of matters. If we brought all matters and anti-matters in the observable universe into large number of such research environments, it is obvious that in all such research environments, number of same charge sign particles are much greater than number of opposite charge sign particles. But we brought all particles in the observable universe into large number of such research environments. Therefore it is capable to conclude that the Universe is biased to have same type matters rather than opposite type of matters. i.e. but scientists have labeled the most existing type of matters as 'Matters' and rarely existing particles as 'Anti-matter' particles.

Therefore it is possible to state that: The Universe is biased to have Matters rather than Antimatters.

Therefore according to (33), the reason to have more matters in the Universe rather than antimatters is: 
The Universe desires to have more positive (electric) potential energy rather than negative (electric) potential energy.

Therefore the Universe that we are living does not allow to have same quantity of matter and anti-matter with it (i.e. there is no any symmetry between the existing amounts of matters and anti-matters). That means the present and recent universe is biased to have matters than antimatters.

\subsection{Conclusion of Methodology part 2}

Solar wind particles those are accelerating towards a supermassive black hole cannot emit any electromagnetic waves (That may create due to their oscillations). Therefore the nearby area of a supermassive black hole is dark.

Moreover, there is a range for the orbital velocity of a planet that is orbiting around a star under the influence of a supermassive black hole. Therefore we can apply this mathematical method to explain more observations in astrophysics/cosmology and in physics as well.

\subsection{Conclusion of Methodology part 3}

It is possible to conclude that the matters/waves of the quantum vacuum become the virtual member particles/waves of the ordinary matters/waves system of the universe. Therefore I can conclude that the matters/waves of the quantum vacuum are the virtual members of the ordinary matter system of the universe (the universe that seeks to expand with an accelerating rate). That means, in the real world, matters/waves of the quantum vacuum do not contribute to the processes and tasks taken by the ordinary matter system for the accelerating expansion of the universe. i.e. the matters/waves in the quantum vacuum do not deal with ordinary matters/waves really, to accelerate the expansion of the universe. But the ordinary matters/waves are the

primary bodies that causes the gravitational repulsion of the universe in order to cause the accelerating expansion of the universe.

Therefore the matters/waves in the quantum vacuum do not contribute much to the expansion of the universe (done by the repulsive forces of the ordinary matters) in the real world. 


\subsection{Conclusion of Methodology part 4}

The external matter/waves creates the cosmological constant to be less than the value of the energy of the zero point energy levels.

Therefore the zero point energy (the quantum state with the lowest possible energy) of the vacuum does not cause a large cosmological constant (when the considering space volume contains enough magnetic field).

\subsection{Conclusion of Methodology part 5}

The dark energy/dark matter causes a difference between the observed energy of satellites flying by Earth and the value predicted by the theory.

The strength of the considering dark matter/ dark energy amount near to the satellite may cause a large and much considerable difference between the observed energy of satellites and the value predicted by the theory.

\subsection{Conclusion of Methodology part 6}

Since I considered star S arbitrary from universe, I can state the below statement.

The dark matter in the universe is responsible for the difference between observed moving velocity of the stars and theoretically calculated moving velocity of the stars in the universe.

Also,

$\Sigma\left[\mathrm{M}_{1} * \mathrm{R}_{1}{ }_{1} * \mathrm{M}_{\mathrm{i}} \cdot \mathrm{R}_{\mathrm{i}}^{2}\right]<\Sigma\left[\mathrm{M}_{1} * \mathrm{R}_{1}{ }_{1} * \mathrm{M}_{\mathrm{j}} \cdot \mathrm{R}_{\mathrm{j}}{ }_{\mathrm{j}}\right]+\mathrm{G} \mathrm{M}^{(1)}+\mathrm{w} \cdot \mathrm{M}_{1} \cdot \mathrm{R}_{1}^{2} \cdot \mathrm{M}_{2} \cdot \mathrm{R}^{2}{ }_{2}-1$

By considering the whole universe. Here ' $j$ ' th terms are indicating the magnetically attractive objects in the universe and ' $\mathrm{i}$ ' th terms indicate magnetically repulsive objects in the universe. 


\section{Appendix}

*** The Time-independent Schrodinger equation can be written as below:

$\frac{-\hbar^{2}}{2 m} \nabla^{2} \Psi+V \Psi=E \Psi$

Where $\mathrm{h}$ is the reduced plank constant, $\mathrm{m}$ is the mass of the matter particle, $\mathrm{V}$ is the potential energy operator of the system, $E$ is the energy term (eigenvalue). And $\Psi$ is the wave function of the matter particle (eigen function).

Superposition of $\mathrm{n}$ 'b' number of eigen states $, \varphi_{1}, \varphi_{2}, \ldots \ldots ., \varphi_{\mathrm{m}}$ can be written as :

$\Phi=\mathrm{c}_{1} \cdot \varphi_{1}+\mathrm{c}_{2} \varphi_{2}+\ldots \ldots+\left(\mathrm{c}_{\mathrm{m}} \cdot \varphi_{\mathrm{m}}\right)$ where each $\mathrm{c}_{\mathrm{i}}$ is non-zero and each $\mathrm{c}_{\mathrm{i}}$ give $\Phi$ as a linear combination of $\varphi_{\mathrm{i}}$

*** The gravitational potential energy of a couple of gravitational bodies can be written as below:

(- G.m.M / r )

(for two gravitational bodies with attractive gravitation between them).

$\mathrm{G}$ is the universal gravitational constant, $\mathrm{m}$ and $\mathrm{M}$ are the masses of the two gravitational bodies. $r$ is the distance between those two matters (The distance between the two center of masses of those 2 objects).

\section{Friedmann Equations :}

$\ddot{X}=(-4 \pi \mathrm{G} / 3) \cdot \mathrm{X}\left(\rho+3 \mathrm{p} / \mathrm{c}^{2}\right)+\mathrm{X} \cdot \Lambda \mathrm{c}^{2} / 3$

Where $\rho$ and $\mathrm{P}$ are the density and pressure of the cosmological fluid respectively. And $\mathrm{X}$ is the scale factor in the Friedmann equations. $G$ is the universal gravitation constant, $c$ is the speed of light,$\Lambda$ is the cosmological constant

The magnetic force $\left(\mathrm{F}_{\mathrm{mg}}\right)$ that acts on a planet can be written as below (When there is an own magnetic field with the planet and by considering the total equivalent magnetic field of the host black hole and with the magnetic field of the host planets): 
$\mathrm{F}_{\mathrm{mg}}=\left(\pi \mu_{0} / 4\right)^{*}\left(\mathrm{M}_{1} \cdot \mathrm{M}_{2} \cdot \mathrm{R}_{1}^{2} \cdot \mathrm{R}_{2}^{2}\right) *\left[\frac{1}{x^{2}}+\frac{1}{(x+L 1+L 2)^{2}}-\frac{1}{(x+L 1)^{2}}-\frac{1}{(x+L 2)^{2}}\right]$

Here $\mathrm{M}_{1}, \mathrm{M}_{2}$ are identified as the magnetization of the virtual equivalent magnet in $\mathrm{S}$ and the magnetization of the equivalent magnet of the black hole respectively (the virtual magnets which produced by the magnetic field of the black hole and $\mathrm{S}$ respectively).

Here $\mathrm{S}$ is an arbitrary star chosen from an arbitrary galaxy.

$\mathrm{R}_{1}, \mathrm{R}_{2}$ are the radiuses of two magnets in meters - identified as the radius of the virtual magnet in $\mathrm{S}$ and the radius of the equivalent magnet of the black hole respectively (the virtual magnets which produced by the magnetic field of the black hole and $S$ ).

$\mathrm{x}$ is the distance between the two virtual magnets in meters - identified as the distance between virtual magnet in $\mathrm{S}$ and the equivalent virtual magnet of the black hole.

$\mathrm{X}_{\mathrm{i}}$ is the distance between the two virtual magnets in meters - identified as the distance between virtual magnet in $\mathrm{S}$ and the virtual magnet of the ' $i$ ' th object.

$L_{1}, L_{2}$ are the lengths of two magnets in meters- identified as the lengths of the magnet in $\mathrm{S}$ and the length of the virtual magnet of the black hole respectively (the virtual magnets which produced by the magnetic field of the black hole and S).

$\mathrm{L}_{\mathrm{i}, 2}$ is the length of two magnet in meters- identified as the length of the virtual magnet in ' $\mathrm{i}$ 'th object.

$\mathrm{R}_{\mathrm{i}}$ is the radius of the virtual magnet in the ' $\mathrm{i}$ ' th object which is nearby to $\mathrm{S}$. $\mu_{0}$ is the permeability of space, which equals to $4 \pi^{*} 10^{-7} \mathrm{~T} \cdot \mathrm{m} / \mathrm{A}$

According to the relativistic Doppler Effect, the experimentally calculated frequency of a photon that is coming from the distant universe can be written as:

$\mathrm{f}_{1}=\mathrm{f}_{0} * \sqrt{\frac{1-\frac{V b+V \cdot \cos \theta}{C}}{1+\frac{V b+V \cdot \cos \theta}{C}}}$

Here $f_{0}$ is the relevant exact original frequency of that considered photon that has been emitted by the star $S . f_{1}$ is the relevant experimentally measured frequency of the considered photon. $V_{b}$ is the velocity of the star $\mathrm{S}$ due to the universal expansion caused due to the Big Bang incident. V is the moving velocity of the star S. 


\section{References}

1. Brian Greene, The elegant Universe

2. P.J. E. Peebles, Principals of Physical Cosmology

3. Michael Rowan, Cosmology, $3^{\text {rd }}$ Edition

4. Brian Greene, Until the End of Time

5. Stephen Hawking, Brief Answers to the Big Questions

6. Sean Carroll, The Big Picture

7. Adam Frank, Light of the Stars

8. Steven Carlip, General Relativity

9. Pamela Eakins, Visionary Cosmology

10. Walt McLaughlin, The Impossible Cosmos

11. Nicola Vittorio, Cosmology

12. P. A. M. Dirac, The Quantum Theory of the Emission and Absorption of Radiation, Proc. Royal Soc. Lond. A 114, pp. 243-265, (1927)

13. Preston, Thomas (1898). "Radiation phenomena in a strong magnetic field". The Scientific Transactions of the Royal Dublin Society. 2nd series. 6: 385-342

14. Tipler, Paul Allen; Llewellyn, Ralph A. (2002). Modern Physics (4th ed.). Macmillan. p. 310. ISBN 978-0-7167-4345-3

15. S. Hollands, Ko Sanders. Lecture notes on General Relativity

16. Dragan Slavkov Hajdukovic1 PH Division CERN CH-1211 Geneva 23

17. Ferris, Timothy (January 2015). "Dark matter". Hidden cosmos. National Geographic Magazine. Retrieved 10 June 2015.

18. Special \& General Relativity Questions and Answers, Stanford University

Retrieved from https://einstein.stanford.edu/content/relativity/q296.html

19. Angular Momentum Operators, University of Texas, USA, 2010, July 20

20. The Friedmann Equations ; Retrieved from: http://hyperphysics.phyastr.gsu.edu/hbase/Astro/fried.html

21. The fate of the Universe, Brian Kay ; Retrieved from : https://uncw.edu/phy/documents/TheFriedmannEquations.pdf

22. https://elements.wlonk.com/Particles.htm

23. https://www2.ph.ed.ac.uk/ ldeldebb/docs/QM/lect17.pdf

24. https://www.kth.se/social/files/5cb029dd56be5b49476c1e27/Lecture\%202\%20Photon\% 20Statistics.pdf

25. http://physics.ucsc.edu/ drip/5D/photons/photons.pdf

26. https://www.omniumbeyondmatter.com/vacuum-energy-versus-dark-energy 
